NBER WORKING PAPER SERIES

\title{
THE STRUCTURE OF STATE CORPORATE TAXATION AND ITS IMPACT ON STATE TAX REVENUES AND ECONOMIC ACTIVITY
}

\author{
Juan Carlos Suárez Serrato \\ Owen M. Zidar \\ Working Paper 23653 \\ http://www.nber.org/papers/w23653 \\ NATIONAL BUREAU OF ECONOMIC RESEARCH \\ 1050 Massachusetts Avenue \\ Cambridge, MA 02138 \\ August 2017, Revised July 2018
}

We are especially thankful to Tim Bartik for providing detailed comments on an early draft as well as to Jim Poterba, Josh Rauh, and Tom Neubig. We also thank Tim Bartik, Dan Wilson and Robert Chirinko, Nathan Seegert, and Jamie Bernthal, Dana Gavrila, Katie Schumacher, Shane Spencer, and Katherine Sydor for generously providing us with data on components of the state corporate tax structure. Tim Anderson, Stephanie Kestelman, Matt Panhans, Francesco Ruggieri, Linh Nguyen, and John Wieselthier provided excellent research assistance. This work is supported by the Kauffman Foundation and the Kathryn and Grant Swick Faculty Research Fund at the University of Chicago Booth School of Business. We declare that we have no relevant or material financial interests that relate to the research described in this paper. The views expressed herein are those of the authors and do not necessarily reflect the views of the National Bureau of Economic Research.

NBER working papers are circulated for discussion and comment purposes. They have not been peer-reviewed or been subject to the review by the NBER Board of Directors that accompanies official NBER publications.

(C) 2017 by Juan Carlos Suárez Serrato and Owen M. Zidar. All rights reserved. Short sections of text, not to exceed two paragraphs, may be quoted without explicit permission provided that full credit, including $\odot$ notice, is given to the source. 
The Structure of State Corporate Taxation and its Impact on State Tax Revenues and Economic Activity

Juan Carlos Suárez Serrato and Owen M. Zidar

NBER Working Paper No. 23653

August 2017, Revised July 2018

JEL No. H2,H25,H71,R5

\section{ABSTRACT}

This paper documents facts about the state corporate tax structure $\mid$ tax rates, base rules, and credits $\mid$ and investigates its consequences for state tax revenue and economic activity. We present three main findings. First, tax base rules and credits explain more of the variation in state corporate tax revenues than tax rates do. Second, although states typically do not offset tax rate changes with base and credit changes, the effects of tax rate changes on tax revenue and economic activity depend on the breadth of the base. Third, as states have narrowed their tax bases, the relationship between tax rates and tax revenues has diminished. Overall, changes in state tax bases have made the state corporate tax system more favorable for corporations and are reducing the extent to which tax rate increases raise corporate tax revenue.

Juan Carlos Suárez Serrato

Department of Economics

Duke University

213 Social Sciences Building

Box 90097

Durham, NC 27708

and NBER

jc@jcsuarez.com

Owen M. Zidar

Department of Economics \& Woodrow Wilson School

Princeton University

237 Julis Romo Rabinowitz Building

Princeton, NJ 08544

and NBER

ozidar@princeton.edu 
How states tax businesses has received renewed interest in both academic and policy circles. Recent work on state corporate tax rates has investigated their impacts on income growth, employment, and business location. ${ }^{1}$ However, state policymakers compete to attract businesses not only by changing tax rates, but also by changing the tax base to enhance several investment incentives, loss provisions, and enforcement mechanisms. ${ }^{2}$ There is a lack of basic facts about the state corporate tax structure, its evolution over recent years, and how it impacts tax revenue and economic activity. This paper describes the state corporate tax structure, documents how it has changed over time, and investigates the consequences of these changes for state tax collections and economic activity.

Our analysis proceeds in four steps. We first describe recent trends in state corporate tax structure. ${ }^{3}$ While average state corporate tax rates have remained relatively stable, state corporate tax revenues as a share of economic activity have declined substantially. Some of this decline is due to other factors (e.g., the rise of pass-throughs (Cooper et al., 2016) and corporate losses (Auerbach and Poterba, 1987)), but we show that tax base and credit changes have substantial impacts on state corporate tax collections. Tax base and credit changes are much more frequent than tax rate changes. Contrary to the view that state tax rate changes are often accompanied by offsetting changes in the tax base, we find that the vast majority of tax base changes are not associated with tax rate changes. Some provisions, such as R\&D credits, investment tax credits, and loss carryforward rules, have become more favorable for corporations while others (e.g., throwback rules and combined reporting) have lead to broader bases.

Second, we estimate the importance of each of these tax base rules for state corporate tax collections from 1980 and 2010. We perform analysis of variance decompositions every five years and document the importance of tax base rules, relative to tax rates, in explaining the variation in corporate tax revenue across states and over time. Overall, tax base components account for the majority of the explained variation in tax revenues. This result remains relatively stable throughout most of our sample, with only a slight increase in the fraction explained by tax rates in 2010. The importance of different tax base components in explaining tax revenues has evolved over our sample. In particular, sales apportionment weights and loss carryback provisions have waned in importance, while franchise taxes, different depreciation rules, and interactions with federal tax policies, such as adopting the federal tax base or allowing for the deductibility of federal taxes, have increased their share of explained variance.

Third, we analyze how tax base provisions affect the relationship between state tax rates and two outcomes: state corporate tax revenue and state GDP. This analysis has two parts. We first explore the degree to which controlling for these tax base provisions affects the relationship between tax rates and revenue and GDP. We find that, while tax base controls explain a large portion of the variation in revenues, the relationships between

\footnotetext{
${ }^{1}$ Recent papers include Heider and Ljungqvist (2015), Giroud and Rauh (2015), Suárez Serrato and Zidar (2016), Fajgelbaum et al. (2015), Ohrn (2016), and Ljungqvist and Smolyansky (2014).

${ }^{2}$ These tax base rules are important determinants of measures of state business climate indexes (e.g., Tax Foundation (2016)). ALEC (2014) reports that 14 states changed taxes in 2014 with many of the changes affecting both tax rates as well as tax base determinants.

${ }^{3}$ The fifteen determinants of the corporate income tax structure that we analyze include tax credits, such as the investment tax credit and the R\&D tax credit. For simplicity, we refer to these credits as determinants of the tax base, along with our other tax base measures.
} 
tax rates and our outcomes of interest are not fundamentally affected by controlling for these tax base measures. This result may be due to the lack of a temporal coincidence between changes to tax rates and determinants of the tax base. However, even if tax base and rate changes do not occur at the same time, the tax base can influence the effects of tax rate changes.

We then explore the extent to which interactions between the tax base and tax rates induce heterogeneous effects of state corporate tax rate changes. Intuitively, when the tax base is narrow, a tax rate increase mechanically raises less revenue since taxable income is a smaller portion of overall income. In addition, tax changes have smaller incentive effects, so the behavioral responses to tax rate increases are likely attenuated. Empirically, we first confirm that states with narrower tax bases collect less revenue from marginal increases in tax rates. The main finding is about tax-base-driven heterogeneity in the time series. While some states have broadened the base (e.g., Michigan, Ohio, Illinois), we observe narrower tax bases on average over the last thirty years. These trends in state tax bases over time have made the state corporate tax system more generous towards corporations, and are reducing the extent to which increases in tax rates raise corporate tax revenue. In addition, we find that including interactions between the state tax base and state tax rates also increases the estimate of the average treatment effect (ATE) of state corporate tax rate changes on state corporate tax revenue. $^{4}$

We conclude by investigating the implications of these results for revenue-maximizing-state-tax rates and for the claim that state corporate tax rate cuts pay for themselves. ${ }^{5}$ We estimate a regression in which tax rates have linear $\left(\beta_{0}\right)$ and quadratic $\left(\delta_{0}\right)$ effects on tax revenue. The revenue-maximizing-state-corporate-tax rate equals the ratio of these effects: $\frac{\beta_{0}}{-2 \delta_{0}}$. The estimate of the quadratic effect $\left(\hat{\delta}_{0}\right)$, which measures decreasing returns from tax rate increases, is not substantially larger than the linear effect $\left(\hat{\beta}_{0}\right)$. Our point estimates imply that the tax rate that maximizes state corporate tax revenue is close to 30 percent. In Suárez Serrato and Zidar (2016), we note that state corporate taxes may have fiscal externalities and may affect tax revenue from sales and personal income taxes. Even when we allow for this externality by considering total state tax revenue instead of only corporate tax revenue, our estimates imply a total-state-tax-revenue-maximizing rate of close to $10 \%$. Since the estimated revenue-maximizing rate is greater than the majority of state corporate tax rates, we reject the hypothesis that tax cuts tend to pay for themselves.

This paper contributes to three literatures. First, relative to recent work on the effects of changes in state business tax rates on economic activity (Heider and Ljungqvist (2015), Giroud and Rauh (2015), Suárez Serrato and Zidar (2016), Fajgelbaum et al. (2015), Ohrn (2016), and Ljungqvist and Smolyansky (2014)), we explore how the relationships between tax rates and revenues and economic activity depend on the structure of the corporate tax system. A contribution of this paper is the collection and description of a comprehensive set of variables that describe the structure of the corporate tax system across all U.S. states since 1980, which we

\footnotetext{
${ }^{4} \mathrm{As}$ is well known (Wooldridge, 2005; Gibbons, Suárez Serrato and Urbancic, 2014), in the presence of heterogeneous treatment effects, regressions that control for the drivers of heterogeneity estimate a weighted-average of the heterogeneous treatment effects that may not be a consistent estimate of the average treatment effect. In this context, the source of heterogeneous effects is the tax base. We discuss treatment effect heterogeneity in Section 5.

${ }^{5}$ See, for instance, claims by Sam Brownback (Mclean, 2017), Thom Tillis (The News \& Observer Editorial Board, 2017), and Mitt Romney (Romney, 2010) for the cases of Kansas, North Carolina, and Massachusetts, respectively, and Rand Paul (Kessler, 2015) for a similar claim at the federal level.
} 
hope will aid future researchers in this literature. In a contemporaneous contribution, Bartik (2017) simulates the tax consequences of locating a new plant in 32 states and 45 industries that cover roughly 90 percent of U.S. economic activity since 1990. These simulations are highly detailed and capture complex interactions between several rules. We view this paper as highly complementary to ours, which takes a reduced-form empirical approach. Specifically, we do not conduct similar simulations at the plant level, but do variance decompositions of observed state corporate tax revenue as a share of state GDP to understand the quantitative importance of different base provisions for state tax revenue. Bartik (2017) also documents several facts about changes in incentives and finds that business incentives are large, vary substantially across states, and have become increasingly generous. Consistent with these results, we document substantial variation across states and a general narrowing of the base on average in the full panel of 50 states since 1980.

Second, this paper is also related to a set of papers that explore whether the tax base affects the relationship between corporate tax rates and corporate income tax revenues. In particular, Clausing (2007), Devereux (2007), and Kawano and Slemrod (2015) study this relationship across 29 OECD member countries, and Dahlby and Ferede (2012) perform a similar analysis across Canadian provinces. We follow Kawano and Slemrod (2015) by collecting a comprehensive set of variables that describe the breadth of the tax base and by controlling for this tax base vector in our estimations. In contrast to Kawano and Slemrod (2015), who focus on the international corporate tax structure, we find that state tax rate changes are not often offset by base and credit changes.

Finally, we find that the relationship between state tax rates and economic activity depends on the structure of the tax base. This point is related to work by Kopczuk (2005), who finds that the elasticity of reported taxable income for individuals depends on the availability of deductions. In our setting, this dependence on the tax base is important for revenue forecasts and assessments of the incidence and efficiency of state corporate taxation.

The paper is organized as follows. Section 1 describes the dataset of tax base determinants, and Section 2 describes trends in the structure of the state corporate tax system. Section 3 performs the variance decomposition analysis, and Section 4 explores the effects of controlling for tax base determinants on various outcomes of economic interest. Section 5 explores tax-base-driven treatment effect heterogeneity across states and over time, Section 6 analyzes the revenue-maximizing-tax rate, and Section 7 concludes with a discussion of policy implications.

\section{Measuring the State Corporate Tax Structure}

We use fifteen measures of the corporate tax base for the main analysis in the paper. Details on each of the variables, sources, and coverage are available in Appendix A. ${ }^{6}$ The following variables comprise our stateyear panel dataset of tax base and credit components: an indicator of having throwback rules, an indicator of

\footnotetext{
${ }^{6}$ Most of the data used in this paper were digitized from a variety of sources including CCH State Tax Handbook (19802010) and CSG Book of the State (1976-2011), but we also rely on data collected and generously provided by Chirinko and Wilson (2008), Wilson (2009), and Bernthal et al. (2012). Unless otherwise indicated, we exclude the District of Columbia from the analysis.
} 
having combined reporting rules, investment tax credit rates, research and development (R\&D) tax credit rates, an indicator for whether the R\&D tax credit applies to an incremental base that is a moving average of past expenditures, an indicator for whether the $R \& D$ tax credit applies to an incremental base that is fixed on a level of past expenditures, the number of years for loss carryback, number of years for loss carryforward, an indicator for franchise taxes, an indicator for federal income tax deductibility, an indicator for federal income tax base as the state tax base, an indicator for follows federal accelerated depreciation, an indicator for follows accelerated cost recovery system (MACRS) depreciation, an indicator for federal bonus depreciation, and corporate tax apportionment weights.

Most of the variables are indicators of whether a state allows a particular policy. Throwback and combined reporting rules come from Bernthal et al. (2012) and describe whether a state requires a unitary business to submit combined reporting and, in the case of throwback rules, whether a state eliminates "nowhere income" that would be untaxed by either the state with the corporation's nexus or the state in which the relevant sales were being made.

Data on state investment tax credits and R\&D tax credits come from Chirinko and Wilson (2008), and Wilson (2009) provides the rate of each of these credits. For the R\&D credit, we use the statutory credit rate adjusted for recapture and type of credit. States vary in how they implement R\&D tax credits. States determine whether the $R \& D$ tax credit applies to all qualified expenditures, or whether the base is incremental based on previous expenditures. In addition, the basis of previous expenditures may be fixed in time or may be a moving average of recent activity. We control for two indicators for whether the base is incremental and fixed, or whether it is incremental and based on a moving average.

Loss rules specify the number of years that a corporation may carry back net operating loss prior to the loss as well as the number of years a corporation may carry forward any excess loss following the loss year. The depreciation indicators describe whether a state conforms to federal depreciation rules and adopts federal bonus depreciation policies that accelerate investment incentives (see Zwick and Mahon (2017) for policy details). Finally, we use apportionment weights for payroll, property, and sales that were digitized from CSG Book of the State (1976-2011). These weights determine the share of national profits of multi-state firms that is taxable in a given state (see section IV.B of Suárez Serrato and Zidar (2016) for policy details on apportionment).

In addition to our data on tax base measures, we use a few other data sources in the analysis. We use statutory state corporate income tax rates from CSG Book of the State (1976-2011), top statutory personal income tax rate from NBER TAXSIM, GDP from the U.S. Bureau of Economic Analysis (1967-2016), and tax revenue data from the U.S. Department of Commerce (1942-2012). ${ }^{7}$

Table 1 provides summary statistics of our main base measures. In the pooled sample from 1980 to 2010, roughly half of the states had throwback rules and franchise taxes. Most used federal income as the state tax base and followed accelerated depreciation schedules (although some states stopped allowing for bonus depreciation for budgetary reasons). Roughly a quarter of states in the pooled sample used combined reporting

\footnotetext{
${ }^{7}$ See Feenberg and Coutts (1993) for more details on NBER TAXSIM. In robustness analysis, we also use use annual payroll from County Business Patterns (2010), and, for a subset of states and year, additional base controls from Bartik (2017), such as property taxes and job creation tax credits.
} 
rules, although this share has been increasing over time. ${ }^{8}$

\section{Trends and Changes in the State Corporate Tax Structure}

The structure of state corporate taxation varies widely across states and over time. Figure 1 shows that the statutory corporate income tax rate varies between 0 and 12\%. Five states (Nevada, South Dakota, Texas, Washington, and Wyoming) currently have no taxes on corporate income. As of 2012, another five states (Alaska, Illinois, Iowa, Minnesota, and Pennsylvania) had tax rates above 9\%. Figure 1 shows that over the past few decades, very modest increases in the state corporate tax rate distribution across states have been accompanied by substantial declines in state corporate tax revenue as a share of economic activity. Panel A of Figure 2 shows this pattern directly - average state corporate tax rates are quite stable, but the average state corporate tax revenue as a share of GDP has declined nearly 40\%. While part of this decline arises from the shift away from the traditional corporate form (Cooper et al. (2016)), losses and other factors (Auerbach and Poterba (1987)), part of this decline is due to changes in the state corporate tax base. ${ }^{9}$

Table 2 describes the number of changes to each of our tax base measures. This table shows that there are more changes categorized as tax base narrowing than broadening, which suggests that an aggregate trend towards narrower bases is partly responsible for the patterns in Figures 1-2. Of these changes, the increase in the number of years allowed for carrying losses forward and the increased reliance on sales as a factor for apportionment are the most frequently reformed measures in our data.

Table 3 compares changes in the tax base with changes in the tax rate. As the resurgent literature studying the effects of state corporate taxes on economic activity has noted, there have been a considerable number of changes to states' tax rates. This table shows that states have decreased rates in 70 occasions, while increasing rates 103 times, for a total of 173 changes. However, this considerable policy activity pales in comparison to changes to the states' tax bases. Table 3 shows that states have adopted changes that narrow the tax base in 283 occasions, while increasing the base 163 times, for a total of 446 tax base changes.

A widespread belief among economists and policy analysts is that increases in tax rates have relatively small effects on firms' tax obligations, since legislatures often change tax rates and tax bases simultaneously. ${ }^{10}$ In particular, if tax increases are accompanied by the narrowing of tax bases, firms' effective tax rates will be less susceptible to changes in the statutory rate. Panel B of Figure 2 shows for each year the number of states that change their corporate tax rates and base provisions. Most points fall below the red 45 degree line, illustrating that in almost all years in which states change their tax base, most of them do not change their tax rates. ${ }^{11}$

\footnotetext{
${ }^{8}$ Panel B in Table 1 provides summary statistics for the cross section of states in 2010 and shows that roughly half the states had combined reporting in 2010. Appendix Table A1 provides summary stats of the additional Bartik (2017) controls for the subset of states and years for which these data are available.

${ }^{9}$ Ideally, one could decompose the importance of these different channels as in Auerbach and Poterba (1987). However, the necessary state level inputs for this exercise are not publicly available. See Bartik (2017) for a detailed industry-state level analysis of business tax incentives since 1990.

${ }^{10}$ This belief is supported by cross-country studies, as in Devereux and Sørensen (2006) and Kawano and Slemrod (2015). At the subnational level, however, other authors have noted cases where the tax base is set at the federal level, while the tax rates are set at the sub-national level (Fuest, Peichl and Siegloch, 2018).

${ }^{11}$ Appendix Figure A1 shows that this finding is also consistent in recent years and states that coincide with the analysis sample in Bartik (2017).
} 
Table 3 provides additional evidence that state tax rates and tax bases are not typically temporally related, by showing the number of times that states changed rates and tax bases. This table shows that in most occasions (43 out of 70) when states lowered tax rates, these changes were not accompanied by a tax base change. Similarly, when states increased tax rates, there were relatively few occasions when states also changed the tax base (only 9 out of 103). Conversely, Table 3 also finds that when states changed tax bases, these changes were very seldom accompanied by changes in the tax rates (23 out of 283 for base-narrowing changes, and 22 out of 163 for base-broadening changes). ${ }^{12}$

Table 4 formalizes this point by presenting probit estimates of the likelihood of a coincidence in base and rate changes. The first panel estimates the probability of a change in tax base as a function of a rate change. This panel shows that changes in tax rates are not predictive of changes in tax bases, and that this pattern is robust to splitting the dependent variable into base-narrowing and broadening events. Panel B estimates the converse relation using changes in tax bases to predict changes in tax rates. In particular, when we estimate the likelihood of a tax increase, we observe that there is no statistical relation with a state also narrowing the tax base. We only find a modest correlation between the likelihood of a tax change and a broadening of the base. The third column shows this result is driven by tax decreases and base broadenings. However, it is sensitive to a few number of observations. ${ }^{13}$ These results contrast with those of Kawano and Slemrod (2015), who estimate similar models for OECD countries and find statistically significant relations in all categories.

We now describe trends in specific tax base and credit provisions. Figure 3 shows how tax credits, loss rules, other base provisions and apportionment weights have evolved over time. Panel A of Figure 3 shows that tax credits, especially R\&D credits, have become much more generous. Panel B shows that loss carryforward provisions have become more favorable, and loss carryback provisions have remained relatively stable. Figure 4 shows how the distributions of many of these provisions have tended to become more generous over the past few decades. In 1980, research and development credits were rare. Beginning in 1990, some states introduced credits, but the vast majority of these were small - below $5 \%$. R\&D tax credits have become more common in the twenty-first century. Many states have increased the size of the credit; as of 2010, a large share of states offer credits even more generous than the most generous provisions in 1990 . However, the generosity of these credits has been reduced by adoption of rules that limit R\&D tax credits to incremental expenditures. The data reveal similar patterns for the investment tax credit and loss carryforward provisions, which have on aggregate changed with the result of narrowing the tax base. ${ }^{14}$

Panel $\mathrm{C}$ of Figure 3 shows that states have continued to narrow their base by increasing the apportionment weight on sales, and decreasing the weights on property and payroll. In 1980, the majority of states placed less than half of the apportionment weight on sales. This share declined steadily until 2010 , leaving only 12 states with sales apportionment shares below 50\%. Figure 4 depicts this shift and the implications for the sales apportioned corporate tax rate, which is the product of the statutory corporate tax rate and the sales weight. Given the secular decline in payroll and property weights, it is not surprising that the range of this distribution

\footnotetext{
${ }^{12}$ Appendix Table A3 provides more detail by describing the co-movement of tax rates and each individual tax base measure.

${ }^{13}$ In particular, the adoption of throwback rules in 2007 by a small number of states is responsible for this result. In Appendix Table A4 we show that this result is not robust to ignoring these changes.

${ }^{14}$ Appendix Figures A5-A19 provide additional detail behind changes in individual tax base measures by state.
} 
is more compressed than the distribution of sales-apportioned corporate rate. However, it is striking that the distribution of the sales-apportioned corporate rate is skewed to the right and has, if anything, become more dispersed in recent years by increasing the density of states with higher sales-apportioned corporate rates.

In contrast, other dimensions of the tax base have expanded over the past few decades. Panel D of Figure 3 shows an increasing number of states have adopted the federal definition of the state tax base for state tax purposes. This policy choice limits the extent to which state lawmakers can tinker with the tax base, but also puts states at risk of changes in federal policy that may have adverse effects on state tax revenues. The panel also shows a slight increase in the number of states adopting throwback rules that limit the ability of companies to have "nowhere income" under state apportionment rules, especially in later years. Similarly, many states adopted combined reporting rules that strengthen the reporting requirements for unitary businesses. This panel also shows that states have moved away from allowing federal income taxes to be deducted from state taxation. The most notable change is the reduction in the number of states adopting bonus depreciation in the early 2000s, which is likely due in part to the substantial fiscal cost of these provisions in a period of reduced tax revenues (Ohrn, 2016).

The structure of the corporate tax system has been an active area for state policymakers. Contrary to conventional wisdom, we do not find evidence of a temporal concomitance in tax rate and tax base changes. ${ }^{15}$ While some aspects of the tax base have become more generous for corporations (e.g., loss carryforward provisions and $\mathrm{R} \& \mathrm{D}$ and investment tax credits), changes in other rules have broadened the tax base (e.g. throwback and combined reporting rules). The following section explores the degree to which these changes to states' corporate tax systems explain changes in tax revenue.

\section{Decomposing Variation in State Corporate Tax Revenue}

The mapping from the state corporate tax structure to state corporate tax revenue is complex. We begin our analysis by taking a first-order approximation of state corporate tax revenue $R(\tau, \mathbf{X})=\tau \times B(\tau, \mathbf{X})$, which is a function of the state corporate tax rate $\tau$ and the tax base $B(\tau, \mathbf{X})$, which depends on a vector of state corporate tax base rules $\mathbf{X}$. An approximation of the state corporate tax revenue function around $\left(\tau^{*}, \mathbf{X}^{*}\right)$ is:

$$
R(\tau, \mathbf{X}) \approx \underbrace{R^{*}\left(1-\frac{\varepsilon_{R, \tau}}{\tau^{*}}-\sum_{j} \frac{\varepsilon_{R, X}}{X^{j, *}}\right)}_{\text {constant }}+\tau \frac{d R^{*}}{d \tau}+\sum_{j} X^{j} \frac{d R^{*}}{d X^{j}}
$$

\footnotetext{
${ }^{15}$ Appendix Table A5 presents estimates of how the probability of changes in the state corporate tax structure relates to changes in the tax structure of neighboring states in Panel A and of similar states in Panel B. For example, from a baseline probability of $3.1 \%$, states are $-0.1,-0.1$ and 0.0 percentage points more likely to increase their state corporate tax if, in the prior year, their neighbor increased their corporate tax rate, cut their corporate tax rate or broadened their tax base, respectively. None of these effects were statistically significant. Appendix Table A6 provides analogous results using changes in the past five years. Appendix B describes how we execute the analysis and define similar states.
} 
where $X^{j}$ is an element of the state corporate tax base that is indexed by $j .{ }^{16}$

We use equation 1 as a point of departure for decomposing state corporate tax revenue into three components: a component related to state corporate tax rates, a component related to the state corporate tax base, and a residual component, i.e.,

$$
R_{s t}=\alpha+\gamma \tau_{s t}+\underbrace{\mathbf{X}_{s t}^{\prime} \mathbf{\Psi}_{s t}^{B A S E}}_{\text {Base Index } s t}+u_{s t}
$$

where $R_{s t}$ is state corporate tax revenue as a share of state GDP and $\mathbf{X}_{s t}$ is a vector of tax base controls described in Section 1. The residual component is $\alpha+u_{s t}$.

We can then study the variation in state corporate tax revenue shares by decomposing the variation in these components.

$$
\operatorname{Var}\left(R_{s t}\right)=\operatorname{Var}\left(\alpha+\gamma \tau_{s t}+\mathbf{X}_{s t}^{\prime} \mathbf{\Psi}_{s t}^{B A S E}+u_{s t}\right)
$$

We estimate the share of the variance in $R_{s t}$ which can be explained by these independent variables overall and then individually.

Figure 5 presents the results. ${ }^{17}$ Panel A shows that roughly half the variation in corporate tax revenue as a share of GDP across states and over time can be explained by the state corporate tax structure. Of this explained variation, state corporate tax base and credits explain more of the variation than state corporate tax rates. Panel $\mathrm{B}$ and $\mathrm{C}$ examine this result further by showing the importance of variation from specific tax base and credit rules. The contribution to the variance from a given base provision $j$ is $\operatorname{Var}\left(x_{s t}^{j} \Psi_{s t}^{j}\right)$, which depends on the variance of the rule $x_{s t}^{j}$ and the magnitude of its relationship with corporate tax revenue as a share of GDP $\Psi_{s t}^{j}$. Panel B shows the overall contribution from each rule, i.e., $\frac{\operatorname{Var}\left(x_{s t}^{j} \Psi_{s t}^{j}\right)}{\sum_{j} \operatorname{Var}\left(x_{s t}^{j} \Psi_{s t}^{j}\right)}$. The five most important rule provisions are having a franchise tax (21\%), sales apportionment weights (20\%), using the federal income tax as state base (17\%), the deductibility of the federal income tax (16\%), and throwback rules (8\%). ${ }^{18}$ To isolate the importance of variation in the effects of base rules $\Psi_{s t}^{j}$, we standardize the rules $\tilde{x}_{s t}^{j}=\frac{x_{s t}^{j}-\bar{x}_{s t}^{j}}{\sigma_{x_{j}}}$ and then regress each standardized rule on revenue as a share of GDP. Panel C shows the results. Each row shows the point estimate of $\tilde{\Psi}_{s t}^{j}$, which is the effect of a one standard deviation increase in standardized tax base measure $\tilde{x}_{s t}^{j}$. Two aspects of this figure are interesting: the direction and magnitude of each effect. First, Panel C shows, for example, that a one standard deviation increase in standardized sales apportionment is associated with a 30 basis point decrease in state corporate tax revenue as a share of GDP. This impact is

16 This expression follows from the following first-order approximation:

$$
R(\tau, \mathbf{X}) \approx R^{*}+\left(\tau-\tau^{*}\right) \frac{d R^{*}}{d \tau}+\sum_{j}\left(X^{j}-X^{j, *}\right) \frac{d R^{*}}{d X^{j}}=R^{*}-\tau^{*} \frac{d R^{*}}{d \tau}-\sum_{j} X^{j, *} \frac{d R^{*}}{d X}+\tau \frac{d R^{*}}{d \tau}+\sum_{j} X^{j} \frac{d R^{*}}{d X^{j}},
$$

where $R\left(\tau^{*}, \mathbf{X}^{*}\right)=R^{*}, \frac{d R^{*}}{d X^{j}}=\tau^{*} \frac{d B\left(\tau^{*}, \mathbf{X}^{*}\right)}{d X^{j, *}}$, and $\frac{d R^{*}}{d \tau}=B\left(\tau^{*}, \mathbf{X}^{*}\right)+\tau^{*} \times \frac{d B\left(\tau^{*}, \mathbf{X}^{*}\right)}{d \tau}$, and from expressing the first group of terms as elasticities. Clausing (2007), Devereux (2007), and Kawano and Slemrod (2015) motivate their analysis with similar derivations.

${ }^{17}$ Each decomposition is weighted by mean state GDP across the full period (1980-2010). Appendix Figures A2 and A3 show a version of equation 2 and equation 3 that uses $\ln R_{s t}$ as the outcome. Appendix Table A7 shows the results for different specifications. Appendix Table A8 shows how the base rules and their changes are correlated. See Appendix Table A2 for variance decomposition results that take Bartik (2017) controls into account for the subset of states and years for which these controls are available.

${ }^{18}$ We present further results of this variance decomposition in Table A7. For example, when we control for an interaction of throwback rules and apportionment weights, the explanatory power of the throwback rule increases. 
positive and relatively large compared the overall contribution to the variance shown in Panel B. The largest negative correlate is an indicator for having a franchise tax, which is more common among southern states and sometimes substitutes for having any corporate tax system at all (e.g., Texas). ${ }^{19}$ Most of the base and credit provisions listed are positively related to revenue as a share of GDP, except for federal income tax deductiblitly, loss provisions, and depreciation provisions, which are associated with less corporate tax revenue as a share of GDP. Overall, tax base and credit rules account for the majority of the explained variation in corporate tax revenues as a share of GDP.

Figure 6 shows that the explanatory power of base and credit rules has evolved over time. Specifically, it shows the share of variation for each five-year interval from 1980-2010 that can be explained by the state corporate tax structure in Panel A, rates versus base and credit rules in Panel B, and for each base rule in Panel C. The upper left panel shows that the state tax policy parameters explain roughly half of the variation in state corporate tax revenues as a share of state GDP. The upper right panel shows that a larger share of the explained variance is accounted for by state corporate tax base rules. Sales apportionment weights and loss provisions were quite important in the first half of the sample period. More recently, however, federal provisions (such as adopting the federal tax base and federal bonus depreciation or allowing for the deductibility of federal taxes) have grown in importance. Additionally, franchise taxes and loss carryforward provisions have also increased their share of explained variance.

\section{Impacts on State Tax Revenue and Economic Activity}

We now analyze how taxes impact state tax revenue and economic activity. Equation 1 shows that tax base controls should be included when estimating the effects of state taxes on state outcomes. In this section we focus on the extent to which omitting state corporate tax base affects these estimates. We first explore an event study approach that flexibly captures the dynamic effects of tax changes. We then summarize these results with a more parsimonious regression specification.

\subsection{Event Study Estimates}

We begin with an analysis of the typical path of state outcomes preceding and following a change in the state corporate tax structure. We use an event study specification of the form:

$$
Y_{s t}=\alpha_{s}+\gamma_{t}+\sum_{k \in\{-4,-3,-2,0,1,2,3,4,5\}} \beta_{k} D_{s t}^{k}+\underline{\beta} \sum_{k<-4} D_{s t}^{k}+\bar{\beta} \sum_{k>5} D_{s t}^{k}+\varepsilon_{s t}
$$

where $D_{s t}^{k}$ is an indicator for state $s$ having changed the state tax rate $k$ periods in the past, $\alpha_{s}$ is a state fixed effect, and $\gamma_{t}$ is a time fixed effect. The coefficients $\beta_{k}$ provide the impact on the time path of mean outcomes relative to the period before the tax rate change (which has been normalized to zero). Additionally, we address imbalance issues by "binning" periods greater than 5 or less than -4 , which is reflected in the $\bar{\beta}$

\footnotetext{
${ }^{19}$ See Appendix Figure A6 for a map of which states have franchise taxes.
} 
and $\underline{\beta}$ coefficients that are assumed to be stable within end point bins. To address serial correlation in $\varepsilon_{i t}$, all standard errors are clustered by state. We consider three main outcomes: state corporate tax revenue as a share of state GDP, log state corporate tax revenue, and log state GDP.

We fit specifications of this type on our state panel data using data from 1980 to 2010. We also consider specifications that control for the leads and lags of key components of the tax base. Specifically, we control for leads and lags of the six most important tax base controls in terms of variance shares of corporate tax revenue: federal income tax treated as state base, sales apportionment weight, throwback rules, federal income tax deductibility, loss carryforward, and franchise tax.

Figure 7 shows the results for corporate tax cuts and corporate tax increases that exceed a 0.5 percentage point change in the rate in absolute value on state outcomes. ${ }^{20}$ Panel A shows that corporate tax decreases that exceed 0.5 percentage point cuts in the rate tend to reduce state corporate tax revenue as a share of state GDP by roughly 6 percentage points cumulatively over a 5 year period. Panels B and C show the importance of the numerator and denominator separately. Despite modestly higher economic activity, corporate tax cuts decrease state tax revenue by roughly $10 \%$. The increases in state GDP are imprecise and not statistically different than zero, though the point estimate is roughly $2 \%$. Controlling for the tax base does not alter these general patterns. Panels D, E, and F show that tax increases have symmetric impacts, though pre-trends are

a bit more noticeable prior to state corporate tax increases. Specifically, the event studies in D and E show that tax revenues were also higher preceding the tax increase events by roughly a similar magnitude, so it is not clear that corporate tax revenues actually increase following tax increases. We view these event studies as describing the typical evolution of outcomes before and after tax changes. Since these tax changes potentially include some endogenous changes that are intended to address current (or expected) economic conditions, these impacts are descriptive and not causal. ${ }^{21}$ Overall, these point estimates of the effect of state corporate tax changes are imprecise, but the key finding for our purposes is that they do not depend strongly on base controls on average.

\subsection{Regression Estimates}

We summarize these relationships by estimating equation 2 with state and year fixed effects, i.e.,

$$
R_{s t}=\alpha_{s}+\phi_{t}+\gamma \tau_{s t}+\mathbf{X}_{s t}^{\prime} \mathbf{\Psi}_{s t}^{B A S E}+u_{s t},
$$

\footnotetext{
${ }^{20}$ We focus on the impacts of non-trivial changes in state corporate tax rates and present analogous results for all state changes in Appendix Figure A23. The threshold of 0.5 percentage points includes roughly half the state corporate tax changes (see Appendix Figure A24 for a histogram). A corporate tax cut that exceeds 0.5 percentage points amounts to roughly a one percentage point cut in state corporate tax rate on average. On average, a corporate tax increase that exceeds 0.5 percentage points corresponds to a 1.5 percentage point increase in the state corporate tax rate. Controlling for leads and lags of the other tax base controls (in addition to the ones in our baseline specification) results in similar but slightly noisier estimates as shown in Appendix Figure A26.

${ }^{21}$ For example, macroeconomic shocks might induce changes in state corporate tax systems. Appendix Figure A25 shows analogous results to Figure 7 for the subset of state corporate tax changes that Giroud and Rauh (2015) classify as exogenous.
} 
This specification increases statistical precision relative to the event study equation 4 by combining the periods before and after tax changes and by imposing symmetry in the effects of tax increases and decreases. ${ }^{22}$ Column (1) of Table 5 shows results when we omit tax base controls. This estimate implies that increasing the state corporate tax rate by 1 percentage point leads to an increase in corporate tax revenues relative to GDP of 1.8 basis points. Relative to the average value of $R_{s t}$ of 35 basis points, a 1 percentage point increase in $\tau$ represents a $(1.8 / 35=) 5 \%$ increase in $R_{s t}$.

Column (2) of Table 5 shows that including controls for the tax base does not affect this estimate, which reinforces the results from the event studies in Figure 7. However, including these controls increases the precision of the estimate. As we discussed in Section 3, these controls have large explanatory power on the revenue-to-GDP ratio. The coefficients on the tax base controls have a similar interpretation as those in Figure 5. For instance, some controls that narrow the base - including the R\&D tax credit, the investment tax credit, and an indicator for allowing the deductibility of federal income taxes - have negative effects on $R_{s t}$. Conversely, controls that correspond to broader bases, such as throwback rules or incremental tax bases for R\&D tax credits, have positive effects on $R_{s t}$. Having a franchise tax also negatively impacts $R_{s t}$, as states with a franchise tax often use it as an alternative to a tax on corporate income.

\subsubsection{Base Index}

We can use these estimates to construct a composite measure of the tax base. We define an index of the breadth of the tax base: Base Index st $=\frac{\sum_{j \in \mathcal{J}} \tilde{x}_{s t}^{j} \tilde{\Psi}_{s t}^{j}}{\sigma^{B}}$, where $\mathcal{J}$ is the set of all 15 base and credit controls, and where we normalize this index to have unit standard deviation. A regression that replaces the base controls with the Base Index recovers $\sigma^{B}$ as a regression coefficient. We report this estimate in the bottom of Column (2), which is statistically significant at the 1-percent level, and implies that increasing the Base Index by 1 standard deviation leads to an increase in $R_{s t}$ of 30 basis points.

\subsubsection{Separating Effects on Revenue and GDP}

Taxes may affect the revenue-to-GDP ratio by increasing revenues or by decreasing GDP. We estimate the effects on the numerator and denominator separately. To facilitate comparisons across states and across time, we present estimates of the effects on log state corporate tax revenue and on log state GDP. For these specifications we report the effect of the $\log$ keep rate, i.e., $\ln (1-\tau) .{ }^{23}$ Columns (3) and (5) of Table 5 show that an increase in the $\log$ keep rate reduces revenue and increases GDP. Columns (4) and (6) further show that controlling for the tax base does not have large effects on these estimates. However, some tax base controls affect these outcomes even when the effect on $R_{s t}$ is not statistically significant. For instance, states with a franchise tax and states that allow for the deductibility of federal income taxes have both lower revenues and lower GDP. ${ }^{24}$

\footnotetext{
${ }^{22}$ In these estimations we weight observations by the mean GDP in the state over our sample, and the standard errors allow for arbitrary correlation between observations from a given state. We scale the revenue-to-GDP variable so that coefficients can be interpreted in terms of basis points.

${ }^{23}$ We use $\ln (1-\tau)$ because these expressions are in $\log$ form and the keep rate formulation avoids taking logs of zeros for states that have no state corporate tax.

${ }^{24}$ It may also be the case that tax base controls have dynamic effects on these outcomes. A full discussion of the effects of each base control is beyond the scope of this paper. Nonetheless, Appendix Figures A30-A44 present results of event studies
} 


\section{Heterogeneous Effects of Tax Rate Changes}

This section relaxes the assumption of homogeneous treatment effects of $\tau$. We show that tax base interactions with the tax rate can lead to heterogeneous effects across time and states, and that omitting these interactions leads to biased estimates of the average treatment effect of state corporate tax rate changes.

Changes in state corporate tax rates may have differential effects on tax revenue and economic activity depending on the breadth of the tax base. Intuitively, a tax increase should raise less revenue whenever the tax base is relatively narrow. This intuition holds (1) for mechanical effects, since narrow bases by definition tax a smaller share of profits; (2) for reporting responses, since firms in states with narrow bases may respond by adopting new deduction strategies; and (3) for behavioral responses, since firms are likely to respond less to a tax increase whenever the tax affects a smaller share of their profits. ${ }^{25}$ As a hypothetical example, suppose that California and New York both increase their state corporate tax rates, but suppose further that California has a much more lenient treatment of loss carryforward provisions. Firms in California with past losses will face a smaller increase in their effective tax liability as firms in New York, since the tax base in California is narrower. Any behavioral response by firms that depends on current rates, such as investment, employment, or relocation, will therefore be more muted in California than in New York. While this example only mentions loss carryforward provisions, the treatment of other aspects of the tax base, such as depreciation allowances or investment tax credits, may also modulate the degree to which tax changes affect tax revenue.

\subsection{Econometric Intuition}

When the effect of a state corporate tax rate change depends on the tax base, estimates that do not account for tax-base-driven heterogeneity can lead to bias in average treatment effects. The intuition for this bias follows directly from the Omitted Variable Bias (OVB) formula. For simplicity, consider the case in which there are two types of states with narrow and broad bases, and that the effects of tax changes depend on the tax base.

The long regression is:

$$
R_{s t}=\alpha+\beta_{1} \tau_{s t}+\beta_{2} \tau_{s t} \times \mathbb{I}\{\text { Narrow Base }\}_{s t}+\delta \mathbb{I}\{\text { Narrow Base }\}_{s t}+u_{s t}
$$

If we assume that the effect of a tax rate change in broad-base states $\left(\beta_{1}\right)$ is greater than in narrow-base states $\left(\beta_{1}+\beta_{2}\right)$, we might worry that a short regression that omits the interaction term $\tau_{s t} \times \mathbb{I}\{\text { Narrow Base }\}_{s t}$ will yield a biased estimate of the average effect across states, i.e., $\beta_{1}+\beta_{2} \operatorname{Pr}$ (Narrow Base). The OVB formula shows that the short regression estimate will be biased: ${ }^{26}$

$$
\mathbb{E}\left[b_{1}\right]=\beta_{1}+\beta_{2} \times \frac{\mathbb{C o v}\left(\tau_{s t}, \tau_{s t} \times \mathbb{I}\{\text { Narrow Base }\}_{s t}\right)}{\operatorname{Var}\left(\tau_{s t}\right)}=\beta_{1}+\beta_{2} \operatorname{Pr}(\text { Narrow Base }) \times \frac{\operatorname{Var}\left(\tau_{s t} \mid \text { Narrow Base }\right)}{\operatorname{Var}\left(\tau_{s t}\right)} .
$$

around changes in the tax base controls. From these graphs, the most interesting case is the adoption of incremental tax base for R\&D tax credits, which led to tax increases in future years by limiting the value of R\&D tax credits.

${ }^{25}$ Indeed, our derivation above implies that the marginal effect of taxes will depend on the base through both mechanical and behavioral effects of taxes: $\frac{d R}{d \tau}=B(\tau, \mathbf{X})+\tau \times \frac{d B(\tau, \mathbf{X})}{d \tau}$.

${ }^{26}$ Where the short regression is given by: $R_{s t}=\stackrel{d \tau}{a}+b_{1} \tau_{s t}+d \mathbb{I}\{\text { Narrow Base }\}_{s t}+u_{s t}$. 
The sign and magnitude of the bias is governed by two forces: (1) heterogeneous effects due to the tax base interactions (i.e., $\beta_{2} \gtrless 0$ ) and $(2)$ the covariance between the interaction term and $\tau$. First, the sign and magnitude of the effect of tax base provision $\beta_{2}$ depends on the base rule. For base-narrowing provisions, we expect $\beta_{2}<0$. Second, the term $\beta_{2}$ is scaled by the covariance between the tax rate and the interaction. In contrast to the average treatment effect, which scales $\beta_{2}$ by the fraction of the population with a narrow base, the short regression scales $\beta_{2}$ by a different term. ${ }^{27}$ In the case of indicator variables, this scaling term is the conditional variance of the state corporate tax rate in narrow-base states.

If $\beta_{2}<0$ and narrow-base states change taxes more frequently (i.e., $\operatorname{Var}\left(\tau_{s t} \mid\right.$ Narrow Base) $\left.>\operatorname{Var}\left(\tau_{s t}\right)\right)$, then omitting the interaction term will result in a downwardly-biased estimate of the average effect of taxes on revenues. The general case with 15 interactions is slightly more complex, but the potential biases from not including interactions have a similar intuition. This type of bias is well known in the econometrics literature (e.g., Wooldridge (2005)), and has been shown to be empirically important across several fields of applied economics (Gibbons, Suárez Serrato and Urbancic, 2014).

\subsection{Estimates of Heterogeneous Effects of Tax Rate Changes}

To explore tax-base-driven heterogeneity, we expand the model of equation 2 to include interaction terms between the tax rate and the tax base controls:

$$
R_{s t}=\alpha_{s}+\gamma_{t}+\beta_{0} \tau_{s t}+\sum_{j=1}^{15} \beta_{j} \tau_{s t} \times \tilde{x}_{s t}^{j}+\tilde{\mathbf{x}}_{s t}^{\prime} \tilde{\mathbf{\Psi}}_{s t}^{B A S E}+u_{s t},
$$

where $\tilde{x}^{j}$ 's are the standardized base rules, which facilitates the interpretation of $\beta_{0}$ as the mean effect of $\tau$. Column (1) of Table 6 presents the results from a model that controls for the tax base but that omits interactions (as in Column (2) of Table 5), and Column (2) includes the interactions. In contrast to the results of Table 5, we find that including interaction terms leads to a larger average effect of the corporate tax rate on the revenue-to-GDP ratio, with the estimate increasing from 1.6 to 2.4 basis points. This effect is $50 \%$ larger, which is strong evidence that tax-base interactions matter and that the OLS estimator is not a consistent estimator for the average effect across states. Relative to the mean value of $R_{s t}=35$ basis points, a 1 percentage point increase in $\tau$ leads to a $(2.4 / 35=) 7 \%$ increase in the revenue-to-GDP ratio.

For a given state with a tax base $\tilde{\mathbf{x}}_{s t}$, the total effect of $\tau$ on $R_{s t}$ is given by:

$$
\beta_{R}\left(\tilde{\mathbf{x}}_{s t}\right)=\beta_{0}+\sigma^{J} \underbrace{\sum_{k=1}^{15} \frac{\beta_{k}}{\sigma^{J}} \tilde{x}_{s t}^{k}}_{\text {Joint Interactions }}
$$

where $\sigma^{J}$ equals the standard deviation of the linear combination $\left(\sum_{k=1}^{15} \beta_{k} \tilde{x}_{s t}^{k}\right)$. The joint interaction term has mean zero, since the $\tilde{x}_{s t}^{k}$ 's are normalized, and a unit standard deviation since we divide by $\sigma^{J} .{ }^{28}$ The

\footnotetext{
${ }^{27}$ Except in knife-edge cases, these weights do not coincide with sample frequencies and the resulting weighted average is not representative of the average effect across states.

${ }^{28}$ We first estimate 5 to recover $\beta_{k}$ 's. By construction, the estimate of $\beta_{0}$ is not affected by this procedure. Note also that,
} 
specification in equation 6 has two main advantages. First, the joint interaction term is a useful data-reduction measure that captures the variation across 15 bases in a single index. Second, the statistical significance of the the total effect $\beta_{R}\left(\mathbf{X}_{s t}\right)$ for a given state depends on the covariance matrix of the individual $\beta_{k}$ terms. While it is hard to evaluate the joint statistical importance of these interactions from individual coefficients, the joint interaction term collapses the covariance structure and allows for a simple univariate statistical analysis.

Column (2) in Table 6 reports the coefficient on the joint interactions. The joint interaction term is statistically significant and shows that interactions between the tax rate and the tax base are economically important. For instance, a 1 percentage point tax increase in a state with a joint interaction term that is two standard deviations above the mean would increase $R_{s t}$ by $(2.4+2 \times 1.25 \approx) 5$ basis points. Conversely, a state with a joint interaction term that is two standard deviations below the mean would not see an increase in revenue. ${ }^{29}$

Columns (3)-(6) in Table 6 report the effects of $\ln (1-\tau)$ on log-GDP and log-revenue. As before, controlling for the tax base does not have large effects on our estimates of $\beta_{0}$. While an increase in $\ln (1-\tau)$ both reduces revenue and increases GDP, we find that the effects on revenue are a larger driver of the net effect on the revenue-to-GDP ratio. In addition, these columns also show that both state GDP and state tax revenue are subject to statistically significant joint interactions between $\ln (1-\tau)$ and the tax base. For the case of logrevenue, we find that the mean effect is much larger in Column (4) than in Column (3), while the mean effect $\beta_{0}$ on log-GDP is less affected by introducing interactions.

This joint interaction term can be decomposed into the individual interactions, which are presented in the remaining rows of Table $6 .{ }^{30}$ Figure 8 further describes how each of the interaction terms contributes to the joint interaction term for each outcome. Panel A plots the fraction of the variation in the total effect $\beta_{Y}\left(\tilde{\mathbf{x}}_{s t}\right)$ for each outcome that is driven by each of the base controls. Each contribution in this graph is driven by the coefficient of each interaction term, as well as by the number of tax base changes for each control. This figure shows that the heterogeneous effects for the revenue-to-GDP ratio are driven mostly by the R\&D tax credit, the presence of a franchise tax, the allowance for federal accelerated depreciation, and the deduction of federal taxes. Of these four policies, the franchise tax and the allowance for federal depreciation drive variation through heterogeneous effects on corporate revenue, while the allowance for the deductibility of federal taxes has a larger effect on GDP. For example, a 1 percentage point tax increase in a state with a franchise tax would increase $R_{s t}$ by $(2.4+0.7 \times 1 \approx) 3.1$ basis points, while an equal increase in a state without a franchise tax would only increase $R_{s t}$ by $(2.4+0.7 \times 0=) 2.4$ basis points. Panel B splits this decomposition by five-year intervals, and shows that the importance of the franchise tax and the deductibility of federal taxes has waned over time, while the importance of the allowance for federal accelerated depreciation and the R\&D tax credit has grown in importance over time.

without the standardization of the joint interaction term, we would obtain a coefficient of one on this variable.

${ }^{29}$ These results are robust to including lagged values of the the tax rate, the tax base, and the joint interactions. Table A10 shows that controlling for 1-5 lags of any of these variables does not affect the total cumulative mean effect of tax rates on revenues. See the note to Table A10 for more detail.

${ }^{30}$ We expect interaction terms to have a positive coefficient whenever they rules broaden the base. Conversely, we expect negative coefficients for rules that narrow the base. In Appendix A.2, we list these predictions for each interaction term. 


\subsection{Tax Base Trends and Implications for the Revenue Responses to Rate Changes}

We now evaluate how $\beta_{Y}\left(\tilde{\mathbf{x}}_{s t}\right)$ varies across states and over time due to changes in the state corporate tax base $\tilde{\mathbf{x}}_{s t}$. Figure 9 plots the average value of $\beta_{Y}\left(\tilde{\mathbf{x}}_{s t}\right)$ in a given year $t$, and shows that changes in tax bases between 1980 and 2000 diminished the effect of taxes on revenue. Consistent with the descriptive evidence in favor of narrowing tax bases in Section 2, this figure shows that tax cuts lead to smaller reductions in 2000 than 1980. This figure also shows that this pattern is slightly reversed during the 2000's. Two trends that we observe during this time are the adoption of combined reporting, which tightens the reporting requirements for unitary businesses, and of throwback rules, which limit the extent to which firms can have "nowhere income" under the apportionment system.

Figure 9 shows how the state average has evolved, but masks considerable heterogeneity across states. Figure 10 plots the estimated total effect $\beta_{Y}\left(\tilde{\mathbf{x}}_{s t}\right)$ for four selected states during our sample period. Delaware, for example, narrowed its tax base, which is reflected by a decrease in the effect of a tax change on revenue over time. This pattern is due to changes to the Delaware corporate tax base in the late 1990's that led to an increase in the number of years allowed for loss carryforward, and by the adoption of a generous $R \& D$ tax credit. In contrast, Michigan broadened its tax base by disallowing both the MACRS depreciation rule and federal accelerated and bonus depreciation rules. In addition, the adoption of throwback and combined reporting rules in the late 2000's further broadened the tax base. As a result, the second panel in Figure 10 shows that revenue became more responsive to changes in tax rates in the later years of our sample for Michigan. Pennsylvania and Rhode Island are examples of states whose experience mirrors the reversal pattern observed on average across states. Pennsylvania narrowed its tax base in the 1990's by increasing the number of years allowed for loss carryforward, as well as introducing R\&D and investment tax credits. In the 2000's, it reversed this trend by reducing the investment tax credit and introducing throwback and combined reporting rules. In Rhode Island, the narrowing of the base was due to the introduction of R\&D and investment tax credits, and the reversal was due to the disallowance of federal bonus depreciation. ${ }^{31}$

\section{Revenue-Maximizing-Tax Rate}

This section evaluates how the structure of the state corporate tax system determines the revenue-maximizingtax rate.

We extend the framework in equation 1 by introducing a quadratic term that can capture the degree to

\footnotetext{
${ }^{31}$ Appendix Figure A47 shows the total effect for each state year, which can be compared to the base changes by state in Appendix Figures A7-A19. Appendix Figure A48 compares the estimated effect across all states in 1985 and 2005 . These maps are consistent with the trends in Figure 9, as the map in 2005 has more states with effects closer to zero. However, this average effect masks considerable heterogeneity in experiences across states. In addition to Michigan, other mid-western states including Wisconsin, Ohio, and Illinois saw a broadening of the tax base between 1985 and 2000. In contrast, several other states including California, Oregon, Florida, and Massachusetts saw a narrowing of the tax base, as evidenced by the diminished effects of taxes on corporate tax revenue.
} 
which tax rate increases raise progressively less revenue, or even result in revenue losses: ${ }^{32}$

$$
R_{s t}=\beta_{0} \tau_{s t}+\delta_{0}\left(\tau_{s t}\right)^{2}+\alpha_{s}+\gamma_{t}+u_{s t}
$$

A positive value of $\beta_{0}$ indicates that introducing a small tax will increase revenue. A negative coefficient for $\delta_{0}$ means that the marginal effect of taxes on revenue is decreasing in $\tau{ }^{33}$ If $\delta_{0}<0$, the revenue-maximizing-tax rate is given by:

$$
\tau^{*}=\frac{\beta_{0}}{-2 \delta_{0}} .
$$

Panel A of Table 7 presents estimates of this regression. Columns (1) and (2) present specifications with and without state fixed effects. These columns show positive estimates for $\beta_{0}$, but the inclusion of state fixed effects reduces the precision of the estimate for $\beta_{0}$. The interpretation of a positive value for $\delta_{0}$ is that these regressions do not detect decreasing returns of increasing taxes, which may be due to the relatively low tax rates observed in the data. Since the implied relationship between tax rates and corporate tax revenues is convex, we cannot identify a revenue-maximizing-tax rate using these estimates of $\beta_{0}$ and $\delta_{0}$.

As in the previous section, we are interested in the possibility that the responsiveness to taxes, and the implied revenue-maximizing-tax rate, depend on the breadth of the tax base. We explore this possibility by allowing the linear and quadratic effects of taxes to depend on the Base Index $s t$ defined in Section 4.2.1. This

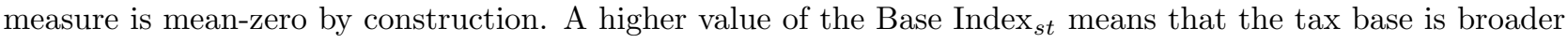
in the sense that the tax base controls are associated with a higher revenue-to-GDP ratio.

Armed with this measure, we estimate the regression:

$$
\begin{aligned}
R_{s t} & =\beta_{1} \tau_{s t}+\beta_{2} \tau_{s t} \times \text { Base Index }_{s t}+\delta_{1}\left(\tau_{s t}\right)^{2}+\delta_{2}\left(\tau_{s t}\right)^{2} \times \text { Base Index }_{s t} \\
& +\alpha_{s}+\gamma_{t}+\theta \text { Base Index } s t+u_{s t} .
\end{aligned}
$$

The revenue-maximizing-tax rate now depends on the base index:

$$
\tau^{*}\left(\text { Base Index }_{s t}\right)=\frac{\beta_{1}+\beta_{2} \times \text { Base Index }_{s t}}{-2\left(\delta_{1}+\delta_{2} \times \text { Base Index }_{s t}\right)} .
$$

Column (3), which includes the Base Index $x_{s t}$ as a control, still yields a positive estimate of $\delta_{0}$. Column (4), however, which includes state fixed effects, results in a negative value of $\delta_{0}$, and implies a value of $\tau^{*}$ of $31 \%$. Column (5), which is our preferred specification, further interacts the Base Index ${ }_{s t}$ and the tax rate. This specification also detects a negative but statistically insignificant coefficient for $\tau^{2}$. Evaluating the revenue-maximizing rate at the mean value of the base index yields a value of $\tau^{*}\left(\right.$ Base $\left.\operatorname{Index}_{s t}=0\right)$ of $27 \%$. Panel A of Figure 11 plots the estimated relation between the state corporate tax rate and $R_{s t}$ at the value Base $\operatorname{Index}_{s t}=0$. We also explore the heterogeneity in $\tau^{*}\left(\right.$ Base $\left.\operatorname{Index}_{s t}\right)$ that is implied by variation in

\footnotetext{
${ }^{32}$ Clausing (2007), Devereux (2007), and Kawano and Slemrod (2015) discuss results of similar specifications using data on OECD countries.

${ }^{33}$ The marginal effect of $\tau$ on revenue is $\frac{d R_{s t}}{d \tau}=\beta_{0}+2 \delta_{0} \times \tau$. For small taxes we have $\left.\frac{d R_{s t}}{d \tau}\right|_{\tau=0}=\beta_{0}>0$.
} 
Base Index $s_{s t}$ Panel B of Figure 11 plots the cumulative distribution function of the estimated $\tau^{*}\left(\right.$ Base $\left.\operatorname{Index}_{s t}\right)$ for every state-year in our data. The average revenue-maximizing rate is greater than $45 \%$ and the minimum value is greater than any corporate tax rate we observe in the data. ${ }^{34}$

Changes in corporate tax rates affect local economic activity and other forms of tax revenue. Indeed, in Suárez Serrato and Zidar (2016) we show that changes to state corporate tax rates affect the location decisions of firms and workers. These decisions affect the demand and supply of labor, which influences local population and income. As a result, state tax revenue from personal income taxes and sales taxes may also be affected by changes in state corporate tax rates. We quantify the importance of these fiscal externalities by estimating equations 7 and 8 on total tax revenue as a share of state GDP. Panel B of Table 7 presents estimates for these regressions. These results are qualitatively similar to those in Panel A, in that we do not find statistically significant decreasing returns to taxation on total tax revenue. Panel $\mathrm{C}$ of Figure 11 plots the estimated relation between the corporate tax rate and the total tax revenue-to-GDP ratio at the mean value of Base Index $_{s t}=0$, and shows that a tax rate of $9.6 \%$ maximizes total state tax revenue. Panel D of Figure 11 plots the CDF of the estimated revenue-maximizing-tax rates and shows a much more compressed distribution that centers around 10\%. As shown in Figure 1, only a few states have ever had tax rates above 10\%, and this fraction has been declining over time. ${ }^{35}$

Given the lack of precision in these estimates, we interpret these results as suggesting that the data do not show strong patterns of decreasing returns from increasing taxes. At the current levels of corporate tax rates, we can rule out the hypothesis that, for states with corporate tax rates below 10\%, cutting corporate tax rates has tended to raise corporate tax revenue.

\section{Discussion of Policy Implications}

This paper has established several facts detailing how state tax rates, base rules, and credits determine the structure of the state corporate tax system. We find that changes to tax base rules and credits are more common than changes in tax rates, and that changes in tax base rules are not enacted to temporally offset changes to tax rates. Further, we show that changes in tax base rules and credits play a more important role in explaining patterns in the revenue-to-GDP ratio across states than do changes in tax rates. We document trends in individual tax base rules over time and provide evidence that, while some states have broadened their tax bases by adopting combined reporting and throwback rules in recent years, most other measures of the tax base point toward a narrowing of the tax base. We analyze the role that tax base rules play in the estimation of the effects of tax rates on tax revenues and economic activity, and find that controlling for these rules does not affect the estimated effects. Instead, we show that accounting for heterogeneous effects of tax changes that depend on the structure of the corporate tax system is important both to obtain consistent estimates of the

\footnotetext{
${ }^{34}$ For many observations we do not find any evidence of decreasing returns, i.e., $\delta_{1}+\delta_{2} \times$ Base Index $_{s t}>0$, which results in a value of $\tau^{*}$ (Base Index $x_{s t}$ ) of $100 \%$. This result should not be interpreted as literally suggesting that revenue will be maximized with a tax rate of $100 \%$. Rather, this result suggests that the low values of $\tau$ in the data fail to identify a value of $\delta_{0}$ that implies strong decreasing returns to increasing taxes.

${ }^{35}$ These results are robust to controlling for state personal income taxes and sales taxes, as shown in Appendix Table A12 and Appendix Figure A49.
} 
average effect of changing taxes, and to more precisely forecast the revenue response of individual states with different corporate tax systems.

These findings have important implications for policy. First, while changes in tax rates receive public and media attention, changes in state tax bases may have larger effects on revenue and may also modulate the effects of state corporate tax rates on revenue and economic activity. For this reason, the public debate should place relatively more attention to policy changes that affect the structure of state corporate taxation, and not only the statutory tax rate.

Second, given the large effects of the structure of the tax base on corporate tax revenue, state policymakers should be careful to use these policies to accomplish particular goals. States that are able to attract businesses for non-tax reasons may prefer to have a lower tax rate and a broader base by, for instance, adopting the federal income tax base as their own. States wishing to increase investment may depart from this strategy by using tax credits or generous depreciation allowances to encourage investment, but they may see substantial declines in revenue. Finally, states wishing to attract or retain innovative businesses may craft a treatment of loss carryforward provisions that is very favorable to new businesses. Policymakers would likely benefit from further research outlining the relative success of these strategies.

Third, as states structure the taxation of corporate income for their particular needs and objectives, state policymakers should bear in mind that changes to the structure of state corporate taxation will influence the distortionary costs of increasing the state corporate tax rate. In particular, we find that when states narrow the tax base, they also diminish the relation between tax rates and corporate tax revenue. By making it harder to raise tax revenue from corporations, it is also likely that state policymakers will be forced to raise revenue from other sources including sales taxes, property taxes, or personal income taxes, or to reduce spending on public goods.

Future work can explore the degree to which tax base determinants affect the incidence of the state corporate income tax by extending the framework in Suárez Serrato and Zidar (2016) to allow for deductions that may affect the response of firms to tax rate changes. Intuitively, a narrower tax base lowers the benefits of a tax cut to business owners as they only pay taxes on a smaller fraction of profits. As there is a smaller benefit from the tax cut, firms are less likely to enter a particular location, which will also mute the effect of the tax cut on employment, wages, and costs of living. Whether the decrease in firm entry is larger than the decrease in the real wage and employment will determine the extent to which the incidence of a state income tax cut is borne by workers, landowners, or firm owners. Overall, many exciting questions on the incidence and efficiency consequences of reforms to the state corporate tax structure remain open. 


\section{References}

ALEC. 2014. "State Tax Cut Roundup 2014 Legislative Session." American Legislative Exchange Council.

Auerbach, Alan J., and James M. Poterba. 1987. "Why Have Corporate Tax Revenues Declined?" Tax Policy and the Economy, , ed. Lawrence H. Summers, 1-28. MIT Press.

Bartik, Timothy J. 2017. "A New Panel Database on Business Incentives for Economic Development Offered by State and Local Governments in the United States." W.E. Upjohn Institute.

Bernthal, Jamie, Dana Gavrila, Katie Schumacher, Shane Spencer, and Katherine Sydor. 2012. "Single Sales-Factor Corporate Income Tax Apportionment: Evaluating the Impact in Wisconsin." The Wisconsin Department of Revenue.

CCH State Tax Handbook. 1980-2010. State Tax Handbook 1980-2010. CCH Incorporated State Tax Handbook, Toolkit Media Group.

Chang, Andrew. 2014. "Tax policy endogeneity: Evidence from R\&D tax credits." FRB Finance and Economics Discussion Series.

Chirinko, Robert S., and Daniel J. Wilson. 2008. "State Investment Tax Incentives: A Zero-Sum Game?" Journal of Public Economics, 92(12): 2362-2384.

Clausing, Kimberly A. 2007. "Corporate tax revenues in OECD countries." International Tax and Public Finance, 14(2): 115-133.

Cooper, Michael, John McClelland, James Pearce, Richard Prisinzano, Joseph Sullivan, Danny Yagan, Owen Zidar, and Eric Zwick. 2016. "Business in the United States: Who Owns It, and How Much Tax Do They Pay?" Tax Policy and the Economy, 30(1): 91-128.

County Business Patterns. 2010. Accessed December 13, 2017.

CSG Book of the State. 1976-2011. Book of the States. Council of State Governments.

Dahlby, Bev, and Ergete Ferede. 2012. "The effects of tax rate changes on tax bases and the marginal cost of public funds for Canadian provincial governments." International Tax and Public Finance, 19(6): 844-883.

Devereux, Michael. 2007. "Developments in the Taxation of Corporate Profit in the OECD Since 1965: Rates, Bases, and Revenues." Oxford University Centre of Business Taxation Working Paper No. 07/04.

Devereux, Michael P., and Peter Birch Sørensen. 2006. "The Corporate Income Tax: International Trends and Options for Fundamental Reform." European Economy European Commission Economic Papers.

Fajgelbaum, Pablo D., Eduardo Morales, Juan Carlos Suárez Serrato, and Owen M. Zidar. 2015. "State Taxes and Spatial Misallocation." National Bureau of Economic Research Working Paper 21760.

Feenberg, Daniel, and Elisabeth Coutts. 1993. "An Introduction to the TAXSIM Model." Journal of Policy Analysis and Management, 12(1): 89-194.

Fuest, Clemens, Andreas Peichl, and Sebastian Siegloch. 2018. "Do Higher Corporate Taxes Reduce Wages? Micro Evidence from Germany." American Economic Review, 108(2): 393-418.

Gibbons, Charles E., Juan Carlos Suárez Serrato, and Michael B. Urbancic. 2014. "Broken or Fixed Effects?" National Bureau of Economic Research Working Paper 20342.

Giroud, Xavier, and Joshua Rauh. 2015. "State Taxation and the Reallocation of Business Activity: Evidence from Establishment-Level Data." National Bureau of Economic Research Working Paper 21534.

Heider, Florian, and Alexander Ljungqvist. 2015. "As Certain as Debt and Taxes: Estimating the Tax Sensitivity of Leverage from Exogenous State Tax Changes." Journal of Financial Economics, 118(3): 684712 . 
Holmes, Thomas J. 1998. "The Effect of State Policies on the Location of Manufacturing: Evidence from State Borders." Journal of Political Economy, 106(4): 667-705.

Kawano, Laura, and Joel Slemrod. 2015. "How do corporate tax bases change when corporate tax rates change? With implications for the tax rate elasticity of corporate tax revenues." International Tax and Public Finance, 23(3): 401-433.

Kessler, Glenn. 2015. "Rand Pauls claim that Reagans tax cuts produced more revenue and tens of millions of jobs." Washington Post, April 10, 2015.

Kopczuk, Wojciech. 2005. "Tax bases, tax rates and the elasticity of reported income." Journal of Public Economics, 89(11-12): 2093 - 2119.

Ljungqvist, Alexander, and Michael Smolyansky. 2014. "To Cut or Not to Cut? On the Impact of Corporate Taxes on Employment and Income." National Bureau of Economic Research Working Paper 20753.

Mclean, Jim. 2017. "Trump's Tax Plan Has Echoes Of The Kansas Tax Cut Experiment." NPR, September 30, 2017.

Ohrn, Eric. 2016. "Investment and Employment Responses to State Adoption of Federal Accelerated Depreciation Policies." Grinnell College.

Rao, Nirupama. 2016. "Do tax credits stimulate R\&D spending? The effect of the R\&D tax credit in its first decade." Journal of Public Economics, 140: 1-12.

Romney, Mitt. 2010. "Romney: Tax deal, bad deal." USA Today, December 14, 2010.

Suárez Serrato, Juan Carlos, and Owen Zidar. 2016. "Who Benefits from State Corporate Tax Cuts? A Local Labor Markets Approach with Heterogeneous Firms." American Economic Review, 106(9): 2582-2624.

Tax Foundation. 2016. "2015 State Business Tax Climate Index.”

The News \& Observer Editorial Board. 2017. "NC is no model for US tax cuts." The News $\& 3$ Observer, September 28, 2017.

U.S. Bureau of Economic Analysis. 1967-2016. "Annual Gross Domestic Product (GDP) by State." Accessed January 21, 2018.

U.S. Department of Commerce. 1942-2012. "Annual Survey of State Government Tax Collections." Accessed March 20, 2013.

Wilson, Daniel. 2005. "The rise and spread of state R\&D tax credits." FRBSF Economic Letter, 26.

Wilson, Daniel J. 2009. "Beggar Thy Neighbor? The In-State, Out-of-State, and Aggregate Effects of R\&D Tax Credits." Review of Economics and Statistics, 91(2): 431-436.

Wooldridge, Jeffrey M. 2005. "Fixed-Effects and Related Estimators for Correlated Random-Coefficient and Treatment-Effect Panel Data Models." Review of Economics and Statistics, 87(2): 385-390.

Zwick, Eric, and James Mahon. 2017. "Tax Policy and Heterogeneous Investment Behavior." American Economic Review, 107(1): 217-48. 
Figure 1: Densities of State Corporate Tax Rate and State Corporate Revenue-to-GDP Ratio by Decade

\section{A. State Corporate Tax Rate}

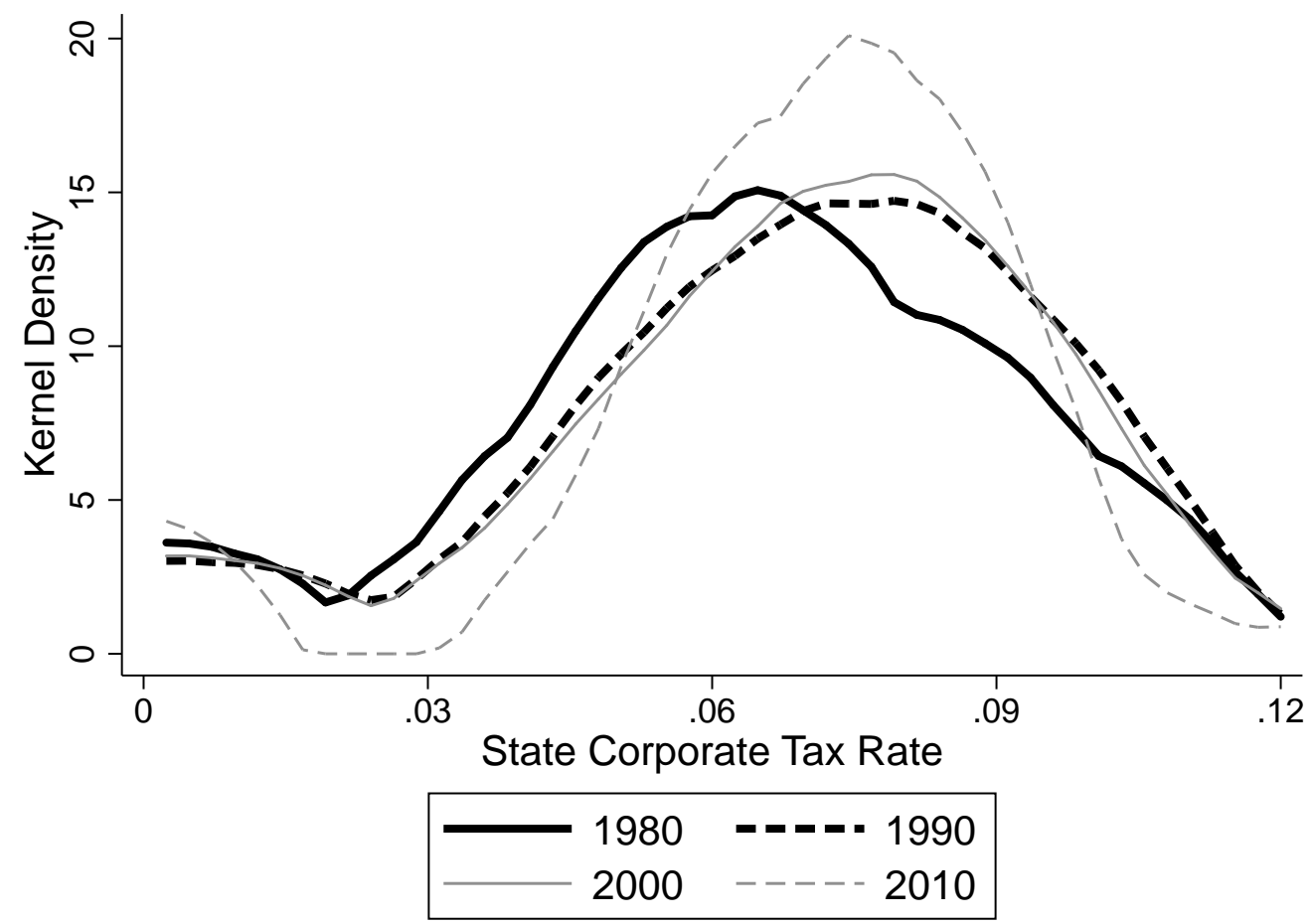

B. State Corporate Tax Revenue as a Share of GDP

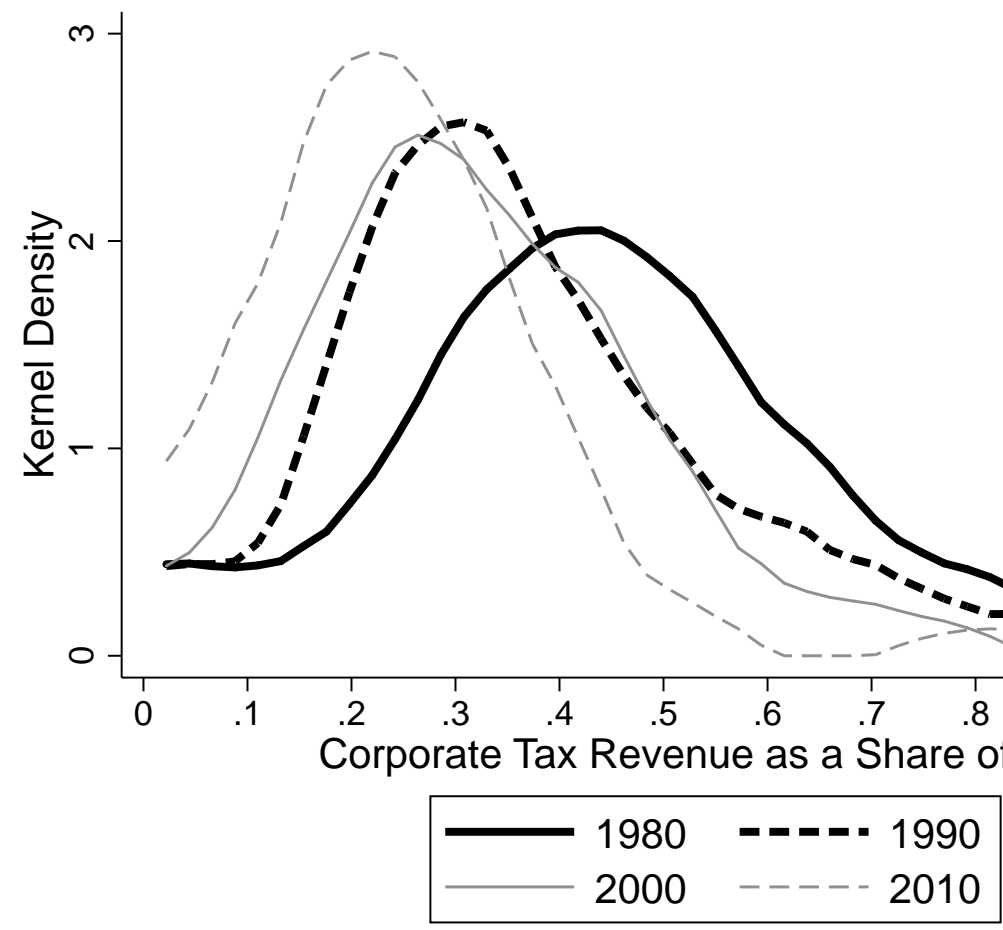

NotES: This figure presents kernel density functions for the state corporate tax rate and the state revenue-to-GDP ratio by decade. See Section 1 for details on data sources. 
Figure 2: Changes in State Corporate Tax Structure

\section{A. Time Series}

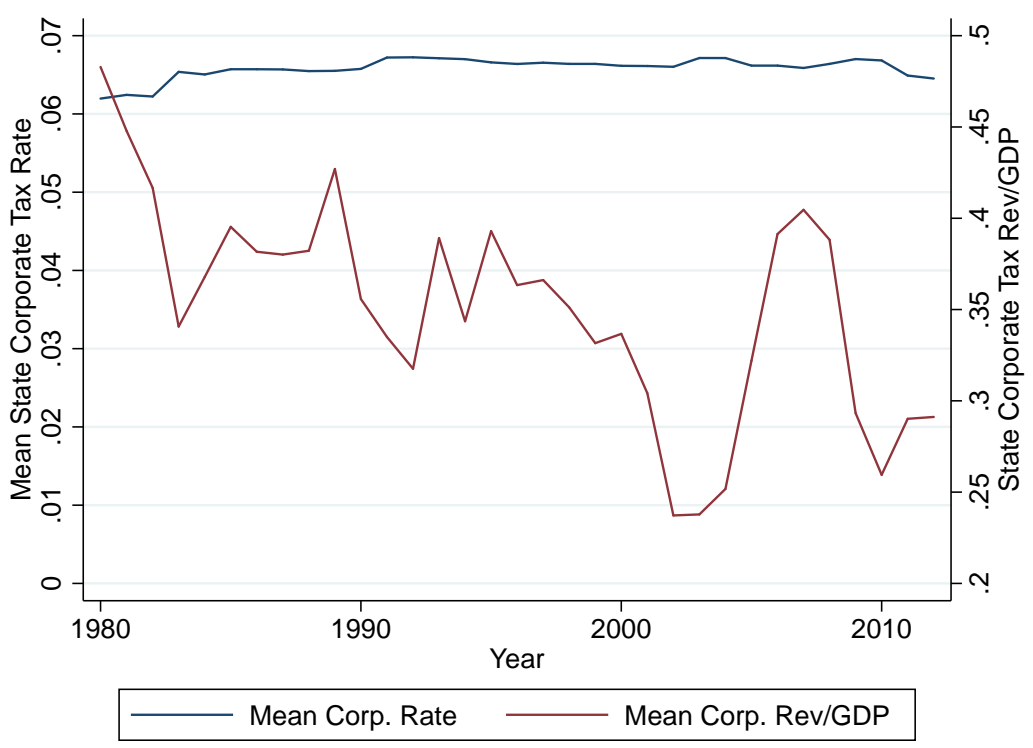

\section{B. Frequency of Changes}

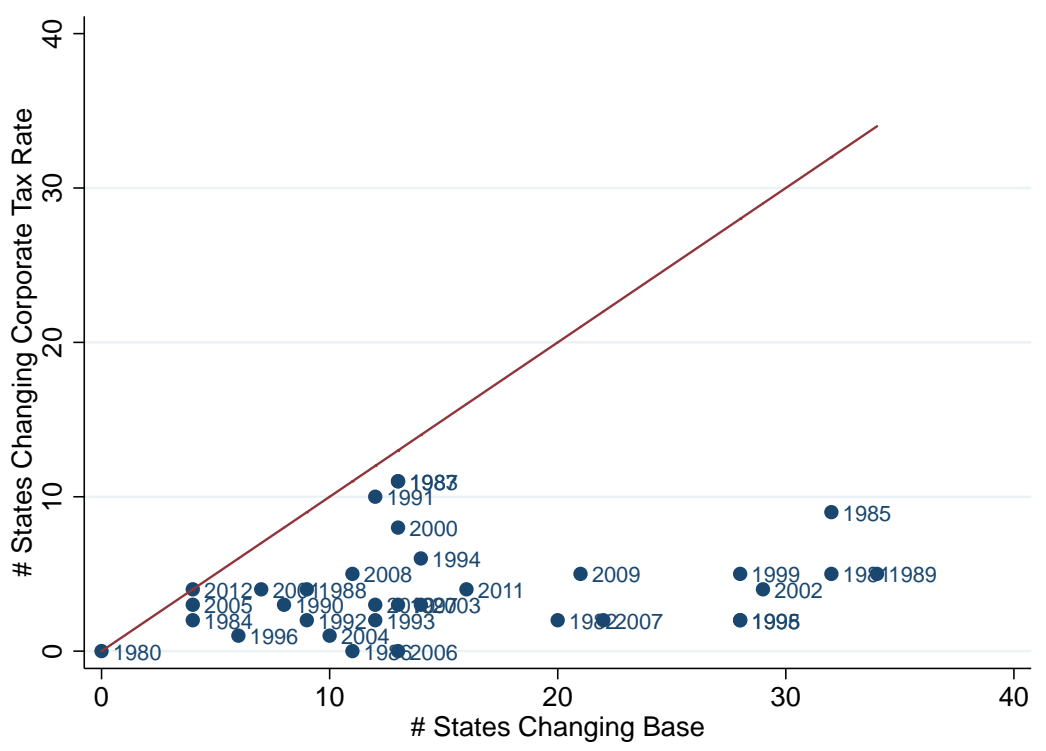

Notes: This figure shows annual trends in both the mean state corporate tax rate across states and state corporate tax revenue as a share of state GDP in Panel A. Panel B shows by year the number of states that changed rates and tax base provisions. It illustrates that these pairs are not on a 45 degree line, so most years in which many states change base provisions are not years in which many states also change rates. See Section 1 for details on data sources. 
A. Tax Credits

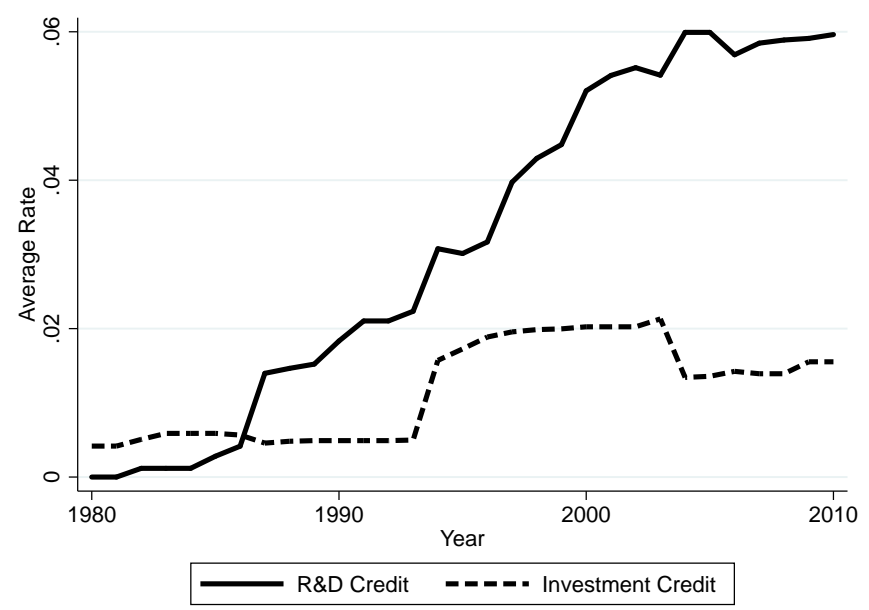

C. Apportionment Weights

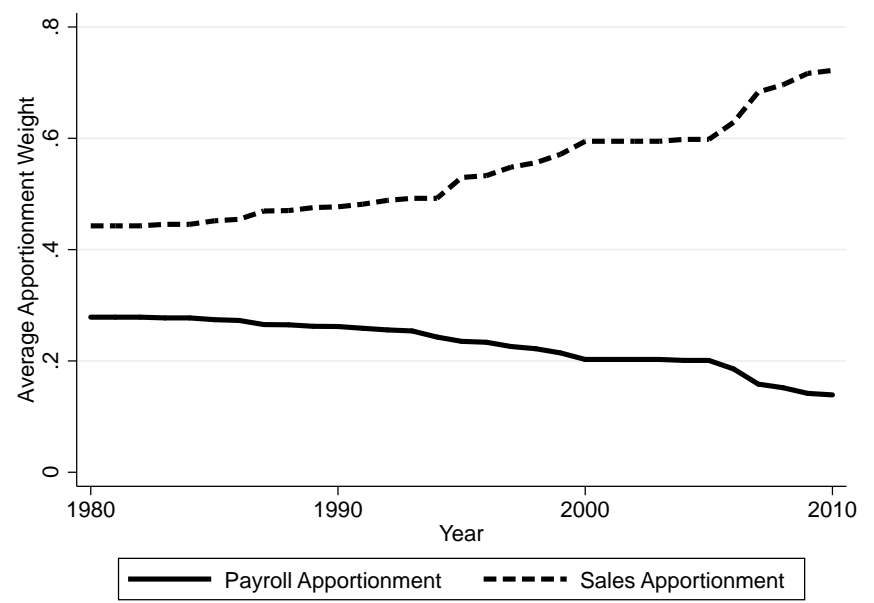

B. Loss Rules

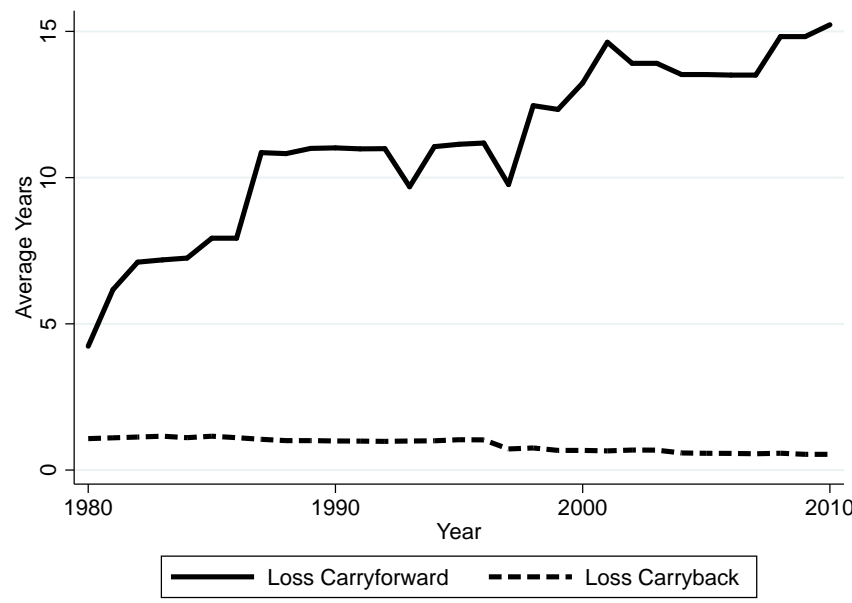

D. Misc. State Tax Base Provisions

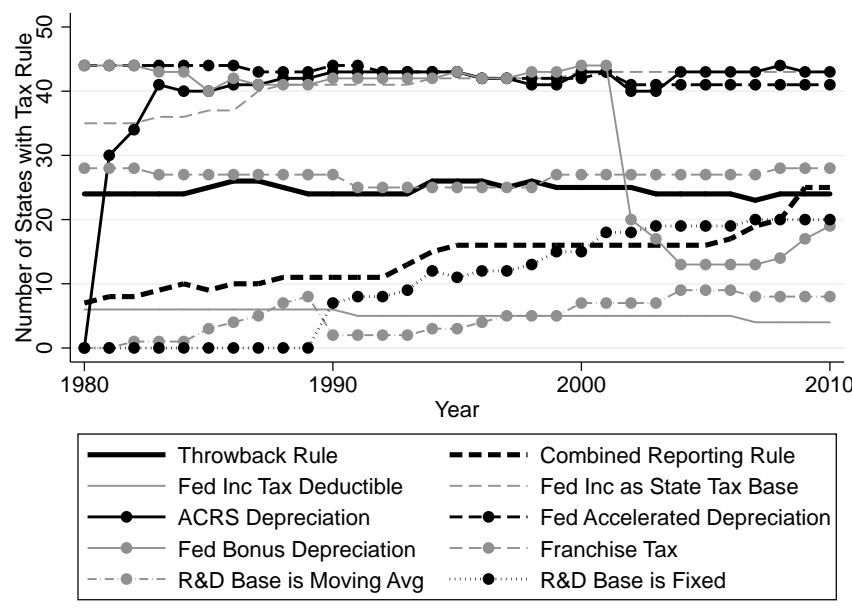

NoтEs: This figure shows state averages of various base rules between 1980 and 2010. Panels A, B, and C use the mean tax credit rate, loss carry allowance, and apportionment weights across all states, respectively. The value is weighted by mean state GDP across the sample period. Panel C does not include property apportionment weights because they are almost always the same as payroll weights. Panel D shows annual state averages for the following indicator variables: throwback rule, combined reporting rule, federal income tax deductibility, federal bonus depreciation, federal income as state tax base, federal accelerated depreciation, ACRS depreciation, franchise tax, base of incremental R\&D credit is a moving average, and base of incremental R\&D credit is fixed. See Section 1 for details on data sources. 
Figure 4: Corporate Tax Base and Credit Densities By Decade
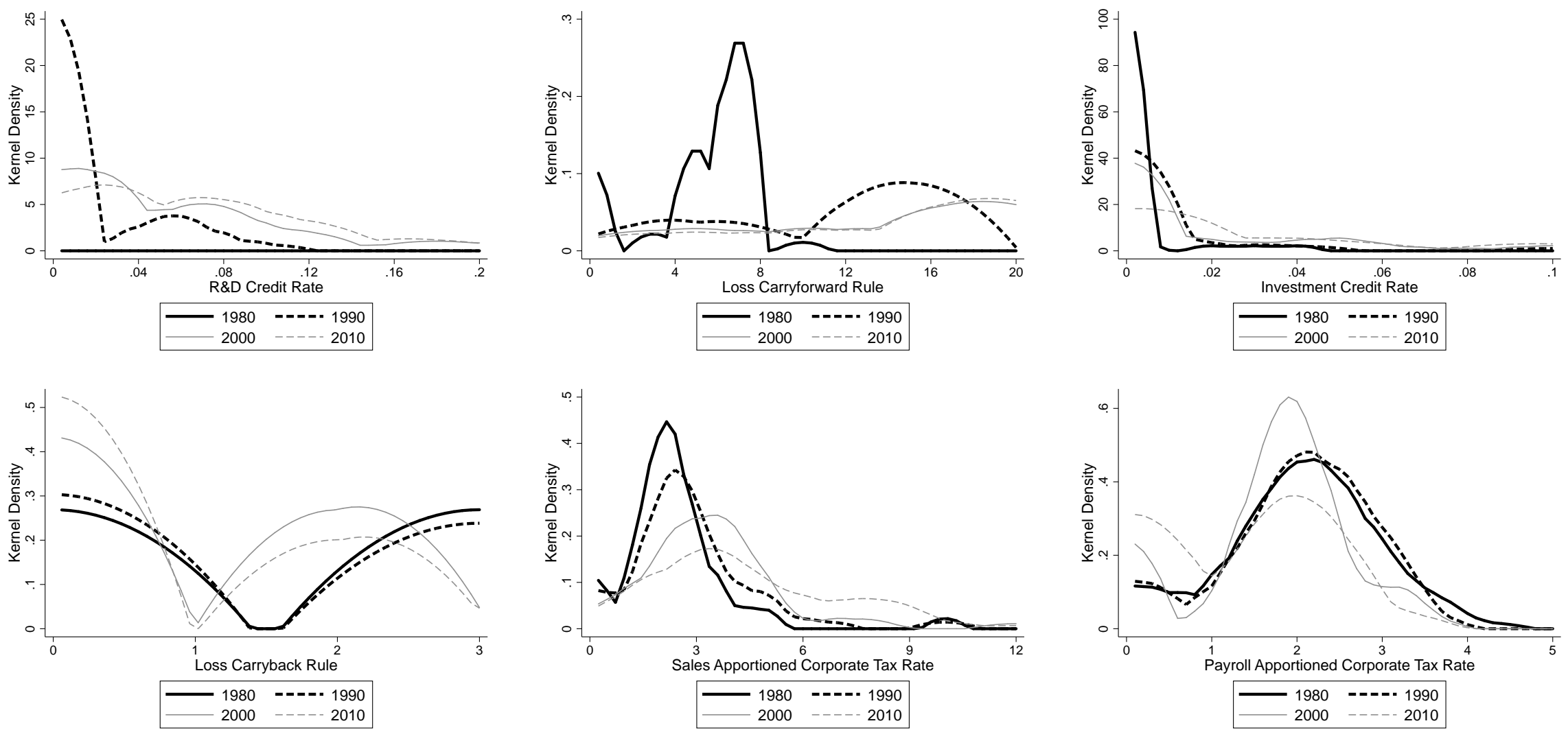

Notes: This figure presents kernel density functions for various tax base rules by decade. Loss carryforward and loss carryback are measured in years allotted by the respective rule. See Section 1 for details on each tax base rule and data sources. 
Figure 5: Variance of State Corporate Tax Revenue as a Share of GDP

A. Variance Decomposition

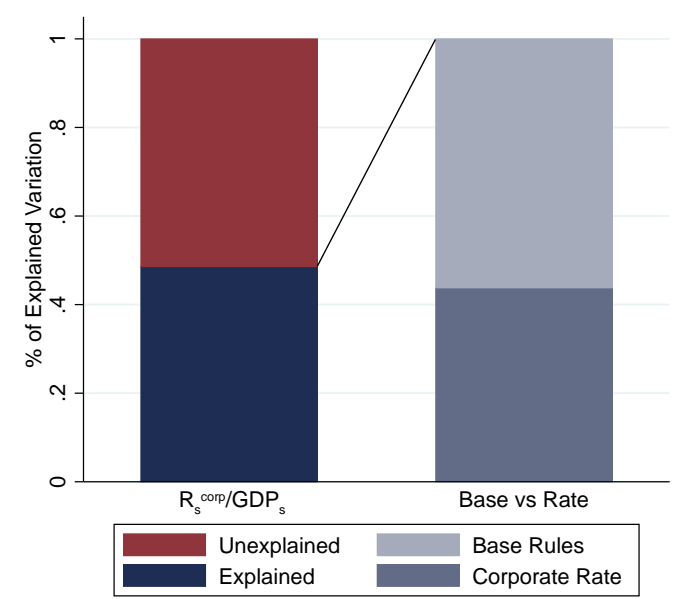

B. Share of Explained Variance by Base Rule (i.e., $\left.\frac{\operatorname{Var}\left(x_{s t}^{j} \Psi_{s t}^{j}\right)}{\sum_{j} \operatorname{Var}\left(x_{s t}^{j} \Psi_{s t}^{j}\right)}\right)$

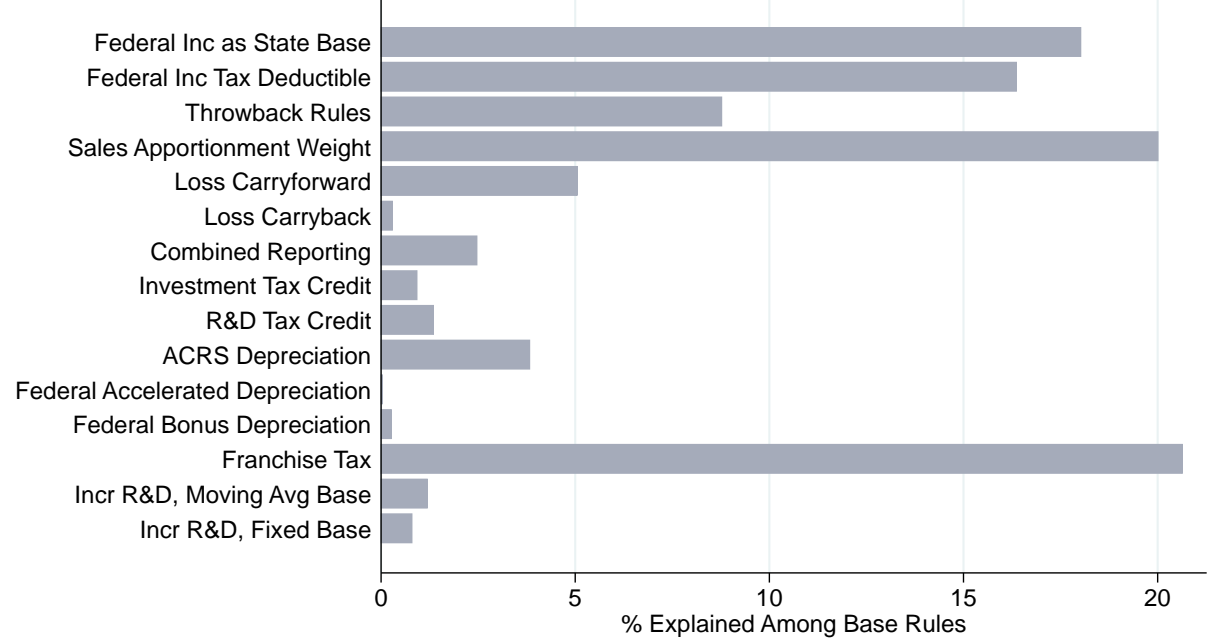

C. Effects of Standardized Base Rules $\tilde{\Psi}_{s t}^{j}$

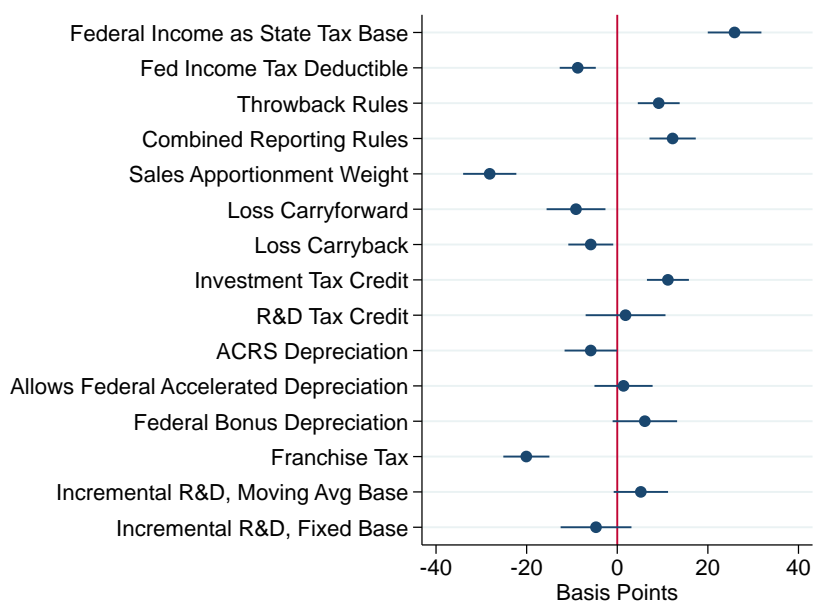

Notes: This figure decomposes the variation in the corporate revenue-to-GDP ratio into corporate tax rate and tax base components. Panel A decomposes the variation in state corporate tax revenue as a share of state GDP from 1980-2010 using equation 2. Panel B displays the contribution to base variation from each base rule. Panel C plots the effect of each base rule on state corporate tax revenue as a share of state GDP from 1980-2010. We standardize each base rule prior to determining the coefficients to facilitate comparisons across base rules with different variances. Revenue-to-GDP ratio is measured in basis points. See Section 3 for details. The decomposition is weighted by mean state GDP across our sample period. See Section 1 for details on data sources. 
Figure 6: Corporate Tax Revenue Share of GDP - Variance Decomposition by Five-Year Period

A. Variance Decomposition

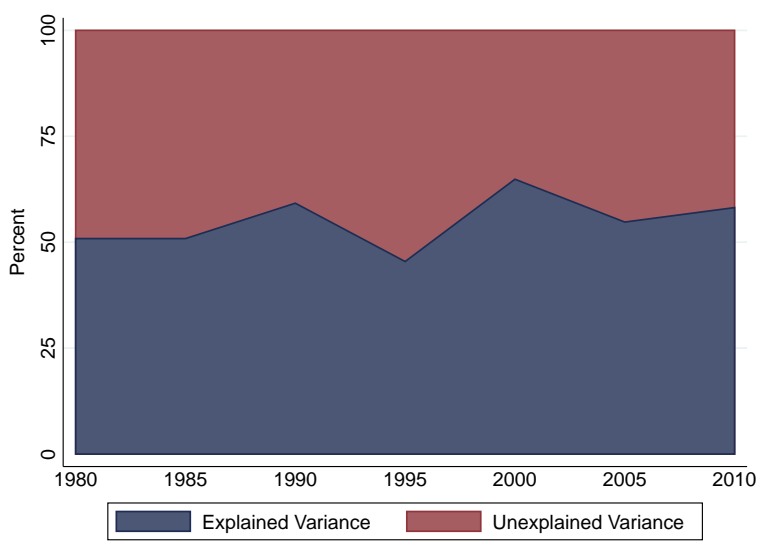

B. Share of Explained Variance, Rate vs. Base

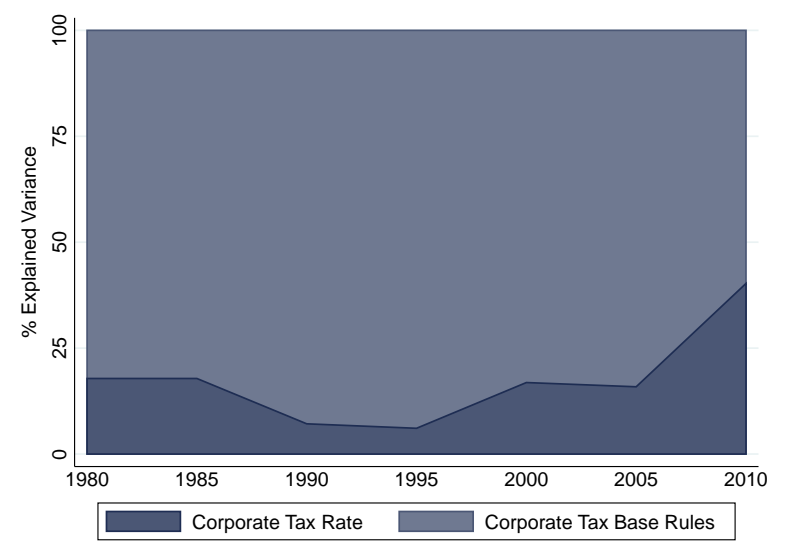

C. Share of Explained Variance by Base Rule (i.e., $\left.\frac{\operatorname{Var}\left(x_{s t}^{j} \Psi_{s t}^{j}\right)}{\sum_{j} \operatorname{Var}\left(x_{s t}^{j} \Psi_{s t}^{j}\right)}\right)$

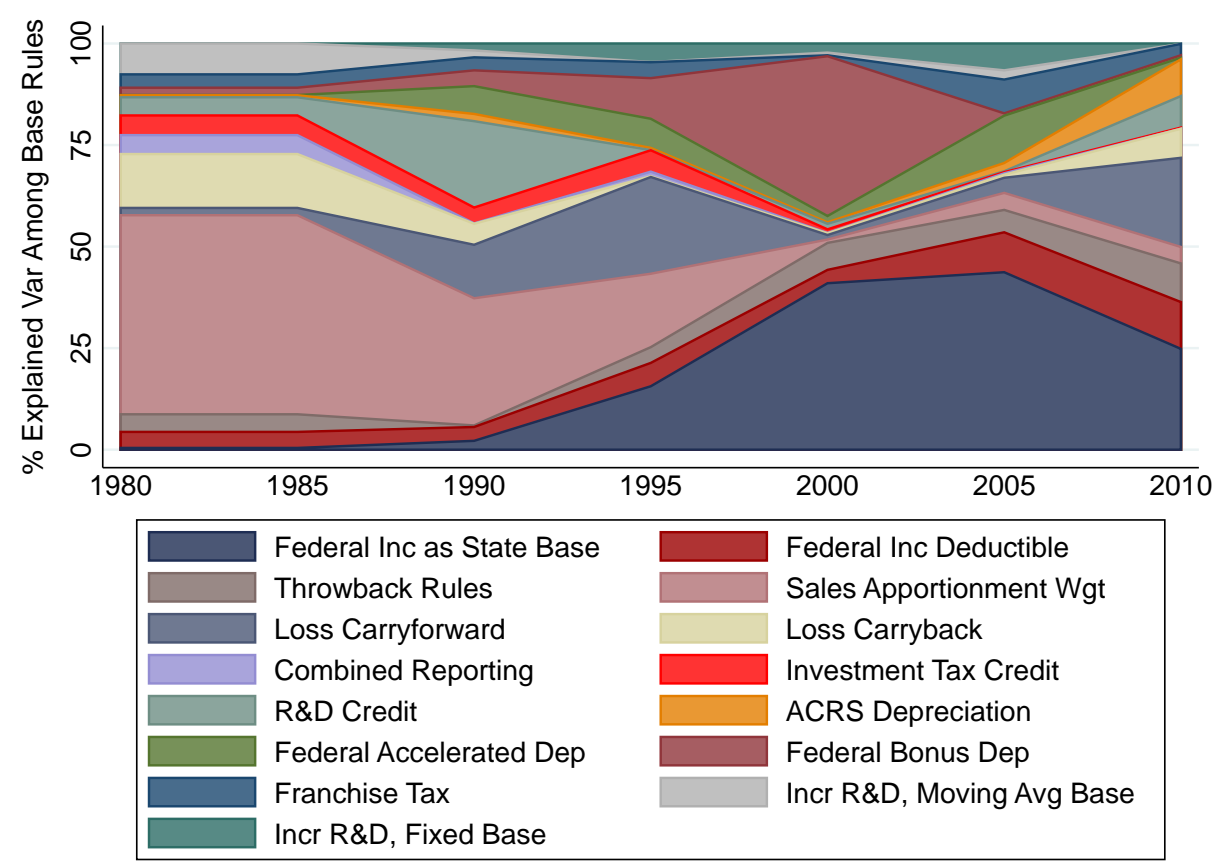

Notes: This figure replicates Figure 5 over five-year periods between 1980 and 2010. Panel A decomposes the variation in state corporate tax revenue as a share of state GDP from 1980-2010 using equation 3. Panel B displays the contribution to base variation from each base rule. Panel $\mathrm{C}$ plots the effect of each base rule on state corporate tax revenue as a share of state GDP from 1980-2010. See Section 3 for details. The decomposition is weighted by mean state GDP across our sample period. See Section 1 for details on data sources. 
Figure 7: Event Analysis: Impacts on State Corporate Tax Revenue and GDP
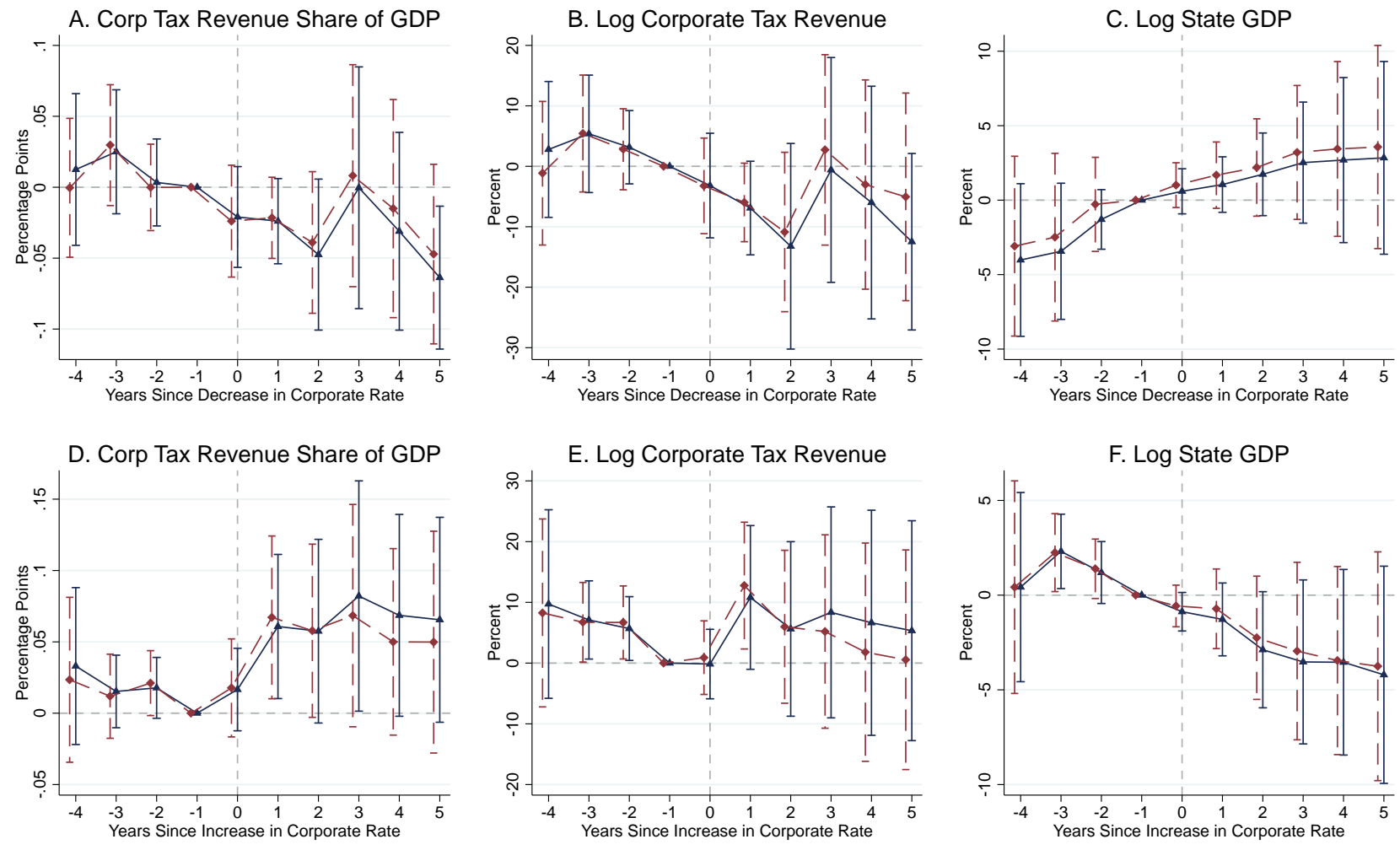

F. Log State GDP
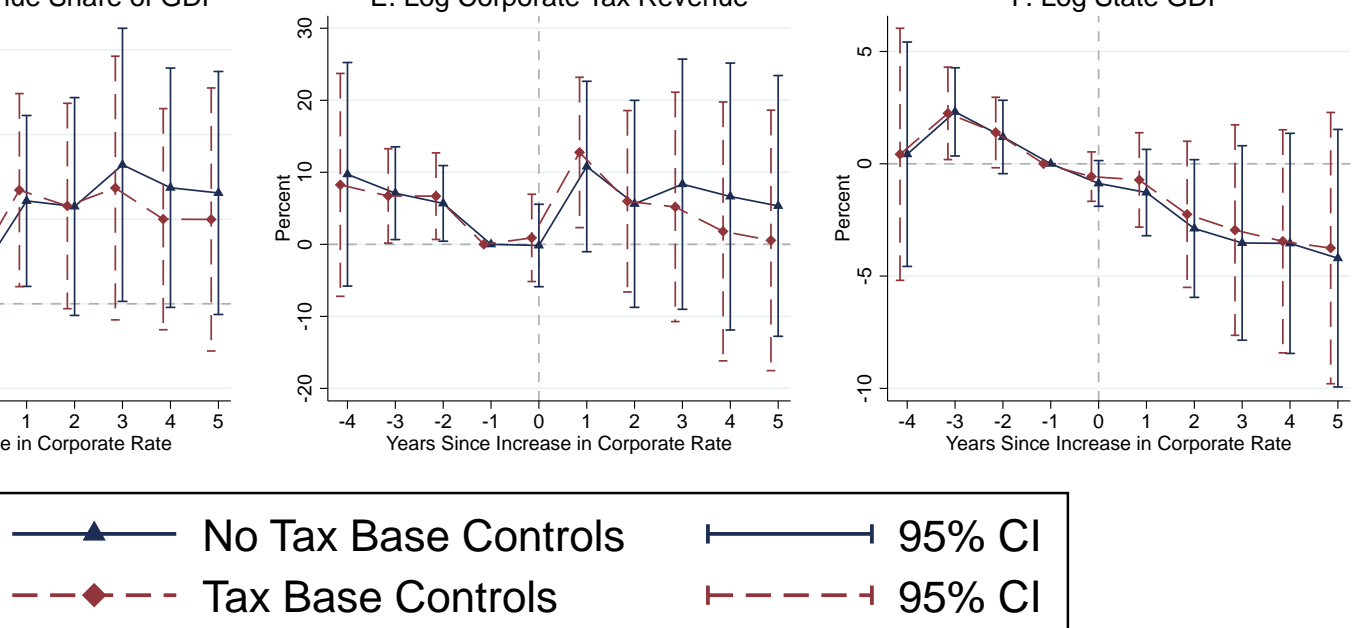

NOTES: This figure shows the effect of changes in the state corporate rate of at least $0.5 \mathrm{pp}$ on state corporate tax revenue as a share of state GDP, log corporate tax revenue, and $\log$ state GDP, respectively. The full navy line indicates a specification without additional controls. The dashed red line plots the coefficients from a specification that additionally controls for the following tax base rules: federal income tax treated as state base, sales apportionment weight, throwback rules, federal income tax deductibility, loss carryforward, and franchise tax. Standard errors are clustered by state. The estimating equation is equation 4. Appendix Figure A23 replicates this figure for changes in the state corporate rate of any magnitude. Appendix Figure A25 shows analogous results for the subset of state corporate tax changes that Giroud and Rauh (2015) classify as exogenous. Appendix Figure A26 compares the estimated impacts when all tax base controls are included, relative to the aforementioned rules. See Section 1 for details on data sources. 
Figure 8: Decomposing the Total Effects of the Corporate Tax Rate

\section{A. Full Decomposition of Total Effects}

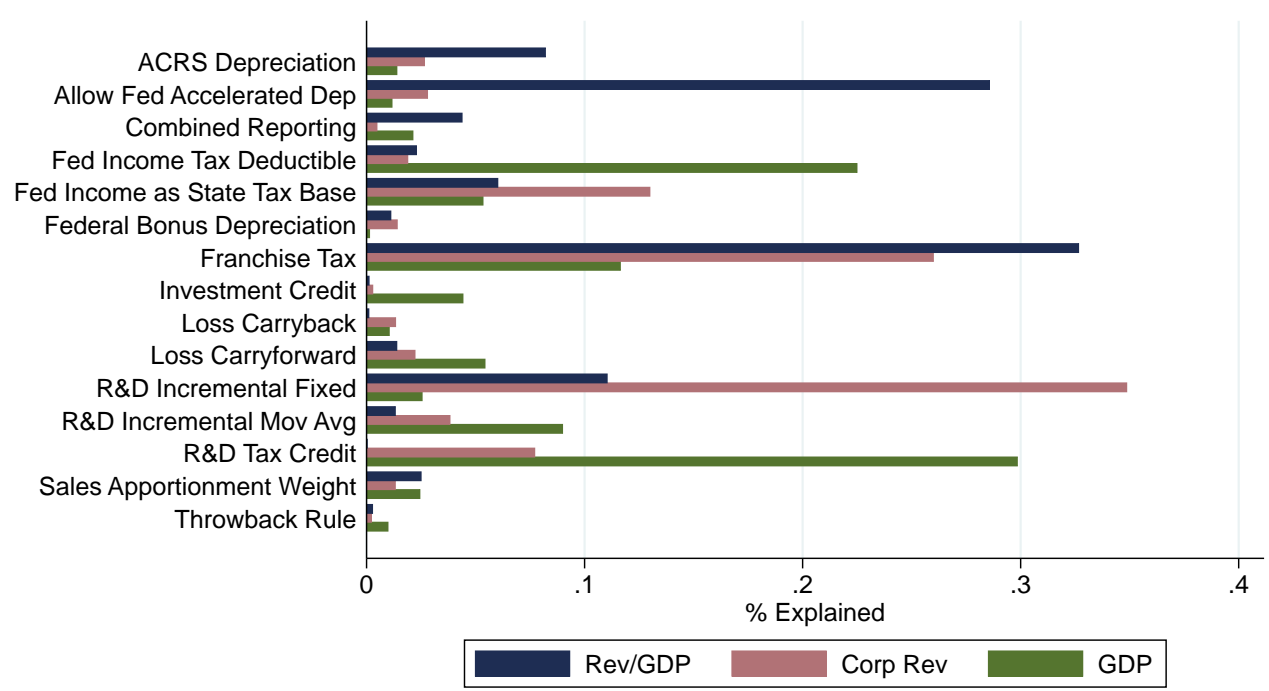

\section{B. Decomposition of Total Effect on Revenue-to-GDP over Time}

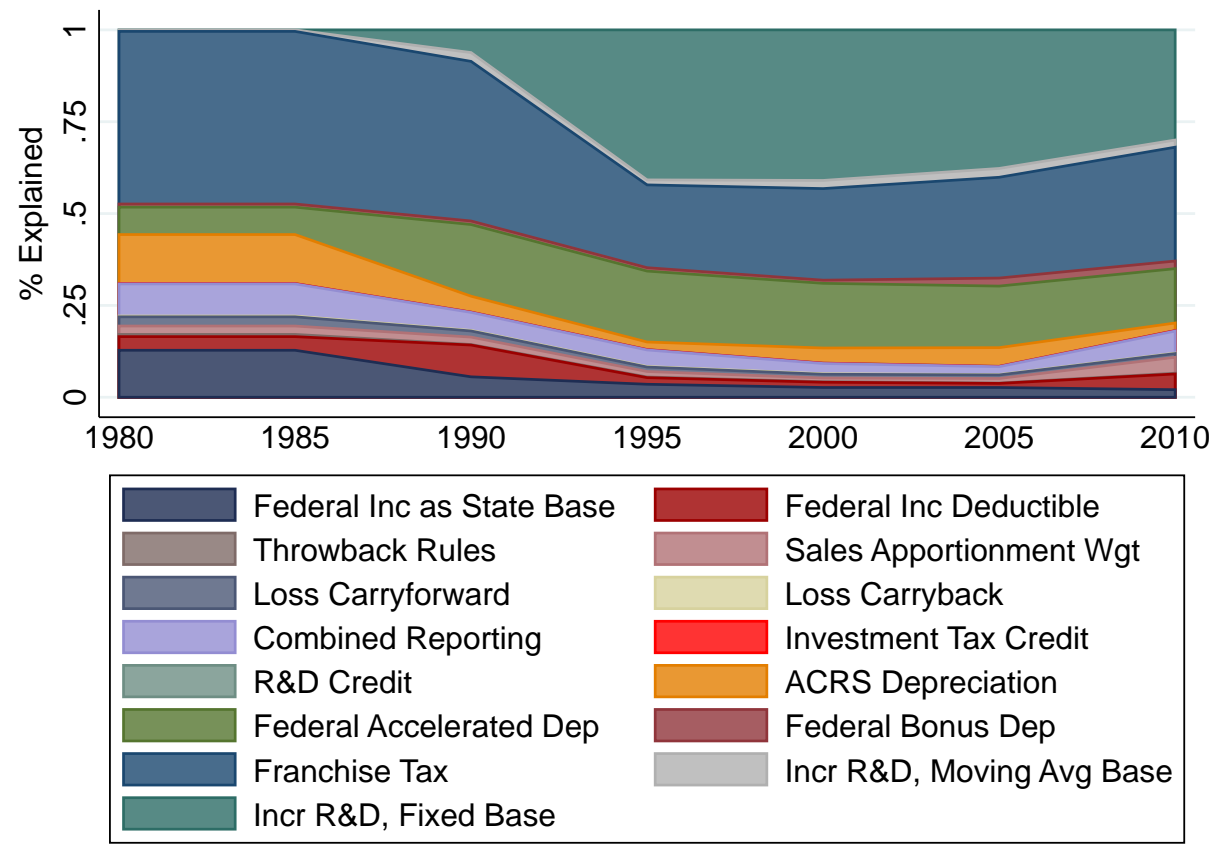

Notes: This figure decomposes the variance in the estimated total effects of $\tau$ on the revenue-to-GDP ratio, and of $\ln (1-\tau)$ on log-GDP and log-revenue. The total effect varies across states and years since it accounts for interactions between the state corporate tax rate and base controls. This figure describes the relative importance of different tax base controls in explaining the heterogeneity in the total effect that is driven by interactions with tax base controls. By construction, the variance in the model is equal to the total variance. The bars in Panel A report the fraction of the variance that is due to changes in each of the tax base parameters for each of the the three estimated total effects. Panel B focuses on the revenue-to-GDP ratio and describes how the importance of different tax base controls has evolved over time. The total effect is defined in equation 6 and estimates of the coefficients for the total effect are reported in Column (3) of Table 6; see Section 5 for more details. 
Figure 9: Average Estimated Total Effect of $\tau$ on the Revenue-to-GDP Ratio by Year

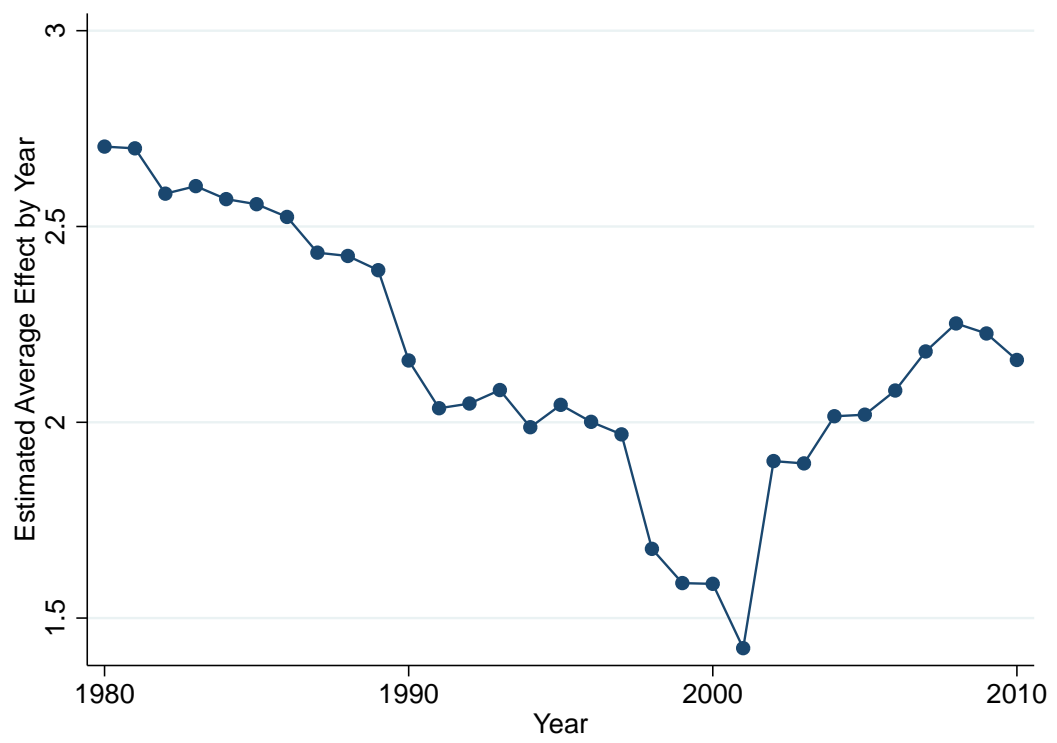

Notes: This figure plots the average total effect of $\tau$ on the revenue-to-GDP ratio by year. The total effect is presented in terms of basis points of the revenue-to-GDP ratio. The effect varies across states and years since it accounts for interactions between the state corporate tax rate and base controls. In general, the effect is smaller when states adopt policies that narrow the tax base. This figure shows that, on average, the total effect declined in magnitude as the tax base narrowed between 1980 and 2000 , and that it increased during the last decade as the tax base broadened. The total effect is defined in equation 6 and estimates of the coefficients for the total effect are reported in Column (3) of Table 6; see Section 5 for more details. 
Figure 10: Estimated Total Effect of $\tau$ on the Revenue-to-GDP Ratio by Year For Selected States

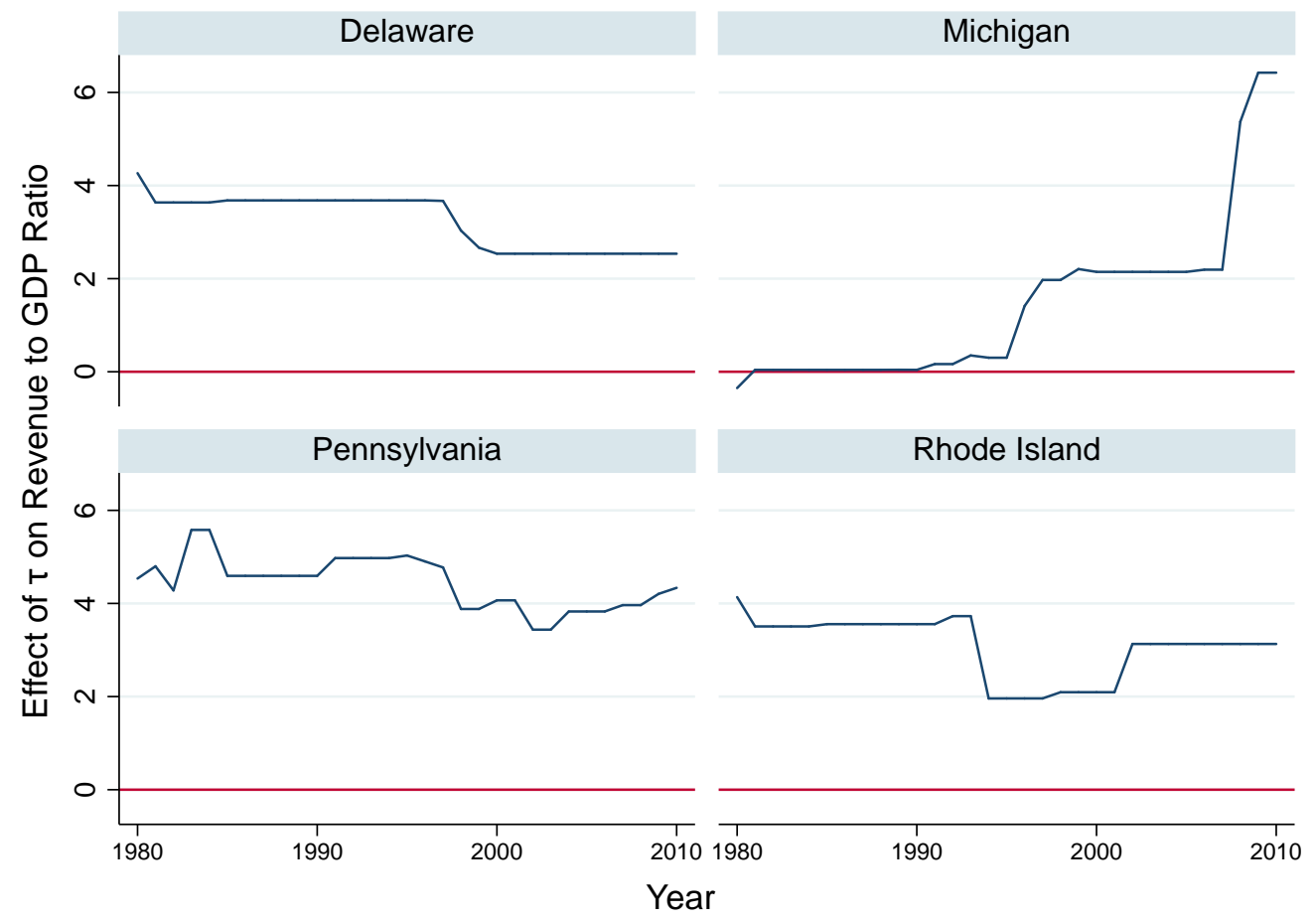

Notes: This figure plots the estimated total effect of $\tau$ on the revenue-to-GDP ratio for selected states. The total effect is presented in terms of basis points of the revenue-to-GDP ratio. The effect varies across states and years since it accounts for interactions between the state corporate tax rate and base controls. These plots show that the aggregate pattern described in Figure 9 is a result of states that have a mirror experience to the national average (such as Pennsylvania and Rhode Island), as well as of states that have contracting (Delaware) and expanding (Michigan) bases. Appendix Figure A47 presents similar plots for the rest of the states. The total effect is defined in equation 6 and estimates of the coefficients for the total effect are reported in Column (3) of Table 6; see Section 5 for more details. 
Figure 11: Estimate Revenue-Maximizing-Tax Rates

A. Estimated Laffer Curve for State Corporate Tax Revenue

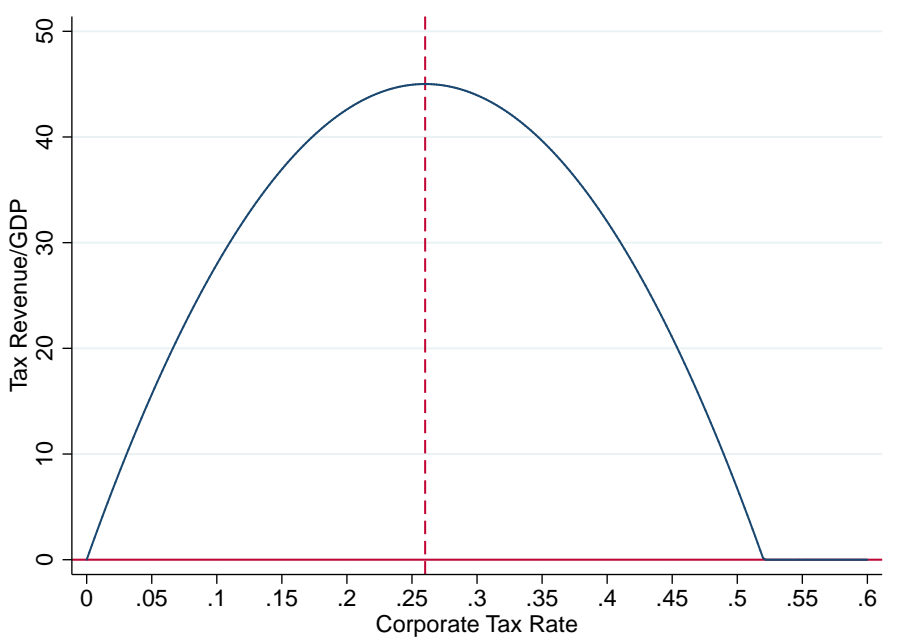

B. CDF of Corporate Tax Revenue Maximizing Tax Rates

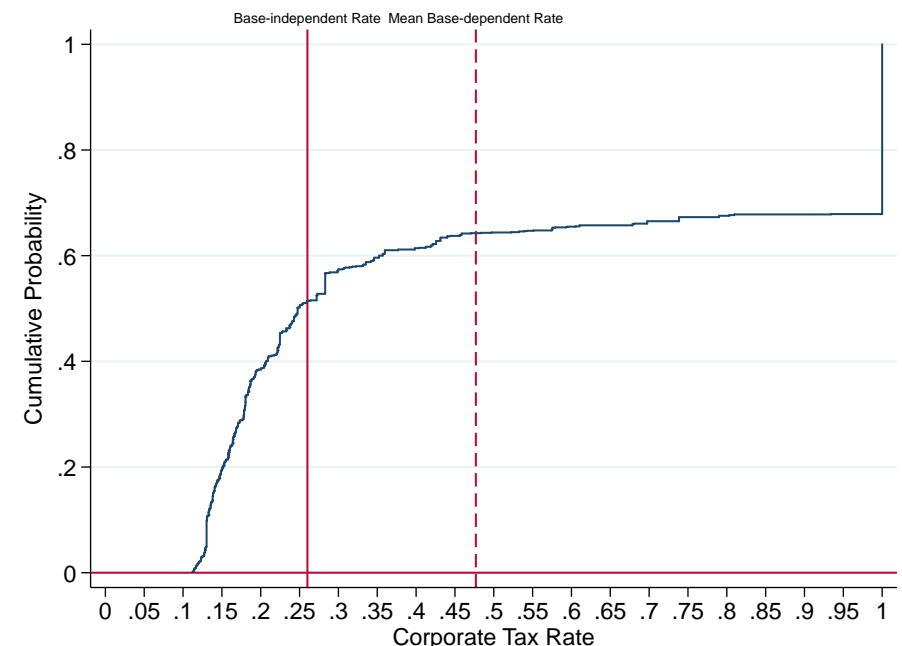

D. CDF of Total State Tax Revenue Maximizing Tax Rates

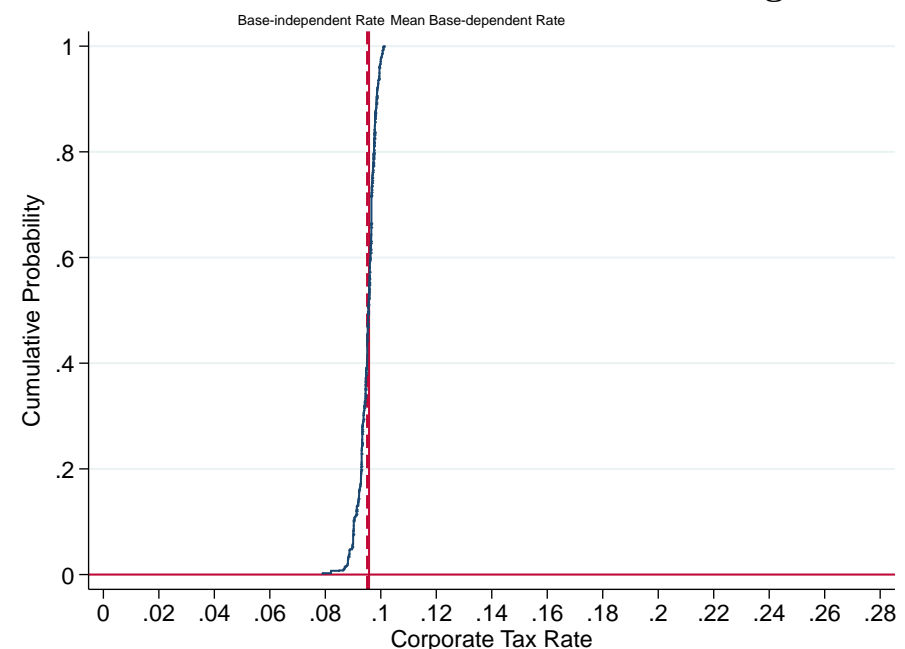

Notes: This figure plots the implied revenue-maximizing-state-corporate-tax rates. Panel A plots the estimated relation between state corporate tax revenues and the state corporate tax rate at the mean value of the base index. Panel B plots the distribution of the estimated revenue-maximizing-tax rates as a function of the base index. These estimates are based on estimates coefficients from equation 8 in Table 7. Panel C and D replicate Panel A and B for total state tax revenue. See Appendix Figure A49 for a version that controls for state sales and top personal income tax rates. See Section 6 for details. Note that the mass of observations in Panel B at $100 \%$ corporate tax rate are cases where we do not find decreasing returns to taxation. We interpret these estimates as suggesting that current levels of tax rates are below revenue maximizing corporate tax rates and therefore the variation in the data do not identify decreasing returns to taxation. See Section 1 for details on data sources. 
Table 1: Summary Statistics

\begin{tabular}{|c|c|c|c|}
\hline \multicolumn{4}{|l|}{ Panel A. 1980-2010 Pooled Sample } \\
\hline & Observations & Mean & Std. Dev. \\
\hline Corp Tax Revenue as Share of GDP (\%) & 1550 & 0.355 & 0.284 \\
\hline Throwback Rules & 1550 & 0.492 & 0.500 \\
\hline Combined Reporting & 1550 & 0.281 & 0.450 \\
\hline Investment Tax Credit & 1550 & 1.062 & 2.323 \\
\hline R\&D Tax Credit & 1550 & 2.629 & 4.369 \\
\hline Loss Carryback Rules & 1550 & 1.183 & 1.381 \\
\hline Loss Carryforward Rules & 1550 & 11.379 & 6.707 \\
\hline Franchise Tax & 1550 & 0.534 & 0.499 \\
\hline Fed Income Tax Deductible & 1550 & 0.105 & 0.306 \\
\hline Fed Income as State Tax Base & 1550 & 0.814 & 0.389 \\
\hline Fed Accelerated Depreciation & 1550 & 0.851 & 0.356 \\
\hline ACRS Depreciation & 1550 & 0.802 & 0.399 \\
\hline Federal Bonus Depreciation & 1550 & 0.692 & 0.462 \\
\hline Sales Apportionment Weight & 1550 & 51.043 & 23.856 \\
\hline Incremental R\&D Credit, Base is Fixed & 1550 & 0.203 & 0.402 \\
\hline Incremental R\&D Credit, Base is Moving Average & 1550 & 0.097 & 0.296 \\
\hline \multicolumn{4}{|l|}{ Panel B. 2010 Cross Section } \\
\hline & Observations & Mean & Std. Dev. \\
\hline Corp Tax Revenue as Share of GDP (\%) & 50 & 0.259 & 0.214 \\
\hline Throwback Rules & 50 & 0.480 & 0.505 \\
\hline Combined Reporting & 50 & 0.500 & 0.505 \\
\hline Investment Tax Credit & 50 & 2.120 & 3.280 \\
\hline R\&D Tax Credit & 50 & 5.695 & 5.608 \\
\hline Loss Carryback Rules & 50 & 0.700 & 1.055 \\
\hline Loss Carryforward Rules & 50 & 14.220 & 7.081 \\
\hline Franchise Tax & 50 & 0.560 & 0.501 \\
\hline Fed Income Tax Deductible & 50 & 0.080 & 0.274 \\
\hline Fed Income as State Tax Base & 50 & 0.860 & 0.351 \\
\hline Fed Accelerated Depreciation & 50 & 0.820 & 0.388 \\
\hline ACRS Depreciation & 50 & 0.860 & 0.351 \\
\hline Federal Bonus Depreciation & 50 & 0.380 & 0.490 \\
\hline Sales Apportionment Weight & 50 & 66.142 & 27.984 \\
\hline Incremental R\&D Credit, Base is Fixed & 50 & 0.400 & 0.495 \\
\hline Incremental R\&D Credit, Base is Moving Average & 50 & 0.160 & 0.370 \\
\hline
\end{tabular}

Notes: This table provides summary statistics for state corporate tax revenue as a share of GDP and the main fifteen tax base measures described in Section 1. Panel A provides pooled summary statistics. Data range from 1980-2010 and include all 50 states. Panel B summarizes the tax base measures for the 2010 cross-section. Indicators for throwback rule and combined reporting equal zero for states with no corporate income tax rate. 
Table 2: Summary of Base Changes

\begin{tabular}{lcccc}
\hline \hline Base narrowing/broadening: & -1 & +1 & Total Changes & No Change \\
\hline Sales Apportionment Weight & 92 & 33 & 125 & 1375 \\
Loss Carryback & 23 & 42 & 65 & 1435 \\
Loss Carryforward & 85 & 15 & 100 & 1400 \\
Franchise Tax & 3 & 3 & 6 & 1494 \\
Federal Income Tax Deductible & 2 & 4 & 6 & 1494 \\
Federal Income Tax as State Tax Base & 0 & 8 & 8 & 1492 \\
Federal Accelerated Depreciation & 2 & 5 & 7 & 1493 \\
ACRS Depreciation & 57 & 14 & 71 & 1429 \\
Federal Bonus Depreciation & 18 & 43 & 61 & 1439 \\
Throwback & 23 & 23 & 46 & 1454 \\
Combined Reporting & 2 & 20 & 22 & 1478 \\
Investment Credit & 34 & 9 & 43 & 1457 \\
R\&D Credit & 51 & 8 & 59 & 1441 \\
Incremental R\&D Credit, Base is Moving Average & 10 & 18 & 28 & 1472 \\
Incremental R\&D Credit, Base is Fixed & 2 & 22 & 24 & 1476 \\
\hline \hline
\end{tabular}

Notes: This table reports the number of state-year observations from 1980-2010 where there was a change in tax base and tax rate. A change that represents a narrowing of the base is counted in the -1 column, while a year that represents a broadening of the base is counted as +1 . An increase in the rate of investment credits, R\&D credits, or sales apportionment weight corresponds to a narrowing of the base, while a decrease corresponds to a broadening. An increase in the number of years allowed for both loss carryforward and loss carryback corresponds to a narrowing of the base, while a decrease corresponds to a broadening. For franchise taxes, federal income tax deductibility, federal accelerated depreciation and ACRS depreciation, the rule being turned off corresponds to a narrowing of the base, while it being turned on corresponds to a narrowing. For instance, if a state adopts MACRS depreciation, then we say that the tax base has narrowed. For throwback rules, combined reporting, moving average base for incremental R\&D, fixed base for incremental R\&D and federal income as state tax base, the rule being turned off corresponds to a narrowing of the base, while it being turned on corresponds to a broadening. For instance, if a state adopts combined reporting, then we say that the tax base has broadened. If that state gets rid of combined reporting, then the tax base has narrowed. See Section 1 for details on data sources, and Appendix A for definitions of broadening and narrowing for each measure. Appendix Table A3 provides a more detailed breakdown along with the co-movement of tax rates.

Table 3: Frequency of State Tax Rate and Base Changes

\begin{tabular}{lcccc}
\hline \hline Base Change & Rate Decrease & No Change & Rate Increase & Total \\
\hline Narrowing & 20.0 & 18.9 & 8.7 & 18.3 \\
& $(14.0)$ & $(260.0)$ & $(9.0)$ & $(283.0)$ \\
No Change & 61.4 & 70.9 & 82.5 & 71.2 \\
& $(43.0)$ & $(976.0)$ & $(85.0)$ & $(1104.0)$ \\
Broadening & 18.6 & 10.2 & 8.7 & 10.5 \\
& $(13.0)$ & $(141.0)$ & $(9.0)$ & $(163.0)$ \\
Total & 100.0 & 100.0 & 100.0 & 100.0 \\
& $(70.0)$ & $(1377.0)$ & $(103.0)$ & $(1550.0)$ \\
\hline \hline
\end{tabular}

Notes: This table reports the fraction of state-year observations that saw a simultaneous change in tax base and in tax rate. Numbers in parenthesis report the number of state-year observations that correspond to a given cell. See Section 1 for details on data sources, and Appendix A for definitions of broadening and narrowing for each measure. Overall, this table shows that the majority of times when there is a change in the tax base (either a narrowing or a broadening) there is no accompanying change in the tax rate. 
Table 4: Probit Estimates of the Coincidence of Base and Rate Changes

Panel A: Base Change

\begin{tabular}{|c|c|c|c|}
\hline & Any Base Change & Base Broadening & Base Narrowing \\
\hline \multirow[t]{2}{*}{ Rate decrease } & 0.1885 & 0.1240 & 0.1827 \\
\hline & $(0.2306)$ & $(0.2662)$ & $(0.3165)$ \\
\hline \multirow[t]{2}{*}{ No rate change } & -0.0983 & -0.2728 & 0.0955 \\
\hline & $(0.1850)$ & $(0.2347)$ & $(0.2040)$ \\
\hline
\end{tabular}

Panel B: Tax Rate Change

\begin{tabular}{|c|c|c|c|}
\hline & Any Tax Change & Tax Increase & Tax Decrease \\
\hline Base narrowed & $\begin{array}{c}0.0705 \\
(0.1440)\end{array}$ & $\begin{array}{c}-0.0558 \\
(0.1734)\end{array}$ & $\begin{array}{c}0.1293 \\
(0.1949)\end{array}$ \\
\hline Base broadened & $\begin{array}{l}0.3102^{*} \\
(0.1322)\end{array}$ & $\begin{array}{c}0.1835 \\
(0.2187)\end{array}$ & $\begin{array}{l}0.3142^{*} \\
(0.1310)\end{array}$ \\
\hline
\end{tabular}

Notes: This table estimates the coincidence of corporate tax base and tax rate changes. Panel A reports coefficients from a probit model estimating the probability of a change in the tax base using changes in tax rates. Panel B reports coefficients from a probit model estimating the probability of a change in the tax rate using changes in the tax base. See Section 1 for details on data sources and Appendix A for definitions of broadening and narrowing for each measure. Year fixed effects are included in each panel. Standard errors are clustered by state $\left({ }^{*} p<.1,{ }^{* *} p<.05,{ }^{* * *} p<.01\right)$. Overall, this table shows that tax rate changes and tax base changes do not occur simultaneously. 
Table 5: Effects of Corporate Tax Rates and Tax Base Controls on Tax Revenues and Economic Activity

\begin{tabular}{|c|c|c|c|c|c|c|}
\hline \multirow[b]{3}{*}{$\tau$} & \multirow{2}{*}{\multicolumn{2}{|c|}{$\begin{array}{cc}(1) & (2) \\
\text { Revenue to GDP Ratio }\end{array}$}} & \multirow{2}{*}{\multicolumn{2}{|c|}{$\begin{array}{l}(3) \\
\log (\text { Revenue })\end{array}$}} & \multirow{2}{*}{\multicolumn{2}{|c|}{$\begin{array}{l}(5) \quad(6) \\
\log (\mathrm{GDP})\end{array}$}} \\
\hline & & & & & & \\
\hline & $\begin{array}{l}1.776^{*} \\
(1.054)\end{array}$ & $\begin{array}{l}1.608^{* *} \\
(0.763)\end{array}$ & & & & \\
\hline $\ln (1-\tau)$ & & & $\begin{array}{l}-2.318 \\
(2.699)\end{array}$ & $\begin{array}{l}-2.585 \\
(1.898)\end{array}$ & $\begin{array}{c}1.077 \\
(1.363)\end{array}$ & $\begin{array}{c}0.818 \\
(0.988)\end{array}$ \\
\hline R\&D Tax Credit & & $\begin{array}{l}-31.171 \\
(31.453)\end{array}$ & & $\begin{array}{c}0.173 \\
(0.969)\end{array}$ & & $\begin{array}{l}-0.078 \\
(0.274)\end{array}$ \\
\hline Sales Apportionment Wgt & & $\begin{array}{l}-0.073 \\
(0.069)\end{array}$ & & $\begin{array}{l}-0.001 \\
(0.002)\end{array}$ & & $\begin{array}{l}-0.001^{*} \\
(0.001)\end{array}$ \\
\hline Loss Carryback & & $\begin{array}{l}-0.357 \\
(0.637)\end{array}$ & & $\begin{array}{c}0.005 \\
(0.022)\end{array}$ & & $\begin{array}{c}0.014 \\
(0.012)\end{array}$ \\
\hline Loss Carryforward & & $\begin{array}{c}0.034 \\
(0.165)\end{array}$ & & $\begin{array}{c}0.001 \\
(0.004)\end{array}$ & & $\begin{array}{c}0.001 \\
(0.002)\end{array}$ \\
\hline Franchise Tax & & $\begin{array}{l}-9.615 \\
(6.834)\end{array}$ & & $\begin{array}{c}-0.406^{* *} \\
(0.164)\end{array}$ & & $\begin{array}{c}-0.126^{* * *} \\
(0.043)\end{array}$ \\
\hline Fed Income Tax Deductible & & $\begin{array}{l}-7.649^{*} \\
(3.847)\end{array}$ & & $\begin{array}{c}-0.336^{* * *} \\
(0.115)\end{array}$ & & $\begin{array}{c}-0.182^{* * *} \\
(0.061)\end{array}$ \\
\hline Fed Income as Tax Base & & $\begin{array}{l}-2.675 \\
(2.536)\end{array}$ & & $\begin{array}{l}-0.028 \\
(0.095)\end{array}$ & & $\begin{array}{l}-0.036 \\
(0.051)\end{array}$ \\
\hline Allow Fed Acc Dep & & $\begin{array}{c}6.242 \\
(5.339)\end{array}$ & & $\begin{array}{c}0.055 \\
(0.132)\end{array}$ & & $\begin{array}{l}-0.007 \\
(0.026)\end{array}$ \\
\hline ACRS Depreciation & & $\begin{array}{l}-0.698 \\
(1.312)\end{array}$ & & $\begin{array}{l}-0.033 \\
(0.032)\end{array}$ & & $\begin{array}{l}-0.018 \\
(0.021)\end{array}$ \\
\hline Federal Bonus Depreciation & & $\begin{array}{l}1.185 \\
(1.575)\end{array}$ & & $\begin{array}{l}-0.006 \\
(0.052)\end{array}$ & & $\begin{array}{c}0.031 \\
(0.021)\end{array}$ \\
\hline Throwback Rules & & $\begin{array}{l}1.431^{*} \\
(0.749)\end{array}$ & & $\begin{array}{l}0.008 \\
(0.045)\end{array}$ & & $\begin{array}{l}-0.022 \\
(0.014)\end{array}$ \\
\hline Combined Reporting & & $\begin{array}{c}-0.699 \\
(1.965)\end{array}$ & & $\begin{array}{l}-0.016 \\
(0.114)\end{array}$ & & $\begin{array}{c}0.004 \\
(0.033)\end{array}$ \\
\hline Investment tax credit & & $\begin{array}{c}-76.918^{* * *} \\
(25.973)\end{array}$ & & $\begin{array}{l}-1.382 \\
(0.837)\end{array}$ & & $\begin{array}{c}0.276 \\
(0.523)\end{array}$ \\
\hline R\&D Incremental Mov Avg & & $\begin{array}{c}2.614 \\
(2.560)\end{array}$ & & $\begin{array}{l}-0.013 \\
(0.085)\end{array}$ & & $\begin{array}{c}0.004 \\
(0.023)\end{array}$ \\
\hline R\&D Incremental Fixed & & $\begin{array}{l}1.875 \\
(3.288) \\
\end{array}$ & & $\begin{array}{c}0.009 \\
(0.113) \\
\end{array}$ & & $\begin{array}{c}0.052 \\
(0.032) \\
\end{array}$ \\
\hline $\begin{array}{l}\text { Observations } \\
\text { Base Index } \\
\text { (se) }\end{array}$ & 1,550 & $\begin{array}{c}1,550 \\
2.663 \\
.788 \\
\end{array}$ & 1,426 & 1,426 & 1,550 & 1,550 \\
\hline
\end{tabular}

NoTES: This table reports the results of regressions that estimate the effects of changes in tax rates on tax revenue and economic activity. Each specification weights observations by the mean state GDP in our sample and includes state and year fixed effects. The 15 base controls included in Columns (2)-(3) are described in Section 1. Details of the specification and the definition of the joint interaction can be found in Section 5. The revenue-to-GDP ratio is measured in basis points. Standard errors are clustered by state $\left({ }^{*} p<.1,{ }^{* *} p<.05,{ }^{* * *} p<.01\right)$. Overall this table shows that, while including tax base controls does not have significant effects on the average effect of taxes on revenues and economic activity, estimators that do not allow for heterogeneous effects of taxes that depend on the structure of the state corporate tax system result in inconsistent estimates of the average partial effect of taxes on revenues and economic activity. 
Table 6: Effects of Corporate Tax Rate Changes on Tax Revenues and Economic Activity

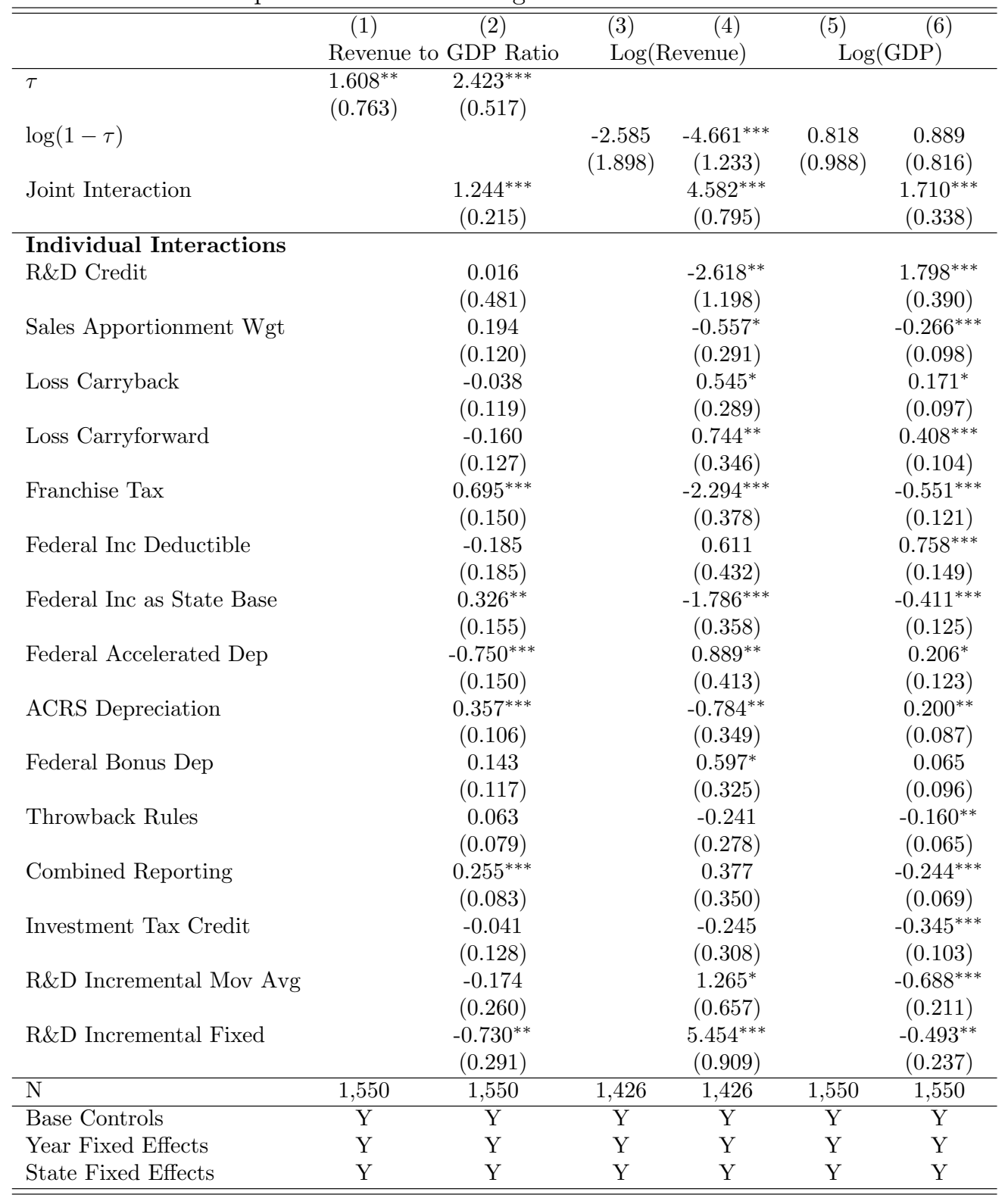

Notes: This table reports the results of regressions that estimate the effects of changes in tax rates on tax revenue and economic activity. Each specification weights observations by the mean state GDP in our sample and includes state and year fixed effects. Standard errors are clustered by state $\left({ }^{*} p<.1,{ }^{* *} p<.05,{ }^{* * *} p<.01\right)$. The 15 base controls included in Columns (1)-(6) are described in Section 1. Details of the specification and the definition of the joint interaction can be found in Section 5 . The revenue-to-GDP ratio is measured in basis points. The number of observations is lower in Columns (3) and (4) because some states do not collect corporate income taxes. Overall this table shows that, while including tax base controls does not have significant effects on the average effect of taxes on revenues and economic activity, estimators that do not allow for heterogeneous effects of taxes that depend on the structure of the state corporate tax system result in inconsistent estimates of the average partial effect of taxes on revenues and economic activity. 
Table 7: Linear and Quadratic Effects of Corporate Tax Rate Changes on Tax Revenues

Panel A. State Corporate Tax Revenue-to-GDP Ratio

\begin{tabular}{|c|c|c|c|c|c|}
\hline & $(1)$ & $(2)$ & $(3)$ & $(4)$ & $(5)$ \\
\hline State Corporate Tax Rate $\tau$ & $\begin{array}{l}3.95^{* *} \\
(1.87)\end{array}$ & $\begin{array}{c}0.49 \\
(4.88)\end{array}$ & $\begin{array}{c}2.74 \\
(2.16)\end{array}$ & $\begin{array}{c}3.10 \\
(3.94)\end{array}$ & $\begin{array}{c}3.46 \\
(3.69)\end{array}$ \\
\hline State Corporate Tax Rate $^{2}(\tau)^{2}$ & $\begin{array}{c}2.53 \\
(23.00)\end{array}$ & $\begin{array}{c}14.12 \\
(31.91)\end{array}$ & $\begin{array}{c}9.99 \\
(24.56)\end{array}$ & $\begin{array}{c}-5.06 \\
(25.00)\end{array}$ & $\begin{array}{c}-6.65 \\
(24.23)\end{array}$ \\
\hline Base Index $\times 100$ & & & $\begin{array}{c}5.33 \\
(3.21)\end{array}$ & $\begin{array}{c}5.32^{* * *} \\
(1.87)\end{array}$ & $\begin{array}{l}11.69 \\
(8.00)\end{array}$ \\
\hline State Corporate Tax Rate $\tau \times$ Base Index & & & & & $\begin{array}{l}-1.78 \\
(1.72)\end{array}$ \\
\hline State Corporate Tax $\operatorname{Rate}^{2}(\tau)^{2} \times$ Base Index & & & & & $\begin{array}{c}11.27 \\
(10.28)\end{array}$ \\
\hline Observations & 1,550 & 1,550 & 1,550 & 1,550 & 1,550 \\
\hline Year Fixed Effects & Yes & Yes & Yes & Yes & Yes \\
\hline State Fixed Effects & & Yes & & Yes & Yes \\
\hline Revenue-Maximizing Rate & & & & 0.307 & 0.260 \\
\hline
\end{tabular}

Panel B. Total State Tax Revenue-to-GDP Ratio

\begin{tabular}{|c|c|c|c|c|c|}
\hline & $\overline{(1)}$ & $(2)$ & $(3)$ & $(4)$ & $(5)$ \\
\hline State Corporate Tax Rate $\tau$ & $\begin{array}{c}6.4 \\
(13.3)\end{array}$ & $\begin{array}{c}26.0 \\
(18.5)\end{array}$ & $\begin{array}{c}6.2 \\
(13.0)\end{array}$ & $\begin{array}{c}20.2 \\
(18.8)\end{array}$ & $\begin{array}{l}29.9^{*} \\
(15.8)\end{array}$ \\
\hline State Corporate Tax $\operatorname{Rate}^{2}(\tau)^{2}$ & $\begin{array}{c}53.1 \\
(112.3)\end{array}$ & $\begin{array}{l}-113.1 \\
(130.3)\end{array}$ & $\begin{array}{c}56.9 \\
(109.1)\end{array}$ & $\begin{array}{c}-98.8 \\
(129.4)\end{array}$ & $\begin{array}{c}-156.2 \\
(106.6)\end{array}$ \\
\hline Base Index $\times 100$ & & & $\begin{array}{c}10.1 \\
(12.2)\end{array}$ & $\begin{array}{c}22.9^{* *} \\
(9.2)\end{array}$ & $\begin{array}{l}-15.5 \\
(25.2)\end{array}$ \\
\hline State Corporate Tax Rate $\tau \times$ Base Index & & & & & $\begin{array}{c}8.3 \\
(7.7)\end{array}$ \\
\hline State Corporate Tax Rate ${ }^{2}(\tau)^{2} \times$ Base Index & & & & & $\begin{array}{l}-38.6 \\
(53.1)\end{array}$ \\
\hline Obse & 1,550 & 1,550 & 1,550 & 1,550 & 1,550 \\
\hline Year Fixe & Yes & Yes & Yes & Yes & Yes \\
\hline State Fixed Effects & & Yes & & Yes & Yes \\
\hline Revenue-Maximizing Rate & & & & 0.102 & 0.096 \\
\hline
\end{tabular}

NOTES: This table reports the results of regressions that estimate the effects of changes in tax rates and tax bases on tax revenue. Each specification weights observations by the mean state GDP in our sample and includes state and year fixed effects. See Appendix Table A12 for a version of that controls for state sales and top personal income tax rates. The revenue-to-GDP ratio is measured in basis points. Standard errors are clustered by state $\left({ }^{*} p<.1,{ }^{* *} p<.05,{ }^{* * *} p<.01\right)$. The 15 base controls included in the base index are described in Section 1. 


\section{Appendices for Online Publication}

\section{A Data}

\section{A.1 Tax Base Rules}

1. Throwback Rules

- Variable: throwback

- Source: Bernthal et al. (2012)

- Definition: Indicator for whether state eliminates "nowhere income" that would be untaxed by either the state with the corporation's nexus or the state in which the relevant sales were being made.

2. Combined Reporting Rules

- Variable: combined

- Source: Bernthal et al. (2012)

- Definition: Indicator for whether a state requires a unitary business to submit combined reporting.

3. Investment Tax Credit

- Variable: investment_credit

- Source: Chirinko and Wilson (2008)

- Definition: Rate of investment tax credit for a given state-year.

4. Research and Development Tax Credit

- Variable: rec_val

- Source: Dan Wilson (2009)

- Definition: Statutory credit rate adjusted for recapture and type of credit.

5. Research and Development Tax Credit Base: Incremental Fixed Period

- Variable: incr_fixed

- Source: Computed using data from Dan Wilson (2009)

- Definition: Indicator for whether the tax base is incremental with a fixed base. See Appendix A.3 for more details.

6. Research and Development Tax Credit Base: Incremental Moving Average

- Variable: incr_ma

- Source: Computed using data from Dan Wilson (2009)

- Definition: Indicator for whether the tax base is incremental with a moving average. See Appendix A.3 for more details.

7. Loss Carryback Rules

- Variable: Losscarryback

- Source: CCH (1980 - 2010)

- Definition: Number of years prior to the loss year that a corporation may carry back net operating loss.

8. Loss Carryforward Rules

- Variable: Losscarryforward

- Source: CCH (1980 - 2010) 
- Definition: Number of years a corporation may carry forward any excess loss following the loss year.

9. Franchise Tax (indicator)

- Variable: FranchiseTax

- Source: CCH (1980 - 2010)

- Definition: An indicator for whether or not a Franchise tax is levied on corporations in a given state-year. Franchise taxes are levied on firms for the "privilege" of doing business in a given state. In Texas, for example, franchise taxes are based on corporate margins, but they may also be based on par value of stock, paid-in capital, net worth, gross receipts or assessed value of property. In some cases, such as Alabama, franchise taxes are based on corporate income, thus raising the effective corporate tax rate. Franchise taxes can therefore be an alternative to a corporate income tax, or to taxing corporate income at a higher rate.

10. Federal Income Tax Deductible

- Variable: FedIncomeTaxDeductible

- Source: CCH (1980 - 2010)

- Definition: An indicator for whether or not federal income tax is deductible in a given state-year.

11. Federal Income as State Tax Base

- Variable: FederalIncomeasStateTaxBase

- Source: CCH (1980 - 2010)

- Definition: An indicator for whether or not federal income is used as the state tax base in a given state-year.

12. Federal Accelerated Depreciation

- Variable: AllowFedAccDep

- Source: CCH (1980 - 2010)

- Definition: An indicator for whether or not federal accelerated depreciation is allowed in a given state-year.

13. Accelerated Cost Recovery System (ACRS) Depreciation

- Variable: ACRSDepreciation

- Source: CCH (1980 - 2010)

- Definition: An indicator for whether or not ACRS is allowed in a given state-year.

14. Federal Bonus Depreciation

- Variable: FederalBonusDepreciation

- Source: CCH (1980 - 2010)

- Definition: An indicator for whether or not federal bonus depreciation is allowed in a given state-year.

15. Sales Apportionment Weight

- Variable: sales_wgt

- Source: Bernthal et al. (2012)

- Definition: The share of national profits of multi-state firms that are allocated to sales (for tax purposes) in a given state. 


\section{A.2 Definitions of Broadening/Narrowing and Expected Sign of Interaction Terms}

In Tables 2-4 and Appendix Table A3 we analyze changes in base rules and code changes as narrowing or broadening. This definition also maps into expected signs for the interaction between taxes and base controls in equation 5 as follows:

- Throwback Rules: "no" to "yes" is base broadening. Expected interaction sign: positive.

- Combined Reporting Rules: "no" to "yes" is base broadening. Expected interaction sign: positive.

- Investment Tax Credit: increase in credit is base narrowing. Expected interaction sign: negative.

- Research and Development Tax Credit: increase in credit is base narrowing. Expected interaction sign: negative.

- Incremental R\&D Credit, Base is Moving Average: "no" to "yes" is base broadening. Expected interaction sign: positive.

- Incremental R\&D Credit, Base is Fixed: "no" to "yes" is base broadening. Expected interaction sign: positive.

- Loss Carryback Rules: increase in years is base narrowing. Expected interaction sign: negative.

- Loss Carryforward Rules: increase in years is base narrowing. Expected interaction sign: negative.

- Franchise Tax (indicator): "no" to "yes" is base narrowing. Expected interaction sign: negative.

- Federal Income Tax Deductible: "no" to "yes" is base narrowing, "yes" to "no" is base broadening. Expected interaction sign: negative.

- Federal Income as State Tax Base: "no" to "yes" is base broadening, "yes" to "no" is base narrowing. Expected interaction sign: positive.

- Federal Accelerated Depreciation: "no" to "yes" is base narrowing. Expected interaction sign: negative.

- Accelerated Cost Recovery System (ACRS) Depreciation: "no" to "yes" is base narrowing. Expected interaction sign: negative.

- Federal Bonus Depreciation: "no" to "yes" is base narrowing. Expected interaction sign: negative.

- Sales Apportionment Weight: increase in sales weight is base narrowing. Expected interaction sign: negative.

\section{A.3 R\&D Tax Credit Base}

The effective $R \& D$ tax credit rate is a combination of 3 factors: the statutory $R \& D$ tax credit rate, the base level definition, and the recapture policy (Wilson, 2005). States vary in the definition of the applicable base for R\&D tax credits. As pointed out in Wilson (2009), such definitions fall into 3 major categories:

1. Non-incremental credit: all R\&D expenditures are eligible for credit.

2. Incremental credit with a moving average base: only $R \& D$ expenditures above a base level determined by the firm's recent activity are eligible for credit. This base level is usually a moving average of the firm's R\&D over the past 1-4 years (Wilson, 2005).

3. Incremental credit with a fixed-period base: only R\&D expenditures above a base level determined by the firm's activity during a fixed past period are eligible for credit. 
From 1980-2010, several states rely on the federal definition of the base level. The federal definition used a 3 -year moving average until 1989, which was computed as the multiplication of current sales and the average R\&D-to-sales ratio over the past 3 years (Wilson (2009); Chang (2014); Rao (2016)). With the passage of Public Law 101-239 on December 19, 1989, the federal R\&D regime shifted to a fixed-period base level definition (Chang, 2014). Under this regime, the base level is computed as a firm's recent sales times the average R\&D-sales ratio over the period 1984-1988 (Wilson, 2005). In addition, states have set their own definitions of the $R \& D$ tax base. To account for the effects of different $R \& D$ tax credit regimes on state tax revenues and economic activity, we control for two indicators of the type of incremental base a state might have: fixed or moving average. We use data from Wilson (2009) to generate these indicators.

\section{A.4 Bartik Tax Base Rules}

1. Property taxes

- Variable: propertytax

- Source: Bartik (2017)

- Definition: Real property tax rate for industrial real property, industrial machinery and equipment, and industrial inventories. Real property includes both land and buildings. For all nonmanufacturing industries, the commercial tax rates are applied. The tax rates are applied to real property, and to personal property excluding inventories. Inventories are assumed to always be exempt. The tax rates were interpolated for missing years, assuming the tax rate changes linearly between the two years given.

2. Property tax abatement

- Variable: propabatement

- Source: Bartik (2017)

- Definition: The nominal value of the property tax abatement rate for each city under consideration in Bartik (2017). The database in Bartik (2017) seeks to determine not just what the state allows in property tax abatements, but what specific cities do.

3. Job creation tax credits

- Variable: jobcreationcred

- Source: Bartik (2017)

- Definition: The nominal value of the job creation tax credit, calculated before considering any limits on the tax credit. 


\section{B Construction of Neighbor and Similar States}

\section{B.1 Neighboring States}

Neighbor states are states that share a border of any length. There exist 109 unique state border pairs, including pairs sharing a single-point border. States with no interstate border are not included in the sample. We draw our border data from Holmes (1998). It includes 48 states (Alaska and Hawaii share no borders with other US states). The District of Columbia is excluded from our sample. We then construct a dataset with 218 state border pairs such that for each bordering states $i$ and $j$, we have the state pair $i j$ and $j i$. We then merge corporate tax rate and base measure data for each state $i$ and bordering state $j$ from 1980-2010.

\section{B.2 Similar States}

We use state-level demographic and economic characteristics to construct a measure of state similarity. For each state $i$ and year $t$ in our sample, we fit a logistic regression to estimate the probability that state $j \neq i$ is state $i$ in year $t$. The estimates from this regression provide a measure of how similar states are to a given state in a given year.

Specifically, for each state-year, we estimate the specification:

$$
\begin{aligned}
\operatorname{Prob}(j=i)_{j t}=\beta_{0} & +\beta_{1} \text { manuf }_{j t}+\beta_{2} \text { service }_{j t}+\beta_{3} \text { agr }_{j t}+\beta_{4} \text { constr_mine } \\
& +\beta_{5} \text { skill }_{j t}+\beta_{6} \log (\text { pop })_{j t}+\varepsilon_{j t}
\end{aligned}
$$

where $\operatorname{Prob}(j=i)$ is the probability that state $j$ is state $i$; manuf is manufacturing share of state GDP; service is information and professional services' share of state GDP; agr is agriculture, forestry, fishing and hunting share of state GDP; constr_mine is construction, mining and utilities share of state GDP; skill is the share of the state population over 18 with a Bachelor's Degree or above; and $\log (p o p)$ is $\log$ state population in year $t$. Appendix Table A13 summarizes the covariates used to construct the similarity index. Industry share of GDP was measured by the Bureau of Economic Analysis. We then calculate the "distance" between $j$ and $i$, defined as $d_{i j}=[\operatorname{LProb}(i=j)-L \operatorname{Prob}(i=i)]^{2}$, or the squared difference between the linear probabilities. ${ }^{36}$ State $i$ 's "similar" state in year $t$ is the state whose estimated probability yields the smallest $d_{i j}$ in year $t-1$.

A key difference between identifying border and similar states is that state similarity is not necessarily reciprocal. In other words, Maine may be similar to Vermont in year $t$, but Vermont is not necessarily similar to Maine.

One shortcoming of this method is that it does not identify similar matches for all states in all years. Only 25 states have a "similar" state for every sample year; the other 25 are missing matches in some or all sample years. The reason is that some states are too economically different from the rest of the nation. For example, California has no matches because it is exactly identified by its population, and the probability that any other state is California is infinitely close to $0 .{ }^{37}$ Appendix Table A14 lists all states in our sample and their "similar" states in the year before a tax rate or base change. We hold the "similar" state constant in the years surrounding an event when estimating the results of Appendix Tables A5 and A6, and Appendix Figure A29.

\section{B.3 Estimating Event Probability Subject to Events in Similar States}

Appendix Tables A5 and A6 describe how the probability of a corporate tax rate or base change is affected by events in states' neighbors and economically similar counterparts. Let $Y_{i t}$ indicate a corporate rate increase or decrease, or broadening or narrowing of the tax base in state $i$ and year $t$. Denote the set of neighbors and similar states $j \neq i$. The results in Appendix Table A5 are estimated by running a probit regression of the

\footnotetext{
${ }^{36}$ We estimate the Hosmer-Lemeshow statistic for each logistic regression, and fail to reject the null that the indicator of wether any state is state $i$ is orthogonal to the covariates listed in equation 9 . This suggests that the matching regression has high predictive power.

${ }^{37}$ We explored using OLS to avoid these issues when estimating $\operatorname{Prob}(j=i)_{j t}$, but this approach can yield predicted probabilities that fall outside the range of 0 to $100 \%$.
} 
form:

$$
\begin{aligned}
P\left(Y_{i t}=1\right)=\beta_{0} & +\beta_{1} D[\text { RateInc }]_{j, t-1}+\beta_{2} D[\text { RateDec }]_{j, t-1} \\
& +\beta_{3} D[\text { BaseNarrow }]_{j, t-1}+\beta_{3} D[\text { BaseBroaden }]_{j, t-1}+\varepsilon_{i t}
\end{aligned}
$$

while the results in Appendix Table A6 are estimated by similarly estimating

$$
\begin{aligned}
P\left(Y_{i t}=1\right)=\beta_{0} & +\beta_{1} D[\text { RateInc }]_{j, t^{\prime}}+\beta_{2} D[\text { RateDec }]_{j, t^{\prime}} \\
& +\beta_{3} D[\text { BaseNarrow }]_{j, t^{\prime}}+\beta_{3} D[\text { BaseBroaden }]_{j, t^{\prime}}+\varepsilon_{i t}
\end{aligned}
$$

where $t^{\prime} \in[t-5, t-1]$.

In the neighbor states case, we consider changes in corporate tax rate and in tax base that took place in any of $i$ 's border states. For example, the indicator for whether a corporate rate increase took place in Maine's neighboring states in the previous year equals 1 if Vermont's corporate tax rate increased in year $t-1$. We present results for $k=1$, i.e., a neighbor changed rates last year, and $k \in[1,5]$, i.e., if an event occurred at least once in the previous five years. 
Figure A1: Changes in State Corporate Tax Structure - Bartik Sample

\section{A. Time Series}

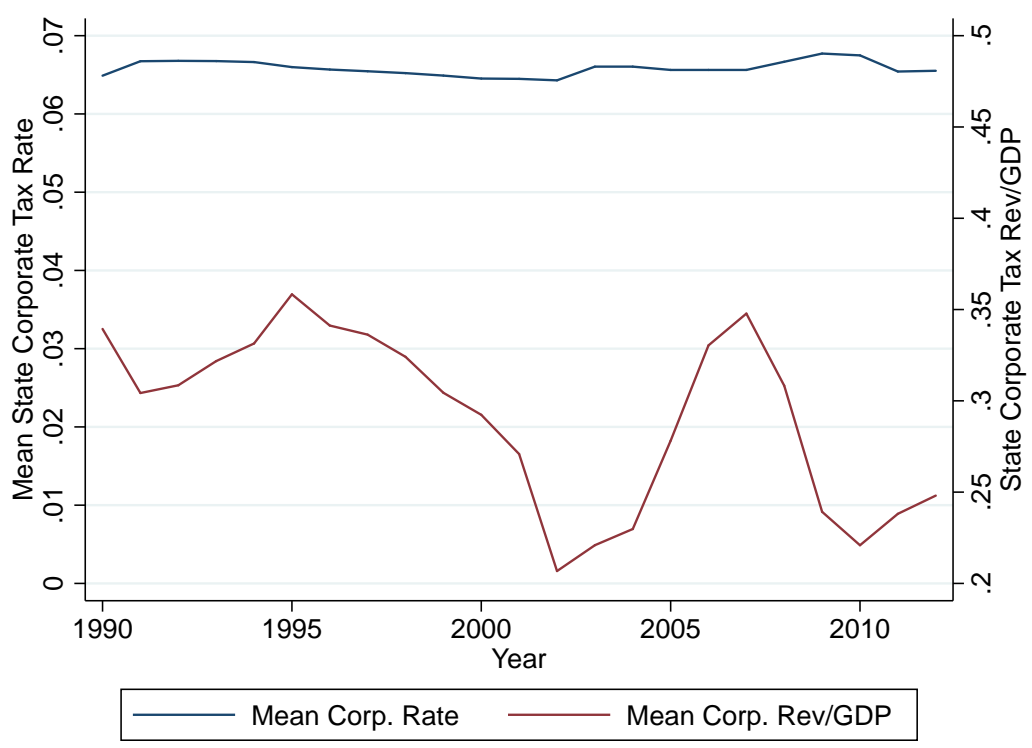

\section{B. Frequency of Changes}

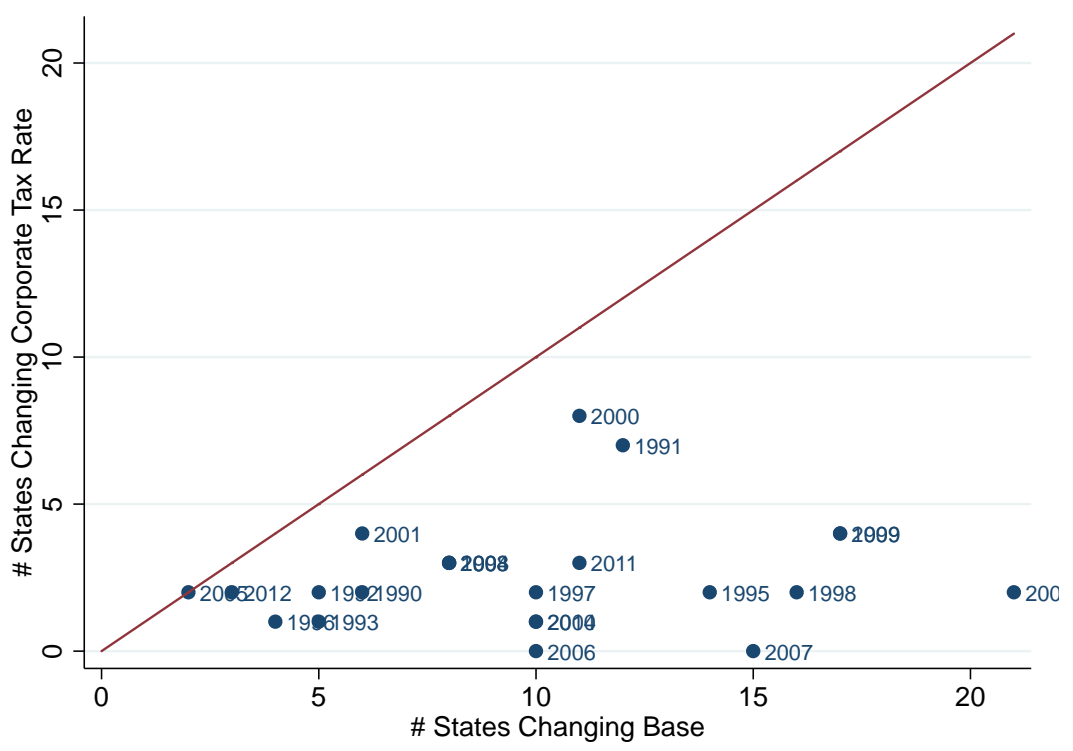

NotEs: This figure shows annual trends in both the mean corporate tax rate across states and corporate tax revenue as a share of GDP in Panel A. Panel B shows by year the number of states that changed rates and tax base provisions. It illustrates that these pairs are not on a 45 degree line, so most years in which many states change base provisions are not years in which many states also change rates. Note that this figure is analogous to Figure 2, but only on 33 states from 1990-2010 (i.e. availability along the Bartik controls dimension). See Section 1 for details on data sources. 
Figure A2: Variance of Log State Corporate Tax Revenue as a Share of GDP

A. Variance Decomposition

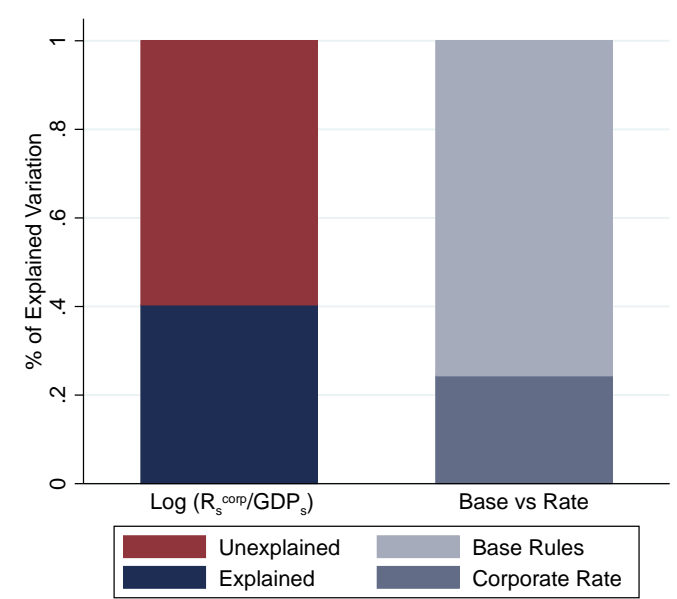

B. Share of Explained Variance by Base Rule (i.e., $\left.\frac{\operatorname{Var}\left(x_{s t}^{j} \Psi_{s t}^{j}\right)}{\sum_{j} \operatorname{Var}\left(x_{s t}^{j} \Psi_{s t}^{j}\right)}\right)$

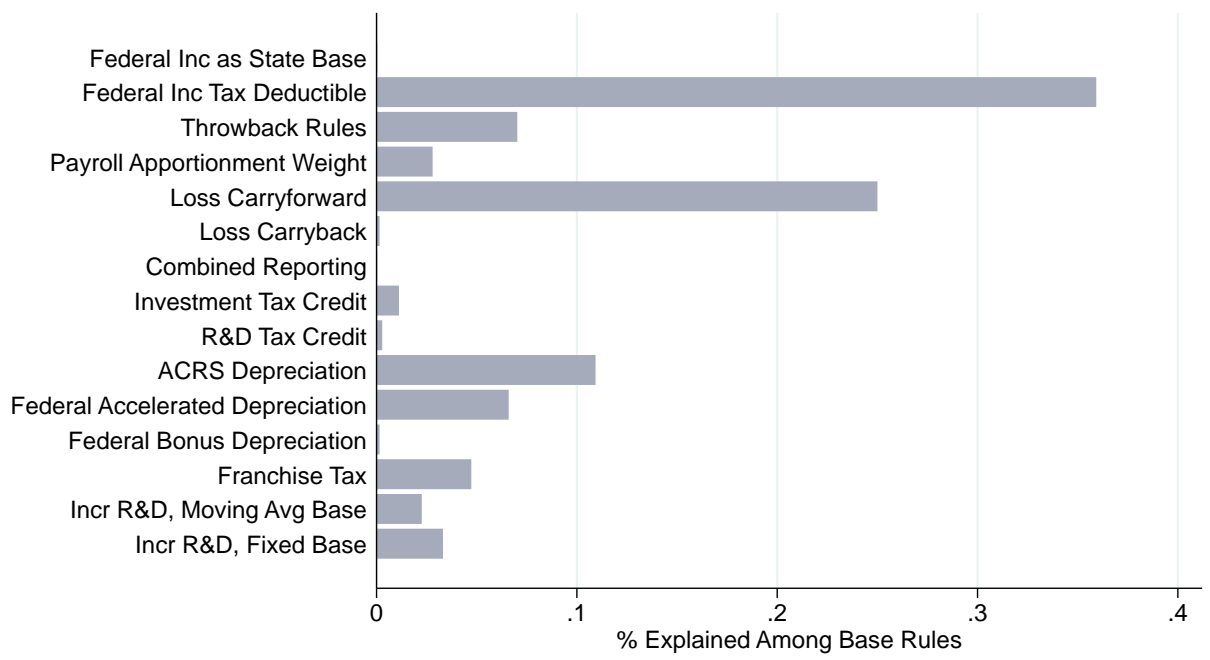

C. Effects of Standardized Base Rules $\tilde{\Psi}_{s t}^{j}$

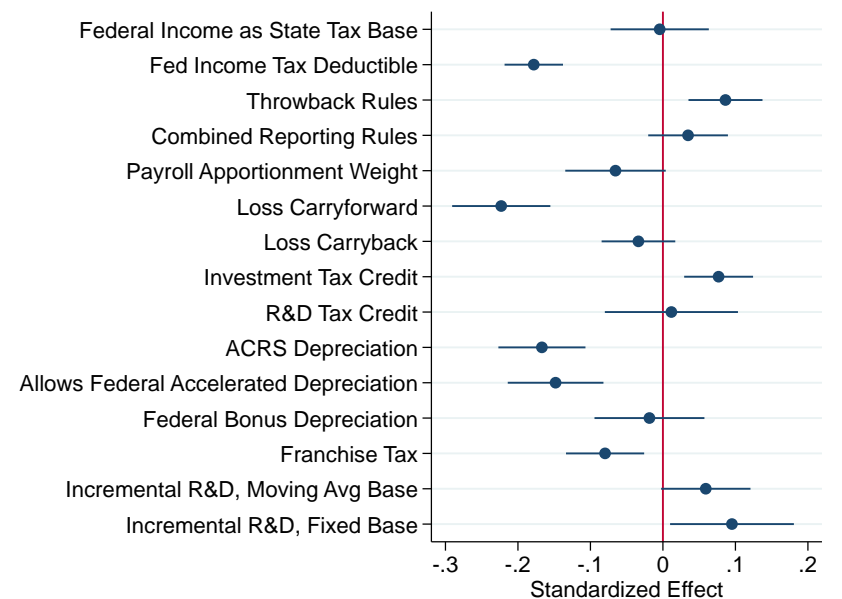

Notes: This figure replicates Figure 5 using $\ln R_{s t}$ as the outcome. Panel A decomposes the variation in log state corporate tax revenue share of state GDP from 1980-2010 using equation 2. Panel B displays the contribution to base variation from each base rule. Panel C plots the effect of each base rule on the state corporate tax revenue share of state GDP from 1980-2010. We standardize each base rule prior to determining the coefficients to facilitate comparisons across base rules with different variances. See Section 3 for details. The decomposition is weighted by mean state GDP across our sample period. See Section 1 for details on data sources. 
Figure A3: Log Corporate Tax Revenue Share of GDP - Variance Decomposition - 5-Year Splits

A. Variance Decomposition

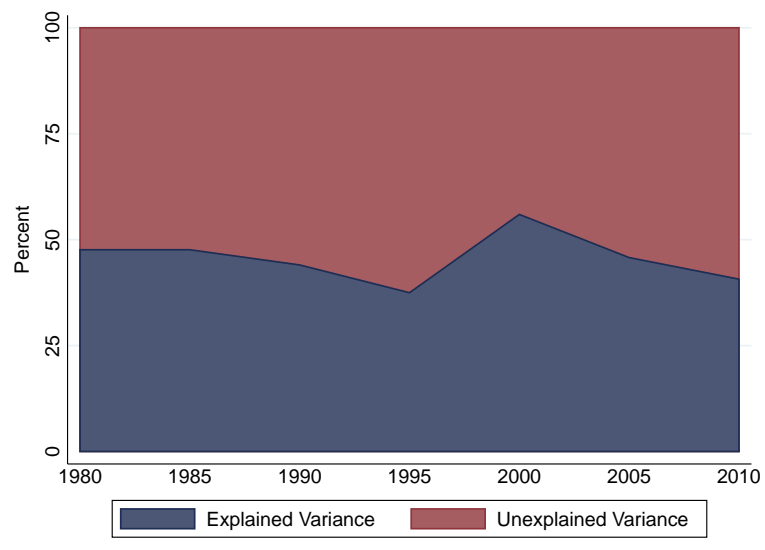

B. Share of Explained Variance, Rate vs. Base

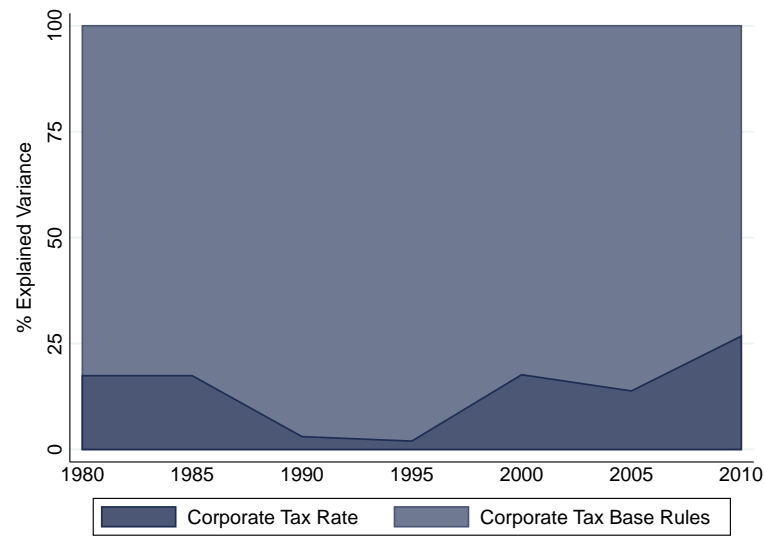

C. Share of Explained Variance by Base Rule (i.e., $\left.\frac{\operatorname{Var}\left(x_{s t}^{j} \Psi_{s t}^{j}\right)}{\sum_{j} \operatorname{Var}\left(x_{s t}^{j} \Psi_{s t}^{j}\right)}\right)$

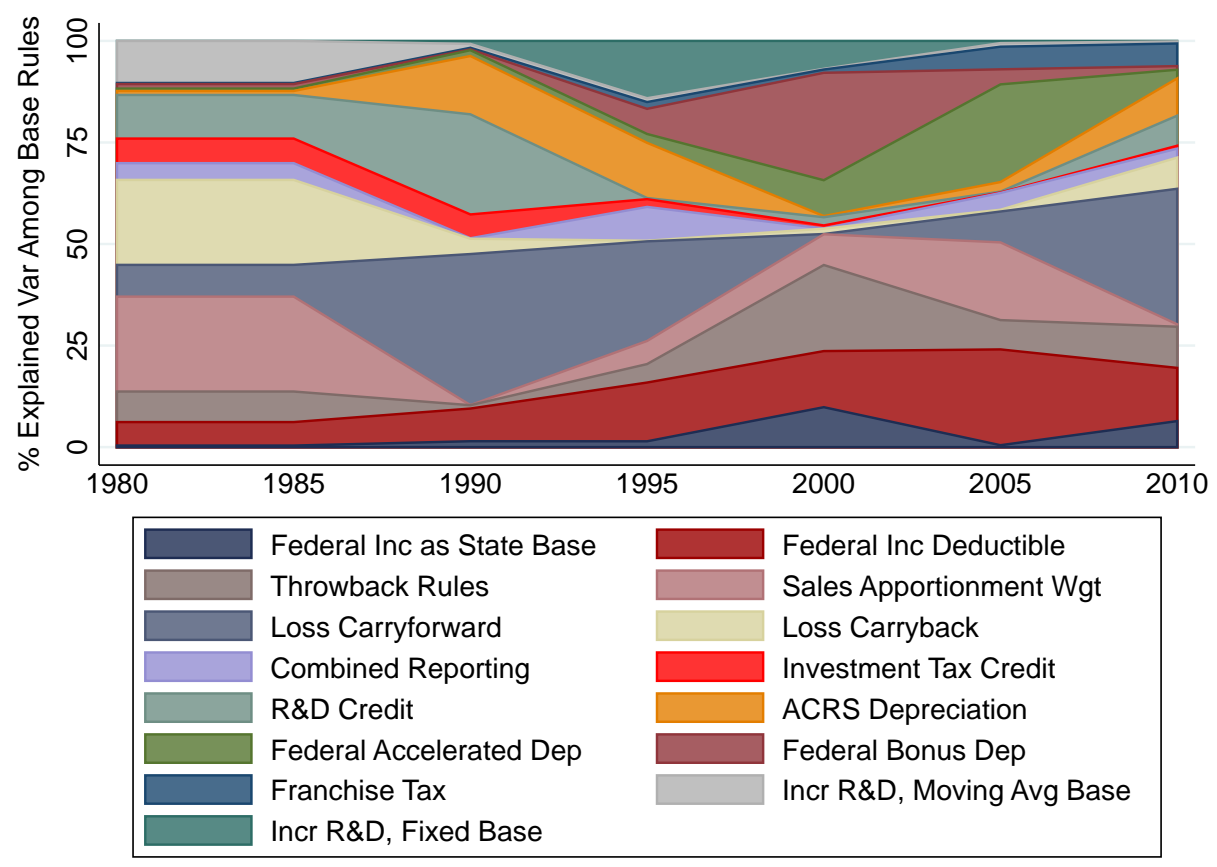

Notes: This figure replicates Figure 6 using $\ln R_{s t}$ as the outcome.Panel A decomposes the variation in log state corporate tax revenue share of state GDP from 1980-2010 using equation 3. Panel B displays the contribution to base variation from each base rule. Panel C plots the effect of each base rule on the state corporate tax revenue share of state GDP from 1980-2010. See Section 3 for details. The decomposition is weighted by mean state GDP across our sample period. See Section 1 for details on data sources. 
Figure A4: Corporate Rate Changes Relative to State Share of Pass-through Activity

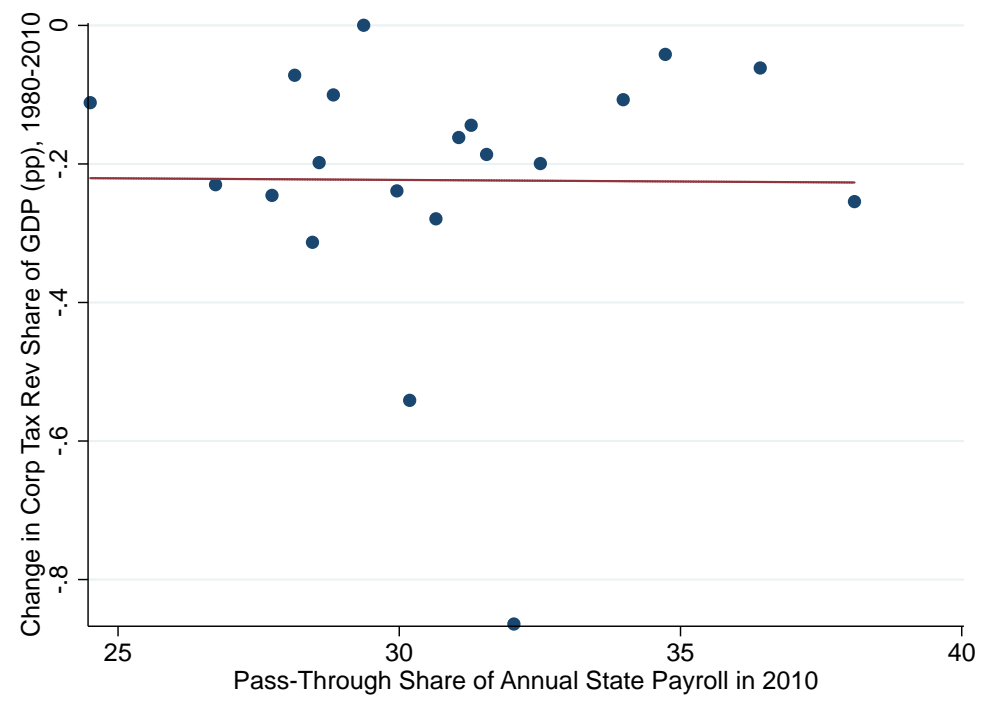

Notes: This figure plots the percentage-point change in state corporate income tax revenue as a share of GDP between 1980 and 2010, relative to share of annual state payroll attributed to pass-through corporations in 2010. The cross-section includes all 50 states. Annual payroll includes all forms of compensation, such as salaries, wages, commissions, dismissal pay, bonuses, vacation allowances, sick-leave pay, and employee contributions to qualified pension plans paid during the year to all employees. For corporations, payroll includes amounts paid to officers and executives; for unincorporated businesses, it does not include profit or other compensation of proprietors or partners. Payroll is reported before deductions for social security, income tax, insurance, union dues, etc. This definition of payroll is the same as that used by the Internal Revenue Service (IRS) on Form 941 as taxable Medicare Wages and Tips (even if not subject to income or FICA tax). Data on annual pass-through payroll are from the 2010 County Business Patterns survey. See Section 1 for details on other data sources. 
Figure A5: Rates \& Revenue

Corporate Tax Rate - 2012

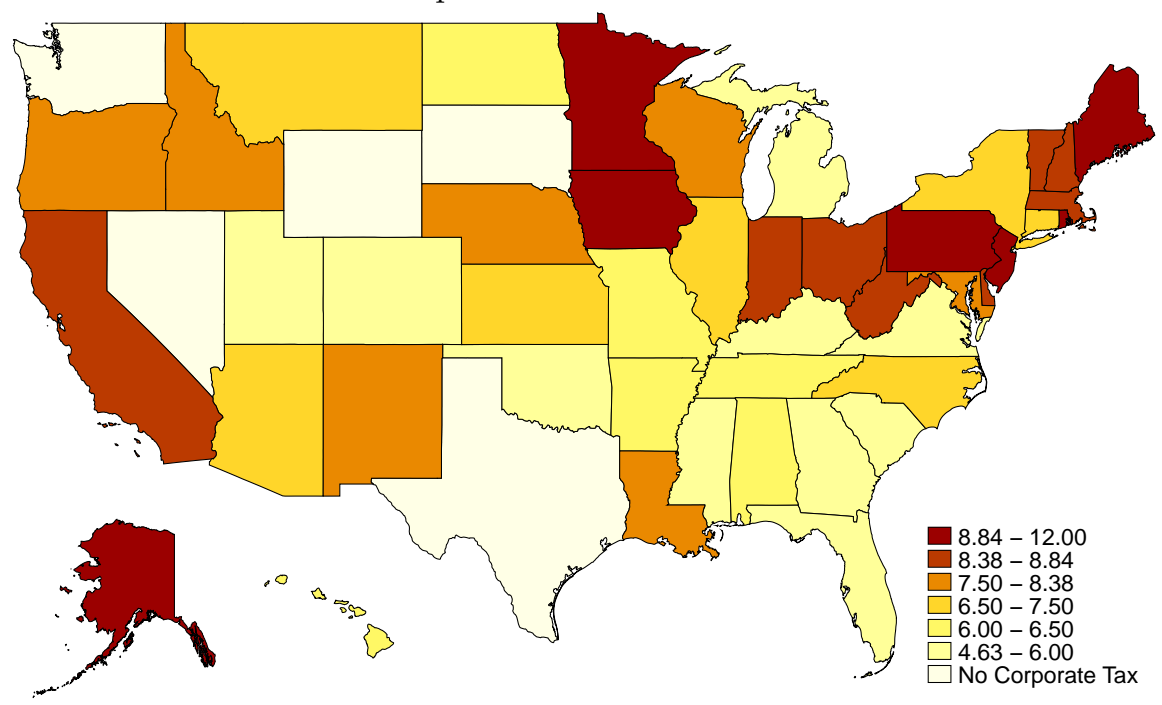

Corporate Revenue Share of Total Tax Revenue (\%) - 2012

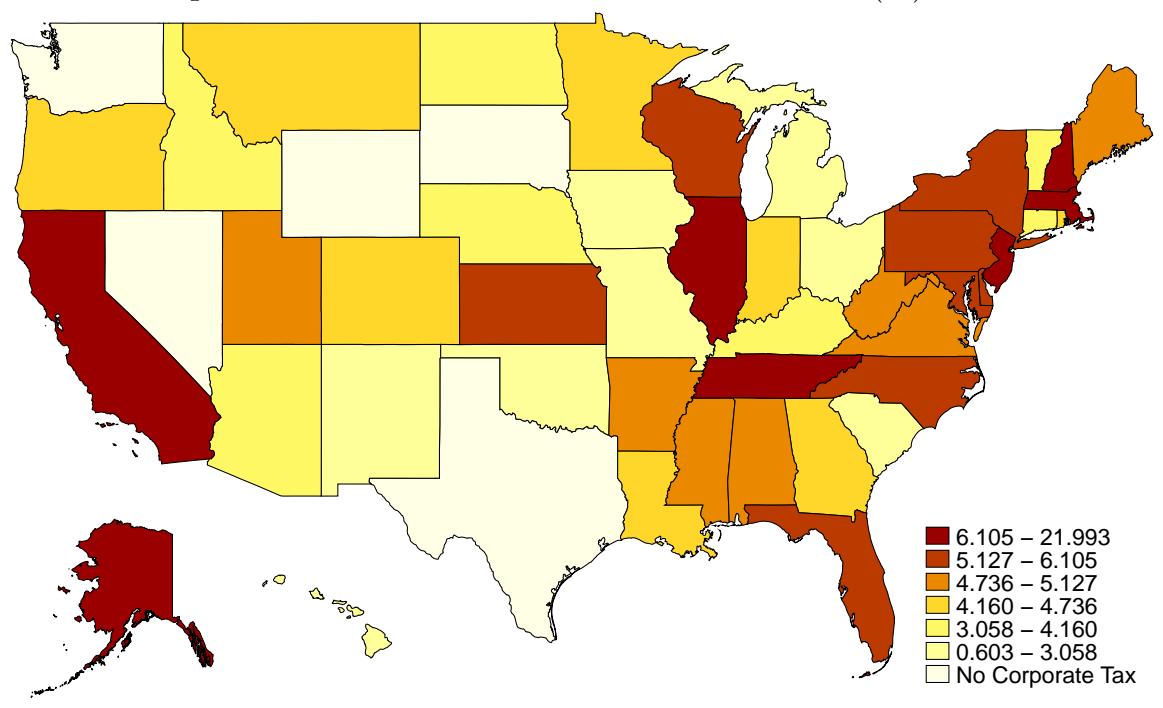

Sales Apportionment Weight - 2012

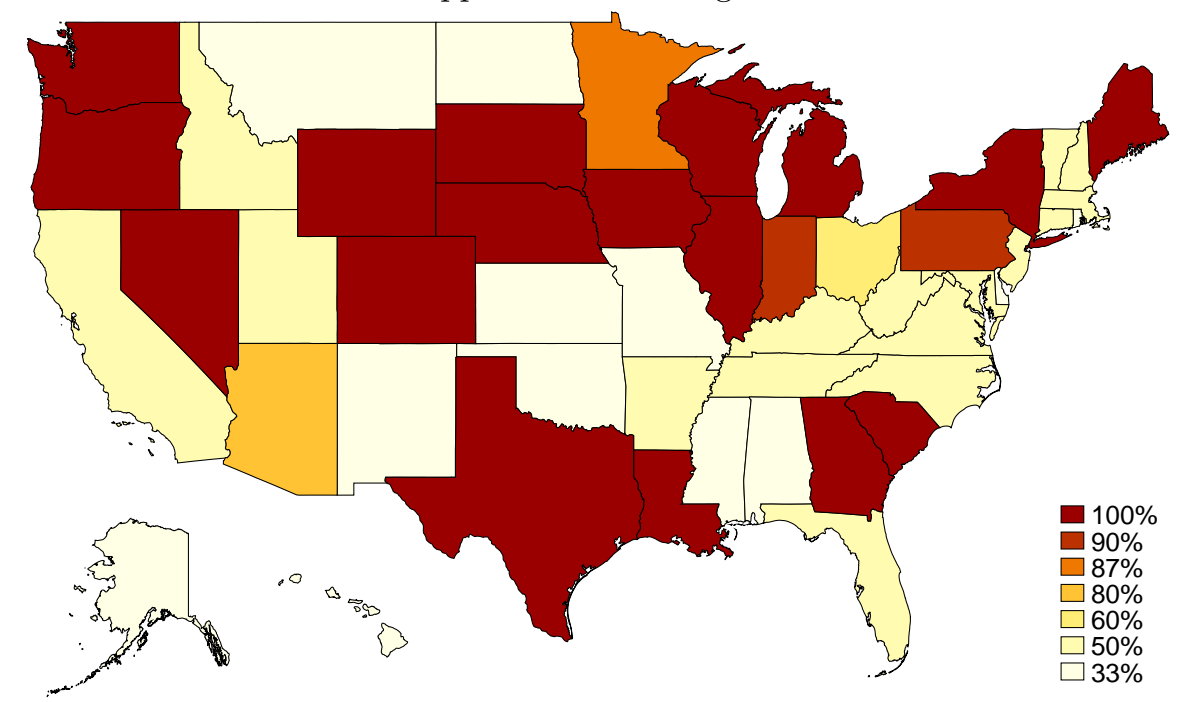


Figure A6: Corporate Tax Base Rules

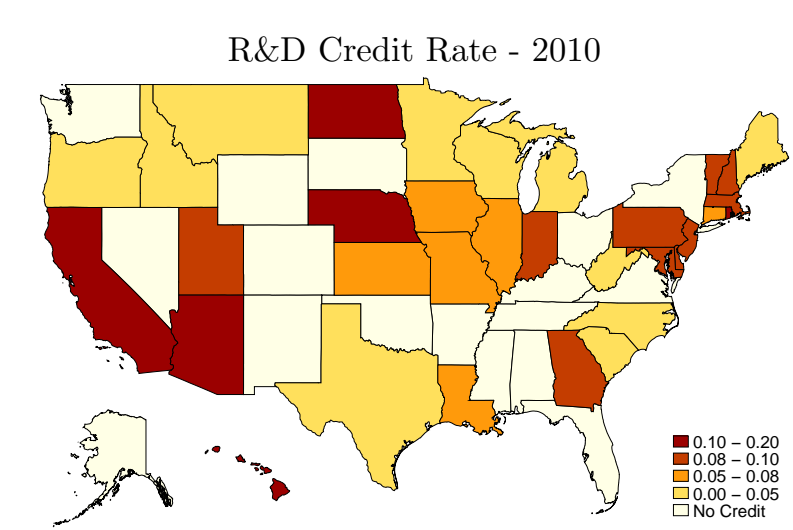

Investment Credit Rate - 2012

g

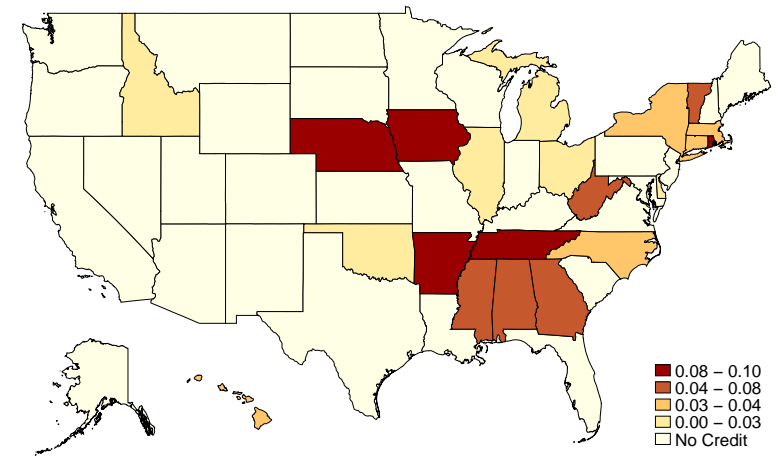

Moving Average R\&D Credit Base - 2010

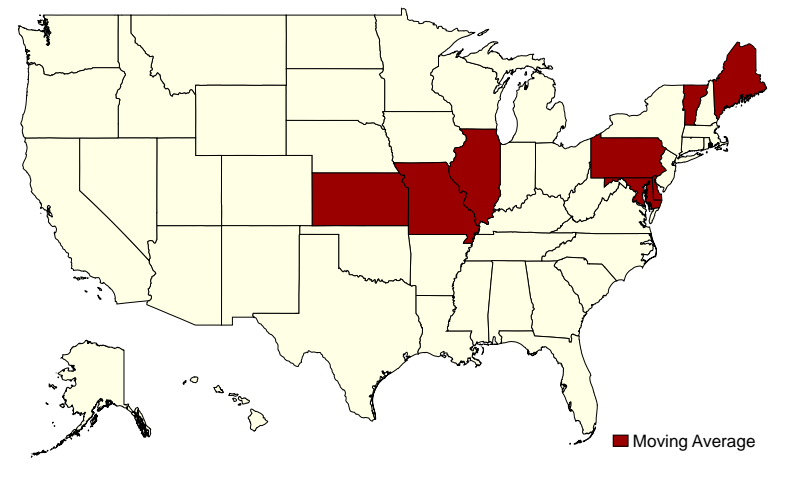

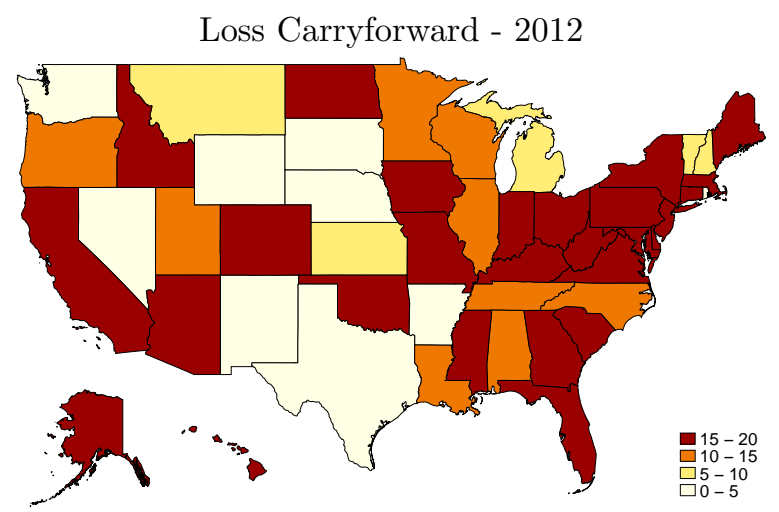

Loss Carryback - 2012

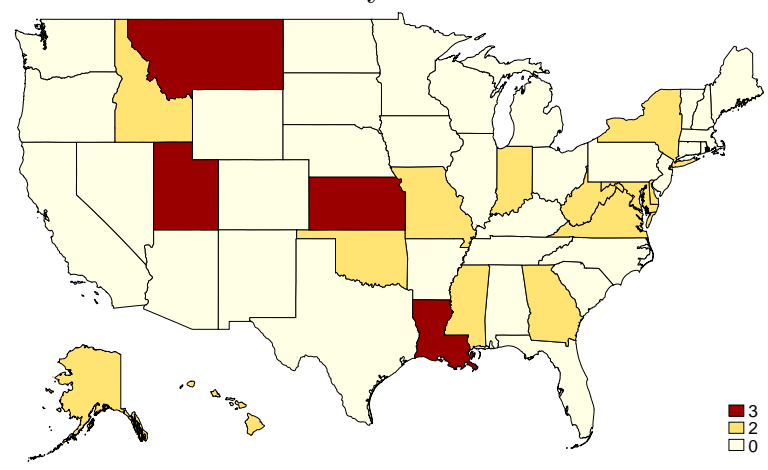

Fixed R\&D Credit Base - 2010

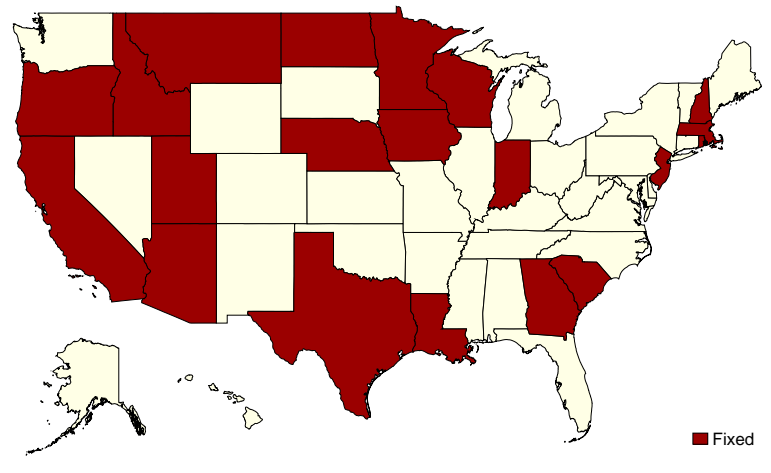

Throwback Rule - 2010

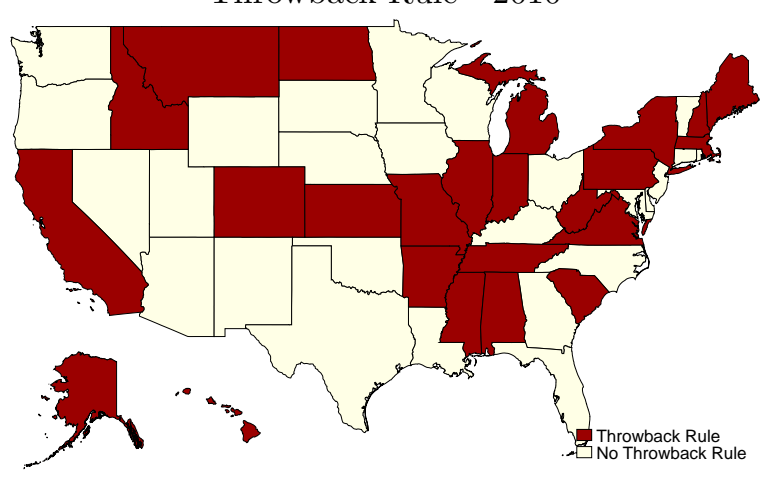

Combined Reporting Rule - 2010

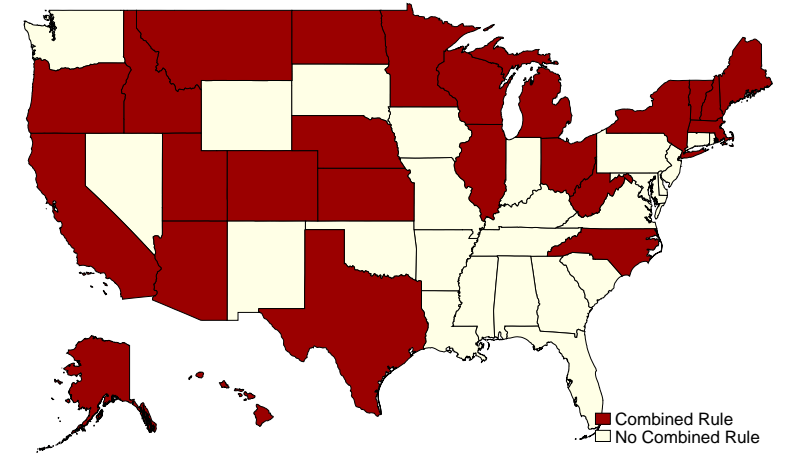

Franchise Tax - 2012

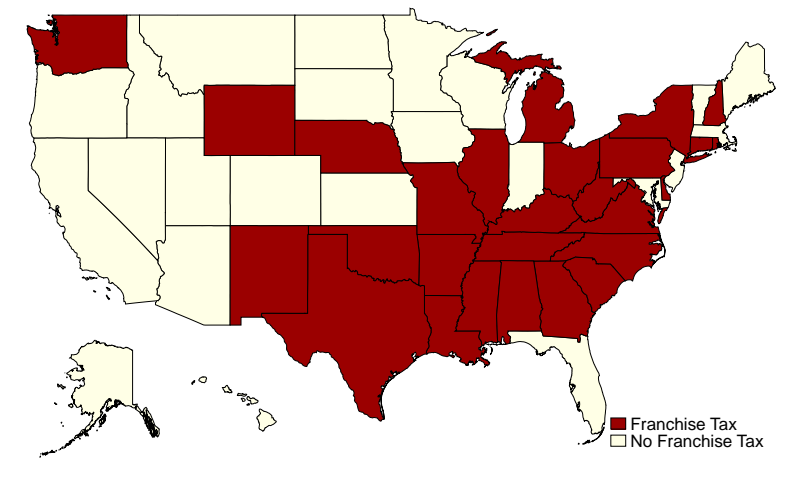


Figure A7: Corporate Tax Rate By State-Year
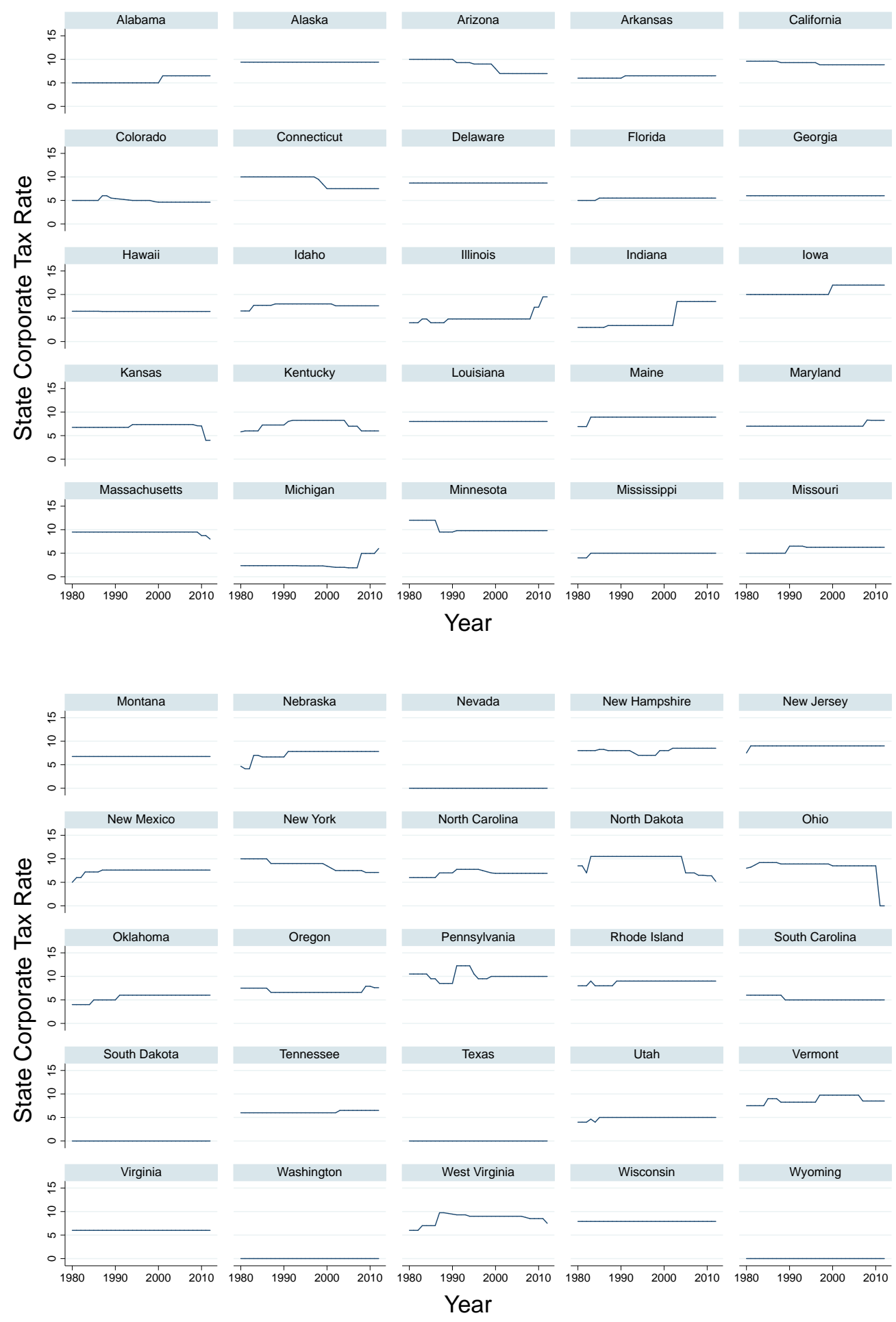

Notes: This figure plots corporate tax rate by state from 1980-2012. See Section 1 for details on data sources. 
Figure A8: Loss Carryforward Rule By State-Year
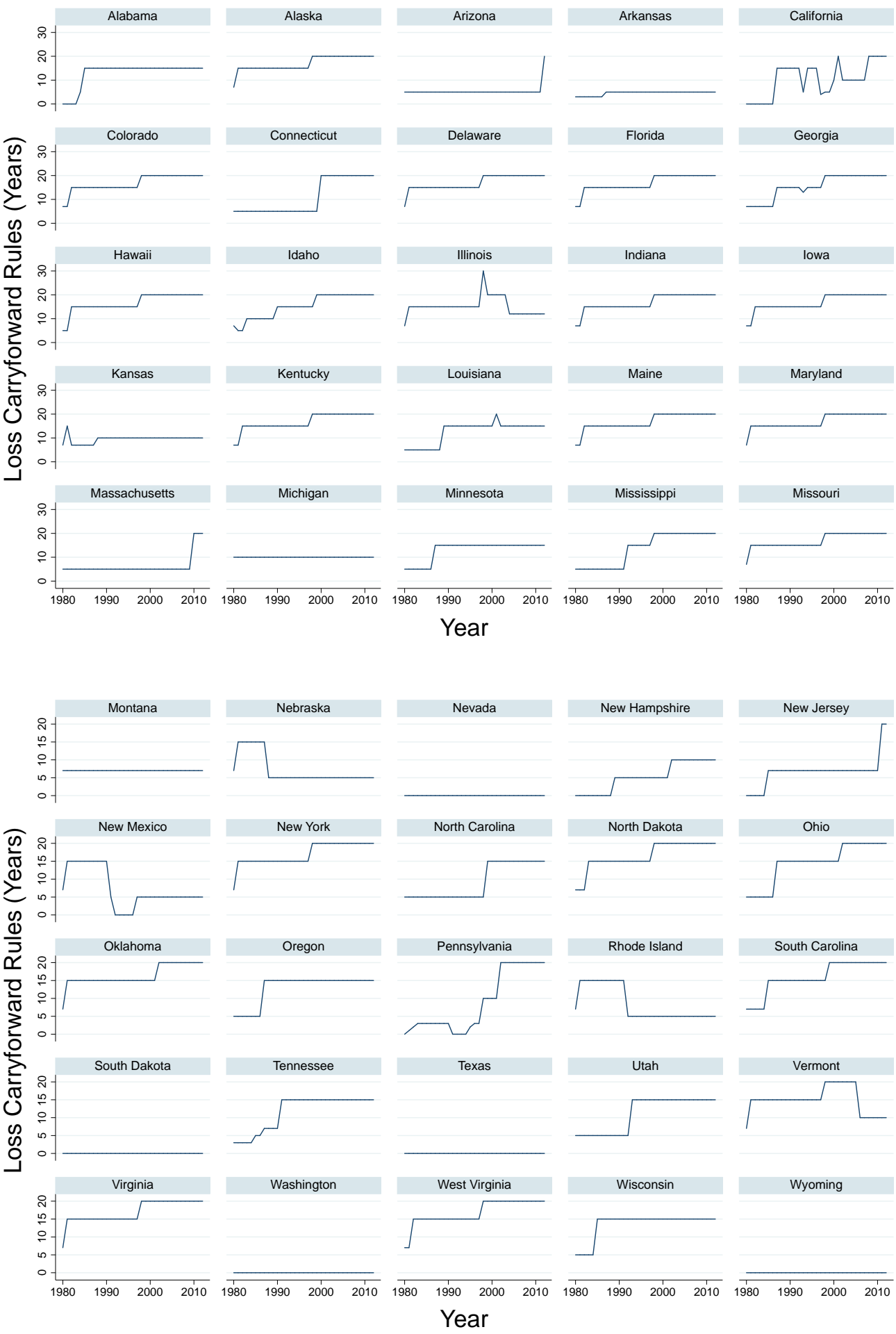

Notes: This figure plots the number of loss carryforward years allowed by state from 1980-2012. See Section 1 for details on data sources. 
Figure A9: Loss Carryback Rule By State-Year
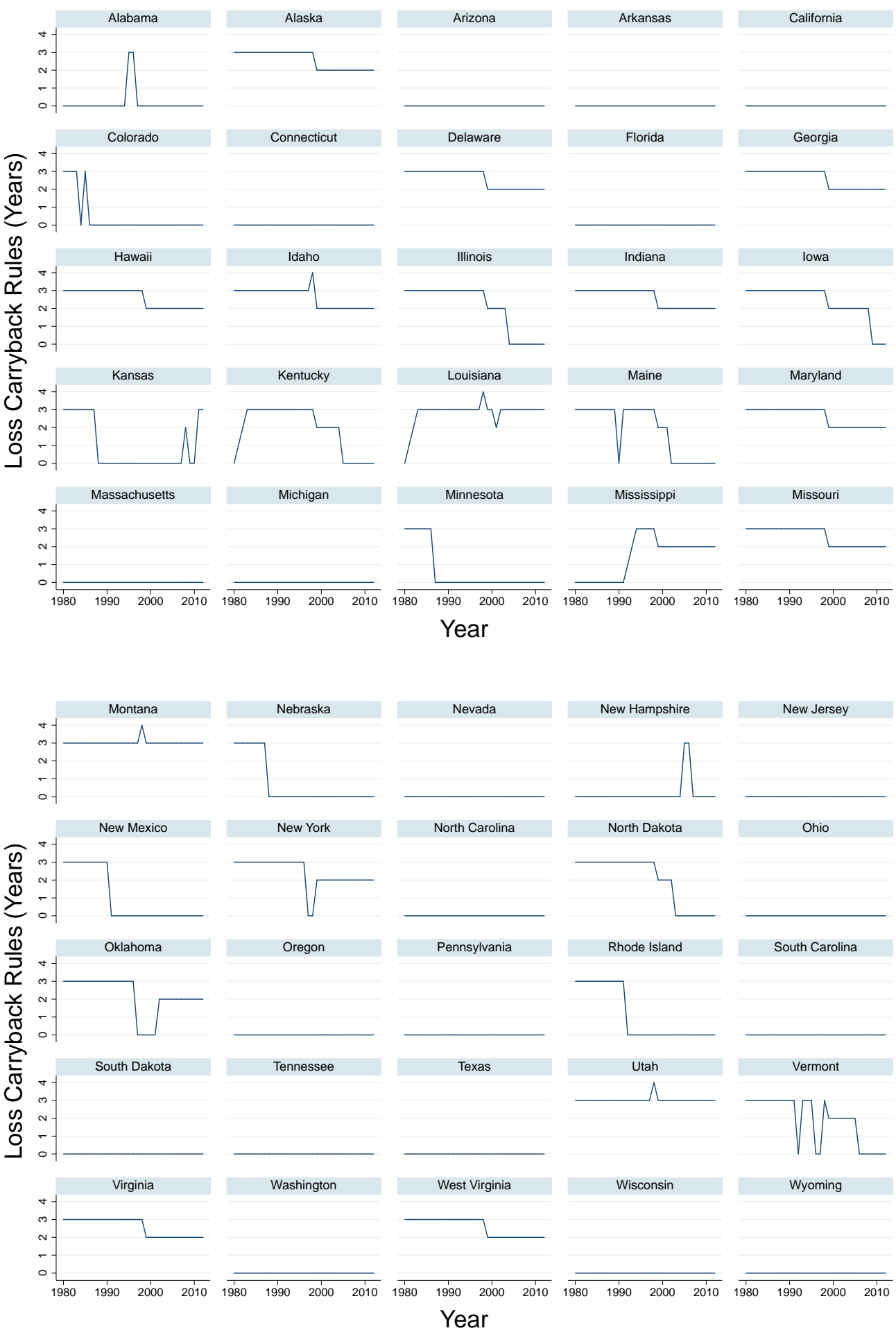

Notes: This figure plots the number of loss carryback years allowed by state from 1980-2012. See Section 1 for details on data sources. 
Figure A10: R\&D Credit Rate By State-Year
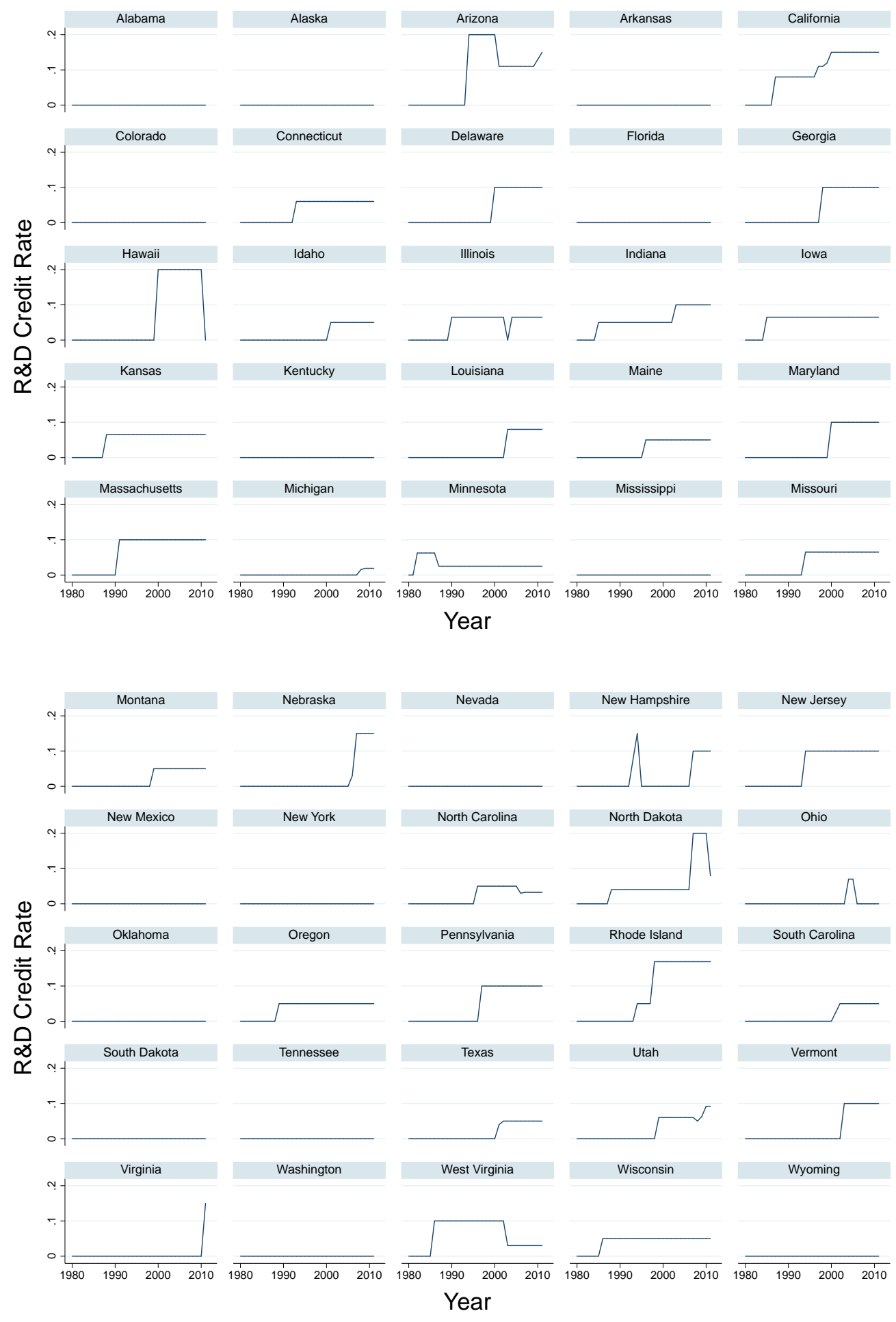

Notes: This figure plots the R\&D credit rates by state from 1980-2011. See Section 1 for details on data sources. 
Figure A11: Investment Credit Rate By State-Year
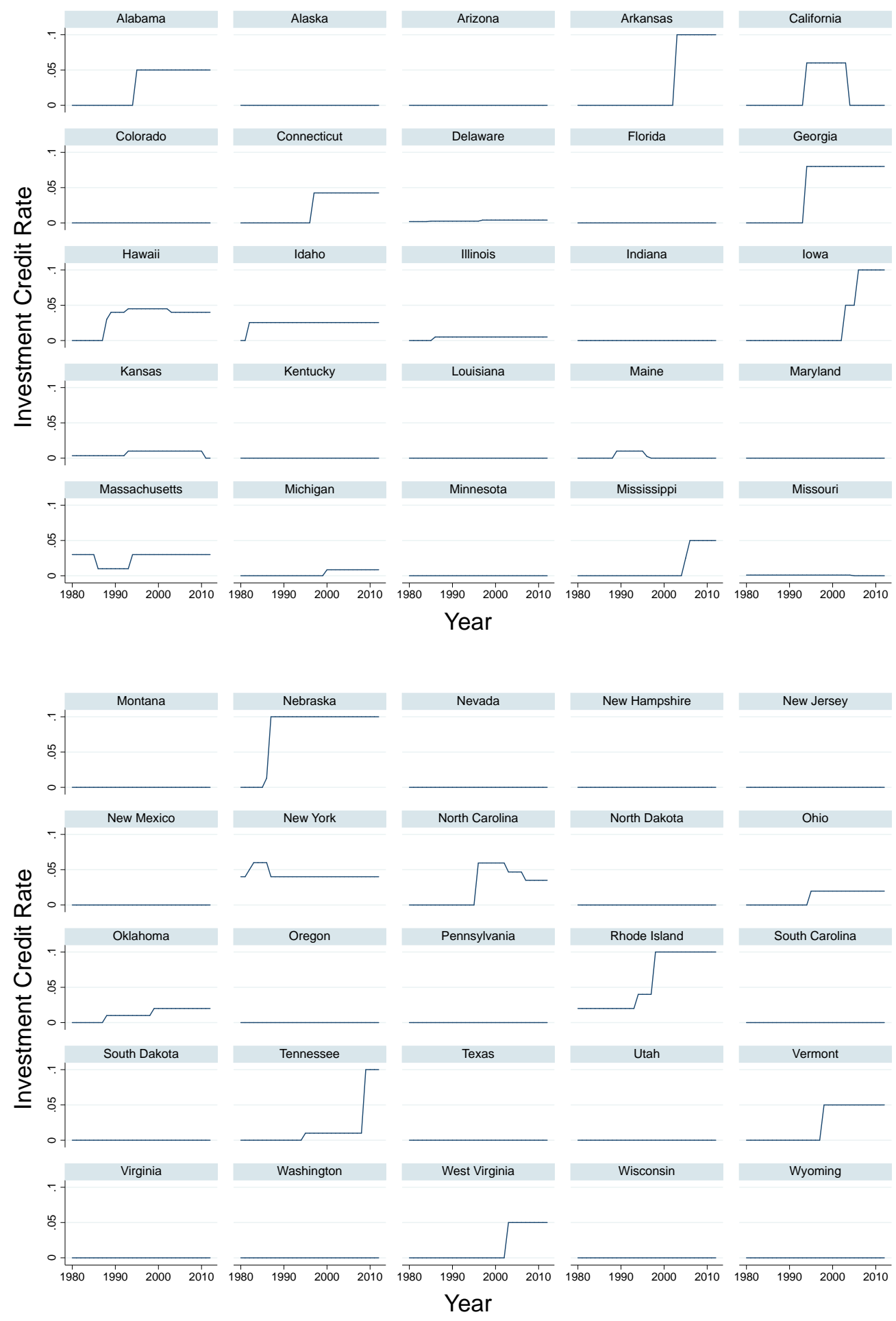

Notes: This figure plots the investment credit rate by state from 1980-2012. See Section 1 for details on data sources. 
Figure A12: Throwback Rule By State-Year
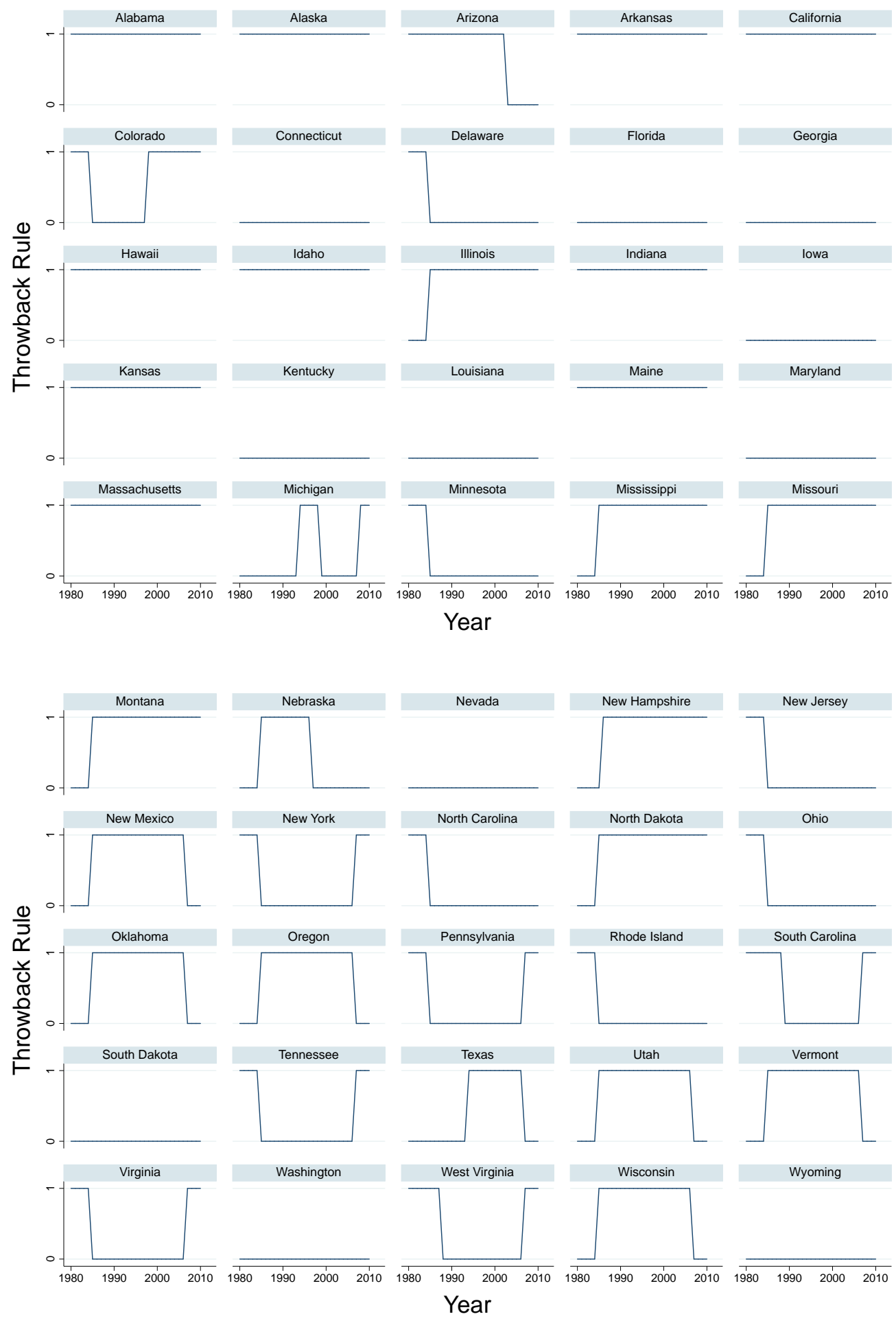

Notes: This figure plots an indicator for having a throwback rule by state from 1980-2010. See Section 1 for details on data sources. 
Figure A13: Combined Reporting Rule By State-Year
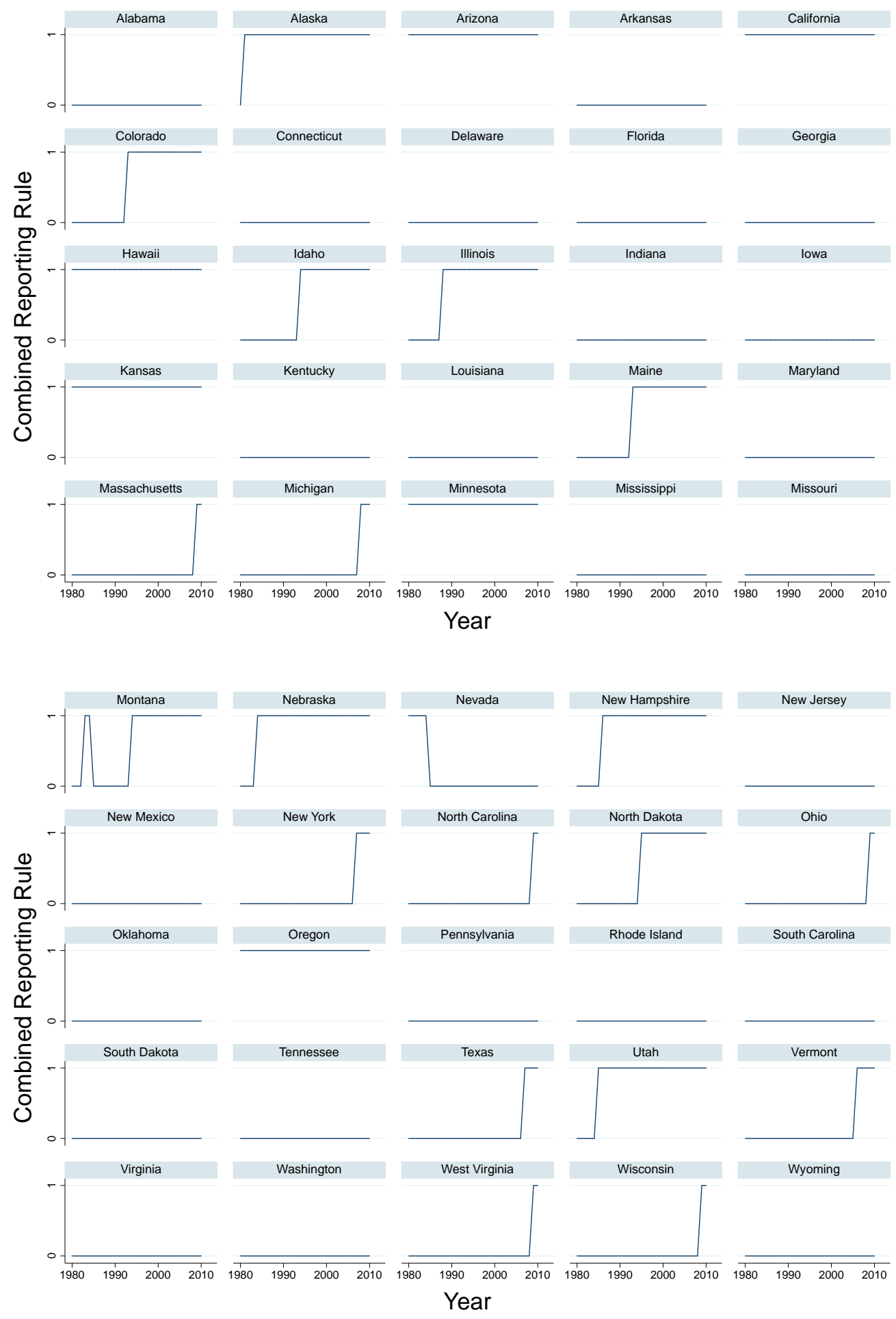

Notes: This figure plots an indicator for having a combined reporting rules by state from 1980-2010. See Section 1 for details on data sources. 
Figure A14: Federal Income Tax Deductible By State-Year
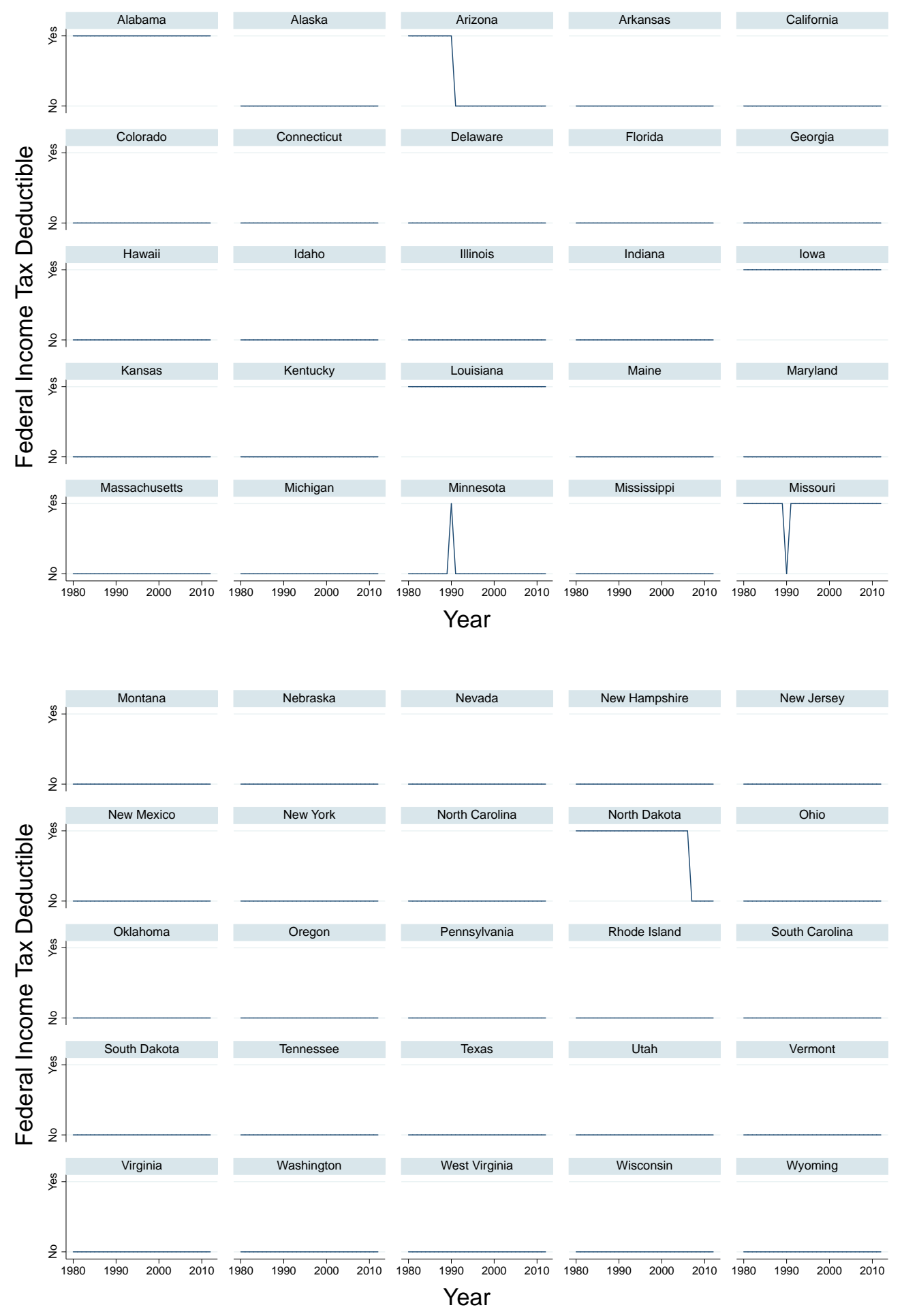

Notes: This figure plots an indicator for federal income tax deductibility by state from 1980-2012. See Section 1 for details on data sources. 
Figure A15: Federal Income as State Tax Base By State-Year
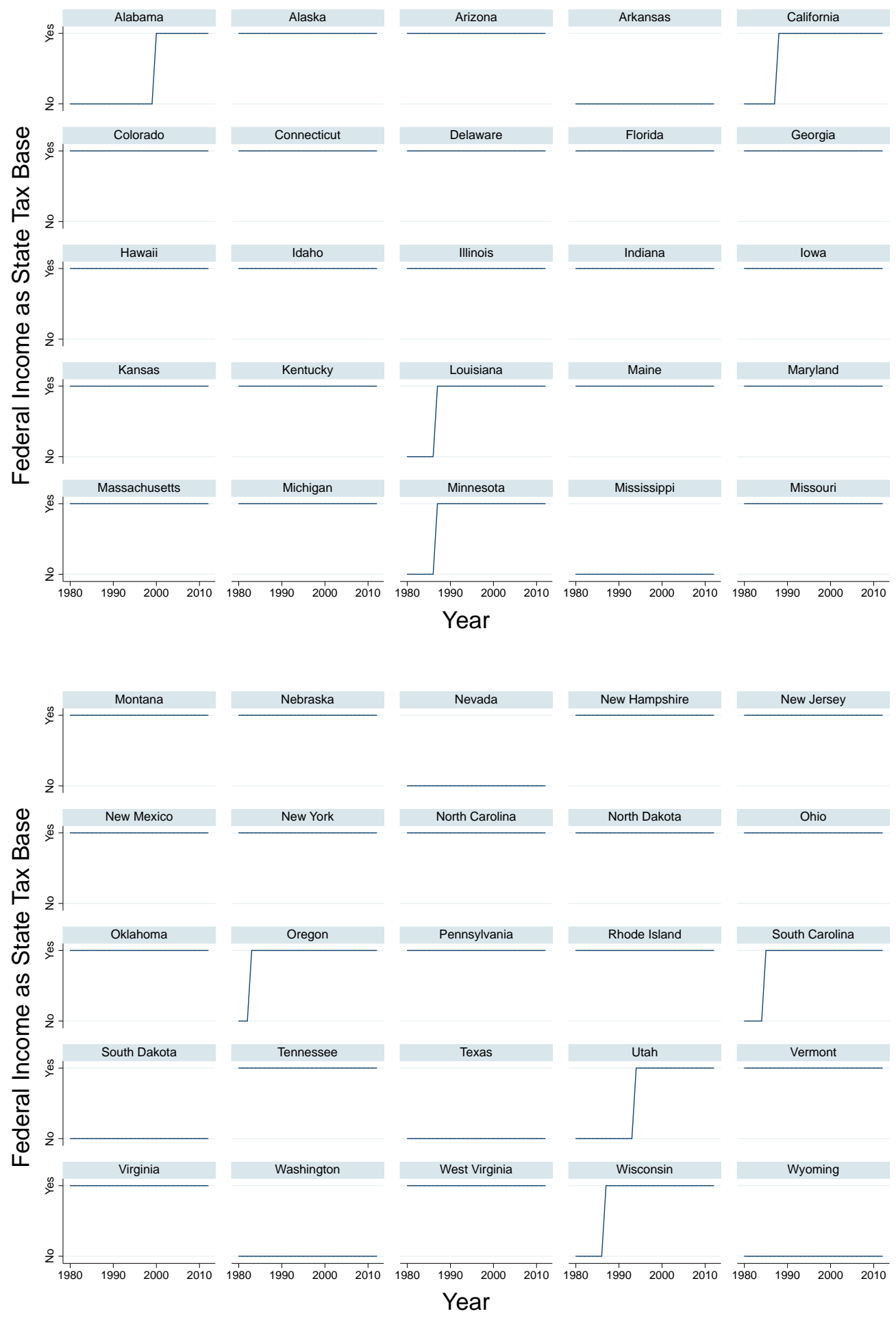

Notes: This figure plots an indicator for federal income as state tax base by state from 1980-2012. See Section 1 for details on data sources. 
Figure A16: ACRS Depreciation Rule By State-Year
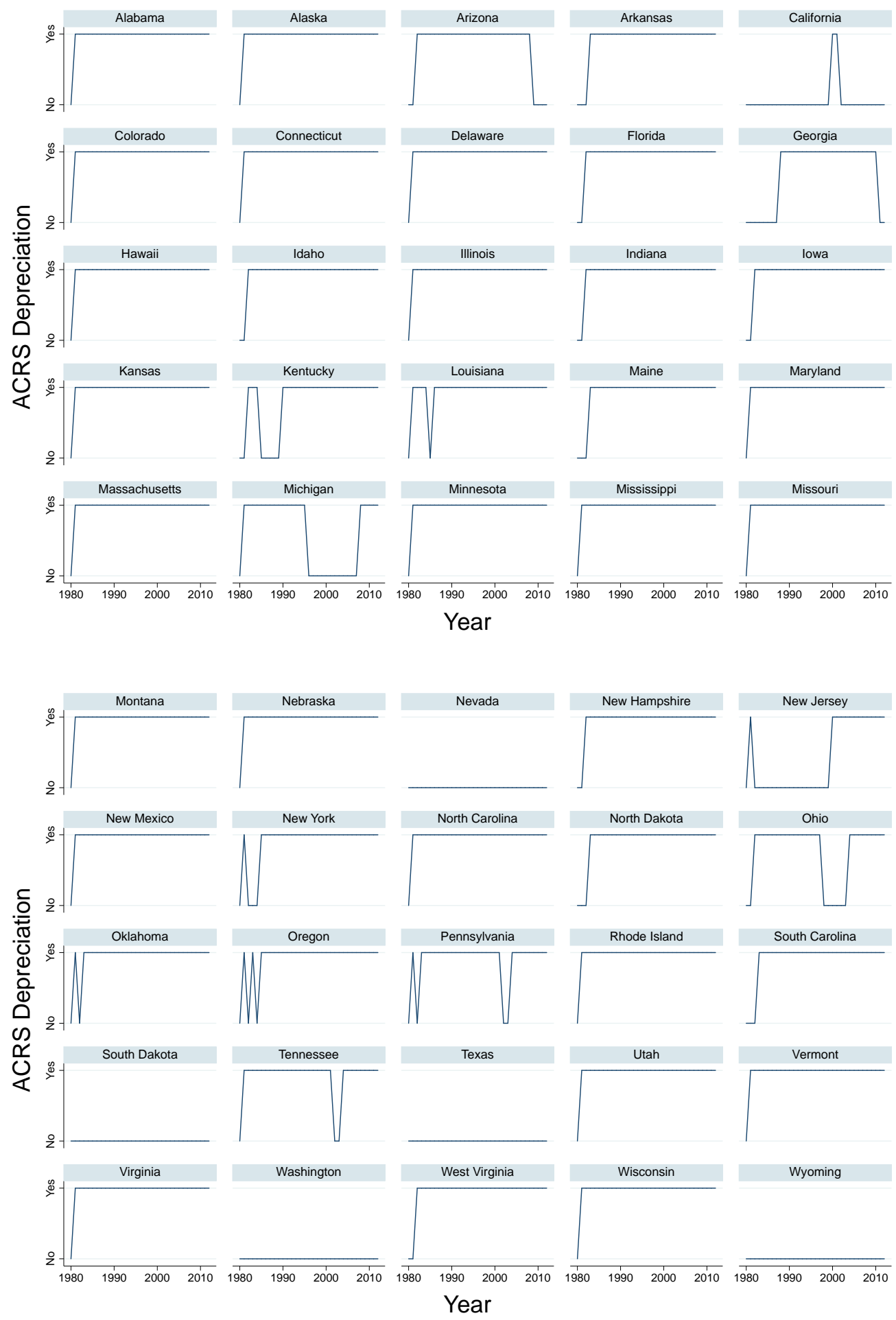

Notes: This figure plots an indicator for ACRS depreciation by state from 1980-2012. See Section 1 for details on data sources. 
Figure A17: Federal Accelerated Depreciation Rule By State-Year
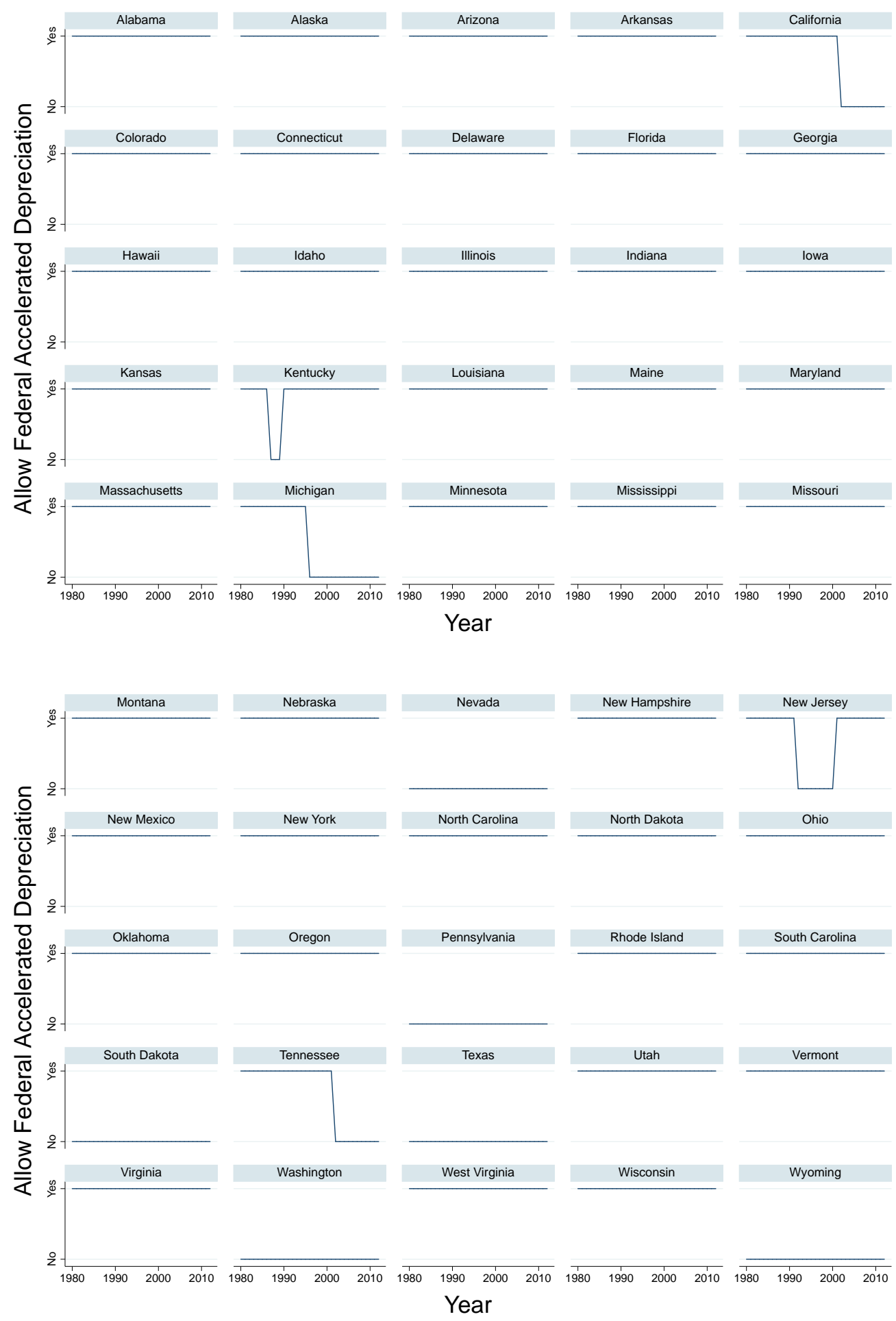

Notes: This figure plots an indicator for federal accelerated depreciation by state from 1980-2012. See Section 1 for details on data sources. 
Figure A18: Federal Bonus Depreciation Rule By State-Year
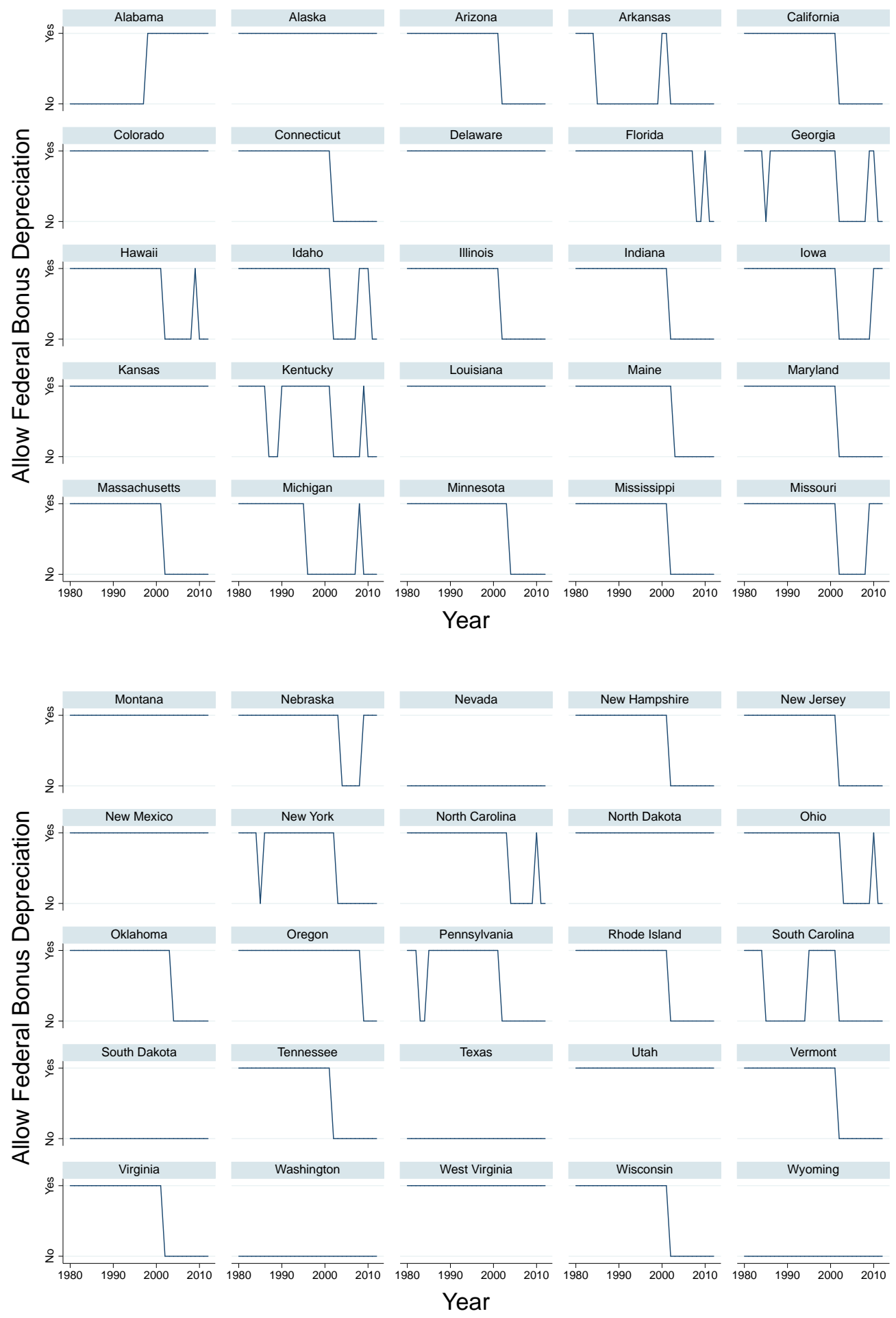

Notes: This figure plots an indicator for federal bonus depreciation by state from 1980-2012. See Section 1 for details on data sources. 
Figure A19: Sales Apportionment Weight By State-Year
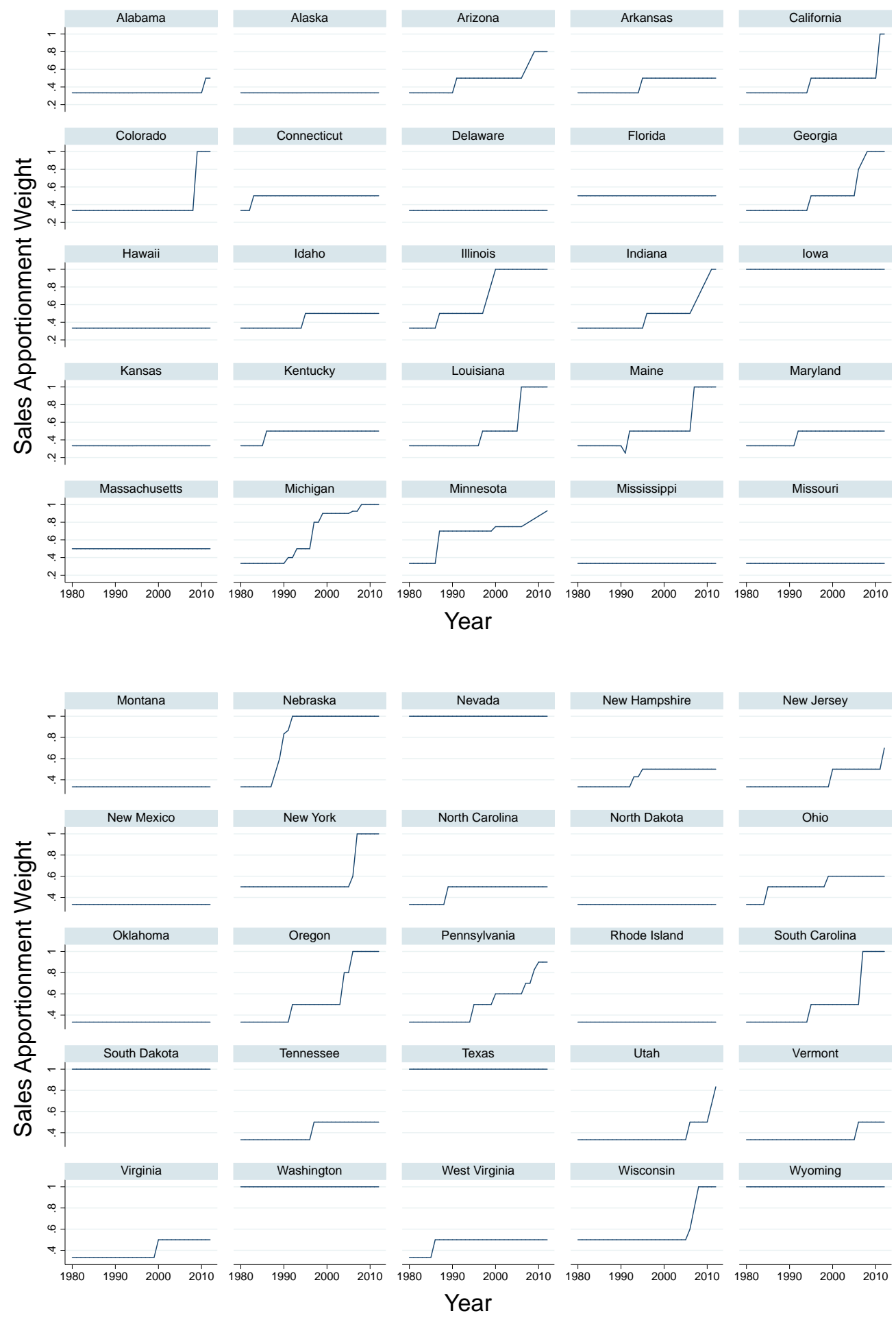

Notes: This figure plots sales apportionment weights by state from 1980-2012. See Section 1 for details on data sources. 
Figure A20: Franchise Tax By State-Year
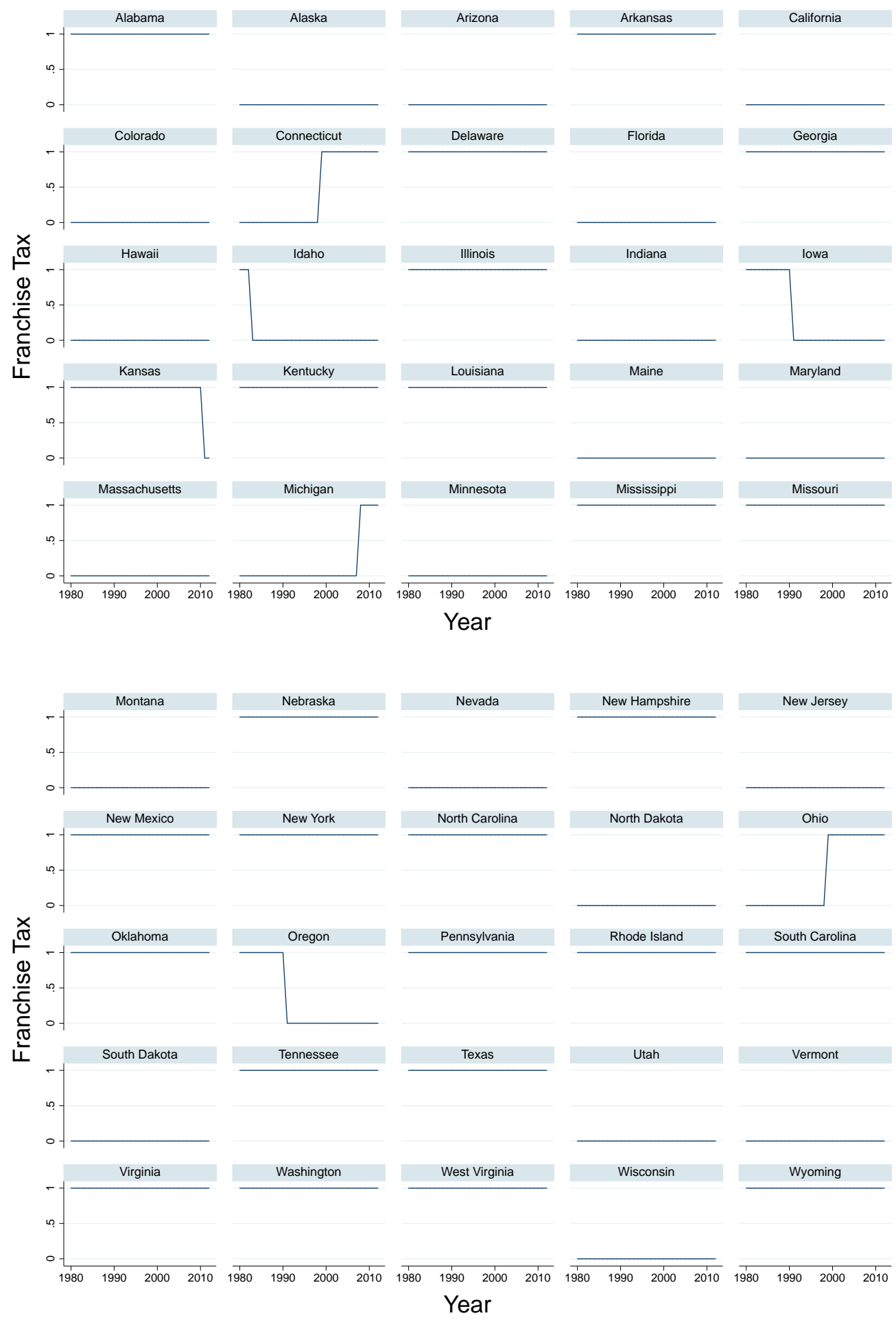

Notes: This figure plots an indicator for franchise taxes by state from 1980-2012. See Section 1 for details on data sources. 
Figure A21: Moving Average Base for Incremental R\&D By State-Year
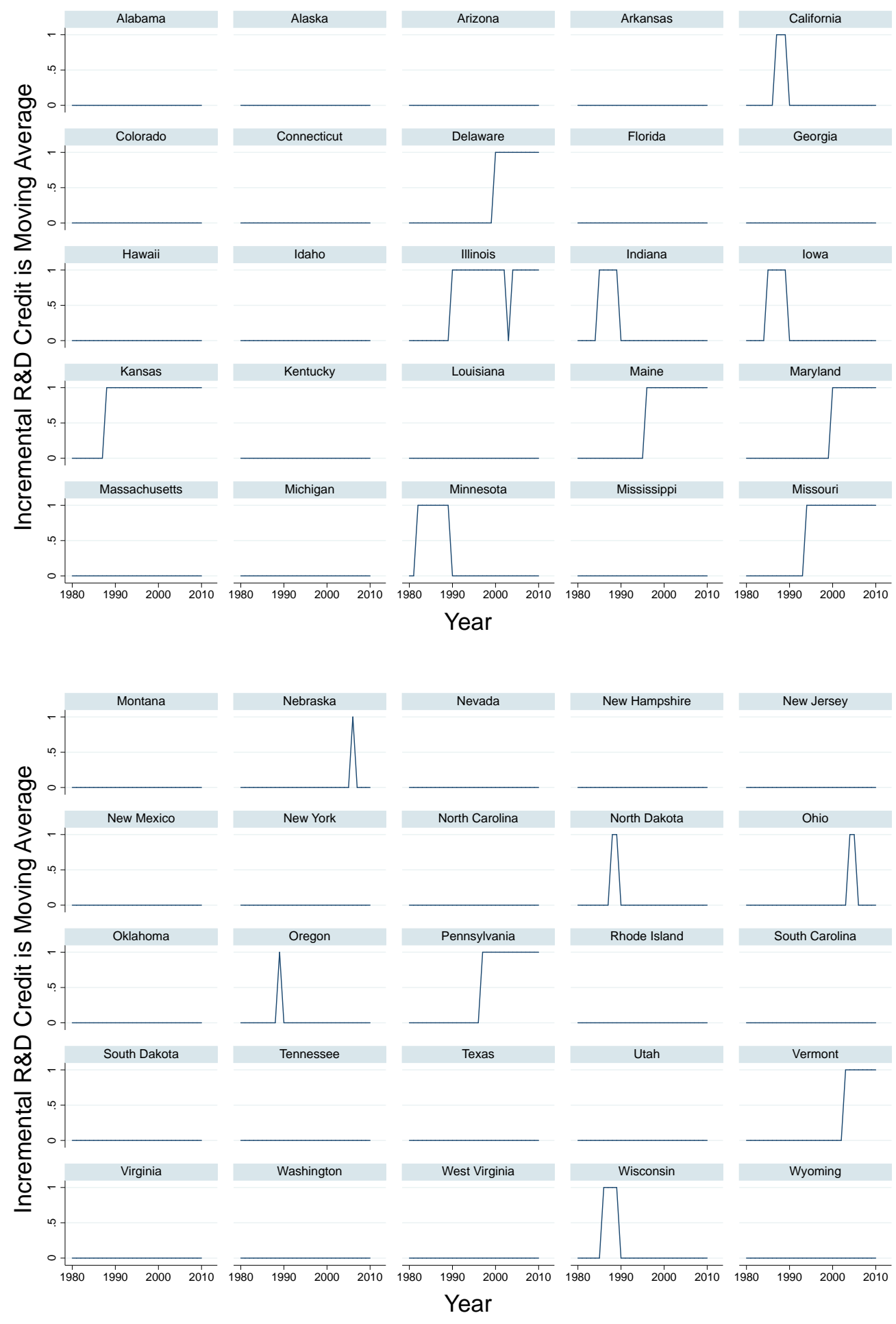

Notes: This figure plots an indicator for whether the incremental R\&D credit base is a moving average. Sample includes all 50 states from 1980-2010. See Section 1 for details on data sources. 
Figure A22: Fixed Base for Incremental R\&D By State-Year
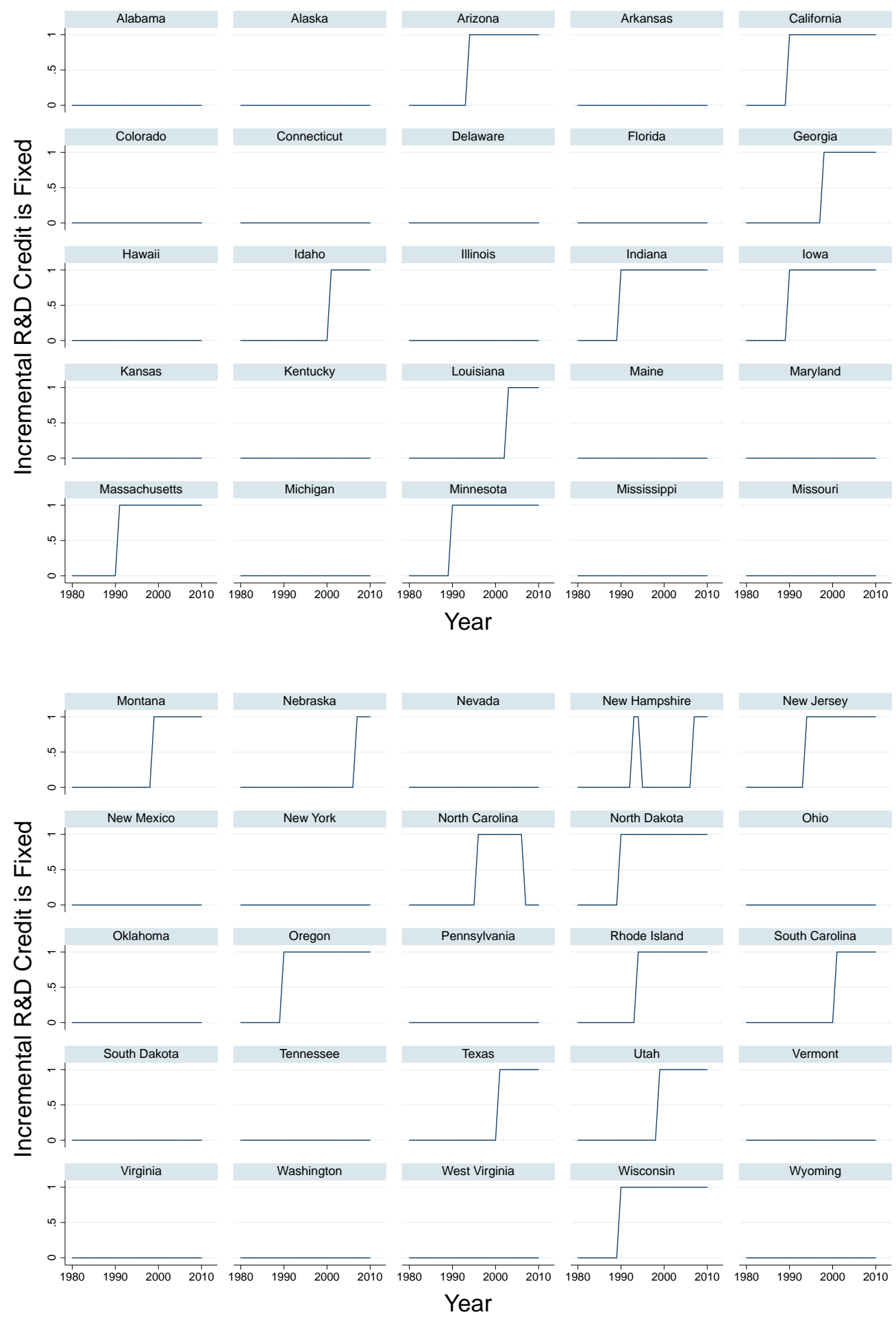

Notes: This figure plots an indicator for whether the incremental R\&D credit base is fixed. Sample includes all 50 states from 1980-2010. See Section 1 for details on data sources. 
Figure A23: Event Analysis: Impact of Corporate Rate Changes of All Magnitudes on State Corporate Tax Revenue and GDP
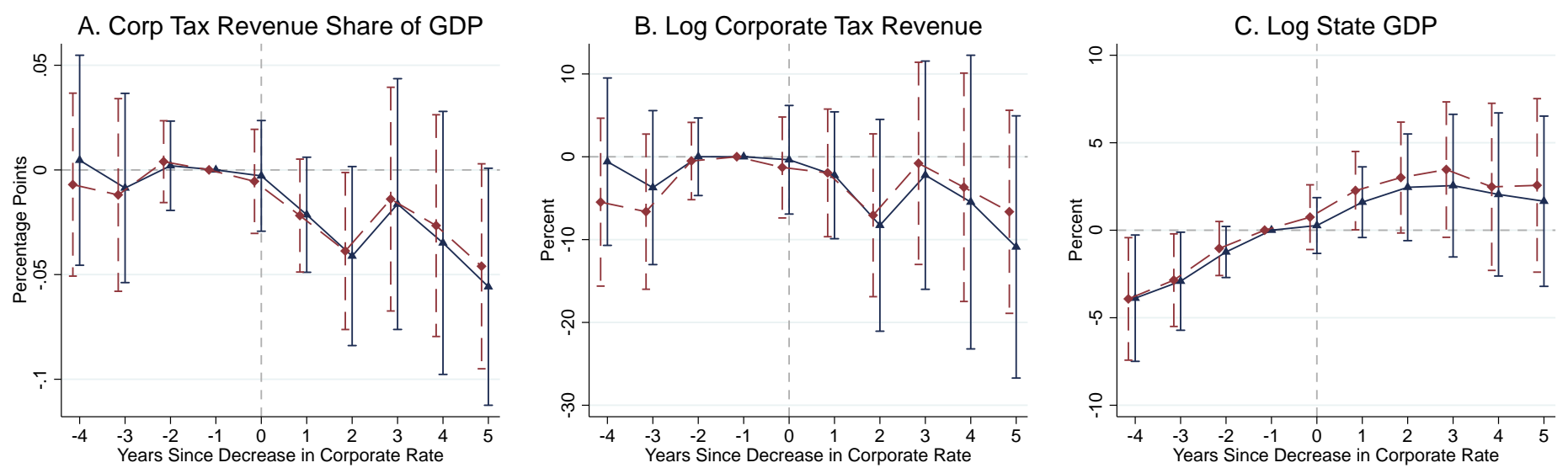

D. Corp Tax Revenue Share of GDP
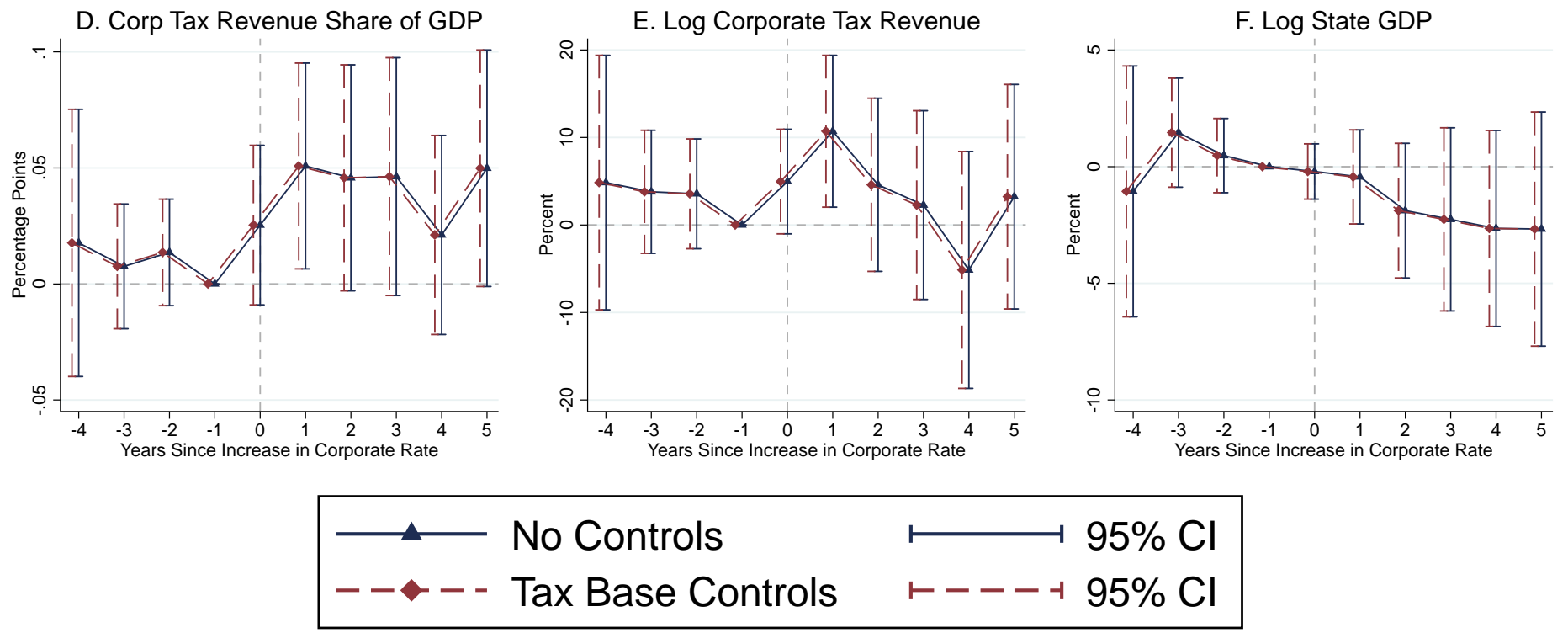

Notes: This figure shows the effect of increases and decreases in the state corporate rate of any magnitude on state corporate tax revenue as a share of state GDP, log corporate tax revenue and log state GDP, respectively. The full navy line indicates a specification without additional controls. The dashed red line plots the coefficients from a specification that additionally controls for the following tax base rules: federal income tax treated as state base, sales apportionment weight, throwback rules, federal income tax deductibility, loss carryforward, and franchise tax. Standard errors are clustered by state. The construction of these event studies follows the form of equation 4 . See Section 1 for details on data sources. 
Figure A24: Histogram of State Corporate Rate Changes

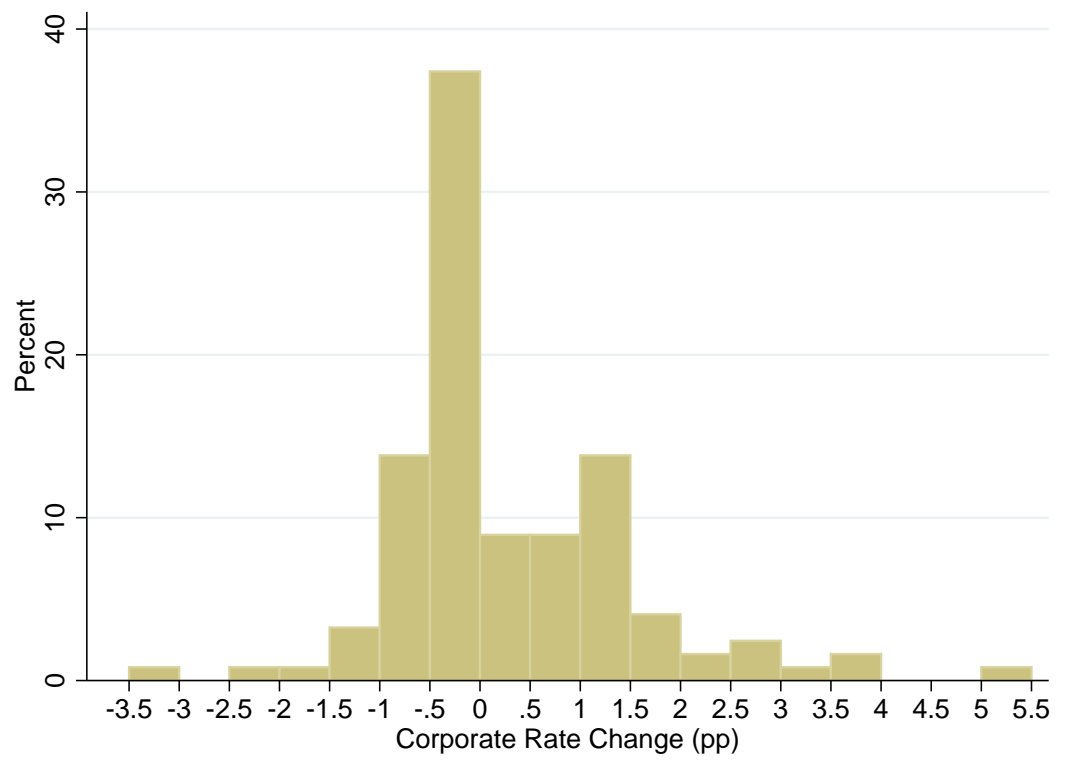

NotEs: This figure plots the magnitude of changes in the corporate tax rate across states between 1980 and 2010. Changes smaller than $0.5 \mathrm{pp}$ in absolute value make up $50.407 \%$ of all changes in the sample. See Section 1 for details on data sources. 
Figure A25: Event Analysis: Impact of Selected Corporate Rate Changes on State Corporate Tax Revenue and GDP
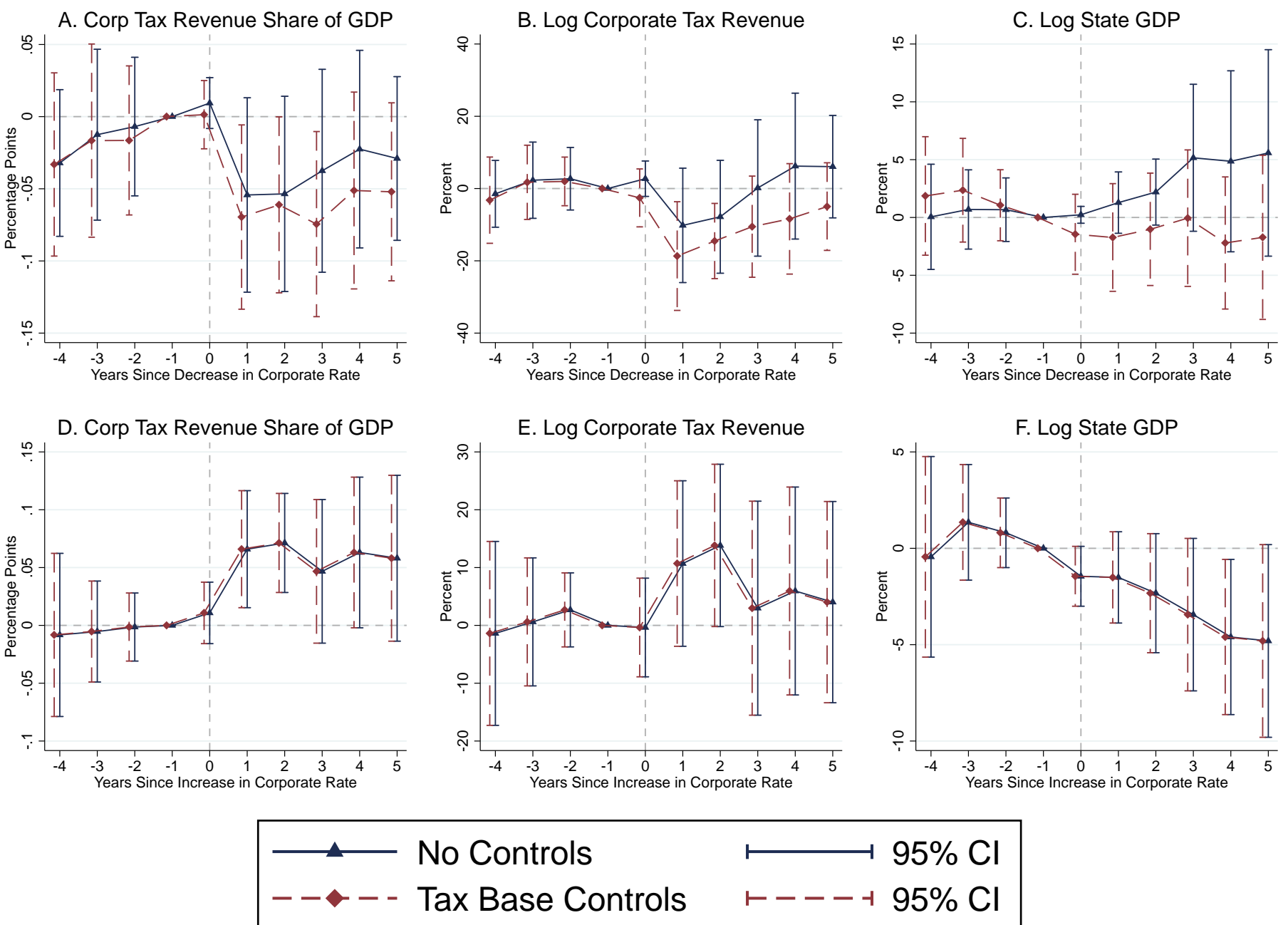

Notes: This figure shows the effect of increases and decreases in the state corporate rate of at least 0.5pp for state corporate tax changes that Giroud and Rauh (2015) classify as exogenous. Year and state fixed effects are included in each specification. The full navy line indicates a specification without additional controls. The dashed red line plots the coefficients from a specification that additionally controls for the following tax base rules: federal income tax treated as state base, sales apportionment weight, throwback rules, federal income tax deductibility, loss carryforward, and franchise tax. Standard errors are clustered by state. The construction of these event studies follows the form of equation 4 . See Section 1 for details on data sources. 
Figure A26: Event Analysis: Impact on State Corporate Tax Revenue and GDP, All Tax Base Controls
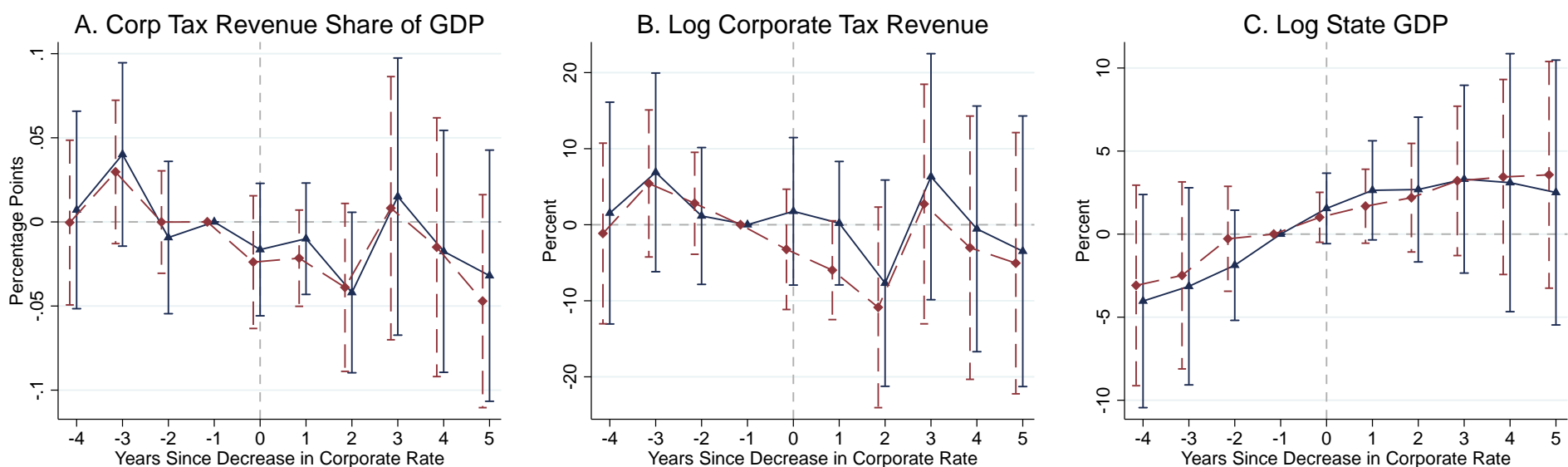

D. Corp Tax Revenue Share of GDP
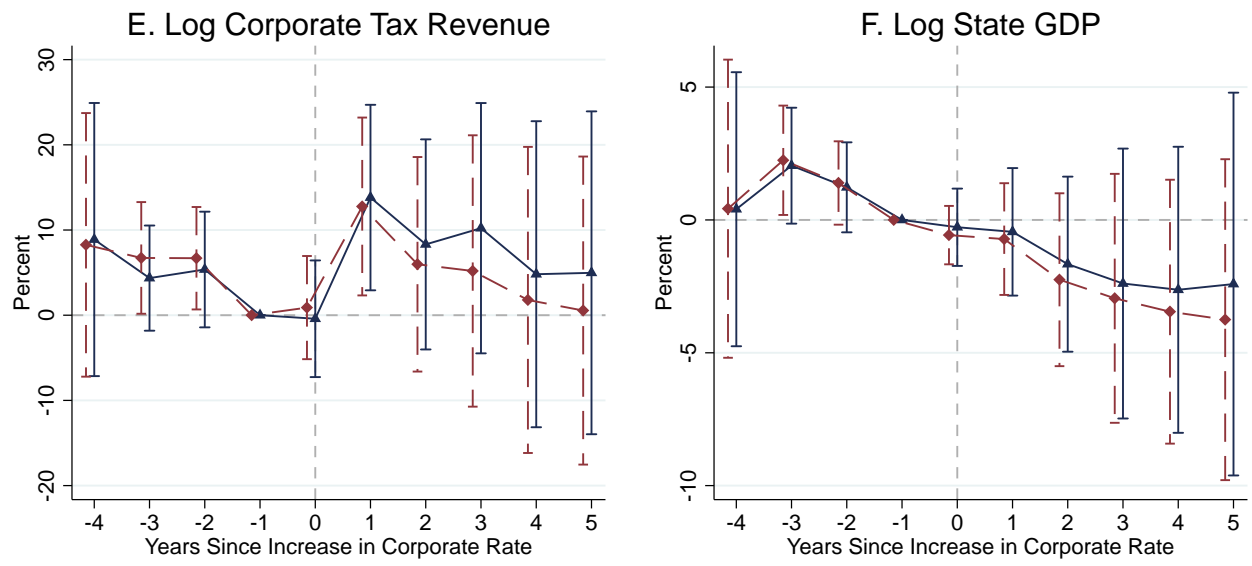

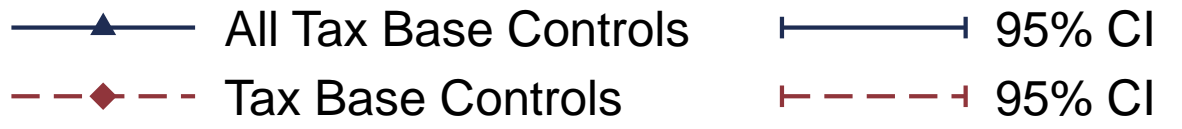

NOTES: This figure shows the effect of increases and decreases in the state corporate rate of at least 0.5pp on state corporate tax revenue as a share of state GDP, log corporate tax revenue and log state GDP, respectively. Year and state fixed effects are included in each specification. The dashed red line plots the coefficients from a specification that additionally controls for the following tax base rules: federal income tax treated as state base, sales apportionment weight, throwback rules, federal income tax deductibility, loss carryforward, and franchise tax. The full navy line includes all tax base controls. Standard errors are clustered by state. The construction of these event studies follows the form of equation 4 . See Section 1 for details on data sources. 
Figure A27: Event Analysis: Impacts on State Wages, Establishments, Employment, and GOS
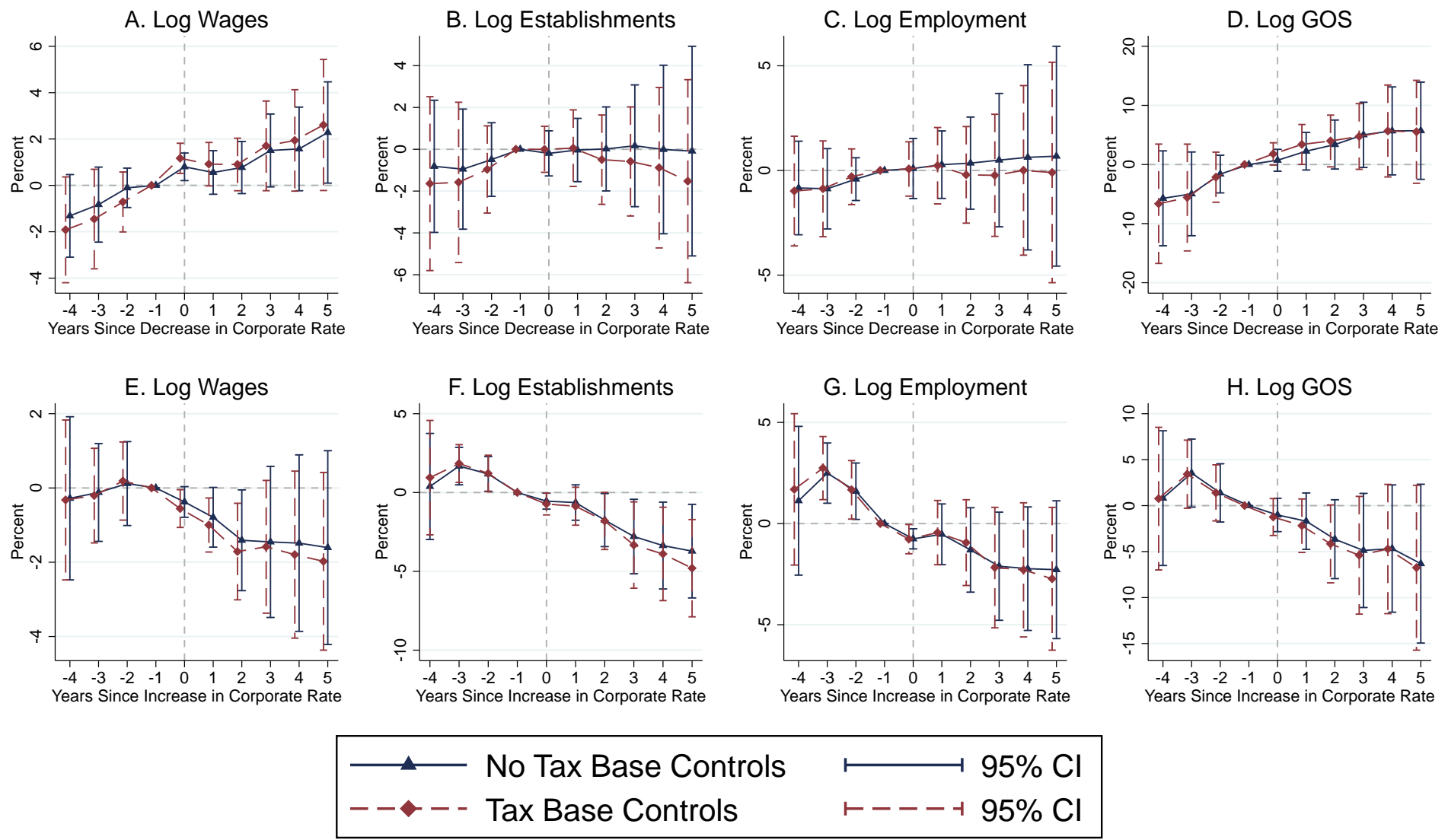

Notes: This figure shows the effect of increases and decreases in the state corporate rate of at least 0.5pp on log state average wages, establishments, employment and gross operating surplus. Year and state fixed effects are included in each specification. The full navy line indicates a specification without additional controls. The dashed red line plots The construction of these event studies follows the form of equation 4. See Section 1 for details on data sources. 
Figure A28: Event Analysis: Impact on State Corporate Tax Revenue and GDP, Neighboring State Controls
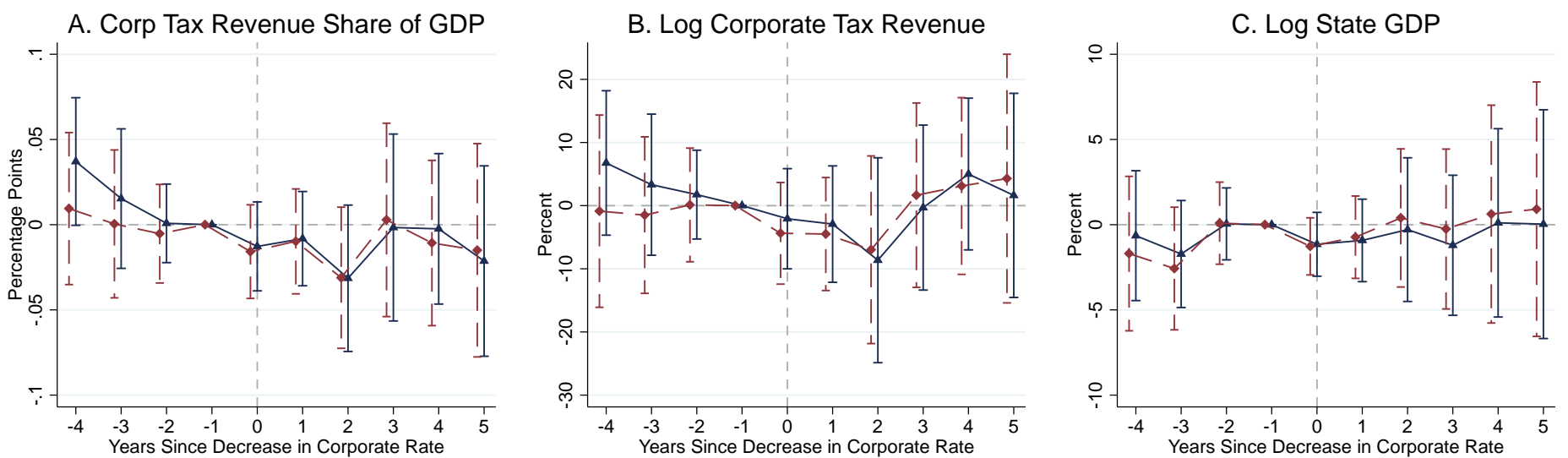

D. Corp Tax Revenue Share of GDP

E. Log Corporate Tax Revenue
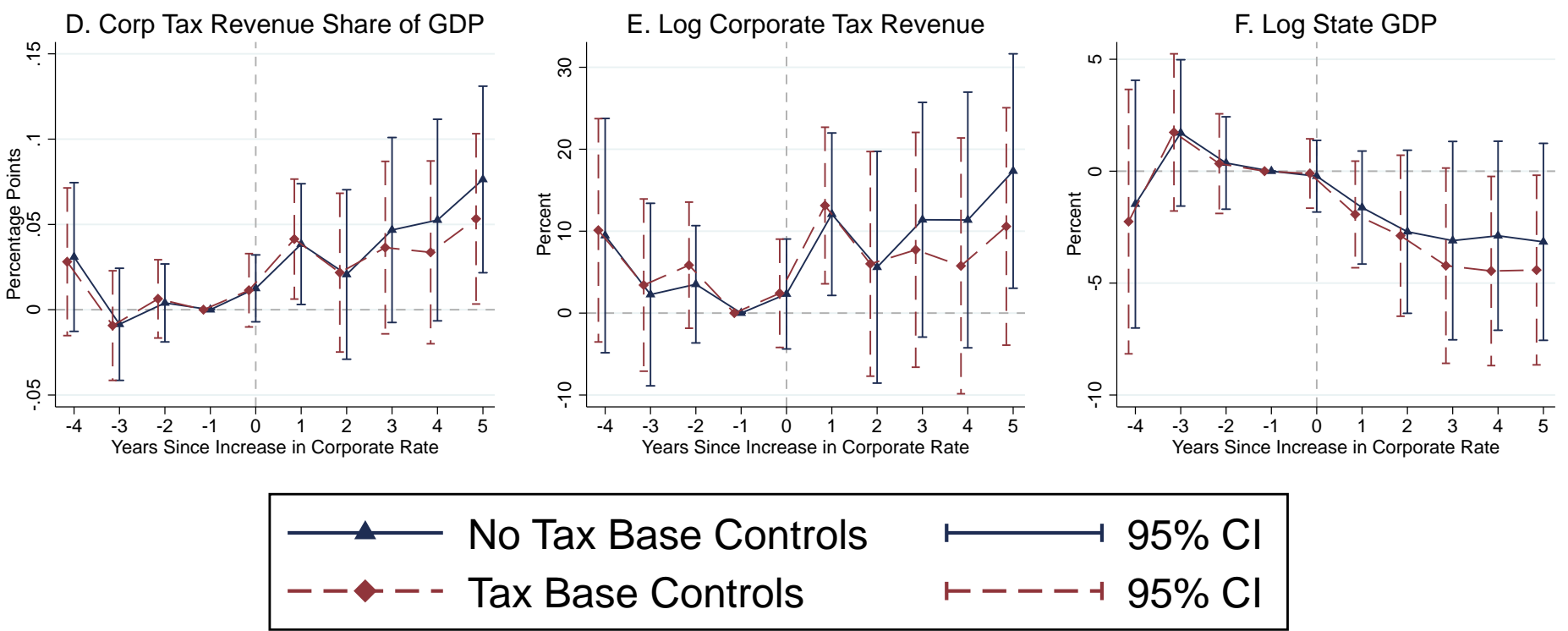

Notes: This figure shows the effect of increases and decreases in the state corporate rate of at least $0.5 p p$ on state corporate tax revenue as a share of state GDP, log corporate tax revenue and log state GDP, respectively. Leads and lags of corporate tax rate and tax base changes in neighboring states are included in each specification. Year and state fixed effects are also included. The full navy line indicates a specification without additional controls. The dashed red line plots the coefficients from a specification that additionally controls for the following tax base rules: federal income tax treated as state base, sales apportionment weight, throwback rules, federal income tax deductibility, loss carryforward, and franchise tax. Standard errors are clustered by state. The construction of these event studies follows the form of equation 4 . Neighboring states are states that share a border, as defined in Section B.2. See Section 1 for details on data sources. 
Figure A29: Event Analysis: Impact on State Corporate Tax Revenue and GDP, Similar State Controls
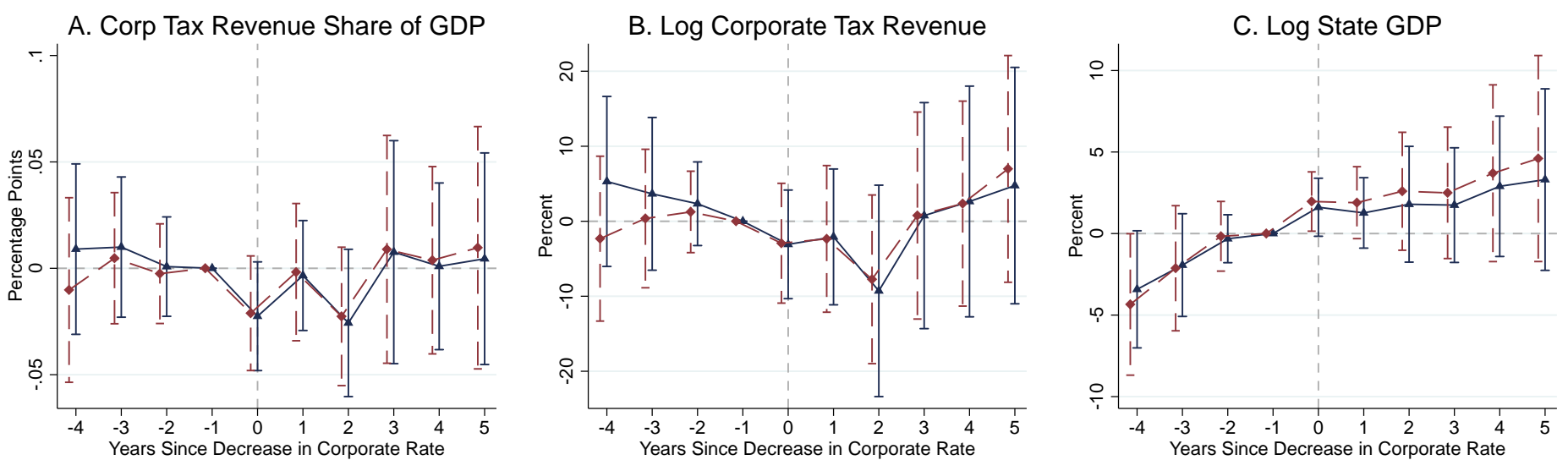

D. Corp Tax Revenue Share of GDP
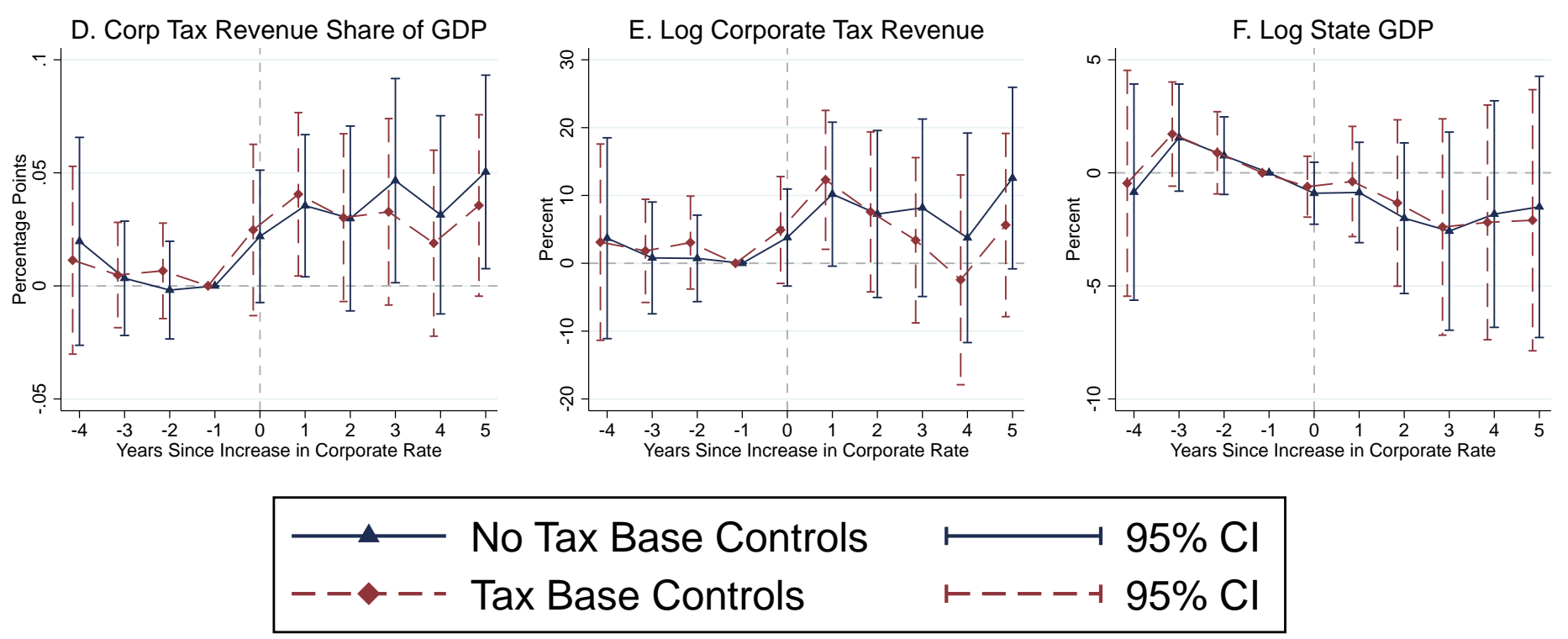

NotES: This figure shows the effect of increases and decreases in the state corporate rate of at least $0.5 p p$ on state corporate tax revenue as a share of state GDP, log corporate tax revenue and log state GDP, respectively. Leads and lags of corporate tax rate and tax base changes in similar states are included in each specification. Year and state fixed effects are also included. The full navy line indicates a specification without additional controls. The dashed red line plots the coefficients from a specification that additionally controls for the following tax base rules: federal income tax treated as state base, sales apportionment weight, throwback rules, federal income tax deductibility, loss carryforward, and franchise tax. Standard errors are clustered by state. The construction of these event studies follows the form of equation 4 . We construct an artificial similar state using the most similar state the year before an event, as defined in Section B.2. See Section 1 for details on data sources. 
Figure A30: Event Analysis: Impacts of Federal Accelerated Depreciation Changes on Revenue and GDP
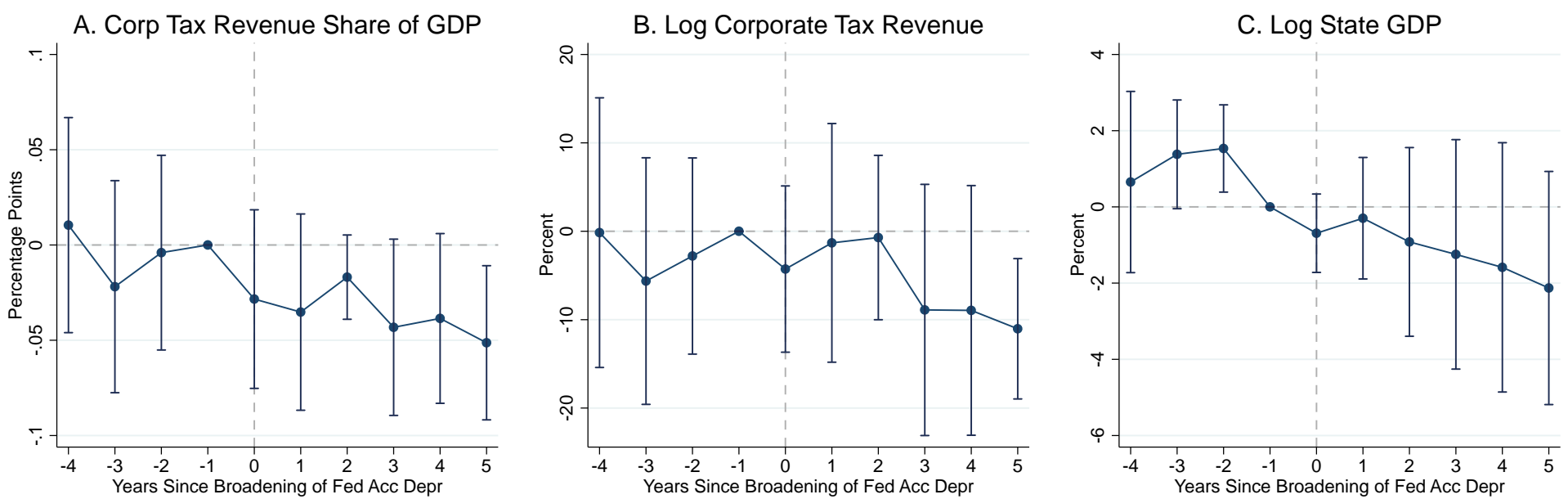

D. Corp Tax Revenue Share of GDP
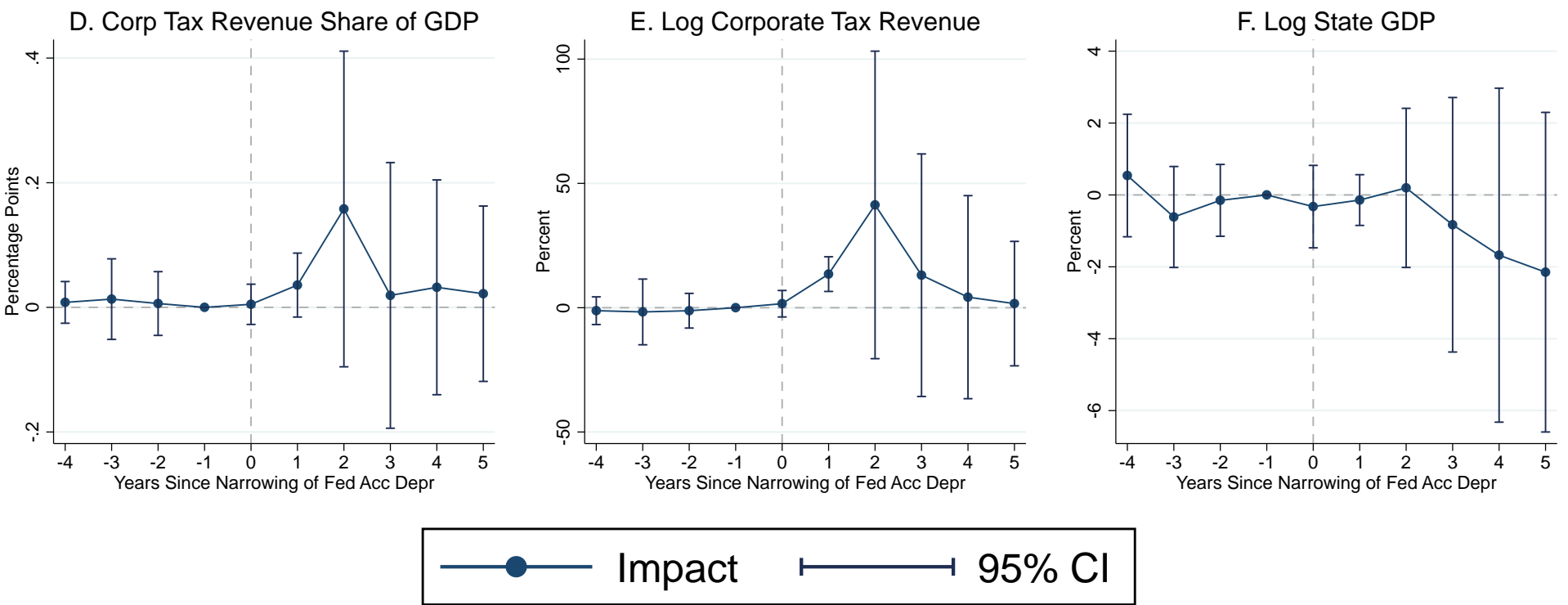

Notes: This figure shows the effect of broadening and narrowing of whether the state allows federal accelerated depreciation on state corporate tax revenue as a share of state GDP, $\log$ corporate tax revenue and log state GDP, respectively. Standard errors are clustered by state. The construction of these event studies follows the form of equation 4 . See Appendix A for detailed definitions of broadening and narrowing for each measure. See Section 1 for details on data sources. 
Figure A31: Event Analysis: Impacts of ACRS Depreciation Changes on Revenue and GDP
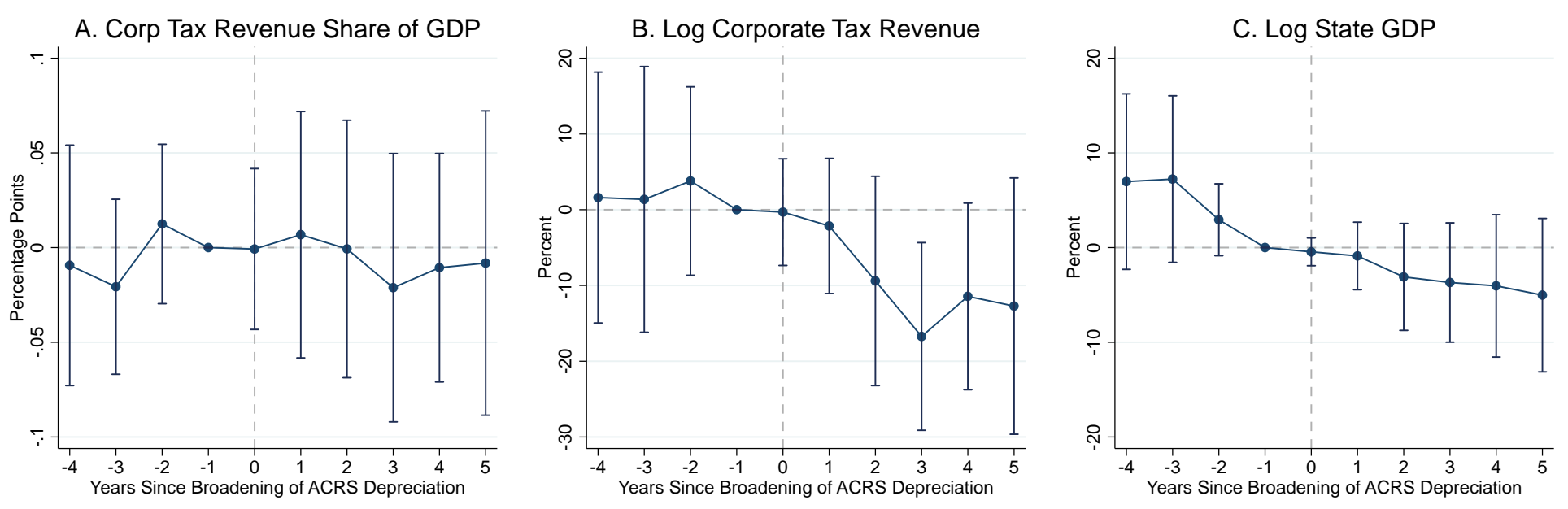

D. Corp Tax Revenue Share of GDP
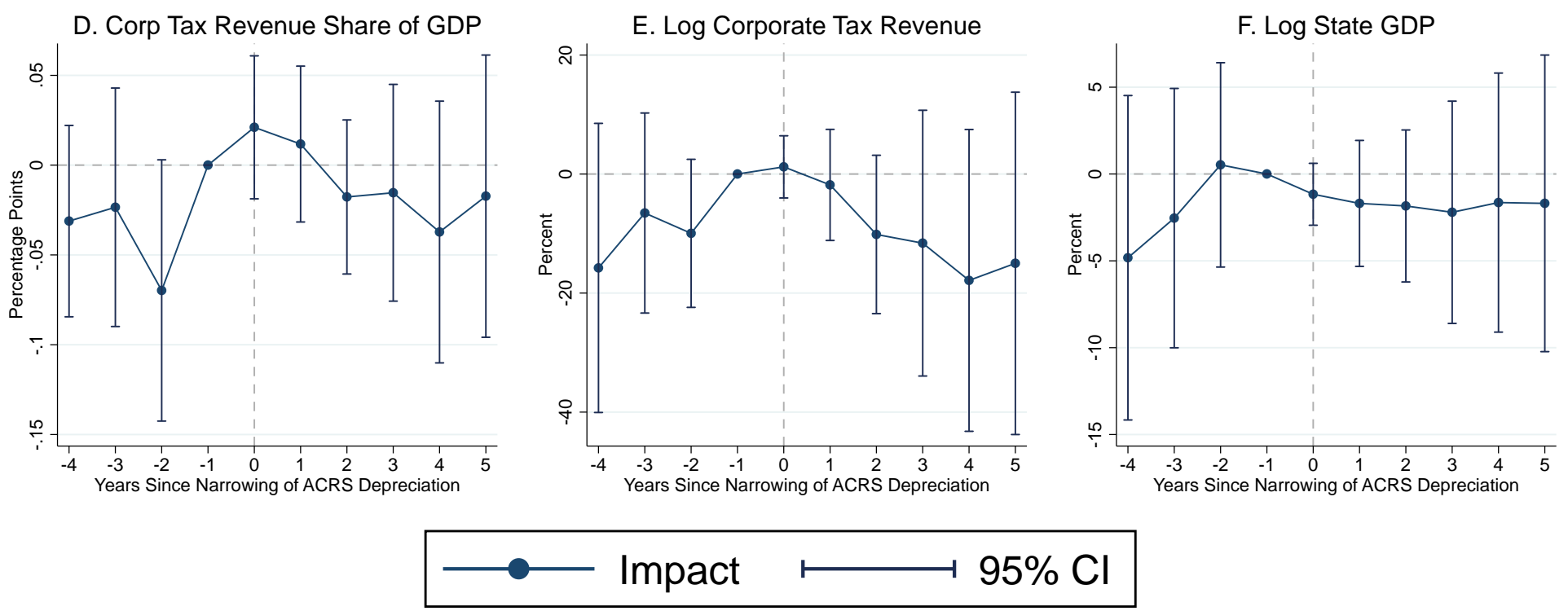

Notes: This figure shows the effect of broadening and narrowing of whether the state allows ACRS depreciation on state corporate tax revenue as a share of state GDP, log corporate tax revenue and log state GDP, respectively. Standard errors are clustered by state. The construction of these event studies follows the form of equation 4 . See Section 1 for details on data sources and Appendix A for detailed definitions of broadening and narrowing for each measure. 
Figure A32: Event Analysis: Impacts of Federal Bonus Depreciation Changes on Revenue and GDP

A. Corp Tax Revenue Share of GDP

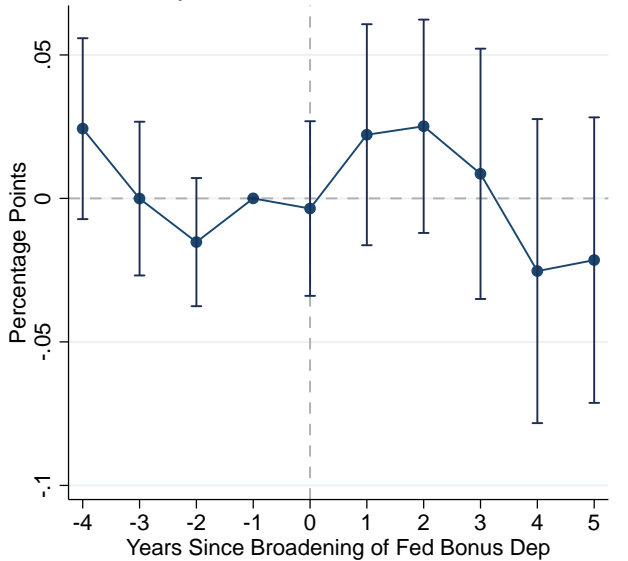

D. Corp Tax Revenue Share of GDP

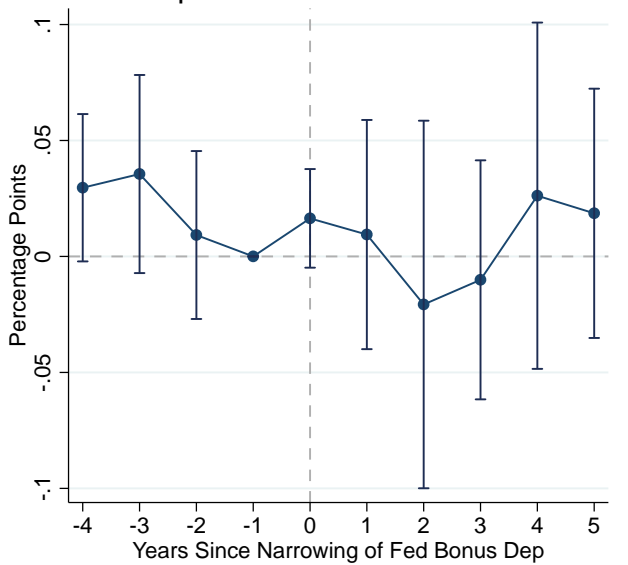

B. Log Corporate Tax Revenue

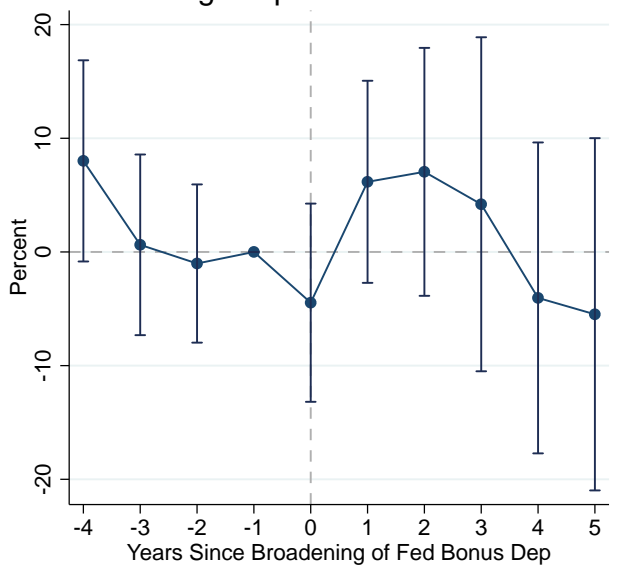

E. Log Corporate Tax Revenue

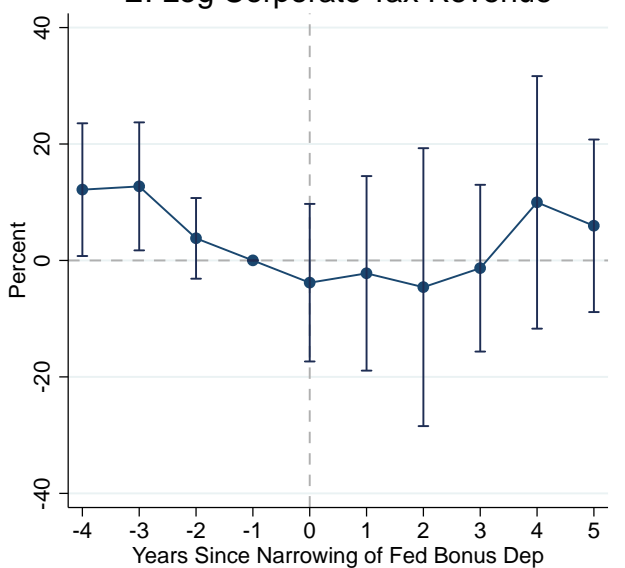

C. Log State GDP

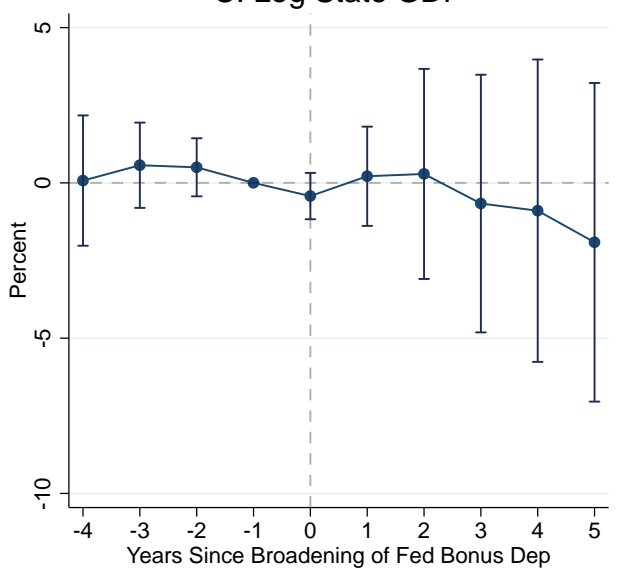

F. Log State GDP

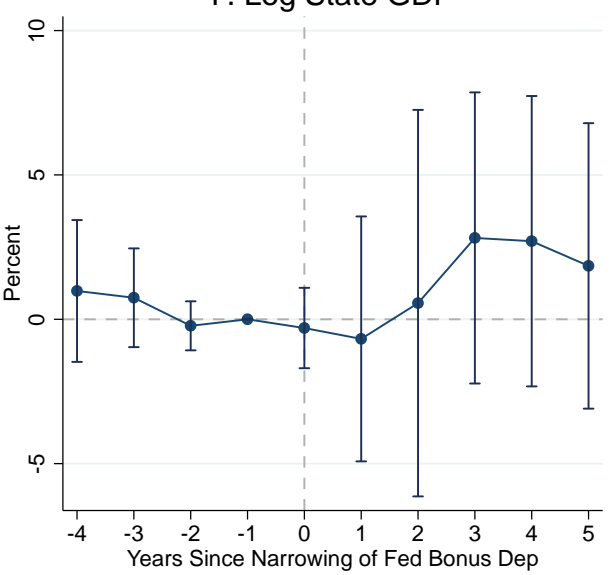

\section{$\longrightarrow$ Impact $\longmapsto 95 \% \mathrm{Cl}$}

NOTES: This figure shows the effect of broadening and narrowing of whether the state allows federal bonus depreciation on state corporate tax revenue as a share of state GDP, log corporate tax revenue and log state GDP, respectively. Standard errors are clustered by state. The construction of these event studies follows the form of equation 4 . See Section 1 for details on data sources and Appendix A for detailed definitions of broadening and narrowing for each measure. 
Figure A33: Event Analysis: Impacts of Federal Income Tax Deductibility Changes on Revenue and GDP

A. Corp Tax Revenue Share of GDP

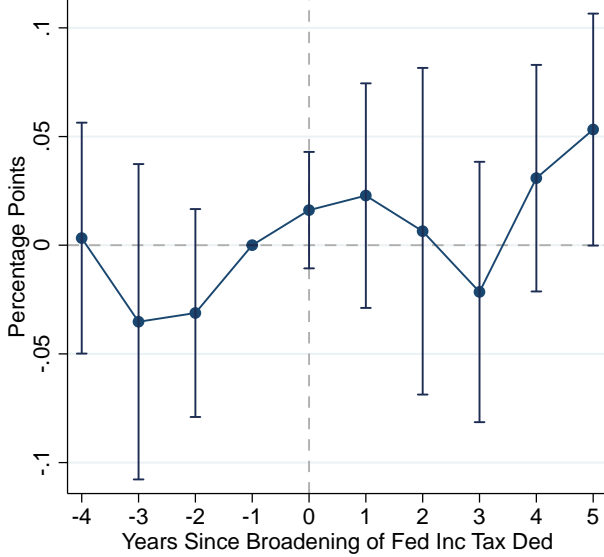

D. Corp Tax Revenue Share of GDP

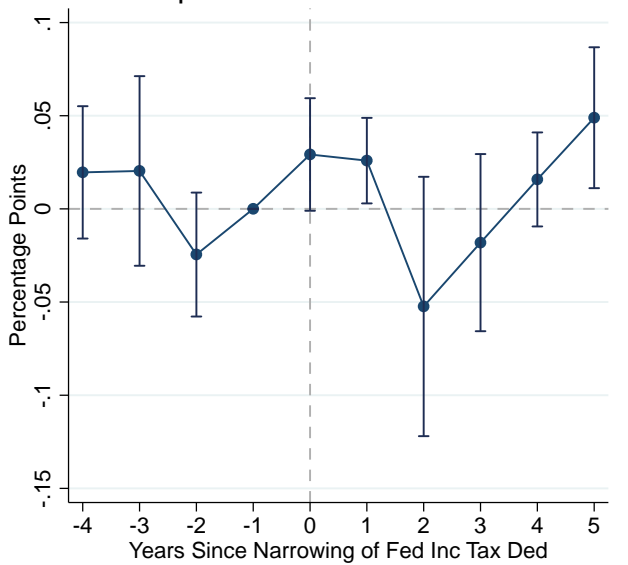

B. Log Corporate Tax Revenue

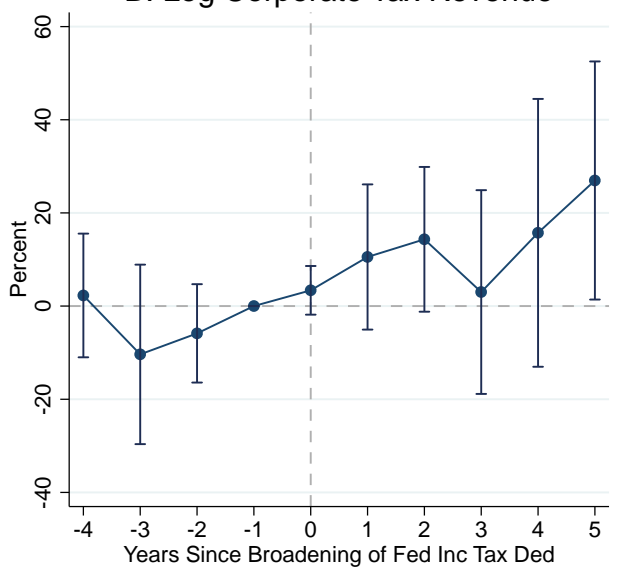

E. Log Corporate Tax Revenue

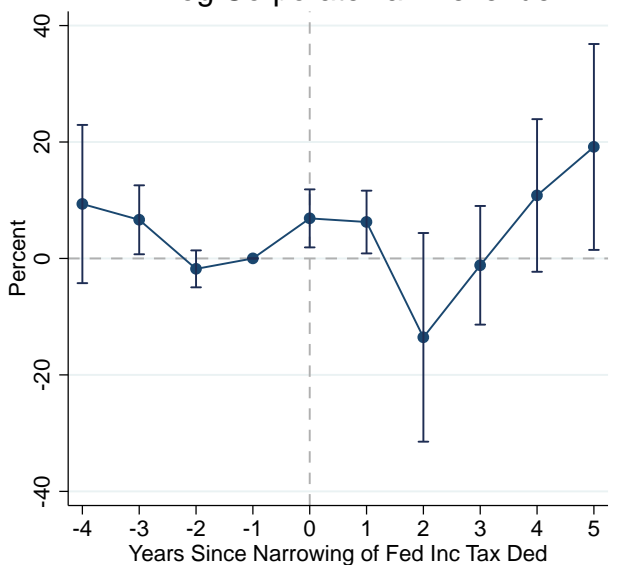

C. Log State GDP

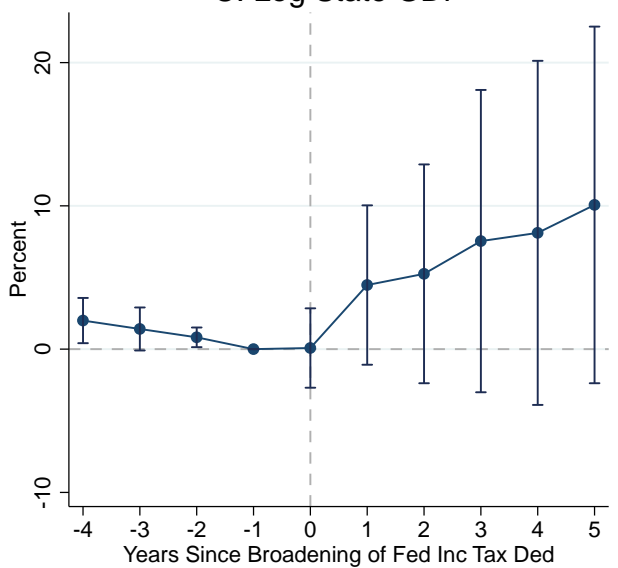

F. Log State GDP

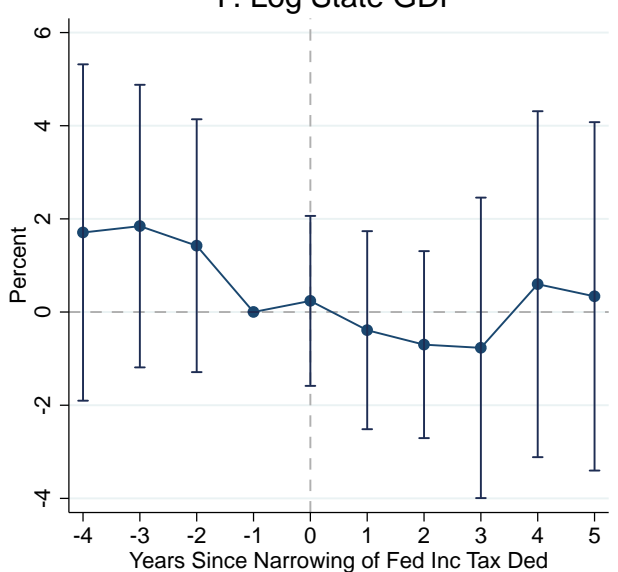

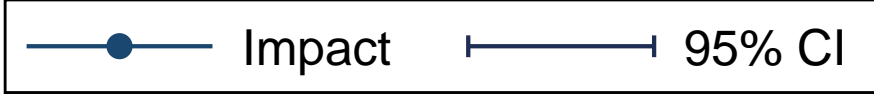

Notes: This figure shows the effect of broadening and narrowing of whether federal income tax is deductible on state corporate tax revenue as a share of state GDP, log corporate tax revenue and log state GDP, respectively. Standard errors are clustered by state. The construction of these event studies follows the form of equation 4 . See Section 1 for details on data sources and Appendix A for detailed definitions of broadening and narrowing for each measure. 
Figure A34: Event Analysis: Impacts of Investment Tax Credit Changes on Revenue and GDP

A. Corp Tax Revenue Share of GDP

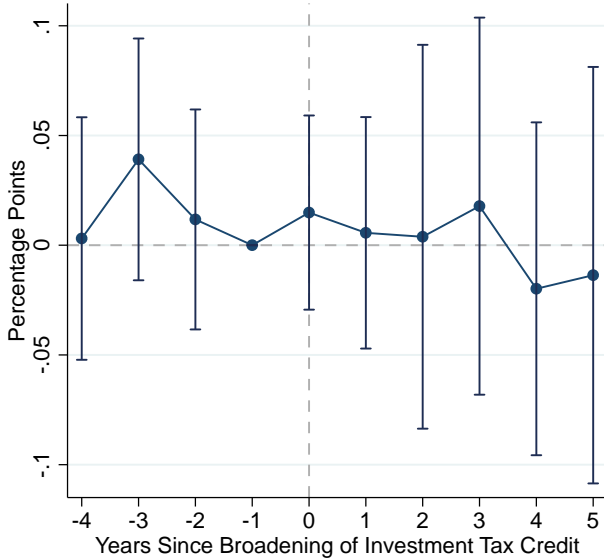

D. Corp Tax Revenue Share of GDP

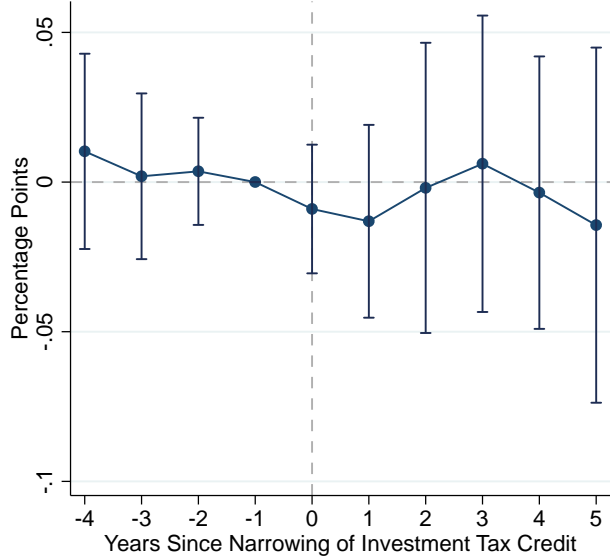

B. Log Corporate Tax Revenue

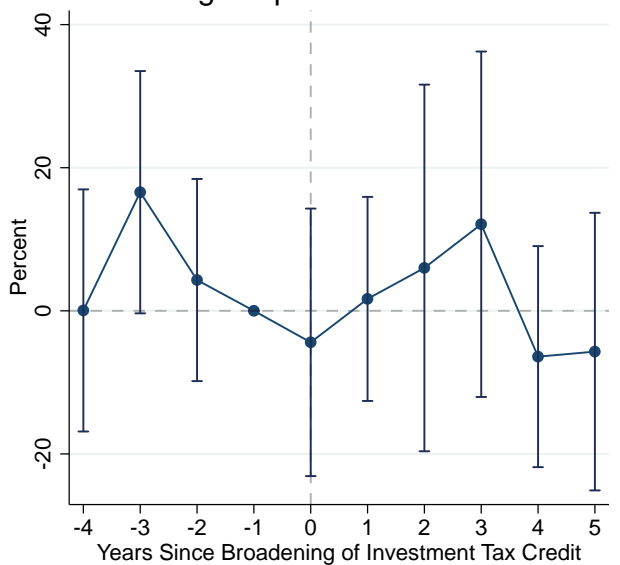

E. Log Corporate Tax Revenue

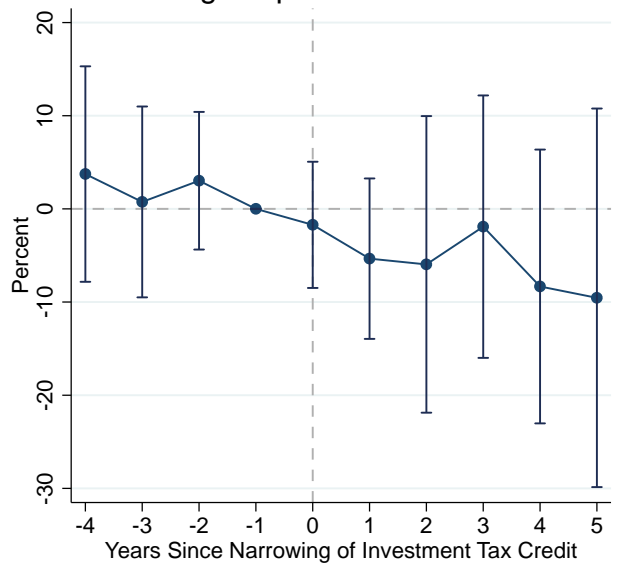

C. Log State GDP

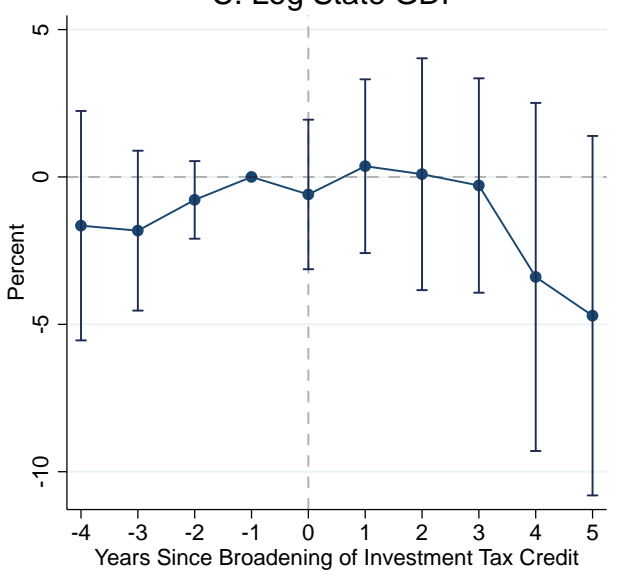

F. Log State GDP

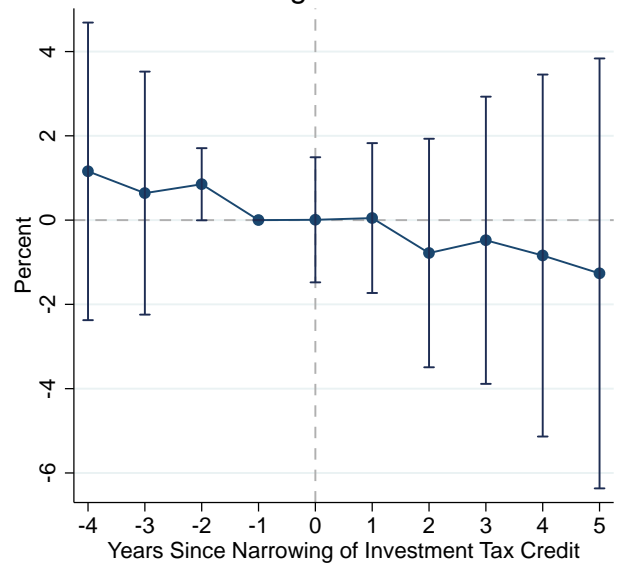

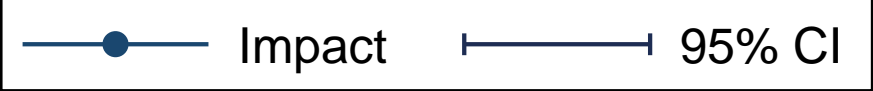

Notes: This figure shows the effect of broadening and narrowing of investment tax credits on state corporate tax revenue as a share of state GDP, log corporate tax revenue and $\log$ state GDP, respectively. Standard errors are clustered by state. The construction of these event studies follows the form of equation 4 . See Section 1 for details on data sources and Appendix A for detailed definitions of broadening and narrowing for each measure. 
Figure A35: Event Analysis: Impacts of Franchise Tax Changes on Revenue and GDP
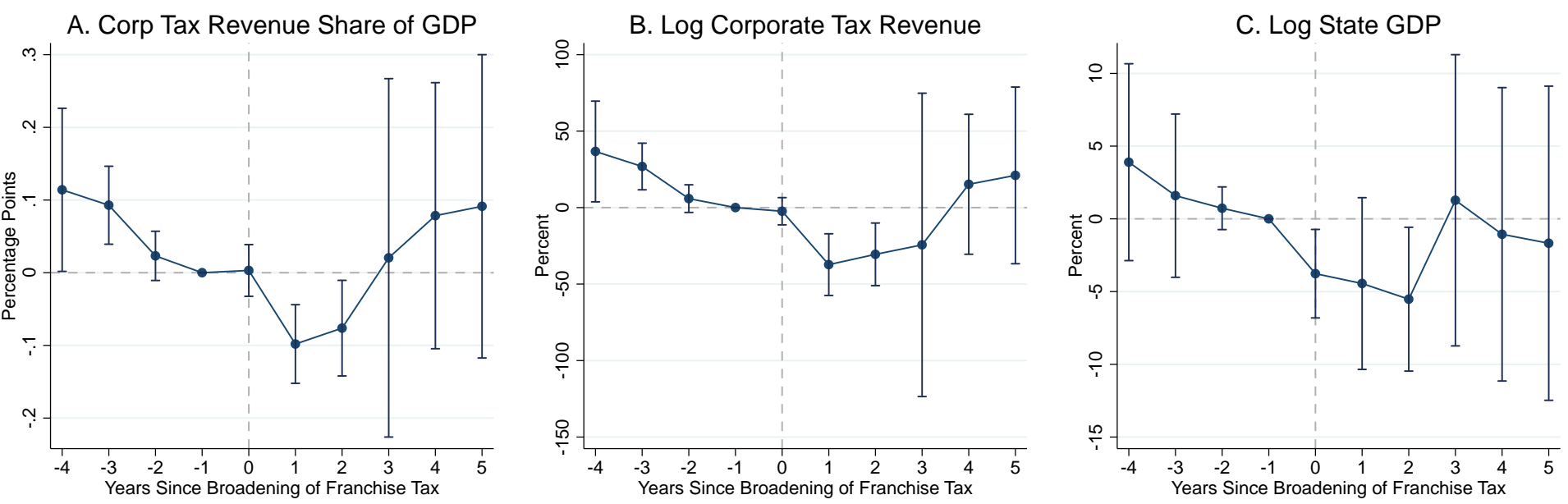

D. Corp Tax Revenue Share of GDP
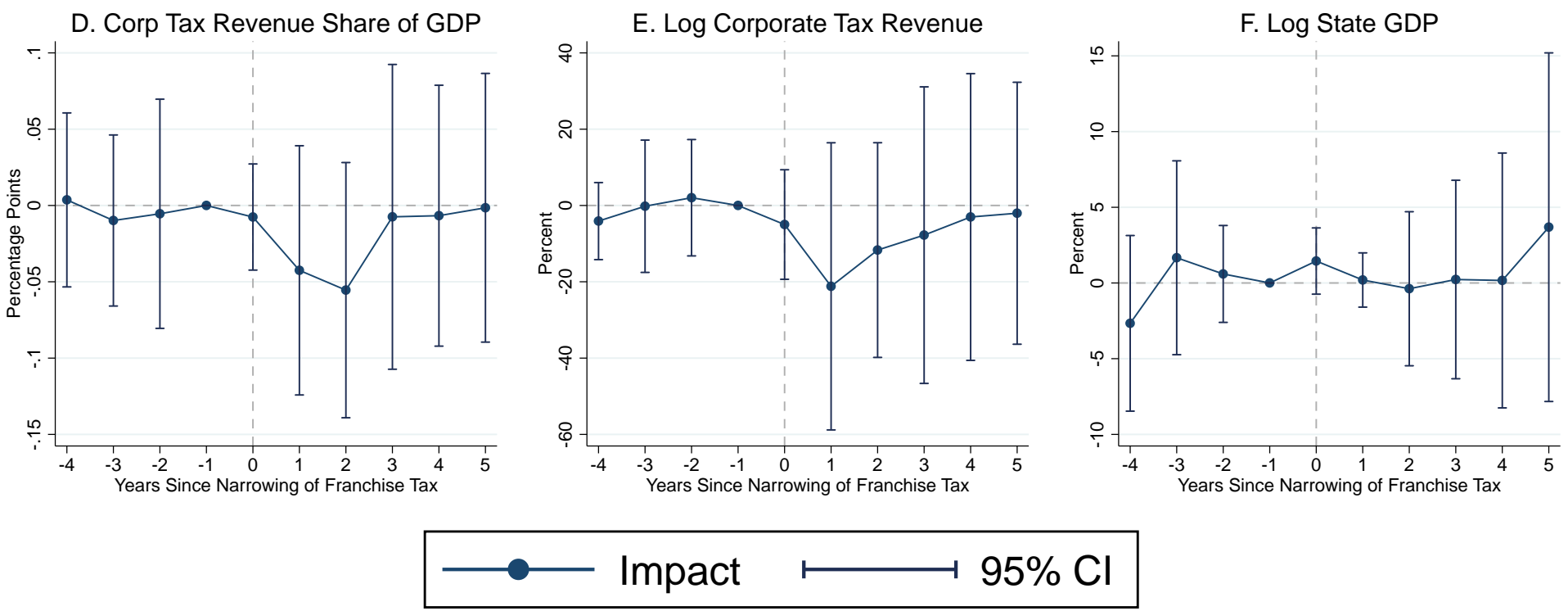

Notes: This figure shows the effect of broadening and narrowing of whether the state has a franchise tax on state corporate tax revenue as a share of state GDP, log corporate tax revenue and log state GDP, respectively. Standard errors are clustered by state. The construction of these event studies follows the form of equation 4 . See Section 1 for details on data sources and Appendix A for detailed definitions of broadening and narrowing for each measure. 
Figure A36: Event Analysis: Impacts of Loss Carryforward Changes on Revenue and GDP
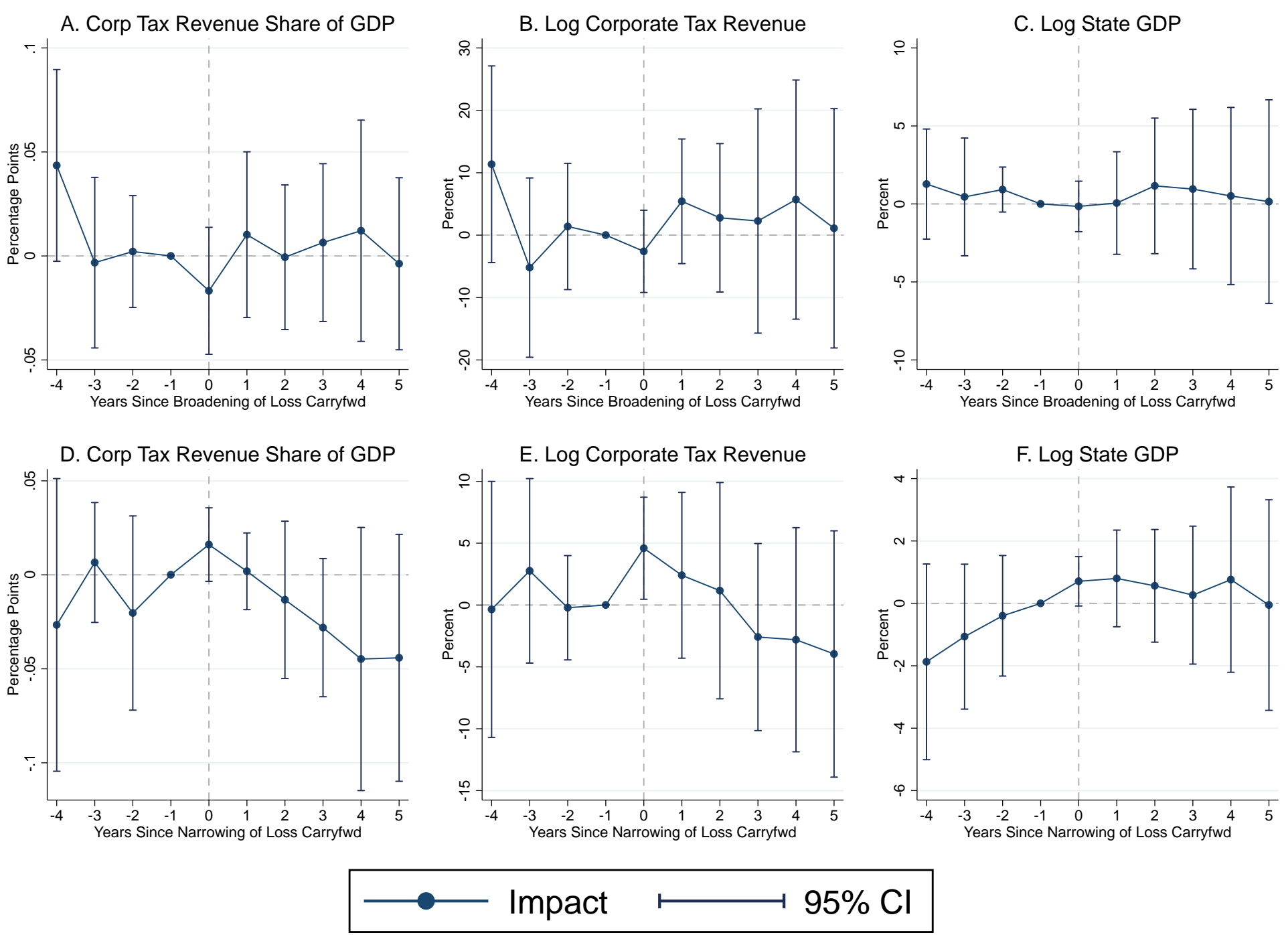

Notes: This figure shows the effect of broadening and narrowing of loss carryforward years on state corporate tax revenue as a share of state GDP, log corporate tax revenue and $\log$ state GDP, respectively. Standard errors are clustered by state. The construction of these event studies follows the form of equation 4 . See Section 1 for details on data sources and Appendix A for detailed definitions of broadening and narrowing for each measure. 
Figure A37: Event Analysis: Impacts of Loss Carryback Changes on Revenue and GDP
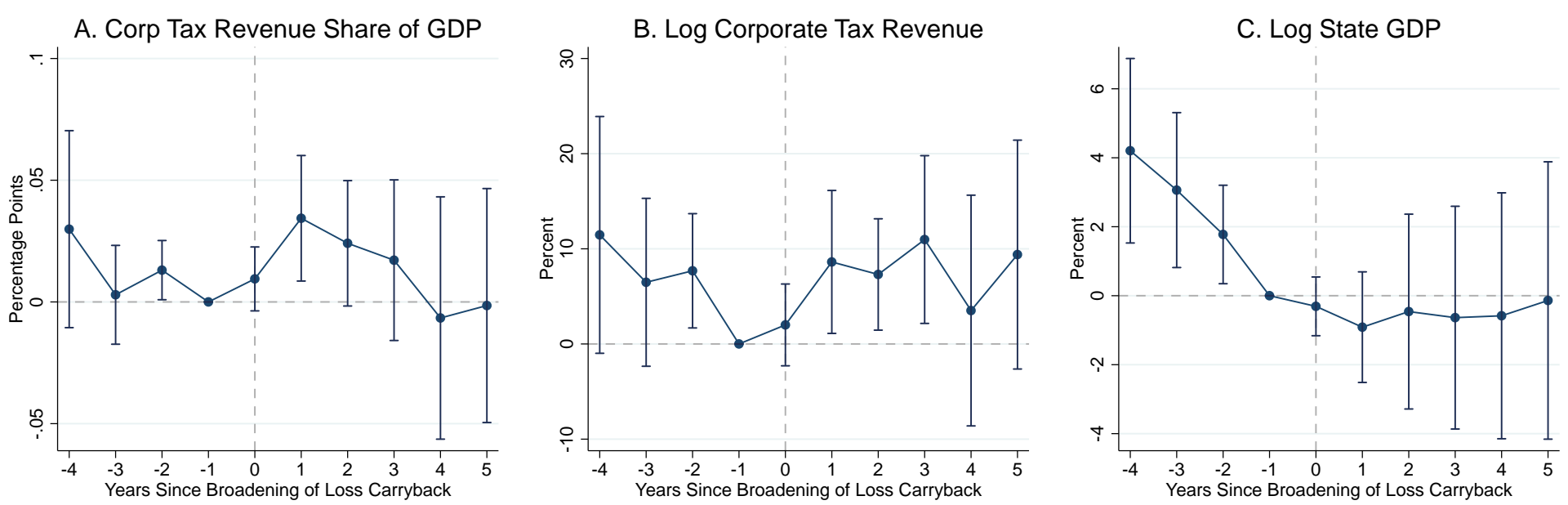

D. Corp Tax Revenue Share of GDP
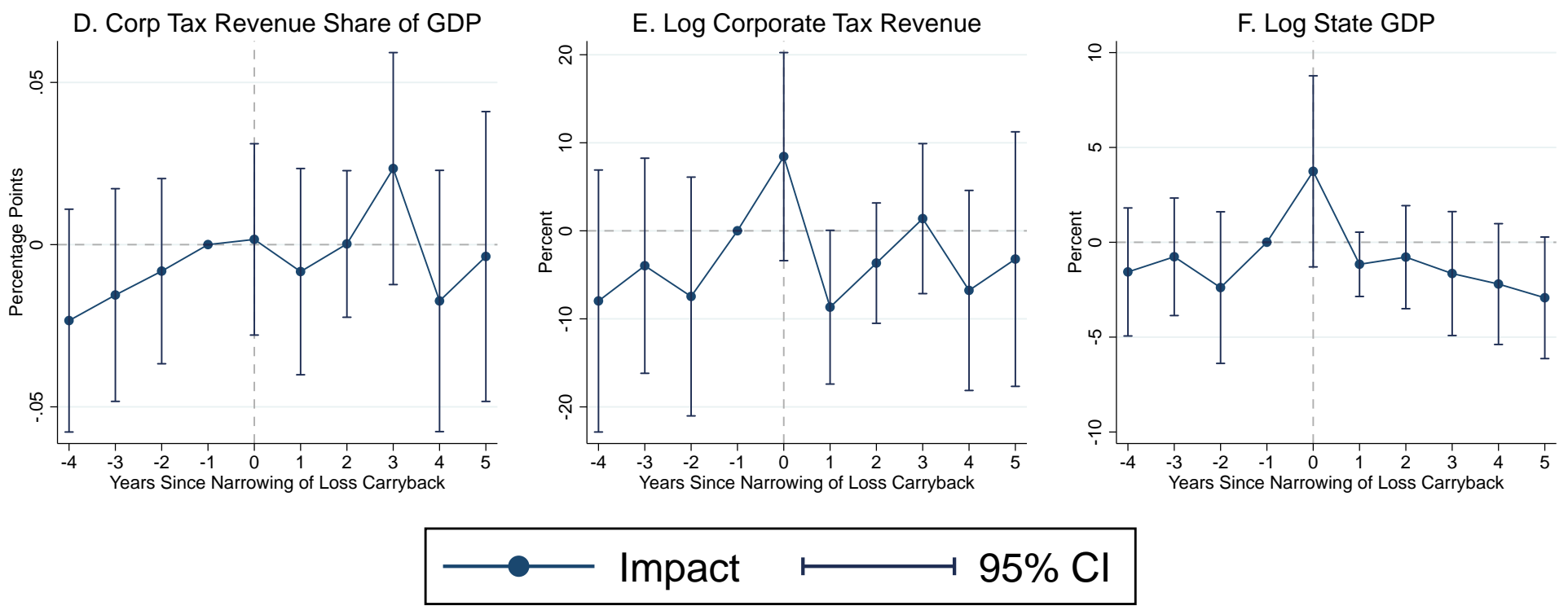

NOTES: This figure shows the effect of broadening and narrowing of loss carryback years on state corporate tax revenue as a share of state GDP, log corporate tax revenue and log state GDP, respectively. Standard errors are clustered by state. The construction of these event studies follows the form of equation 4 . See Section 1 for details on data sources and Appendix A for detailed definitions of broadening and narrowing for each measure. 
Figure A38: Event Analysis: Impacts of R\&D Credit Changes on Revenue and GDP
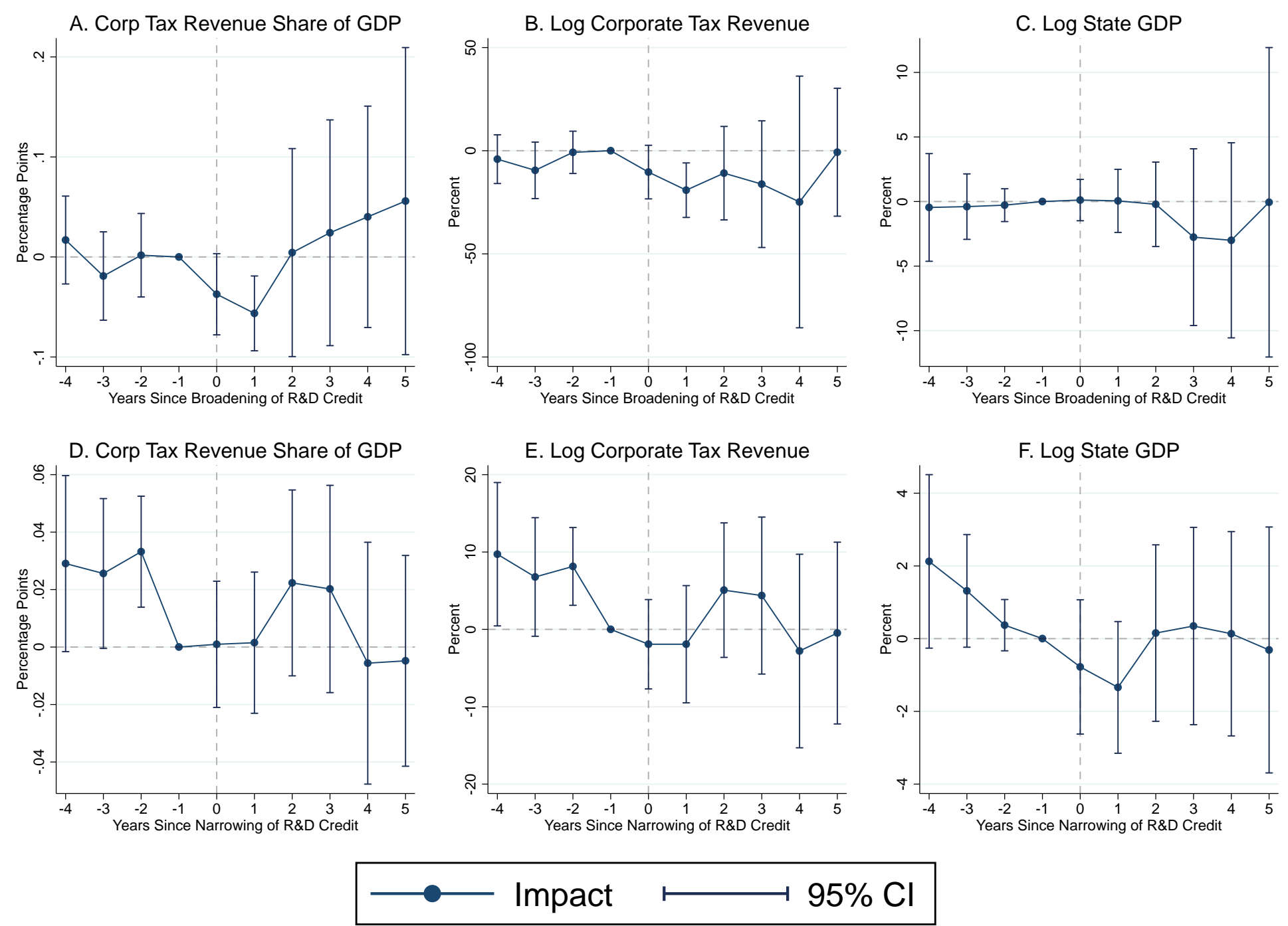

NotES: This figure shows the effect of broadening and narrowing of R\&D tax credits on state corporate tax revenue as a share of state GDP, log corporate tax revenue and log state GDP, respectively. Standard errors are clustered by state. The construction of these event studies follows the form of equation 4 . See Section 1 for details on data sources and Appendix A for detailed definitions of broadening and narrowing for each measure. 
Figure A39: Event Analysis: Impacts of Sales Apportionment Weight Changes on Revenue and GDP
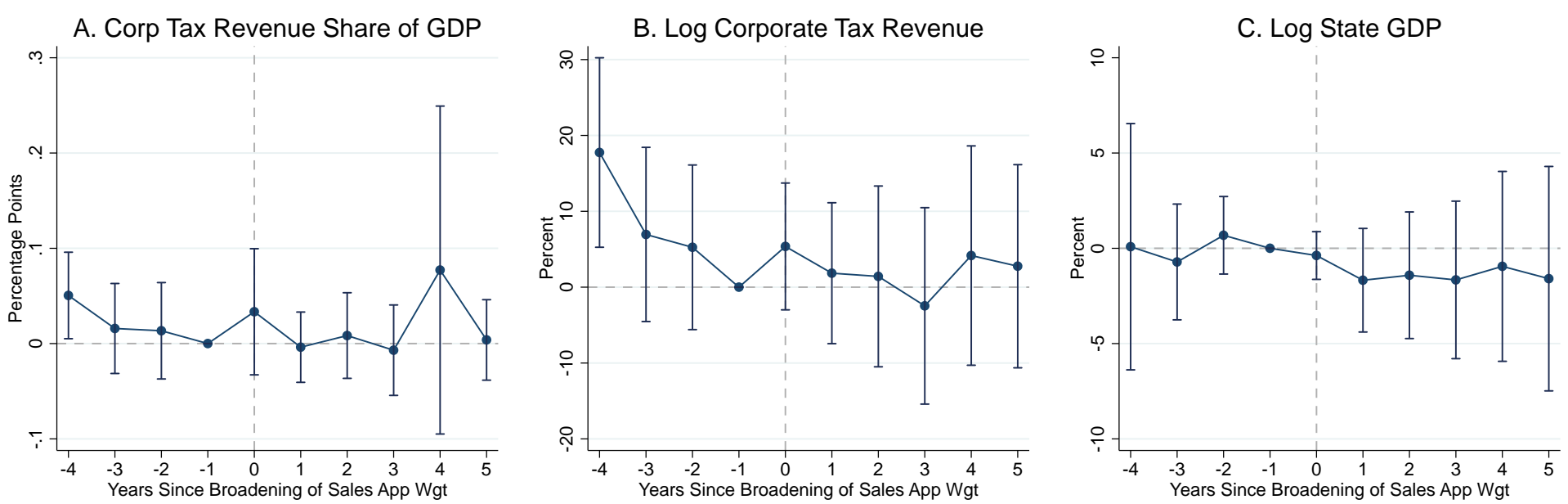

D. Corp Tax Revenue Share of GDP
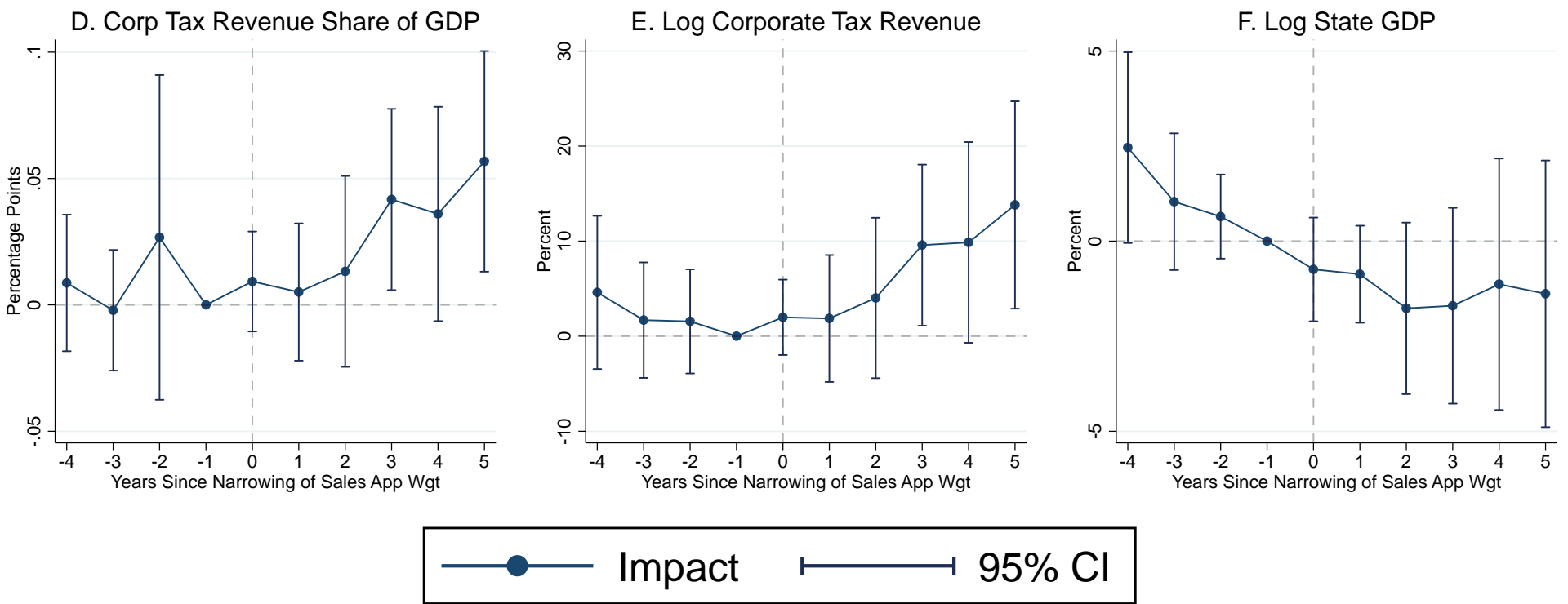

NotES: This figure shows the effect of broadening and narrowing of sales apportionment weights on state corporate tax revenue as a share of state GDP, log corporate tax revenue and $\log$ state GDP, respectively. Standard errors are clustered by state. The construction of these event studies follows the form of equation 4 . See Section 1 for details on data sources and Appendix A for detailed definitions of broadening and narrowing for each measure. 
Figure A40: Event Analysis: Impacts of Federal Income as State Base Changes on Revenue and GDP
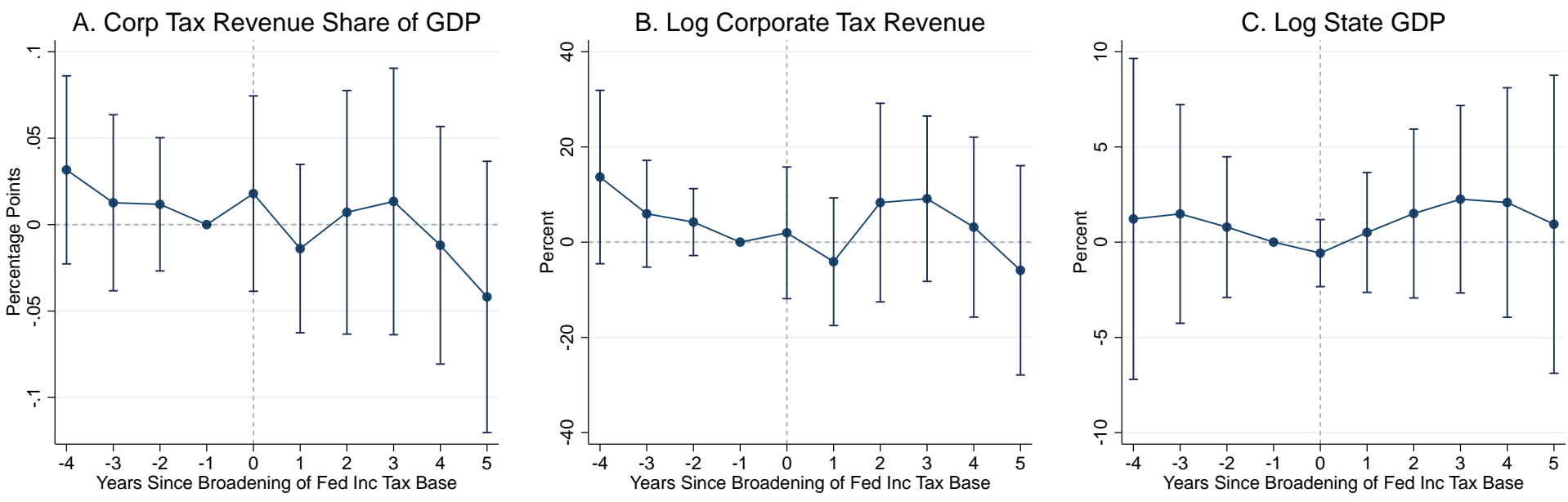

Impact

$95 \% \mathrm{Cl}$

NOTES: This figure shows the effect of broadening and narrowing of whether states use federal income as the tax base on state corporate tax revenue as a share of state GDP, log corporate tax revenue and $\log$ state GDP, respectively. Standard errors are clustered by state. The construction of these event studies follows the form of equation 4 . See Section 1 for details on data sources and Appendix A for detailed definitions of broadening and narrowing for each measure. 
Figure A41: Event Analysis: Impacts of Combined Reporting Changes on Revenue and GDP

A. Corp Tax Revenue Share of GDP

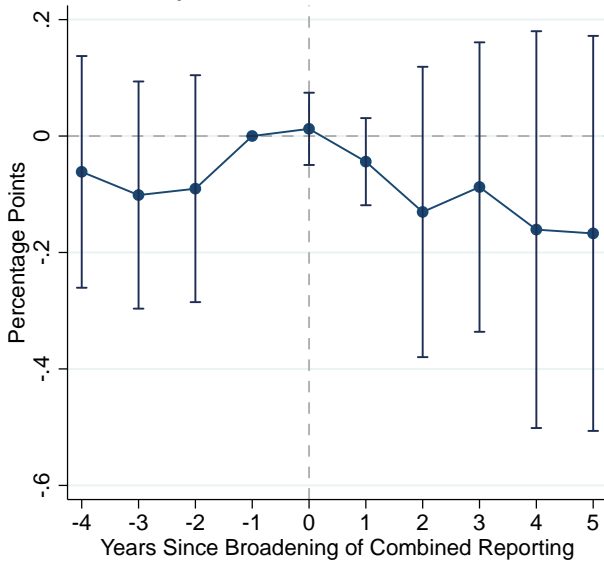

D. Corp Tax Revenue Share of GDP

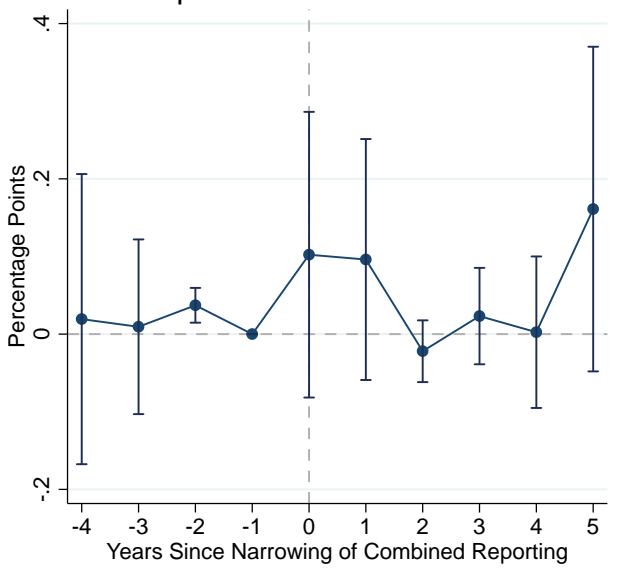

B. Log Corporate Tax Revenue

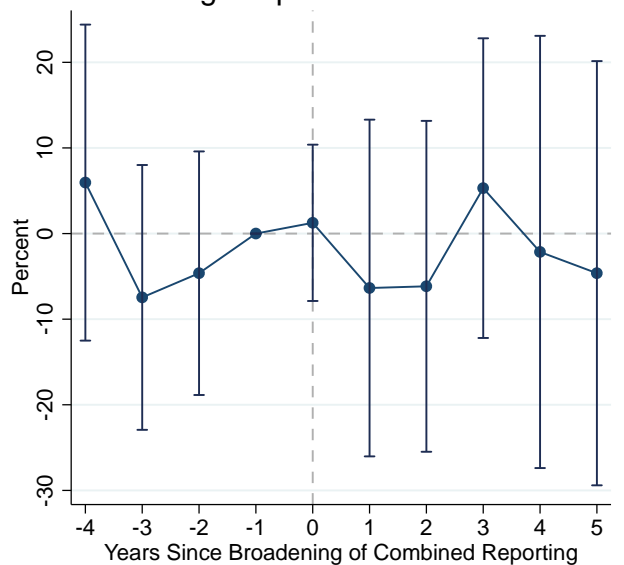

E. Log Corporate Tax Revenue

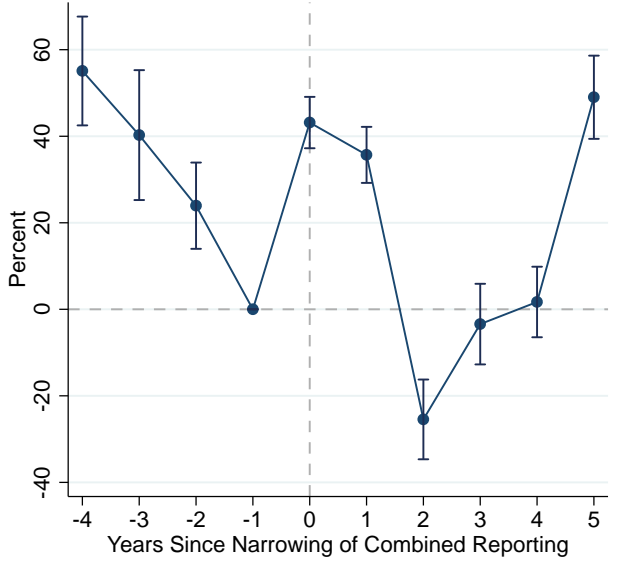

C. Log State GDP

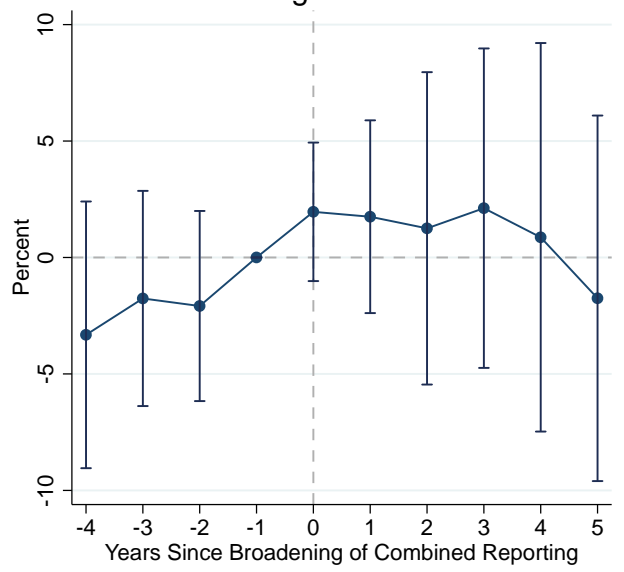

F. Log State GDP

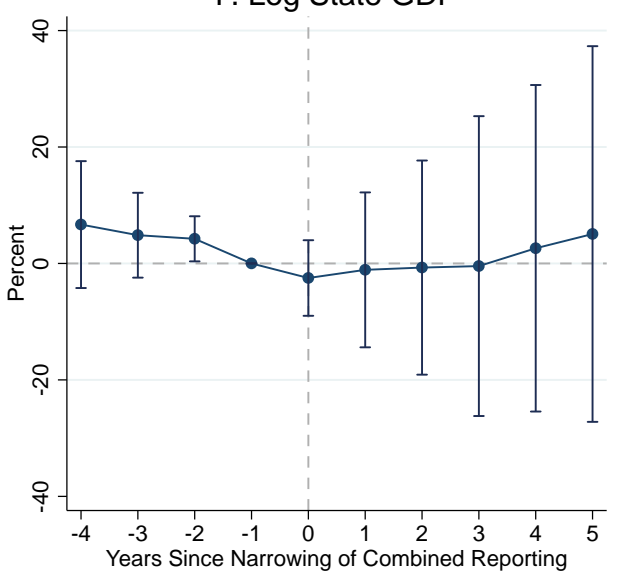

\section{$\longrightarrow$ Impact $\longmapsto 95 \% \mathrm{Cl}$}

NOTES: This figure shows the effect of broadening and narrowing of combined reporting on state corporate tax revenue as a share of state GDP, log corporate tax revenue and log state GDP, respectively. Standard errors are clustered by state. The construction of these event studies follows the form of equation 4 . See Section 1 for details on data sources and Appendix A for detailed definitions of broadening and narrowing for each measure. 
Figure A42: Event Analysis: Impacts of Throwback Rule Changes on Revenue and GDP

A. Corp Tax Revenue Share of GDP

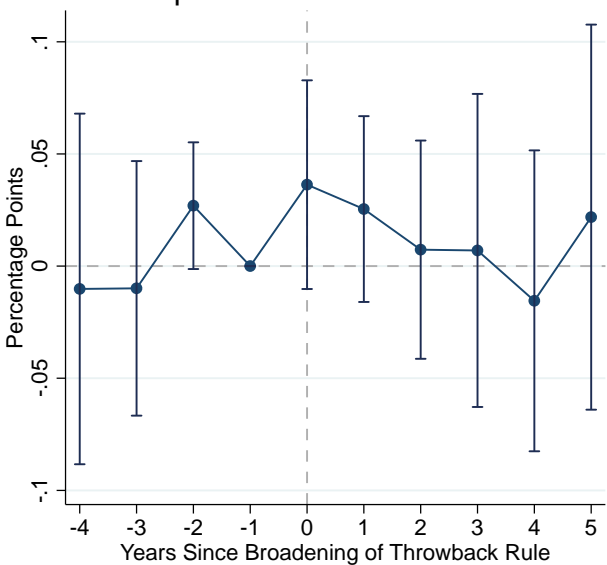

D. Corp Tax Revenue Share of GDP

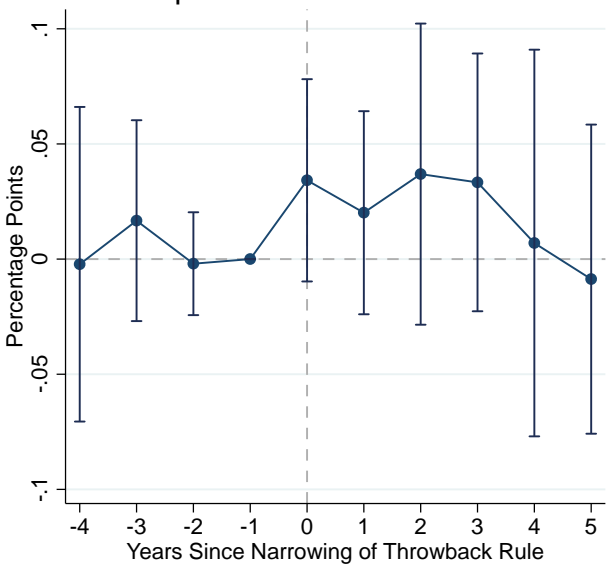

B. Log Corporate Tax Revenue

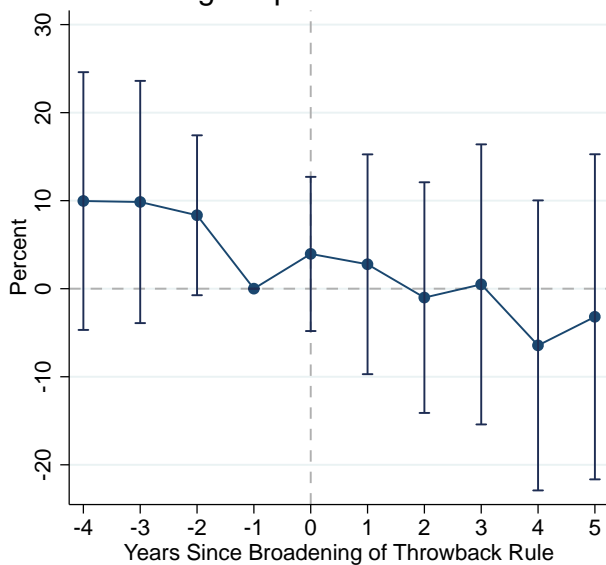

E. Log Corporate Tax Revenue

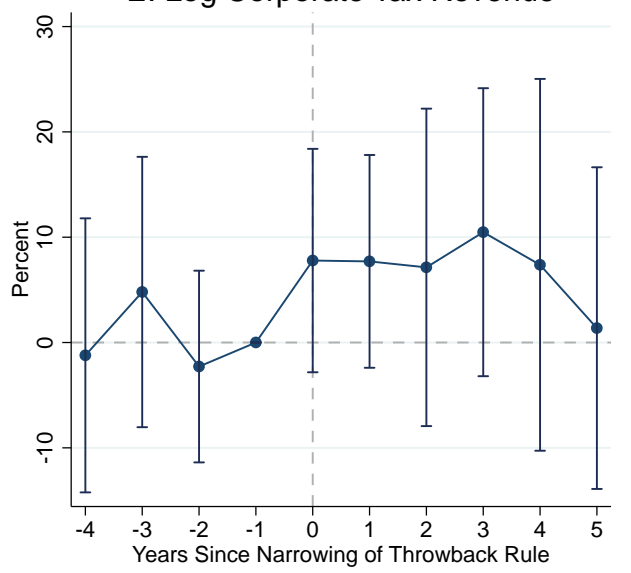

C. Log State GDP

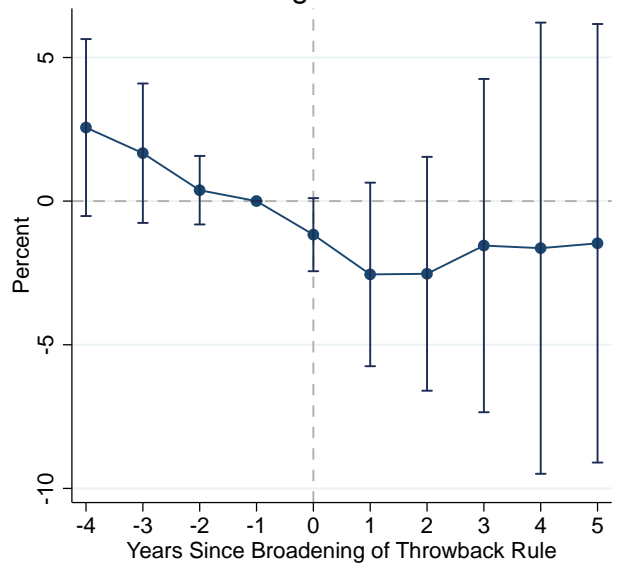

F. Log State GDP

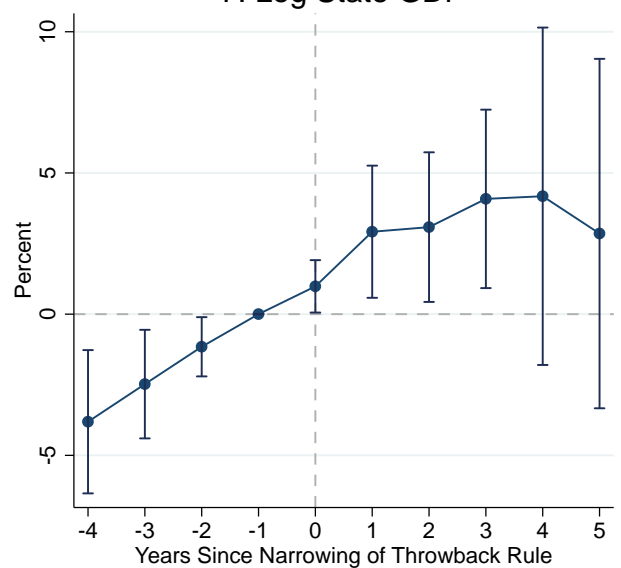

\section{$\longrightarrow$ Impact $\longmapsto 95 \% \mathrm{Cl}$}

NOTES: This figure shows the effect of broadening and narrowing of throwback rules on state corporate tax revenue as a share of state GDP, log corporate tax revenue and log state GDP, respectively. Standard errors are clustered by state. The construction of these event studies follows the form of equation 4 . See Section 1 for details on data sources and Appendix A for detailed definitions of broadening and narrowing for each measure. 
Figure A43: Event Analysis: Impacts of Incremental R\&D Base as Moving Average Changes on Revenue and GDP
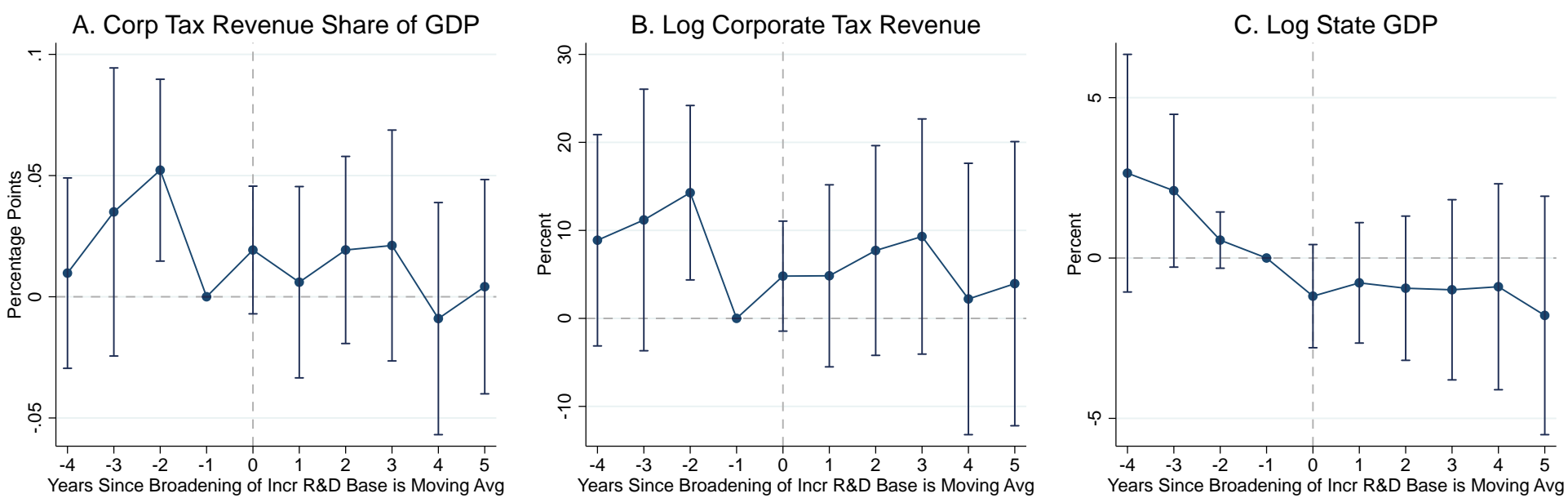

D. Corp Tax Revenue Share of GDP
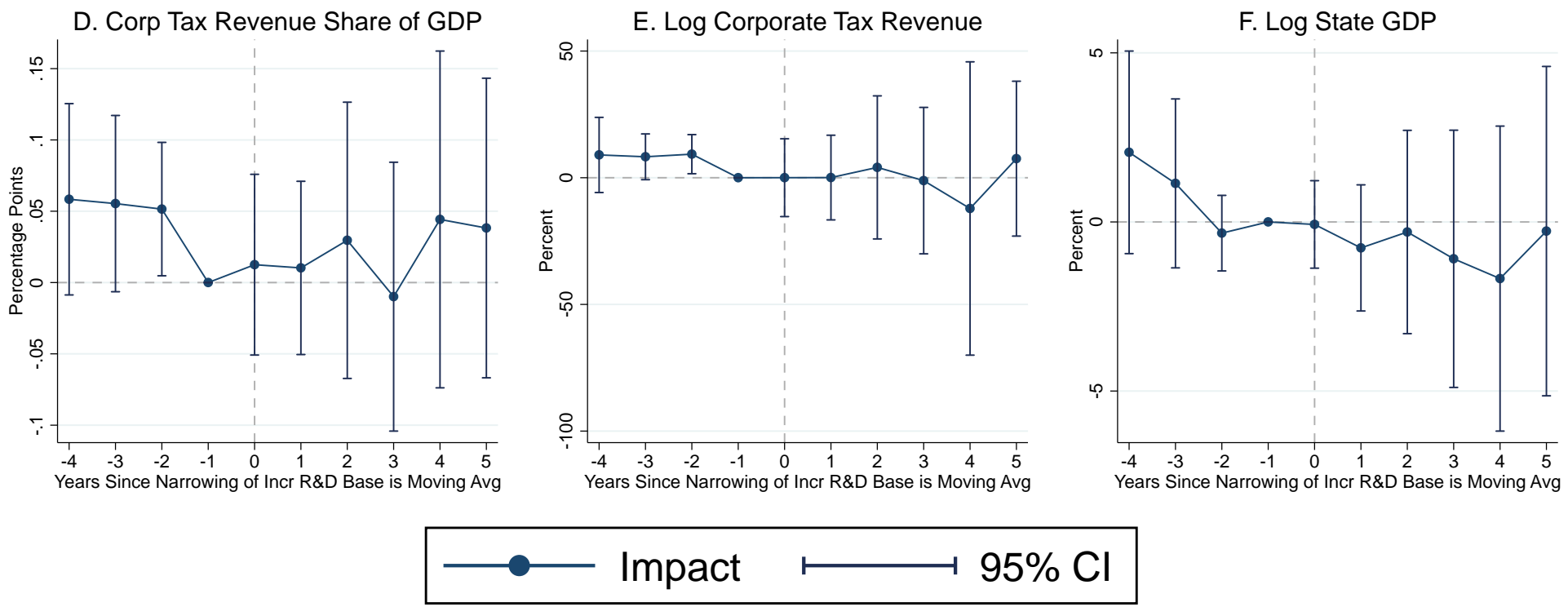

Notes: This figure shows the effect of broadening and narrowing of whether the incremental R\&D base is a moving average on state corporate tax revenue as a share of state GDP, $\log$ corporate tax revenue and log state GDP, respectively. Standard errors are clustered by state. The construction of these event studies follows the form of equation 4 . See Section 1 for details on data sources and Appendix A for detailed definitions of broadening and narrowing for each measure. 
Figure A44: Event Analysis: Impacts of Fixed Incremental R\&D Base Changes on Revenue and GDP

A. Corp Tax Revenue Share of GDP

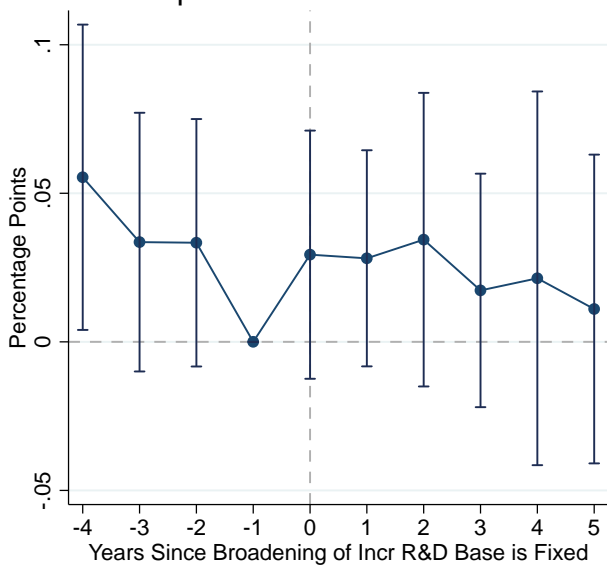

D. Corp Tax Revenue Share of GDP

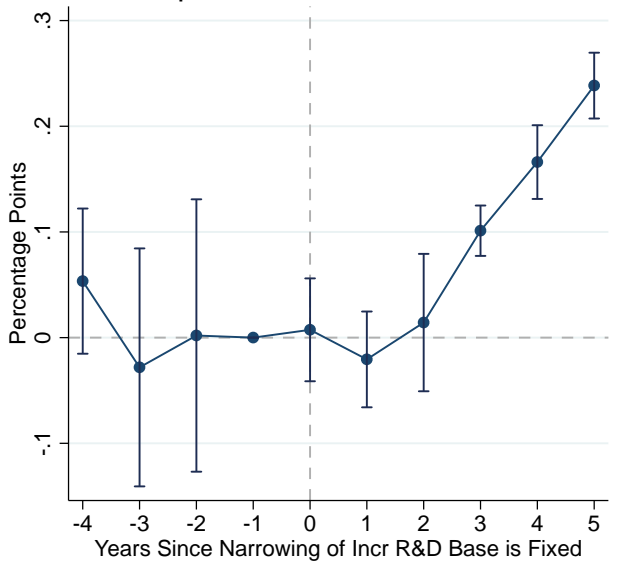

B. Log Corporate Tax Revenue

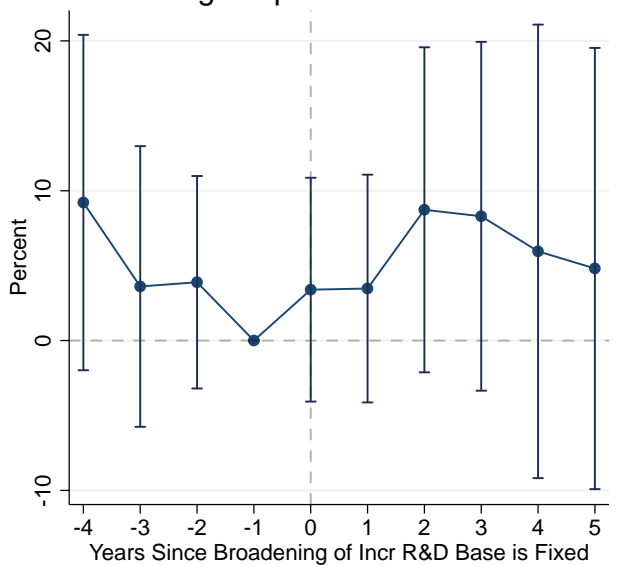

E. Log Corporate Tax Revenue

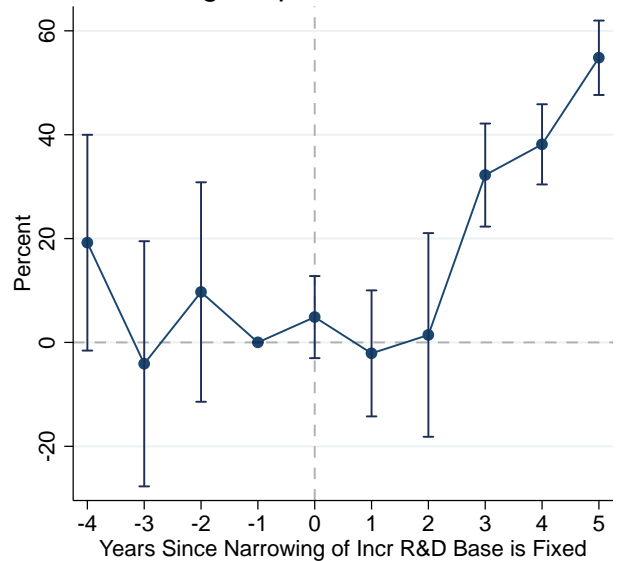

C. Log State GDP

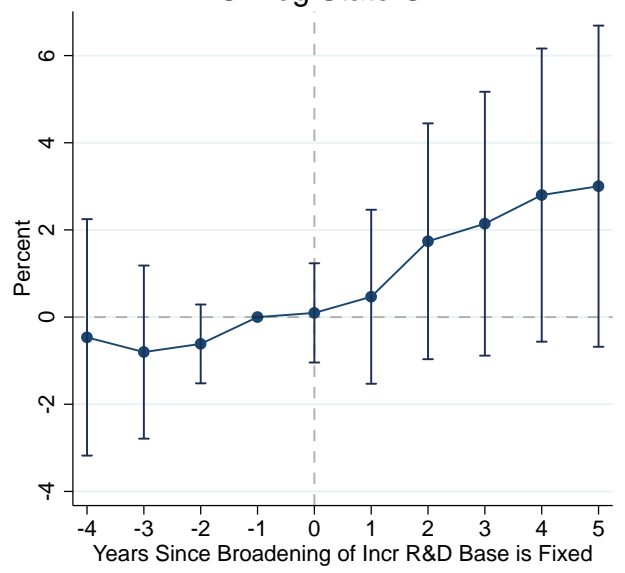

F. Log State GDP

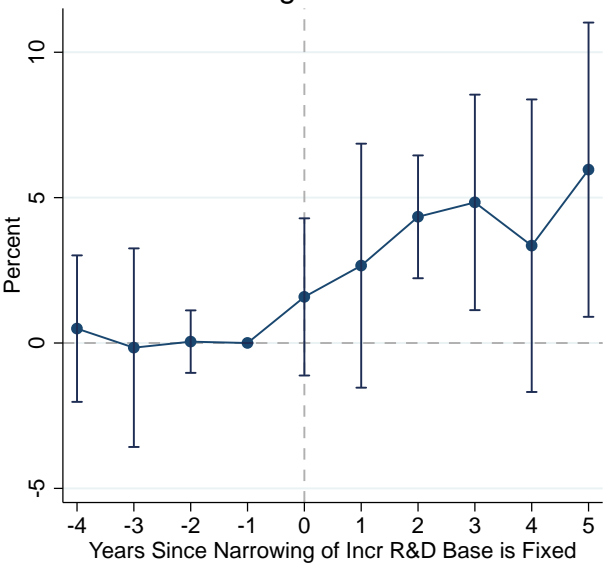

\section{$\longrightarrow$ Impact $\longmapsto 95 \% \mathrm{Cl}$}

NOTES: This figure shows the effect of broadening and narrowing of whether the incremental R\&D base is fixed on state corporate tax revenue as a share of state GDP, log corporate tax revenue and log state GDP, respectively. Standard errors are clustered by state. The construction of these event studies follows the form of equation 4 . See Section 1 for details on data sources and Appendix A for detailed definitions of broadening and narrowing for each measure. 
Figure A45: Corporate Tax Revenue Share by Region
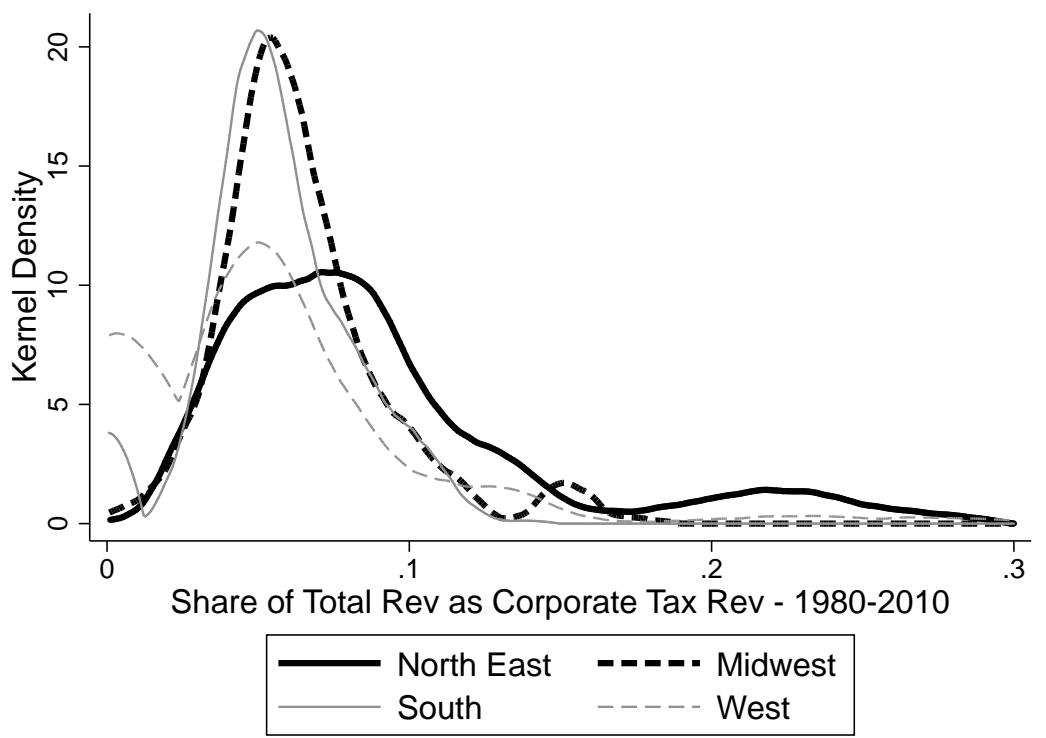

Figure A46: Individual Income Tax Revenue Share by Region

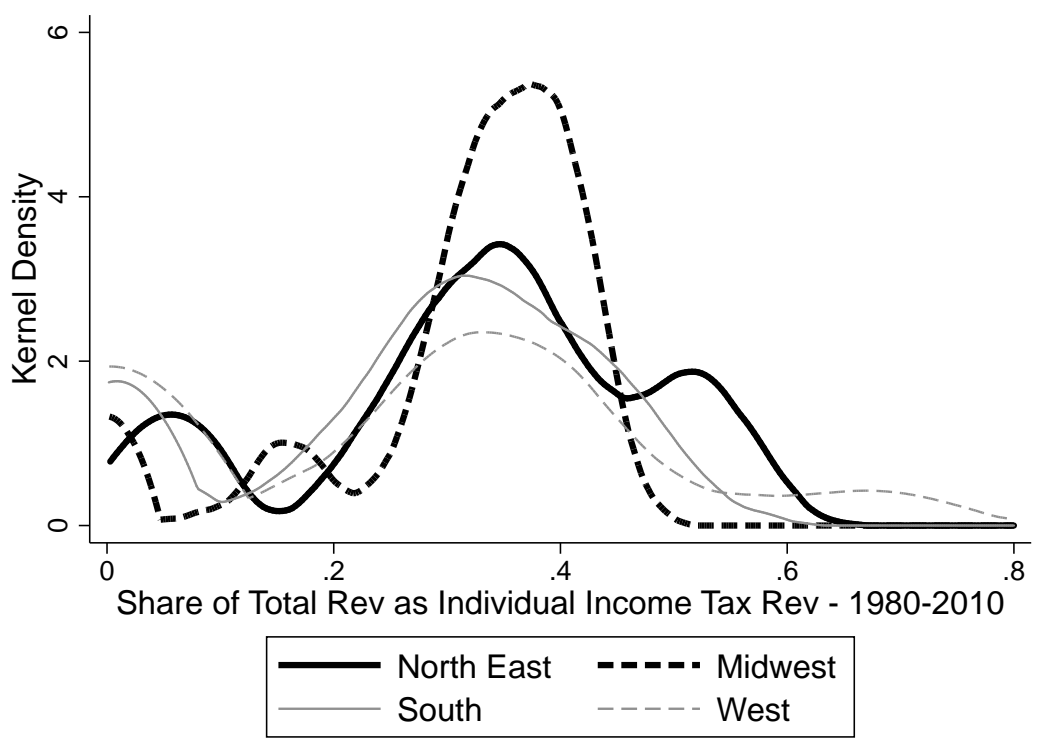

Notes: Sample spans 1980-2010. Regions are based on standard U.S. Census regions. The District of Columbia is excluded from the density calculation. Note that the kernel density is equally weighted by state-year observation. That is, a single observation is one state-year (within a single region). The alternative would be to take the total single tax revenue for a given state over the sample period (1980-2010) and divide it by the total tax revenue for that state over the sample period. Both produce similar results. See Section 1 for details on data sources. 
Figure A47: Estimated Total Effect of $\tau$ on the Revenue-to-GDP Ratio By State-Year
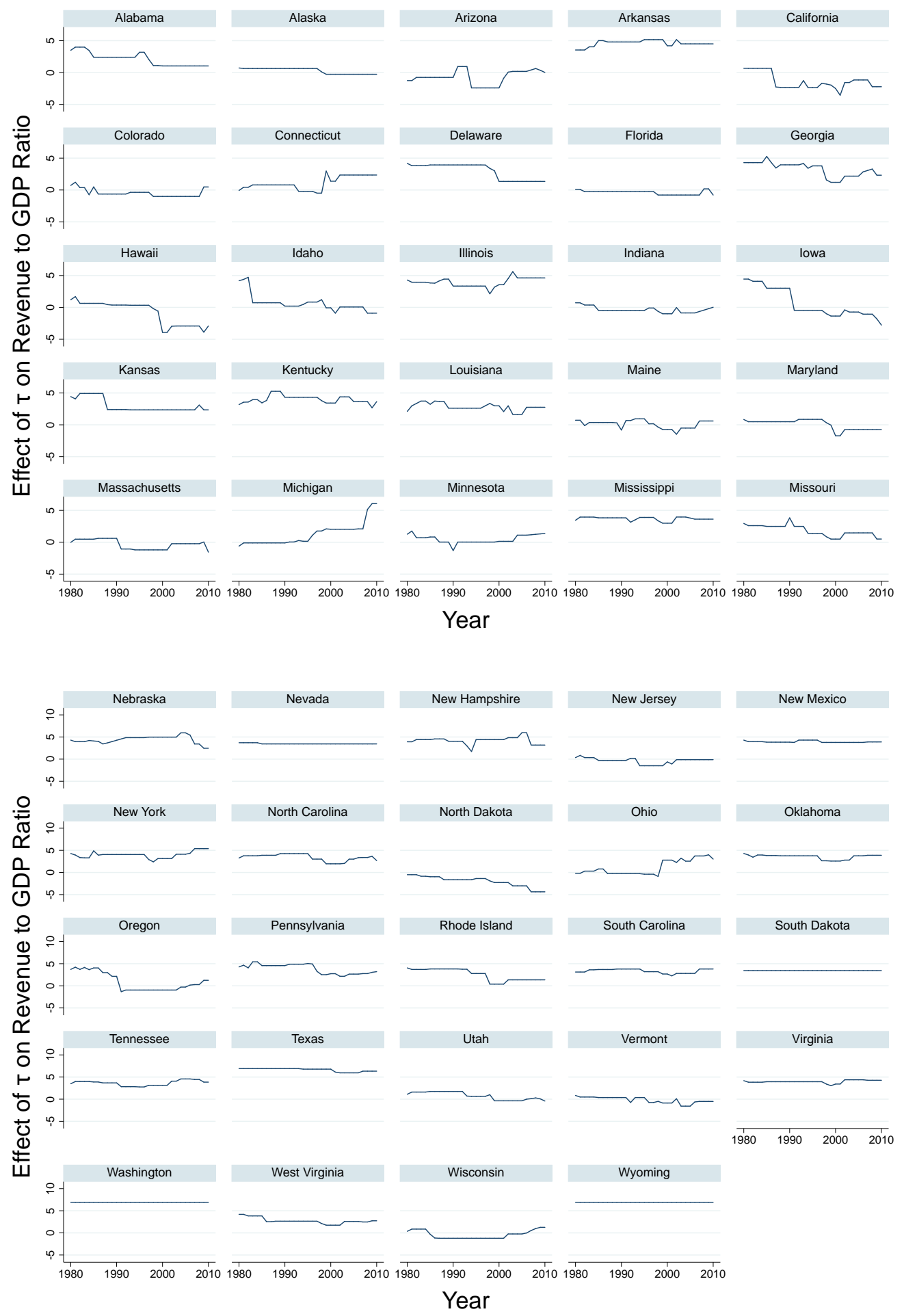

NotEs: This figure plots estimated total effects of $\tau$ on the revenue-to-GDP ratio for every state-year. The total effect is defined in equation 6 as a result of estimating equation 5, which is reported in Column (3) of Table 6. Data used for this estimation is discussed in Section 1, and details of the estimation can be found in Section 5. The coefficients on the terms $\tau$ and interactions are multiplied by 100 to ease interpretation. 
Figure A48: Maps of the Estimated Total Effect of $\tau$ on the Revenue-to-GDP Ratio
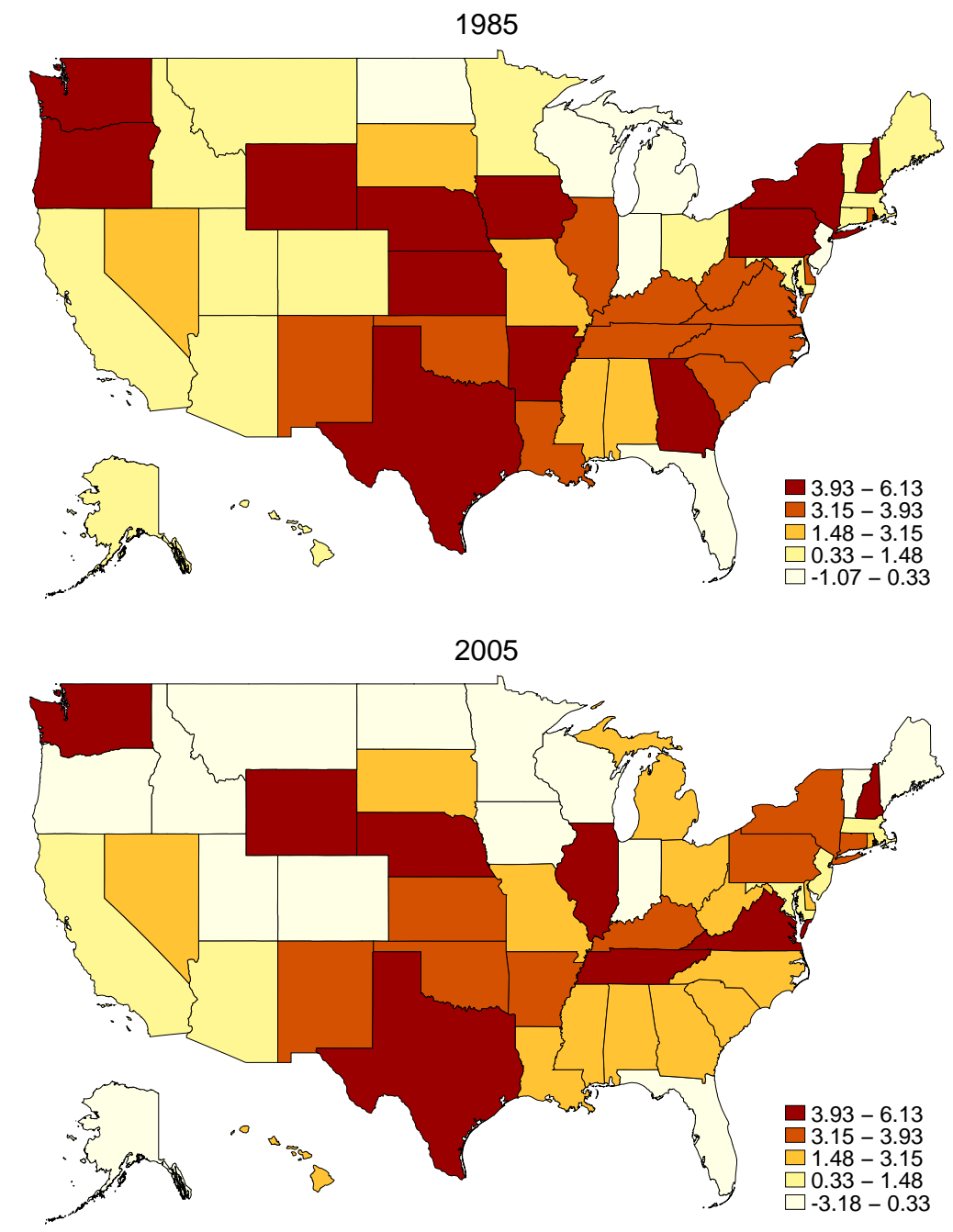

Notes: These maps plot total effects of $\tau$ on the revenue-to-GDP ratio for every state in 1985 and 2005. The category (color) ranges are held constant across time except for the maximum and minimum values. The total effect is defined in equation 6 as a result of estimating equation 5, which is reported in Column (3) of Table 6. Data used for this estimation is discussed in Section 1, and details of the estimation can be found in Section 5. The revenue-to-GDP ratio is measured in basis points. Overall, these maps show a decrease in the absolute value of the total effect of $\tau$ on the revenue-to-GDP ratio, while showcasing considerable heterogeneity across states. 
Figure A49: Estimate Revenue-Maximizing-Tax Rates: Robustness to State Tax Controls

A. Estimated Laffer Curve for State Corporate Tax Revenue

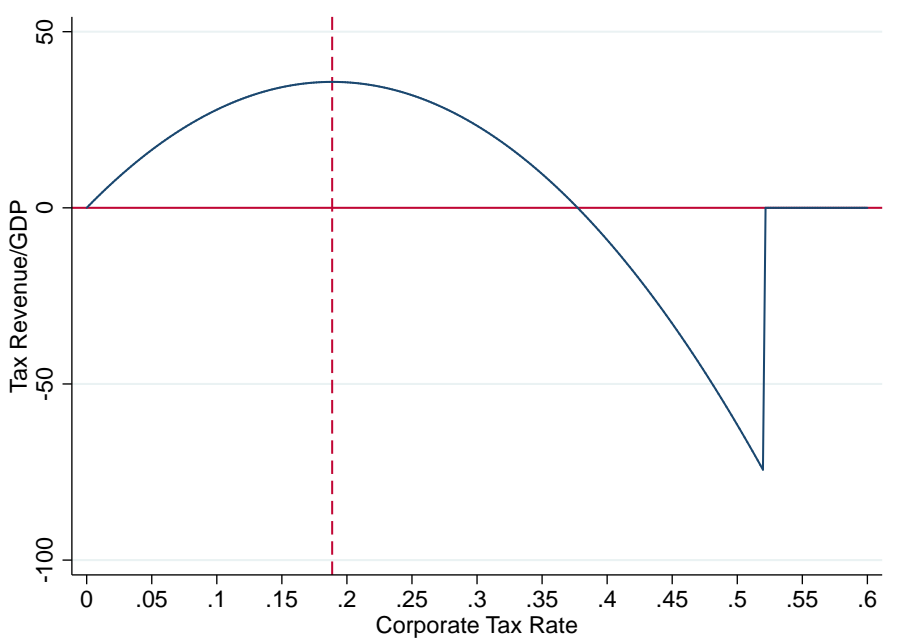

B. CDF of Corporate Tax Revenue Maximizing Tax Rates

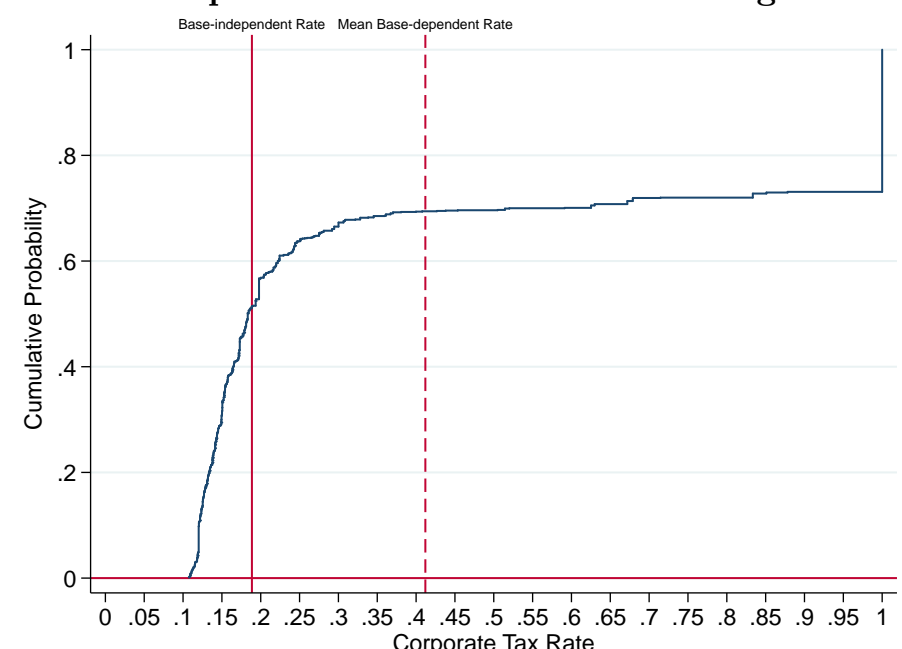

D. CDF of Total State Tax Revenue Maximizing Tax Rates

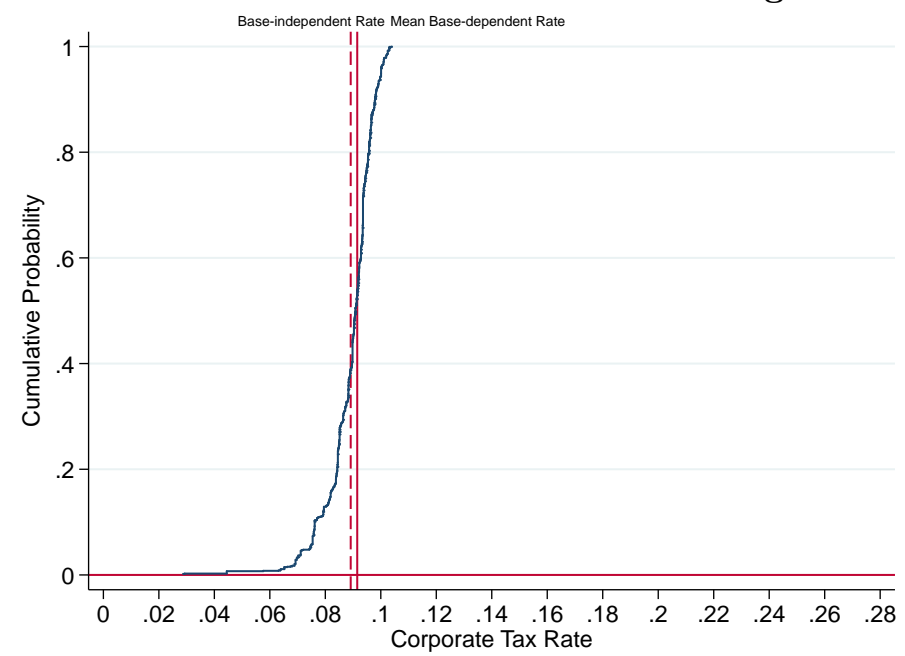

Notes: This figure plots the implied revenue-maximizing-state-corporate-tax rates, replicating Figure 11 and additionally controlling for state sales tax rates and top personal income tax rates. These estimates are based on estimates coefficients from equation 8 in Table A12. See Section 6 for details on estimation. See Section 1 for details on data sources. 
Table A1: Bartik Tax Base Summary Statistics

\begin{tabular}{lccc}
\hline \hline Panel A. 1980-2010 Pooled Sample & & \\
\hline & Observations & Mean & Std. Dev. \\
\hline Property Tax Rate & 672 & 2.545 & 0.939 \\
Property Tax Abatement & 672 & 0.353 & 0.529 \\
Job Creation Tax Credit & 672 & 0.300 & 0.514
\end{tabular}

Panel B. 2010 Cross Section

\begin{tabular}{lccc}
\hline & Observations & Mean & Std. Dev. \\
\hline Property Tax Rate & 32 & 2.223 & 0.787 \\
Property Tax Abatement & 32 & 0.411 & 0.590 \\
Job Creation Tax Credit & 32 & 0.572 & 0.674 \\
\hline \hline
\end{tabular}

Notes: This table provides summary statistics for the measures from Bartik (2017). Panel A provides pooled summary statistics. Data on property tax rates, property tax abatement and job creation tax credits range from 1990 to 2015. Panel B summarizes the tax base measures for the 2010 cross-section. Data on property tax rates, property tax abatement and job creation tax credits are from the Bartik (2017) dataset, which is restricted to 46 cities in 32 states that make up roughly 90 percent of aggregate U.S. GDP. Details on each of the variables, sources, and coverage are available in Appendix A. 
Table A2: Variance Decomposition - Corporate Tax Revenue Share of GDP - Bartik and Unweighted

\begin{tabular}{lccc}
\hline \hline & \multicolumn{3}{c}{ Corp Rev Share of GDP } \\
\hline \% Variance Explained & 66.06 & 27.53 & 51.04 \\
Corporate Rate \% of Explained Variance & 0.31 & 71.29 & 3.82 \\
Base Measures \% of Explained Variance & 99.69 & 28.71 & 96.18 \\
& & & \\
\% Base Variation Explained by Base Rule & & & \\
Federal Inc as State Base & 71.96 & 2.72 & 61.05 \\
Federal Inc Deductible & 1.63 & 24.55 & 3.65 \\
Throwback Rules & 2.20 & 8.02 & 1.98 \\
Sales Apportionment Wgt & 1.16 & 8.52 & 6.78 \\
Loss Carryforward & 6.67 & 1.34 & 7.05 \\
Loss Carryback & 0.08 & 0.56 & 0.03 \\
Combined Reporting & 0.06 & 6.15 & 0.30 \\
Investment Tax Credit & 0.07 & 13.77 & 0.40 \\
R\&D Credit & 0.11 & 2.04 & 0.65 \\
ACRS Depreciation & 0.53 & 7.96 & 0.31 \\
Federal Accelerated Dep & 0.69 & 0.03 & 1.83 \\
Federal Bonus Dep & 0.40 & 0.37 & 0.02 \\
Franchise Tax & 4.08 & 5.91 & 6.35 \\
Incremental R\&D, Moving Avg & 0.53 & 7.56 & 1.15 \\
Incremental R\&D, Fixed & 0.75 & 10.51 & 1.90 \\
Property Tax & 0.66 & & 0.31 \\
Property Tax Abatement & 7.96 & & 6.07 \\
Job Creation Credit & 0.45 & & 0.16 \\
\hline Mean GDP Weighted & Yes & No & No \\
\hline \hline
\end{tabular}

Notes: This table shows the general explanatory power for the corporate tax rate, base rules, and additional bartik controls. The following tax base rules are included in all decompositions: loss carryforward, loss carryback, R\&D credit, investment credit, throwback rule, combined reporting rule, federal income tax deductibility, federal bonus depreciation, federal income as state tax base, federal accelerated depreciation, ACRS depreciation, and the sales apportionment weight. In addition, we include the job creation tax credit rate, property tax rate, and property tax abatement as part of the "Bartik" controls where indicated. Decompositions are not weighted by state GDP where specified. Note that the variance decomposition shown in this figure is only performed on 33 states due to data limitations along the "Bartik" dimension. This table replicates Figure 5. See Section 1 for details on data sources. 
Table A3: Frequency of tax base changes accompanying rate changes

\begin{tabular}{lcccccccc}
\hline \hline Tax Rate Change: & Dec. & Dec. & Inc. & Inc. & None & None & Total & Total \\
Total Rate Changes: & 76 & & 237 & & 1469 & & 313 & \\
Base narrowing/broadening: & -1 & +1 & -1 & +1 & -1 & +1 & -1 & +1 \\
\hline Sales Apportionment Weight & 4 & 2 & 2 & 1 & 86 & 30 & 92 & 33 \\
Loss Carryback & 0 & 3 & 1 & 0 & 22 & 39 & 23 & 42 \\
Loss Carryforward & 8 & 1 & 4 & 1 & 73 & 13 & 85 & 15 \\
Francise Tax & 1 & 0 & 1 & 1 & 1 & 2 & 3 & 3 \\
Federal Income Tax Deductible & 0 & 1 & 0 & 2 & 2 & 1 & 2 & 4 \\
Federal Income Tax as State Tax Base & 0 & 2 & 0 & 0 & 0 & 6 & 0 & 8 \\
Federal Accelerated Depreciation & 0 & 0 & 0 & 0 & 2 & 5 & 2 & 5 \\
ACRS Depreciation & 1 & 0 & 6 & 1 & 50 & 13 & 57 & 14 \\
Federal Bonus Depreciation & 1 & 1 & 1 & 2 & 16 & 40 & 18 & 43 \\
Throwback & 3 & 4 & 0 & 4 & 20 & 15 & 23 & 23 \\
Combined Reporting & 0 & 1 & 0 & 2 & 2 & 17 & 2 & 20 \\
Investment Credit & 1 & 1 & 0 & 0 & 33 & 8 & 34 & 9 \\
R\&D Credit & 4 & 2 & 2 & 0 & 45 & 6 & 51 & 8 \\
R\&D Credit Incremental Base, Mov Avg & 0 & 1 & 0 & 0 & 10 & 17 & 10 & 18 \\
R\&D Credit Incremental Base, Fixed & 0 & 1 & 0 & 0 & 2 & 21 & 2 & 22 \\
\hline \hline
\end{tabular}

NoтES: This table reports the number of state-year observations where there was a change in tax base and tax rate. A change that represents a narrowing of the base is counted in the -1 column, while a year that represents a broadening of the base is counted as +1 . The data used for this table are described in Section 1. See Appendix A for detailed definitions of broadening and narrowing for each measure. 
Table A4: Sensitivity of Probit Estimates of the Coincidence of Base and Rate Changes

Panel A: Base Change

\begin{tabular}{|c|c|c|c|}
\hline & Any Base Change & Base Broadening & Base Narrowing \\
\hline Rate decrease & $\begin{array}{c}0.1157 \\
(0.2408)\end{array}$ & $\begin{array}{c}0.0703 \\
(0.2769)\end{array}$ & $\begin{array}{c}0.1304 \\
(0.3173)\end{array}$ \\
\hline No rate change & $\begin{array}{l}-0.0942 \\
(0.1851)\end{array}$ & $\begin{array}{l}-0.2683 \\
(0.2349)\end{array}$ & $\begin{array}{c}0.0981 \\
(0.2043)\end{array}$ \\
\hline
\end{tabular}

Panel B: Tax Rate Change

\begin{tabular}{|c|c|c|c|}
\hline & Any Tax Change & Tax Increase & Tax Decrease \\
\hline Base narrowed & $\begin{array}{c}0.0231 \\
(0.1467)\end{array}$ & $\begin{array}{c}-0.0558 \\
(0.1734)\end{array}$ & $\begin{array}{c}0.0621 \\
(0.1993)\end{array}$ \\
\hline Base broadened & $\begin{array}{l}0.2611^{*} \\
(0.1466)\end{array}$ & $\begin{array}{c}0.1835 \\
(0.2187)\end{array}$ & $\begin{array}{c}0.2449 \\
(0.1563)\end{array}$ \\
\hline
\end{tabular}

Notes: This table describes the relationship between the timing of tax rate changes and the timing of tax base changes. Panel A reports coefficients from a probit model estimating the probability of a change in the tax base using changes in tax rates. Panel B reports coefficients from a probit model estimating the probability of a change in the tax rate using changes in the tax base. The data used for this table are described in Section 1. See Appendix A for definitions of broadening and narrowing for each measure. Year fixed effects are included in each panel. Standard errors are clustered by state $\left({ }^{*} p<.1,{ }^{* *} p<.05,{ }^{* * *} p<.01\right)$. Overall, this table shows that tax rate changes and tax base changes do not occur simultaneously. 
Table A5: Probability of Rate and Base Changes Border and Similar State Changes in Past Year

Panel A. Neighboring States

\begin{tabular}{|c|c|c|c|c|c|}
\hline Dep Var & $\begin{array}{c}(1) \\
\text { Baseline }\end{array}$ & $\begin{array}{c}(2) \\
\text { Corp Rate Inc }\end{array}$ & $\begin{array}{c}(3) \\
\text { Corp Rate Dec }\end{array}$ & $\begin{array}{c}(4) \\
\text { Base Broadened }\end{array}$ & $\begin{array}{c}(5) \\
\text { Base Narrowed }\end{array}$ \\
\hline $\begin{array}{l}\text { Corp Rate Increase } \\
(\mathrm{N}=1476)\end{array}$ & 0.313 & $\begin{array}{l}-0.077 \\
(0.183)\end{array}$ & $\begin{array}{l}-0.190 \\
(0.429)\end{array}$ & $\begin{array}{c}0.000^{* * *} \\
(0.362)\end{array}$ & \\
\hline $\begin{array}{l}\text { Corp Rate Decrease } \\
(\mathrm{N}=1458)\end{array}$ & 0.025 & $\begin{array}{l}-0.018 \\
(0.383)\end{array}$ & $\begin{array}{l}0.000 \\
(0.290)\end{array}$ & & \\
\hline $\begin{array}{l}\text { Tax Base Broadening } \\
(\mathrm{N}=1326)\end{array}$ & 0.008 & $\begin{array}{c}0.000 \\
(0.399)\end{array}$ & & & \\
\hline \multicolumn{6}{|l|}{$\begin{array}{l}\text { Tax Base Narrowing } \\
(\mathrm{N}=1193)\end{array}$} \\
\hline \multicolumn{6}{|c|}{ Panel B. Similar States } \\
\hline Dep Var & $\begin{array}{c}\text { (1) } \\
\text { Baseline }\end{array}$ & $\begin{array}{c}(2) \\
\text { Corp Rate Inc }\end{array}$ & $\begin{array}{c}(3) \\
\text { Corp Rate Dec }\end{array}$ & $\begin{array}{c}(4) \\
\text { Base Broadened }\end{array}$ & $\begin{array}{c}5) \\
\text { Base Narrowed }\end{array}$ \\
\hline $\begin{array}{l}\text { Corp Rate Increase } \\
(\mathrm{N}=1186)\end{array}$ & 0.058 & $\begin{array}{l}-0.003 \\
(0.405)\end{array}$ & & $\begin{array}{l}-0.023 \\
(0.254)\end{array}$ & $\begin{array}{l}0.000^{* *} \\
(0.167)\end{array}$ \\
\hline $\begin{array}{l}\text { Corp Rate Decrease } \\
(\mathrm{N}=1210)\end{array}$ & 0.055 & $\begin{array}{c}0.043 \\
(0.336)\end{array}$ & $\begin{array}{c}0.012 \\
(0.440)\end{array}$ & $\begin{array}{c}0.043 \\
(0.193)\end{array}$ & $\begin{array}{c}0.022 \\
(0.225)\end{array}$ \\
\hline $\begin{array}{l}\text { Tax Base Broadening } \\
(\mathrm{N}=1210)\end{array}$ & 0.271 & $\begin{array}{l}-0.107 \\
(0.329)\end{array}$ & $\begin{array}{l}0.069^{* *} \\
(0.296)\end{array}$ & $\begin{array}{c}-0.180^{* * *} \\
(0.243)\end{array}$ & $\begin{array}{l}0.069^{* *} \\
(0.101)\end{array}$ \\
\hline $\begin{array}{l}\text { Tax Base Narrowing } \\
(\mathrm{N}=1210)\end{array}$ & 0.224 & $\begin{array}{l}-0.093 \\
(0.274)\end{array}$ & $\begin{array}{l}0.000 \\
(0.337)\end{array}$ & $\begin{array}{l}-0.080 \\
(0.195)\end{array}$ & $\begin{array}{l}-0.032 \\
(0.110)\end{array}$ \\
\hline
\end{tabular}

NoTES: This table describes how the probability of a rate or base change in a given state in year $t$ ("event") is affected by changes in other states in $t-1$. Panel A calculates the impact of an increase or decrease in the corporate tax rate of at least $0.5 \mathrm{pp}$, and/or the broadening or narrowing of the tax base in neighboring states. Panel B does the same for similar states. These estimates follow the form of equation 10. Column (1) indicates the probability of an event absent a rate of base change in comparison states. Column (2) calculates the change in probability of an event given a corporate rate increase of at least $0.5 \mathrm{pp}$ in a border or similar state. Columns (3)-(5) replicate Column (2) for a decrease of at least 0.5pp in the corporate rate, broadening of the tax base and narrowing of the tax base, respectively. Note 57 observations are excluded when calculating the probability of corporate tax rate decreases in neighboring states because the absence of base narrowing changes in the previous 5 years perfectly predicts that corporate rates will not decrease. Standard errors are clustered by state $\left({ }^{*} p<.1,{ }^{* *} p<.05,{ }^{* * *} p<.01\right)$. Section B describes the construction of neighbor and similar state matches. 
Table A6: Probability of Rate and Base Changes Given Border and Similar State Changes in Past 5 Years

Panel A. Neighboring States

\begin{tabular}{|c|c|c|c|c|c|}
\hline Dep Var & $\begin{array}{c}(1) \\
\text { Baseline }\end{array}$ & $\begin{array}{c}(2) \\
\text { Corp Rate Inc }\end{array}$ & $\begin{array}{c}(3) \\
\text { Corp Rate Dec }\end{array}$ & $\begin{array}{c}(4) \\
\text { Base Broadened }\end{array}$ & $\begin{array}{c}(5) \\
\text { Base Narrowed }\end{array}$ \\
\hline $\begin{array}{l}\text { Corp Rate Increase } \\
(\mathrm{N}=1488)\end{array}$ & 0.112 & $\begin{array}{c}0.023 \\
(0.143)\end{array}$ & $\begin{array}{l}-0.019 \\
(0.163)\end{array}$ & $\begin{array}{l}0.023^{* *} \\
(0.315)\end{array}$ & $\begin{array}{l}-0.086 \\
(0.560)\end{array}$ \\
\hline $\begin{array}{l}\text { Corp Rate Decrease } \\
(\mathrm{N}=1388)\end{array}$ & 0.027 & $\begin{array}{c}0.008 \\
(0.184)\end{array}$ & $\begin{array}{c}0.008 \\
(0.209)\end{array}$ & & \\
\hline $\begin{array}{l}\text { Tax Base Broadening } \\
(\mathrm{N}=1388)\end{array}$ & 0.004 & $\begin{array}{c}0.002 \\
(0.244)\end{array}$ & $\begin{array}{c}0.002 \\
(0.256)\end{array}$ & & \\
\hline $\begin{array}{l}\text { Tax Base Narrowing } \\
(\mathrm{N}=1018)\end{array}$ & 0.004 & $\begin{array}{c}0.000 \\
(0.375)\end{array}$ & & & \\
\hline \multicolumn{6}{|c|}{ Panel B. Similar States } \\
\hline Dep Var & $\begin{array}{c}(1) \\
\text { Baseline }\end{array}$ & $\begin{array}{c}(2) \\
\text { Corp Rate Inc }\end{array}$ & $\begin{array}{c}(3) \\
\text { Corp Rate Dec }\end{array}$ & $\begin{array}{c}(4) \\
\text { Base Broadened }\end{array}$ & $\begin{array}{c}(5) \\
\text { Base Narrowed }\end{array}$ \\
\hline $\begin{array}{l}\text { Corp Rate Increase } \\
(\mathrm{N}=1210)\end{array}$ & 0.086 & $\begin{array}{c}0.000 \\
(0.204)\end{array}$ & $\begin{array}{c}0.000 \\
(0.258)\end{array}$ & $\begin{array}{c}-0.043^{* *} \\
(0.164)\end{array}$ & $\begin{array}{c}0.000 \\
(0.153)\end{array}$ \\
\hline $\begin{array}{l}\text { Corp Rate Decrease } \\
(\mathrm{N}=1210)\end{array}$ & 0.072 & $\begin{array}{c}0.000 \\
(0.226)\end{array}$ & $\begin{array}{c}0.000 \\
(0.315)\end{array}$ & $\begin{array}{c}0.000 \\
(0.146)\end{array}$ & $\begin{array}{l}-0.008 \\
(0.177)\end{array}$ \\
\hline $\begin{array}{l}\text { Tax Base Broadening } \\
(\mathrm{N}=1210)\end{array}$ & 0.206 & $\begin{array}{c}0.000 \\
(0.164)\end{array}$ & $\begin{array}{c}0.000 \\
(0.194)\end{array}$ & $\begin{array}{l}-0.048^{*} \\
(0.096)\end{array}$ & $\begin{array}{c}0.000 \\
(0.091)\end{array}$ \\
\hline $\begin{array}{l}\text { Tax Base Narrowing } \\
(\mathrm{N}=1210)\end{array}$ & 0.219 & $\begin{array}{l}-0.044 \\
(0.129)\end{array}$ & $\begin{array}{c}0.006 \\
(0.239)\end{array}$ & $\begin{array}{c}0.006 \\
(0.094)\end{array}$ & $\begin{array}{l}-0.043^{*} \\
(0.090)\end{array}$ \\
\hline
\end{tabular}

Notes: This table describes how the probability of a rate or base change in a given state in year $t$ ("event") is affected by changes in other states in years $t-1, t-2, t-3, t-4$ or $t-5$. Panel A calculates the impact of an increase or decrease in the corporate tax rate of at least $0.5 \mathrm{pp}$, and/or the broadening or narrowing of the tax base in neighboring states. Panel B does the same for similar states. These estimates follow the form of equation 11. Column (1) indicates the probability of an event absent a rate of base change in comparison states. Column (2) calculates the change in probability of an event given a corporate rate increase of at least 0.5pp in a border or similar state. Columns (3)-(5) replicate Column (2) for a decrease of at least 0.5pp in the corporate rate, broadening of the tax base and narrowing of the tax base, respectively. Standard errors are clustered by state $\left({ }^{*} p<.1,{ }^{* *} p<.05\right.$, $\left.{ }^{* * *} p<.01\right)$. Section B describes the construction of neighbor and similar state matches. 
Table A7: Variance Decomposition - Corporate Revenue Share of GDP, Level and Log

\begin{tabular}{|c|c|c|c|c|c|c|c|c|c|c|c|c|c|c|}
\hline \multirow[b]{2}{*}{$\%$ Variance Explained } & \multicolumn{7}{|c|}{ Corp Rev Share of GDP } & \multicolumn{7}{|c|}{ Log Corp Rev Share of GDP } \\
\hline & 48.57 & 83.88 & 85.50 & 57.23 & 84.97 & 86.70 & 85.56 & 40.35 & 78.13 & 82.29 & 46.40 & 79.76 & 83.82 & 82.36 \\
\hline Corporate Rate \% of Explained Variance & 43.78 & 19.54 & 32.08 & 0.85 & 0.97 & 1.23 & 29.11 & 24.33 & 12.76 & 30.10 & 2.47 & 0.21 & 0.86 & 26.46 \\
\hline Base Measures \% of Explained Variance & 56.22 & 80.46 & 67.92 & 49.63 & 61.82 & 61.83 & 70.89 & 75.67 & 87.24 & 69.90 & 50.54 & 51.29 & 51.66 & 73.54 \\
\hline \multicolumn{15}{|l|}{ \% Base Variation Explained by Base Rule } \\
\hline Federal Inc as State Base & 18.02 & 1.67 & 2.41 & 18.63 & 1.04 & 1.69 & 2.02 & 0.01 & 0.10 & 0.05 & 6.77 & 1.63 & 2.02 & 0.01 \\
\hline Federal Inc Deductible & 16.36 & 7.92 & 12.17 & 0.00 & 1.12 & 0.00 & 10.31 & 35.88 & 3.79 & 8.36 & 0.25 & 7.37 & 3.85 & 6.89 \\
\hline Throwback Rules & 8.77 & 1.24 & 1.14 & 0.04 & 0.25 & 0.08 & 2.18 & 7.00 & 1.28 & 0.99 & 0.02 & 0.01 & 0.04 & 2.31 \\
\hline Loss Carryforward & 5.05 & 0.68 & 0.12 & 3.63 & 9.02 & 11.91 & 0.18 & 24.87 & 3.46 & 0.08 & 3.31 & 0.75 & 2.76 & 0.09 \\
\hline Loss Carryback & 0.29 & 0.18 & 0.54 & 7.46 & 5.63 & 4.73 & 0.30 & 0.13 & 0.02 & 0.10 & 4.86 & 0.28 & 0.22 & 0.01 \\
\hline Combined Reporting & 2.47 & 2.12 & 0.22 & 2.13 & 0.58 & 0.58 & 0.11 & 0.01 & 6.37 & 0.60 & 4.15 & 2.20 & 1.47 & 1.34 \\
\hline Investment Tax Credit & 0.92 & 5.38 & 7.09 & 0.55 & 0.00 & 0.03 & 5.40 & 1.13 & 4.93 & 6.65 & 0.49 & 0.04 & 0.03 & 5.60 \\
\hline R\&D Credit & 1.35 & 3.09 & 4.12 & 31.02 & 3.26 & 1.16 & 3.81 & 0.27 & 0.03 & 0.06 & 43.07 & 26.29 & 22.01 & 0.00 \\
\hline ACRS Depreciation & 3.83 & 1.49 & 0.17 & 0.18 & 3.42 & 0.70 & 0.22 & 10.96 & 1.19 & 0.16 & 0.26 & 3.77 & 2.05 & 0.25 \\
\hline Federal Accelerated Dep & 0.04 & 12.72 & 10.98 & 0.23 & 5.93 & 2.49 & 9.43 & 6.58 & 3.26 & 2.03 & 0.45 & 0.71 & 0.15 & 1.91 \\
\hline Federal Bonus Dep & 0.26 & 0.71 & 0.66 & 0.04 & 2.24 & 2.41 & 0.55 & 0.13 & 0.00 & 0.43 & 0.44 & 2.25 & 2.80 & 0.32 \\
\hline Franchise Tax & 20.64 & 52.62 & 51.14 & 4.18 & 57.01 & 66.13 & 46.71 & 4.72 & 73.88 & 79.72 & 1.94 & 22.59 & 33.11 & 71.32 \\
\hline Incremental R\&D, Fixed & 0.80 & 0.76 & 1.26 & 12.47 & 5.64 & 5.04 & 1.18 & 3.35 & 0.45 & 0.54 & 13.24 & 26.40 & 25.97 & 0.20 \\
\hline Throwback Rules $\times$ Sales App Wgt & & & & & & & 4.28 & & & & & & & 6.49 \\
\hline State Fixed Effects & No & Yes & Yes & No & Yes & Yes & Yes & No & Yes & Yes & No & Yes & Yes & Yes \\
\hline Year Fixed Effects & No & No & Yes & No & No & Yes & Yes & No & No & Yes & No & No & Yes & Yes \\
\hline Base Measures $\times$ Corporate Rate & No & No & No & Yes & Yes & Yes & No & No & No & No & Yes & Yes & Yes & No \\
\hline
\end{tabular}

NotES: This table decomposes the variation of corporate revenue share of GDP and its logged counterpart. State fixed effects are included where indicated. Five-year-period fixed effects are included in all specifications where year fixed effects are not included. See Section 1 for details on data sources. 
Table A8: Correlation Between Tax Base Measures and Change in Corporate Keep Rate

Panel A. Level of Tax Base Rules

\begin{tabular}{|c|c|c|c|c|c|c|c|c|c|c|c|c|c|c|c|c|}
\hline & $\frac{\bar{c}}{d(1-\tau)}$ & ACRSDep & FedAccDep & "FedIncTxDed & "FedBonusDep & "FedIncTxBase & $\begin{array}{l}\text { FranchiseTx } \\
\end{array}$ & LossCarryback & LossCarryfwd & Combined & $\begin{array}{l}\text { ITC } \\
\end{array}$ & R\&D & 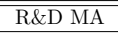 & R\&D Fixed & PayAppWgt & $\begin{array}{l}\text { Throwback } \\
\end{array}$ \\
\hline$d(1-\tau)$ & 1.000 & & & & & & & & & & & & & & & \\
\hline ACRSDep & -0.026 & 1.000 & & & & & & & & & & & & & & \\
\hline FedAccDep & -0.006 & 0.736 & 1.000 & & & & & & & & & & & & & \\
\hline FedIncTxDed & 0.005 & 0.126 & 0.143 & 1.000 & & & & & & & & & & & & \\
\hline FedBonusDepr & -0.010 & 0.386 & 0.504 & 0.080 & 1.000 & & & & & & & & & & & \\
\hline FedIncTxBase & -0.010 & 0.533 & 0.528 & 0.019 & 0.425 & 1.000 & & & & & & & & & & \\
\hline FranchiseTx & -0.014 & 0.032 & -0.057 & 0.070 & -0.101 & -0.123 & 1.000 & & & & & & & & & \\
\hline LossCarryback & $\begin{array}{l}-0.014 \\
-0.067\end{array}$ & $\begin{array}{l}0.290 \\
0.290\end{array}$ & 0.346 & 0.192 & 0.350 & 0.251 & 0.002 & 1.000 & & & & & & & & \\
\hline LossCarryfwd & -0.006 & 0.525 & 0.513 & 0.148 & 0.172 & 0.556 & -0.045 & 0.432 & 1.000 & & & & & & & \\
\hline CombinedRep & 0.049 & 0.127 & 0.183 & -0.104 & 0.120 & 0.176 & -0.285 & -0.013 & 0.071 & 1.000 & & & & & & \\
\hline ITC & 0.032 & 0.147 & 0.157 & -0.021 & -0.098 & 0.122 & 0.172 & -0.057 & 0.078 & 0.050 & 1.000 & & & & & \\
\hline R\&DCredit & 0.029 & 0.119 & 0.090 & -0.001 & -0.136 & 0.254 & -0.144 & -0.078 & 0.173 & 0.233 & 0.238 & 1.000 & & & & \\
\hline R\&D Base is MA & 0.012 & 0.122 & 0.053 & 0.061 & -0.023 & 0.117 & 0.063 & 0.026 & 0.200 & 0.163 & -0.070 & 0.336 & 1.000 & & & \\
\hline Fixed R\&D Base & 0.030 & 0.073 & 0.097 & 0.077 & -0.079 & 0.200 & -0.283 & -0.110 & 0.088 & 0.211 & 0.148 & 0.596 & -0.172 & 1.000 & & \\
\hline SalesAppWgt & -0.000 & -0.502 & -0.594 & -0.026 & -0.527 & -0.395 & 0.011 & -0.328 & -0.311 & -0.025 & 0.068 & 0.026 & -0.005 & 0.132 & 1.000 & \\
\hline ThrowbackRules & -0.031 & 0.228 & 0.264 & 0.045 & 0.143 & 0.070 & -0.142 & 0.126 & 0.115 & 0.389 & -0.004 & 0.075 & 0.121 & 0.057 & -0.337 & 1.000 \\
\hline
\end{tabular}

Panel B. Change in Tax Base Rules

\begin{tabular}{|c|c|c|c|c|c|c|c|c|c|c|c|c|c|c|c|c|}
\hline & $1-\tau$ & $\begin{array}{l}\text { ACRSDep } \\
\end{array}$ & $\begin{array}{l}\text { FedAccDep } \\
\end{array}$ & $\begin{array}{l}\text { FedIncTxDed } \\
\end{array}$ & FedBonusDep & FedIncTxBase & $\begin{array}{l}\text { FranchiseTx } \\
\end{array}$ & LossCarryback & 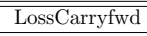 & Combined & 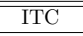 & $\begin{array}{l}\text { R\&D } \\
\end{array}$ & R\&D MA & PR\&D Fixed & PayAppWgt & $\begin{array}{l}\text { Throwback } \\
\end{array}$ \\
\hline $1-\tau$ & 1.000 & & & & & & & & & & & & & & & \\
\hline ACRSDep & -0.082 & 1.000 & & & & & & & & & & & & & & \\
\hline FedAccDep & -0.001 & 0.185 & 1.000 & & & & & & & & & & & & & \\
\hline FedIncTxDed & 0.033 & 0.003 & -0.001 & 1.000 & & & & & & & & & & & & \\
\hline FedBonusDepr & -0.010 & 0.073 & 0.240 & $\begin{array}{l}1.0002 \\
-0.002-1\end{array}$ & 1.000 & & & & & & & & & & & \\
\hline FedIncTxBase & 0.079 & 0.033 & 0.002 & 0.002 & -0.039 & 1.000 & & & & & & & & & & \\
\hline FranchiseTx & -0.026 & 0.049 & 0.000 & 0.000 & 0.052 & 0.000 & 1.000 & & & & & & & & & \\
\hline LossCarryback & -0.054 & 0.024 & -0.002 & -0.001 & -0.005 & -0.062 & 0.000 & 1.000 & & & & & & & & \\
\hline LossCarryfwd & 0.041 & 0.232 & 0.055 & 0.003 & -0.011 & 0.074 & -0.027 & 0.110 & 1.000 & & & & & & & \\
\hline CombinedRep & -0.059 & 0.038 & 0.003 & 0.002 & 0.036 & -0.007 & 0.087 & -0.020 & -0.022 & 1.000 & & & & & & \\
\hline ITC & -0.001 & -0.006 & 0.003 & 0.002 & 0.008 & -0.007 & 0.000 & 0.079 & 0.037 & -0.010 & 1.000 & & & & & \\
\hline R\&DCredit & -0.043 & 0.007 & 0.004 & -0.107 & 0.007 & -0.031 & 0.010 & -0.057 & -0.001 & -0.007 & 0.035 & 1.000 & & & & \\
\hline$R \& D$ Base is MA & 0.005 & 0.017 & 0.001 & -0.076 & 0.003 & -0.003 & 0.000 & -0.056 & 0.019 & -0.004 & -0.009 & 0.382 & 1.000 & & & \\
\hline Fixed R\&D Base & 0.013 & -0.014 & 0.003 & 0.086 & 0.009 & -0.008 & 0.000 & -0.057 & -0.003 & -0.011 & 0.062 & 0.449 & -0.315 & 1.000 & & \\
\hline SalesAppWgt & 0.058 & -0.014 & 0.005 & -0.036 & 0.033 & 0.064 & 0.042 & -0.071 & -0.014 & 0.063 & -0.017 & -0.022 & -0.007 & -0.016 & 1.000 & \\
\hline ThrowbackRules & -0.093 & 0.018 & 0.000 & 0.000 & 0.019 & 0.000 & 0.060 & -0.028 & 0.012 & 0.063 & -0.000 & 0.004 & 0.000 & 0.000 & 0.053 & 1.000 \\
\hline
\end{tabular}

NotES: This table shows the correlation between tax base measures and changes in the corporate keep rate. Panel A and B calculate the correlation for levels of and changes in tax base rules, respectively. Corporate keep rate is denoted $1-\tau$. See Section 1 for details on data sources. 
Table A9: Pass-through Share of State Economic Activity (2010)

\begin{tabular}{|c|c|c|c|}
\hline \multirow[b]{2}{*}{ State } & \multicolumn{3}{|c|}{ "Pass-through Share of State } \\
\hline & Employment & Establishments & Payroll \\
\hline Alabama & 35.47 & 45.67 & 32.21 \\
\hline Alaska & 35.83 & 45.77 & 32.00 \\
\hline Arizona & 35.39 & 54.00 & 27.88 \\
\hline Arkansas & 34.61 & 49.91 & 28.78 \\
\hline California & 33.21 & 42.22 & 27.62 \\
\hline Colorado & 38.30 & 60.96 & 31.68 \\
\hline Connecticut & 29.73 & 39.57 & 27.29 \\
\hline Delaware & 33.86 & 47.33 & 31.17 \\
\hline Florida & 37.97 & 64.14 & 33.87 \\
\hline Georgia & 33.93 & 54.89 & 28.47 \\
\hline Hawaii & 26.73 & 37.26 & 22.99 \\
\hline Idaho & 43.93 & 57.31 & 39.18 \\
\hline Illinois & 35.56 & 51.35 & 31.05 \\
\hline Indiana & 39.76 & 54.14 & 35.07 \\
\hline Iowa & 33.01 & 43.50 & 28.83 \\
\hline Kansas & 32.77 & 43.17 & 27.72 \\
\hline Kentucky & 35.04 & 49.25 & 29.86 \\
\hline Louisiana & 38.98 & 47.25 & 36.69 \\
\hline Maine & 35.71 & 48.04 & 31.34 \\
\hline Maryland & 34.61 & 48.82 & 31.33 \\
\hline Massachusetts & 29.73 & 44.75 & 25.49 \\
\hline Michigan & 35.06 & 45.90 & 30.12 \\
\hline Minnesota & 35.07 & 54.20 & 28.43 \\
\hline Mississippi & 32.63 & 42.66 & 28.34 \\
\hline Missouri & 32.69 & 43.01 & 27.94 \\
\hline Montana & 42.74 & 56.31 & 37.01 \\
\hline Nebraska & 35.39 & 49.69 & 31.07 \\
\hline Nevada & 37.68 & 54.00 & 34.39 \\
\hline New Hampshire & 31.83 & 36.53 & 28.97 \\
\hline New Jersey & 35.77 & 47.60 & 29.76 \\
\hline New Mexico & 37.39 & 45.90 & 34.23 \\
\hline New York & 34.36 & 47.88 & 31.91 \\
\hline North Carolina & 34.50 & 50.28 & 28.46 \\
\hline North Dakota & 35.98 & 45.02 & 31.42 \\
\hline Ohio & 33.36 & 42.88 & 28.61 \\
\hline Oklahoma & 36.98 & 50.29 & 32.36 \\
\hline Oregon & 37.34 & 50.67 & 30.25 \\
\hline Pennsylvania & 33.32 & 44.96 & 29.92 \\
\hline Rhode Island & 37.77 & 54.41 & 32.65 \\
\hline South Carolina & 35.46 & 48.06 & 30.34 \\
\hline South Dakota & 39.29 & 49.18 & 36.26 \\
\hline Tennessee & 29.06 & 35.31 & 26.18 \\
\hline Texas & 33.70 & 43.06 & 28.88 \\
\hline Utah & 40.45 & 65.33 & 33.84 \\
\hline Vermont & 34.11 & 48.10 & 30.62 \\
\hline Virginia & 34.02 & 48.81 & 30.09 \\
\hline Washington & 35.59 & 50.79 & 28.54 \\
\hline West Virginia & 29.22 & 35.26 & 25.04 \\
\hline Wisconsin & 35.81 & 43.91 & 30.99 \\
\hline Wyoming & 41.12 & 54.48 & 36.30 \\
\hline
\end{tabular}

Notes: This table describes the share of state-level economic activity attributed to pass-through corporations in 2010. Aggregate activity is the sum of employment, establishments and annual payroll across all business forms. The cross-section was drawn from County Business Patterns and includes all 50 states. See Section 1 for details on data sources. 
Table A10: Heterogeneous Effects of Corp Tax Rates on $R_{s}^{c o r p} / G D P_{s}$ : Robustness to Including Lagged Values

\begin{tabular}{|c|c|c|c|c|c|c|}
\hline & (1) & (2) & (3) & (4) & (5) & (6) \\
\hline \multirow[t]{2}{*}{$\tau$} & 0.004 & -0.001 & 0.010 & 0.002 & 0.001 & -0.001 \\
\hline & $(0.010)$ & $(0.005)$ & $(0.007)$ & $(0.005)$ & $(0.006)$ & $(0.006)$ \\
\hline \multirow[t]{2}{*}{ L1 Lagged $\tau$} & $0.014^{*}$ & $0.019^{* *}$ & $0.018^{*}$ & $0.029^{* *}$ & $0.022^{* * *}$ & $0.023^{* *}$ \\
\hline & $(0.008)$ & $(0.008)$ & $(0.010)$ & $(0.012)$ & $(0.007)$ & $(0.009)$ \\
\hline \multirow[t]{2}{*}{ L2 Lagged $\tau$} & & & & -0.008 & & -0.002 \\
\hline & & & & $(0.009)$ & & $(0.008)$ \\
\hline \multirow[t]{2}{*}{ L3 Lagged $\tau$} & & & & 0.002 & & -0.000 \\
\hline & & & & $(0.005)$ & & $(0.006)$ \\
\hline \multirow[t]{2}{*}{ L4 Lagged $\tau$} & & & & -0.007 & & -0.001 \\
\hline & & & & $(0.006)$ & & $(0.008)$ \\
\hline \multirow[t]{2}{*}{ L5 Lagged $\tau$} & & & & 0.008 & & -0.001 \\
\hline & & & & $(0.006)$ & & $(0.007)$ \\
\hline \multirow[t]{2}{*}{$\tau \times$ Joint Interactions From Table 4} & & & $0.013^{* * *}$ & 0.001 & & \\
\hline & & & $(0.003)$ & $(0.003)$ & & \\
\hline \multirow[t]{2}{*}{ L1 Lagged $\tau \times$ Lagged Joint Interactions From Table 4} & & & 0.001 & $0.007 * * *$ & & \\
\hline & & & $(0.001)$ & $(0.002)$ & & \\
\hline \multirow[t]{2}{*}{ L2 Lagged $\tau \times$ Lagged Joint Interactions From Table 4} & & & & 0.000 & & \\
\hline & & & & $(0.002)$ & & \\
\hline \multirow[t]{2}{*}{ L3 Lagged $\tau \times$ Lagged Joint Interactions From Table 4} & & & & 0.004 & & \\
\hline & & & & $(0.002)$ & & \\
\hline \multirow[t]{2}{*}{ L4 Lagged $\tau \times$ Lagged Joint Interactions From Table 4} & & & & 0.002 & & \\
\hline & & & & $(0.002)$ & & \\
\hline \multirow[t]{2}{*}{ L5 Lagged $\tau \times$ Lagged Joint Interactions From Table 4} & & & & 0.003 & & \\
\hline & & & & $(0.002)$ & & \\
\hline \multirow{3}{*}{ Total Effect $\sum_{t} \beta_{i}^{\tau}$} & 0.019 & 0.019 & 0.028 & 0.025 & 0.023 & 0.019 \\
\hline & $(0.011)$ & $(0.009)$ & $(0.006)$ & $(0.013)$ & $(0.011)$ & $(0.012)$ \\
\hline & 0.083 & 0.031 & 0.000 & 0.052 & 0.026 & 0.110 \\
\hline Base and L1 Lagged Base Controls & $\mathrm{N}$ & $\mathrm{Y}$ & $\mathrm{Y}$ & $\mathrm{Y}$ & $\mathrm{Y}$ & $\mathrm{Y}$ \\
\hline L2-L5 Lagged Base Controls & $\mathrm{N}$ & $\mathrm{N}$ & $\mathrm{N}$ & $\mathrm{Y}$ & $\mathrm{N}$ & $\mathrm{Y}$ \\
\hline Base Interaction and Lagged Base Interaction & $\mathrm{N}$ & $\mathrm{N}$ & $\mathrm{N}$ & $\mathrm{N}$ & $\mathrm{Y}$ & $\mathrm{Y}$ \\
\hline L2-L5 Lagged Base Interaction & $\mathrm{N}$ & $\mathrm{N}$ & $\mathrm{N}$ & $\mathrm{N}$ & $\mathrm{N}$ & $\mathrm{Y}$ \\
\hline State Fixed Effects & $\mathrm{Y}$ & $\mathrm{Y}$ & $\mathrm{Y}$ & $\mathrm{Y}$ & $\mathrm{Y}$ & $\mathrm{Y}$ \\
\hline Year Fixed Effects & $\mathrm{Y}$ & $\mathrm{Y}$ & $\mathrm{Y}$ & $\mathrm{Y}$ & $\mathrm{Y}$ & $\mathrm{Y}$ \\
\hline
\end{tabular}

Notes: This table reports the coefficients of regressions of the revenue-to-GDP ratio on the corporate tax rate $\tau$. The models in this table expand those of Table 6 by including lagged values of $\tau$, the tax base measures, and the joint interactions. Each specification includes state and year fixed effects and we report the total effect $\sum_{t} \beta_{t}^{\tau}$ in the table, along with standard error and p-value. Columns (1) and (2) show that including lagged values of $\tau$ and the base measures does not impact the total effect. By comparison, Table 6, Column (2), reports a value of 0.016, while this table reports 0.019. Columns (3) and (4) include lagged values of the the joint interaction term from Table 6 . This table finds a total effect of 0.028 , compared to the effect reported in Table 6 of 0.024 . Columns (5) and (6) include interactions between lagged values of the tax rate and each of the controls and also find quantitatively similar effects to those in Table 6. The data used for this table are described in Section 1. Standard errors are clustered by state $\left({ }^{*} p<.1,{ }^{* *} p<.05,{ }^{* * *} p<.01\right)$. 
Table A11: Variance Decomposition - Corporate Revenue Share of GDP - Including Top Income Tax Rate

\begin{tabular}{lcc}
\hline \hline & Corp Tax Rev Share of GDP \\
\hline \% Explained & 47.02 & 47.06 \\
Corporate Rate & 42.35 & 40.22 \\
Base Measures & 57.65 & 59.47 \\
Top Personal Rate & & 0.31 \\
& & \\
\% Explained Var Among Base Rules & & \\
Federal Inc as State Base & 15.24 & 16.33 \\
Federal Inc Deductible & 14.25 & 13.62 \\
Throwback Rules & 8.12 & 8.04 \\
Payroll Apportionment Wgt & 18.55 & 17.64 \\
Loss Carryforward & 9.74 & 10.50 \\
Loss Carryback & 0.01 & 0.00 \\
Combined Reporting & 2.73 & 2.27 \\
Investment Tax Credit & 0.20 & 0.12 \\
R\&D Credit & 1.77 & 1.84 \\
ACRS Depreciation & 4.89 & 4.22 \\
Federal Accelerated Dep & 0.29 & 0.17 \\
Federal Bonus Dep & 0.81 & 0.96 \\
Franchise Tax & 19.63 & 20.04 \\
Incremental R\&D, Moving Avg & 0.66 & 0.76 \\
Incremental R\&D, Fixed & 3.10 & 3.51 \\
\hline \hline
\end{tabular}

Notes: This table replicates the baseline specification in Table A7, but includes the top statutory personal income tax rate as an additional control. See Section 1 for details on data sources. 
Table A12: Effects of Corporate Tax Rate Changes on Tax Revenues: Robustness to State Tax Controls

Panel A. State Corporate Tax Revenue-to-GDP Ratio

\begin{tabular}{lccccc}
\hline \hline & $(1)$ & $(2)$ & $(3)$ & $(4)$ & $(5)$ \\
\hline State Corporate Tax Rate $\tau$ & $6.13^{* * *}$ & 0.98 & $4.17^{* *}$ & 2.99 & 3.04 \\
& $(2.23)$ & $(4.67)$ & $(2.05)$ & $(3.98)$ & $(3.84)$ \\
State Corporate Tax Rate ${ }^{2}(\tau)^{2}$ & -5.15 & 9.93 & 8.86 & -5.01 & -4.82 \\
& $(20.58)$ & $(30.79)$ & $(20.84)$ & $(25.31)$ & $(24.94)$ \\
Base Index $\times 100$ & & & $5.87^{* *}$ & $5.12^{* * *}$ & $11.74^{* *}$ \\
& & & $(2.54)$ & $(1.66)$ & $(5.83)$ \\
State Corporate Tax Rate $\tau \times$ Base Index & & & & & -1.95 \\
& & & & & $(1.33)$ \\
State Corporate Tax Rate ${ }^{2}(\tau)^{2} \times$ Base Index & & & & & $(8.90)$ \\
& 1,550 & 1,550 & 1,550 & 1,550 & 1,550 \\
Observations & Yes & Yes & Yes & Yes & Yes \\
Year Fixed Effects & & Yes & & Yes & Yes \\
State Fixed Effects & Yes & Yes & Yes & Yes & Yes \\
Sales and Personal Income Tax & & & & 0.299 & 0.315 \\
Revenue-Maximizing Rate & & & & & \\
\hline \hline
\end{tabular}

Panel B. Total State Tax Revenue-to-GDP Ratio

\begin{tabular}{lccccc}
\hline \hline & $(1)$ & $(2)$ & $(3)$ & $(4)$ & $(5)$ \\
\hline State Corporate Tax Rate $\tau$ & -9.5 & 16.7 & -9.4 & 11.9 & 23.1 \\
& $(13.5)$ & $(18.8)$ & $(13.5)$ & $(18.5)$ & $(14.7)$ \\
State Corporate Tax Rate ${ }^{2}(\tau)^{2}$ & 132.5 & -70.3 & 133.6 & -59.3 & -126.0 \\
& $(108.1)$ & $(130.0)$ & $(107.2)$ & $(128.0)$ & $(101.1)$ \\
Base Index $\times 100$ & & & 7.9 & $21.8^{* *}$ & -20.6 \\
& & & $(10.8)$ & $(9.0)$ & $(26.8)$ \\
State Corporate Tax Rate $\tau \times$ Base Index & & & & & 8.8 \\
& & & & & $(7.9)$ \\
State Corporate Tax Rate ${ }^{2}(\tau)^{2} \times$ Base Index & & & & & -38.4 \\
& & & & & \\
& 1,550 & 1,550 & 1,550 & 1,550 & 1,550 \\
Observations & Yes & Yes & Yes & Yes & Yes \\
Year Fixed Effects & & Yes & & Yes & Yes \\
State Fixed Effects & Yes & Yes & Yes & Yes & Yes \\
Sales and Personal Income Tax & & & & 0.101 & 0.092 \\
Revenue-Maximizing Rate & & & & & \\
\hline \hline
\end{tabular}

Notes: This table reports the results of regressions that estimate the effects of changes in tax rates and tax bases on tax revenue. Panel A and B replicate those in Table 7, and additionally control for state sales tax rates and top personal income tax rates. Each specification weights observations by the mean state GDP in our sample and includes state and year fixed effects. The revenue-to-GDP ratio is measured in basis points. Standard errors are clustered by state $\left({ }^{*} p<.1,{ }^{* *} p<.05,{ }^{* * *} p<.01\right)$. The 15 base controls included in the base index are described in Section 1. 
Table A13: Summary of State Characteristics Used in Constructing Similarity Scores

\begin{tabular}{|c|c|c|c|c|c|c|c|c|c|c|c|c|}
\hline \multirow[b]{3}{*}{ State } & \multirow{2}{*}{\multicolumn{2}{|c|}{ Log Pop }} & \multirow{2}{*}{\multicolumn{2}{|c|}{ Skill Share }} & \multicolumn{8}{|c|}{ Share of GDP } \\
\hline & & & & & \multicolumn{2}{|c|}{ Agric } & \multicolumn{2}{|c|}{ Constr\&Mine } & \multicolumn{2}{|c|}{ Manuf } & \multicolumn{2}{|c|}{ Services } \\
\hline & 1980 & 2010 & 1980 & 2010 & 1980 & 2010 & 1980 & 2010 & 1980 & 2010 & 1980 & 2010 \\
\hline Alabama & 15.2 & 15.4 & 10.2 & 19.7 & 1.9 & 1.3 & 1.9 & 1.3 & 24.4 & 15.8 & 14.8 & 27.1 \\
\hline Alaska & 12.9 & 13.5 & 19.9 & 23.7 & 1.8 & 1.0 & 1.8 & 1.0 & 3.7 & 2.1 & 8.6 & 17.6 \\
\hline Arizona & 14.8 & 15.7 & 16.6 & 27.3 & 3.0 & 0.7 & 3.0 & 0.7 & 13.7 & 8.6 & 20.0 & 34.7 \\
\hline Arkansas & 14.6 & 14.9 & 11.1 & 16.8 & 4.9 & 2.5 & 4.9 & 2.5 & 24.2 & 14.6 & 16.3 & 27.5 \\
\hline California & 17.0 & 17.4 & 19.2 & 29.8 & 2.9 & 1.6 & 2.9 & 1.6 & 17.5 & 11.3 & 23.8 & 41.3 \\
\hline Colorado & 14.9 & 15.4 & 24.8 & 37.7 & 2.7 & 0.9 & 2.7 & 0.9 & 13.4 & 7.8 & 21.2 & 40.4 \\
\hline Connecticut & 15.0 & 15.1 & 19.6 & 36.1 & 0.6 & 0.1 & 0.6 & 0.1 & 28.3 & 12.0 & 25.7 & 46.0 \\
\hline Delaware & 13.3 & 13.7 & 16.1 & 26.3 & 0.8 & 0.7 & 0.8 & 0.7 & 33.6 & 7.5 & 19.5 & 55.5 \\
\hline Florida & 16.1 & 16.7 & 12.9 & 27.2 & 3.1 & 1.0 & 3.1 & 1.0 & 11.0 & 5.0 & 22.5 & 37.9 \\
\hline Georgia & 15.5 & 16.1 & 15.5 & 27.4 & 1.5 & 0.9 & 1.5 & 0.9 & 21.9 & 11.1 & 17.4 & 37.9 \\
\hline Hawaii & 13.8 & 14.1 & 18.0 & 26.6 & 3.2 & 0.6 & 3.2 & 0.6 & 5.1 & 1.9 & 23.4 & 35.0 \\
\hline Idaho & 13.8 & 14.3 & 13.9 & 23.9 & 9.8 & 5.5 & 9.8 & 5.5 & 16.2 & 11.4 & 19.6 & 30.0 \\
\hline Illinois & 16.3 & 16.4 & 14.9 & 30.0 & 2.0 & 0.8 & 2.0 & 0.8 & 24.9 & 13.0 & 22.1 & 38.9 \\
\hline Indiana & 15.5 & 15.7 & 9.8 & 20.8 & 3.0 & 1.3 & 3.0 & 1.3 & 32.5 & 29.6 & 17.7 & 24.4 \\
\hline Iowa & 14.9 & 14.9 & 13.5 & 23.1 & 9.9 & 5.2 & 9.9 & 5.2 & 24.8 & 18.9 & 19.9 & 29.6 \\
\hline Kansas & 14.7 & 14.9 & 15.1 & 29.2 & 4.7 & 3.9 & 4.7 & 3.9 & 18.5 & 15.3 & 17.8 & 28.7 \\
\hline Kentucky & 15.1 & 15.3 & 8.4 & 21.0 & 3.7 & 1.1 & 3.7 & 1.1 & 26.0 & 17.2 & 15.6 & 25.2 \\
\hline Louisiana & 15.3 & 15.3 & 11.8 & 22.8 & 1.2 & 0.8 & 1.2 & 0.8 & 13.4 & 22.7 & 11.3 & 22.6 \\
\hline Maine & 13.9 & 14.1 & 12.5 & 27.0 & 2.8 & 1.6 & 2.8 & 1.6 & 24.2 & 10.7 & 17.7 & 31.5 \\
\hline Maryland & 15.3 & 15.6 & 18.5 & 35.2 & 0.9 & 0.3 & 0.9 & 0.3 & 14.1 & 6.3 & 24.6 & 40.1 \\
\hline Massachusetts & 15.6 & 15.7 & 17.3 & 37.1 & 0.7 & 0.3 & 0.7 & 0.3 & 24.7 & 10.8 & 27.3 & 44.0 \\
\hline Michigan & 16.0 & 16.1 & 13.7 & 25.7 & 1.5 & 0.8 & 1.5 & 0.8 & 30.1 & 17.6 & 19.2 & 32.2 \\
\hline Minnesota & 15.2 & 15.5 & 14.5 & 29.9 & 5.5 & 2.3 & 5.5 & 2.3 & 21.0 & 13.7 & 20.8 & 36.1 \\
\hline Mississippi & 14.7 & 14.9 & 11.8 & 16.7 & 3.7 & 2.4 & 3.7 & 2.4 & 22.8 & 15.1 & 13.9 & 24.2 \\
\hline Missouri & 15.4 & 15.6 & 14.8 & 20.6 & 2.9 & 1.4 & 2.9 & 1.4 & 22.6 & 12.6 & 17.9 & 36.0 \\
\hline Montana & 13.6 & 13.8 & 14.8 & 26.5 & 7.1 & 4.1 & 7.1 & 4.1 & 8.4 & 5.2 & 14.3 & 27.3 \\
\hline Nebraska & 14.3 & 14.4 & 14.0 & 27.3 & 9.0 & 6.8 & 9.0 & 6.8 & 14.2 & 12.1 & 20.1 & 28.7 \\
\hline Nevada & 13.6 & 14.8 & 13.4 & 21.1 & 1.3 & 0.2 & 1.3 & 0.2 & 5.1 & 4.1 & 17.3 & 31.9 \\
\hline New Hampshire & 13.7 & 14.1 & 19.6 & 34.5 & 0.7 & 0.2 & 0.7 & 0.2 & 30.7 & 11.3 & 20.2 & 35.8 \\
\hline New Jersey & 15.8 & 16.0 & 16.0 & 32.4 & 0.5 & 0.2 & 0.5 & 0.2 & 25.5 & 9.4 & 21.5 & 42.6 \\
\hline New Mexico & 14.1 & 14.5 & 16.0 & 24.6 & 2.4 & 1.5 & 2.4 & 1.5 & 5.3 & 5.3 & 14.7 & 29.4 \\
\hline New York & 16.7 & 16.8 & 15.5 & 31.5 & 0.7 & 0.2 & 0.7 & 0.2 & 18.4 & 5.9 & 30.7 & 50.4 \\
\hline North Carolina & 15.6 & 16.1 & 15.7 & 25.5 & 2.6 & 1.1 & 2.6 & 1.1 & 32.7 & 21.1 & 14.5 & 31.5 \\
\hline North Dakota & 13.4 & 13.4 & 13.7 & 26.6 & 6.9 & 8.8 & 6.9 & 8.8 & 5.1 & 7.1 & 14.5 & 23.1 \\
\hline Ohio & 16.2 & 16.3 & 12.0 & 20.9 & 1.6 & 0.7 & 1.6 & 0.7 & 32.6 & 16.4 & 16.4 & 34.5 \\
\hline Oklahoma & 14.9 & 15.1 & 13.2 & 23.1 & 2.9 & 1.6 & 2.9 & 1.6 & 14.5 & 9.5 & 14.6 & 24.5 \\
\hline Oregon & 14.8 & 15.2 & 17.0 & 27.5 & 3.8 & 1.7 & 3.8 & 1.7 & 23.0 & 29.5 & 18.6 & 27.8 \\
\hline Pennsylvania & 16.3 & 16.4 & 13.2 & 24.8 & 1.1 & 0.5 & 1.1 & 0.5 & 28.2 & 12.3 & 19.1 & 37.3 \\
\hline Rhode Island & 13.8 & 13.9 & 16.0 & 28.5 & 0.9 & 0.2 & 0.9 & 0.2 & 28.3 & 8.1 & 21.3 & 38.8 \\
\hline South Carolina & 15.0 & 15.3 & 11.8 & 23.5 & 1.5 & 0.8 & 1.5 & 0.8 & 30.2 & 16.3 & 14.0 & 29.9 \\
\hline South Dakota & 13.4 & 13.6 & 11.3 & 24.3 & 13.4 & 8.2 & 13.4 & 8.2 & 9.5 & 8.8 & 17.6 & 32.9 \\
\hline Tennessee & 15.3 & 15.7 & 12.1 & 22.4 & 2.0 & 0.6 & 2.0 & 0.6 & 25.9 & 15.6 & 16.4 & 29.9 \\
\hline Texas & 16.5 & 17.0 & 14.7 & 24.1 & 1.5 & 0.8 & 1.5 & 0.8 & 16.6 & 14.5 & 16.0 & 27.5 \\
\hline Utah & 14.2 & 14.8 & 18.8 & 26.4 & 1.6 & 0.5 & 1.6 & 0.5 & 15.0 & 14.9 & 17.6 & 32.7 \\
\hline Vermont & 13.1 & 13.3 & 16.9 & 32.0 & 4.0 & 1.3 & 4.0 & 1.3 & 26.9 & 11.4 & 18.3 & 31.0 \\
\hline Virginia & 15.5 & 15.9 & 18.2 & 34.2 & 1.1 & 0.3 & 1.1 & 0.3 & 19.0 & 9.7 & 17.8 & 40.9 \\
\hline Washington & 15.2 & 15.7 & 20.1 & 31.3 & 3.6 & 1.8 & 3.6 & 1.8 & 20.6 & 13.9 & 17.6 & 37.2 \\
\hline West Virginia & 14.5 & 14.4 & 6.7 & 19.4 & 0.7 & 0.4 & 0.7 & 0.4 & 19.4 & 9.8 & 13.1 & 21.7 \\
\hline Wisconsin & 15.4 & 15.6 & 13.8 & 26.5 & 5.3 & 1.6 & 5.3 & 1.6 & 31.0 & 18.9 & 17.9 & 32.0 \\
\hline Wyoming & 13.1 & 13.2 & 16.6 & 21.8 & 2.6 & 1.3 & 2.6 & 1.3 & 4.1 & 4.7 & 8.5 & 16.0 \\
\hline United States & & & 15.1 & 27.4 & 2.3 & 1.1 & 2.3 & 1.1 & 21.3 & 12.3 & 20.2 & 36.4 \\
\hline
\end{tabular}

Notes: This table summarizes log population, state skill share, agriculture share of GDP, construction and mining share of GDP, manufacturing share of GDP and services industries' share of GDP for all 50 states in the first and last years of the sample. The table also includes the national average. Skill share is the share of the population 18 or older with a Bachelor's Degree or above. 
Table A14: States Considered "Similar" in the year before an event

\begin{tabular}{ll}
\hline \hline State & Similar States \\
\hline AK & NM, WY \\
AL & AR, KY, MS, TX, WV \\
AR & DE, ID, KY, ND, TN, WY \\
AZ & CA, GA, HI, IL, NM, OH, TX, WY \\
CO & AK, HI, IA, MA, ND, WY \\
CT & IN, MA, MI, WY \\
DE & NH \\
FL & AL, CA, HI, NE, TX \\
GA & CA, DE, NC, NJ, PA, SC, TN, TX, VA, WA \\
HI & NV, SD \\
IA & CA, CO, NC, ND, OR, WI, WY \\
ID & AR, CT, KY, NE, NY, SD, VT, WV, WY \\
IL & CA, MA, MI, NJ, NY, PA, TX \\
IN & AR \\
KS & CA, IA, IN, KY, UT, VT, WI \\
KY & AK, AR, IA, IN, LA, MS, NC, ND \\
LA & IN, KY, ND, OH, TX, WY \\
MA & NJ, NY, WI \\
MD & AK, CA, MA, NY, VA \\
ME & AR, HI, ID, MS, NH, NV, RI, SD, WV \\
MI & CT, DE, IL, IN, NH, NY, OH, WI \\
MN & CA, CO, CT, IN, NJ, WI, WY \\
MO & AL, CT, FL, GA, MI, NE, NV, NY, PA, WA \\
MS & AK, AR, HI, KY, SC, TN, TX, WY \\
MT & AK, HI, MD, ND, NV \\
NC & AR, CA, DE, IN, KS, NE, OH, WA, WI \\
ND & AK, IA, MT, NC, SD \\
NE & CA, HI, ID, MA, NY, SD, TN, WA \\
NH & CT, IN, MA, MD, RI, SC, VA, VT \\
NJ & MA, NY, WV \\
NM & AK, HI, MS, NE, NY, TX, WY \\
NV & HI \\
NY & NJ \\
OH & IN, NC, NJ, NV, NY, PA, SC, TN, VA \\
OK & AK, FL, LA, MS, NC, NM, TN, VA, WV \\
OR & CT, DE, HI, IN, NE, NH, TN, WI \\
PA & CA, FL, HI, IA, NV, NY, OH, TN, VA, WV \\
RI & NH, NV, TN \\
SC & NC, NM, OH, WV \\
TN & AL, AR, FL, ID, NE, OH, VA, WA \\
TX & AK, CA \\
UT & AK, DE, HI, LA, NH, NM, NV, SC, VA, WV \\
VA & AK, CA, CO, MA, MI, NJ, OH, SC \\
VT & DE, ID, KS, MT, ND, NH, SD \\
WI & CT, IA, MI, NC, OR, TN \\
WV & HI, IN, WY \\
\hline \hline & \\
\hline
\end{tabular}

Notes: This table lists all states for whom there is a similar state match in the year before a corporate tax rate or a tax base change. See Section B.2 for a description of how similar states were defined. 